University of San Diego

Digital USD

Theses

Theses and Dissertations

Summer 8-1-2015

\title{
Factors Affecting Terrigenous Sedimentation in Coastal Bays with Coral Reefs: Implications for Monitoring the Effectiveness of Watershed Restoration
}

Whitney Sears

University of San Diego

Follow this and additional works at: https://digital.sandiego.edu/theses

Part of the Environmental Monitoring Commons, Geology Commons, Marine Biology Commons, Natural Resources Management and Policy Commons, and the Sedimentology Commons

\section{Digital USD Citation}

Sears, Whitney, "Factors Affecting Terrigenous Sedimentation in Coastal Bays with Coral Reefs: Implications for Monitoring the Effectiveness of Watershed Restoration" (2015). Theses. 7. https://digital.sandiego.edu/theses/7

This Thesis: Open Access is brought to you for free and open access by the Theses and Dissertations at Digital USD. It has been accepted for inclusion in Theses by an authorized administrator of Digital USD. For more information, please contact digital@sandiego.edu. 


\title{
UNIVERSITY OF SAN DIEGO
}

\begin{abstract}
San Diego
Factors Affecting Terrigenous Sedimentation in Coastal Bays with Coral Reefs: Implications for Monitoring the Effectiveness of Watershed Restoration
\end{abstract}

A thesis submitted in partial satisfaction of the requirements for the degree of

Master of Science in Marine Science

\author{
By \\ Whitney Taylor Sears \\ Thesis Committee \\ Sarah C. Gray, Ph.D., Advisor, Chair \\ Zhi-Yong Yin, Ph.D. \\ Carlos Ramos-Scharrón, Ph.D.
}


The thesis of Whitney Taylor Sears is approved by:

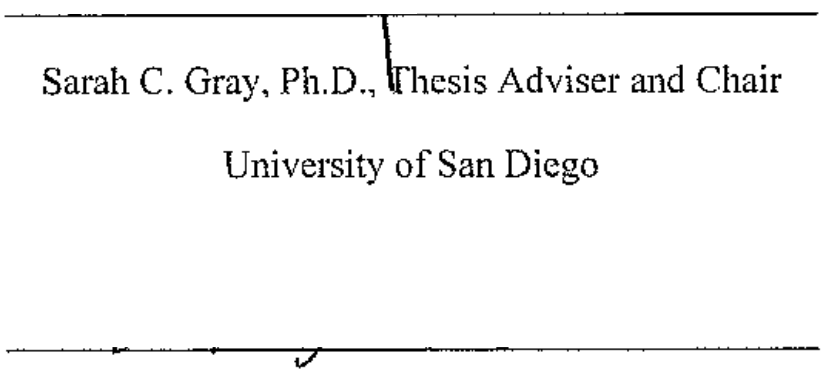

Zhi-Yong Yin, Ph.D., Committee Member ,University of San Diego

\title{
Carlos Ramos-Scharrón, Ph.D., Committee Member University of Texas at Austin
}

\author{
University of San Diego
}

San Diego

2015 


\section{Copyright (C) 2015 Whitney Sears}




\section{DEDICATION}

This thesis is dedicated to my grandparents, Gilbert and Jane Sears. Without their unwavering support throughout my life, I simply would not have had all of the amazing opportunities that ultimately lead to obtaining this master's degree.

Thank you for supporting me, believing in my abilities, and your disproportionate amount of influence in my character and intellectual development, work ethic and value of education. 


\section{ACKNOWLEDGMENTS}

Firstly, I would like to thank my friends and family for their support and encouragement throughout this process. Thank you in particular to Jamie Irving. Completing a master's degree can be stressful sometimes, and Jamie endured those times with me firsthand. Thank you for your emotional support and your unwavering friendship over the past eight years.

I would also like to thank my advisor, Sarah Gray, and my committee. Sarah is devoted to the success of her graduate students, and she provided guidance and an exceptional amount of time and attention during my thesis development. Thank you also to my other committee members, Zhi-Yong Yin and Carlos Ramos-Scharrón for essential advice on analyses approaches, statistics, and for utilizing their expertise to enrich this thesis.

All of the staff and faculty in the EOS Department at USD were instrumental in some way to my thesis development, but there are some who I would like to specifically thank. Thank you to Ron Kaufmann, who helped me develop my thesis focus in Graduate Seminar and guided me through administrative duties throughout my graduate career; thank you to Drew Talley, who taught me most of what I know about statistics; and thank you to Kathy Andrews, who helped get a wide range of "stuff" done during my career at USD.

I am very grateful to be part of the EOS graduate student community. In particular, I would like to thank my entire cohort: Sam San Francisco, Morgan Martin, Brain Juhl, and Kevin Stolzenbach. There is a special kind of support and understanding that only your cohort can understand from going through the initial period of graduate school together. I would also like to thank Bobby Harrington and Stephen Campbell, who are my good friends, lab mates, and with whom I share a unique sense of camaraderie.

This thesis is the result of a collaborative effort among a huge group of individuals; a list of people too long to name in entirety. Thank you to all of the field technicians who helped collect the data I used in my thesis: Kimbrie Gobbi, Mike Fox, Meg Kolupski, Nick Przyuski, Zoe Hastings, and Lindsay Sturtevant; to field support: Phil Strenger, Roy Proctor, Hew Schlereth, Matt Knoblock, Katie Day; the Coral Bay Community Council: Sharon Coldren, Patricia Reed, Barry Devine among others; and to Amalia DeGrood, a great friend who spent countless hours training me on the lab methods for this project and orienting me to USD and San Diego, and who processed many of the samples for this project. Thank you also to Randy Brown, the director at VIERS, and to VIERS operational managers Jamie Irving and Randy Fish who assisted me in many various ways while conducting field research.

I am grateful for my funding sources and scholarships, sources of which came from grants to S. Gray from the NOAA Coral Reef Conservation Program, the USD Graduate Grant, and the USD Dean's Graduate Scholarship. This research was conducted with scientific research permits from the USVI Department of Natural Resources and Planning (DPNR) and the Virgin Islands National Park. 


\section{TABLE OF CONTENTS}

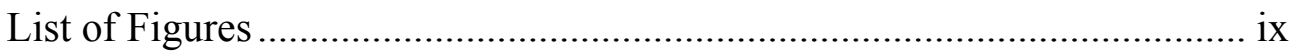

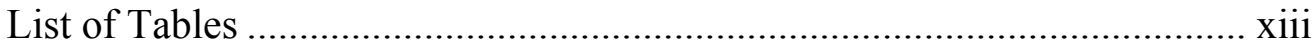

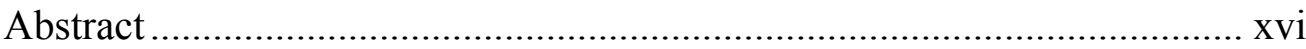

Chapter 1: Introduction

1.1 Scientific Problem and Research Objectives ............................ 1

1.2 Land-based (Terrigenous Sedimentation) ................................ 2

1.3 Findings of Previous Marine Sedimentation Studies................. 5

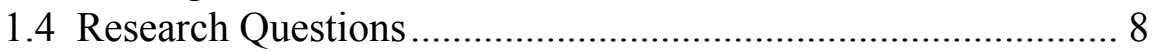

1.5 Significance of Study ……………………………................. 12

Chapter 2: Location and Methods

2.1 Study Site: St. John, U.S. Virgin Islands ..................................... 14

2.1.1 Coral Bay ................................................................... 15

2.1.2 Great and Little Lameshur Bays ...................................... 18

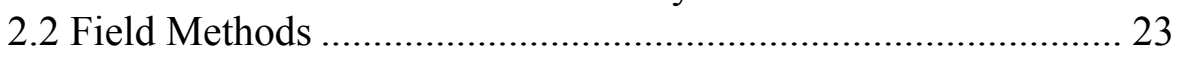

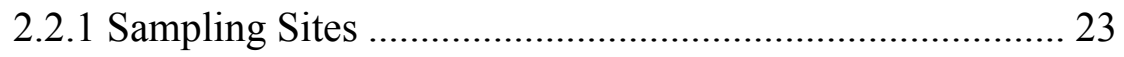

2.2.2 Sediment Trap and Benthic Surface Sediments................. 26

2.2.3 Rainfall and Storms....................................................... 31

2.3 Lab Methods ............................................................................ 31

2.3.1 Sediment Processing and Accumulation Rates .................. 31

2.3.2 Sediment Composition........................................................ 32

2.3.3 Grain Size Analysis (texture) and Siltation Rates............. 33

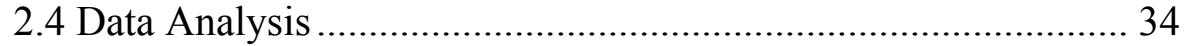

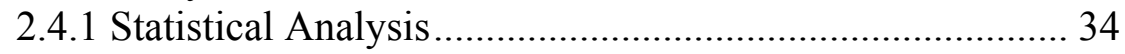

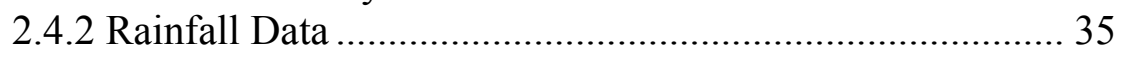

2.4.3 Relationship between Rainfall Characteristics and

Terrigenous Sediment Accumulation ......................................... 43

2.4.4 Resuspension of Sediments.................................................. 43

2.4.5 Pre- and Post-Restoration Terrigenous Accumulation during

Fall Periods .............................................................................. 44

2.4.6 Terrigenous Accumulation during Equivalent Storms Preand Post-Restoration ............................................................. 45

2.4.7 Wave Height ................................................................... 46 
Chapter 3: Results

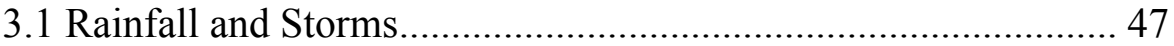

3.1.1 Introduction.............................................................. 47

3.1.2 Seasonal and Annual Means Compared with Historical

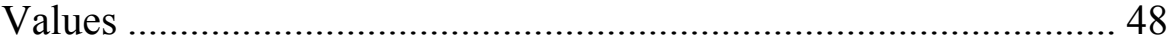

3.1.3 Temporal Variability in Rainfall and Storms.................... 52

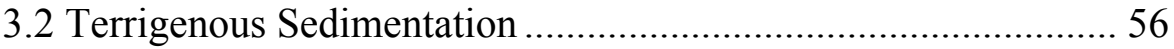

3.2.1 Introduction: \% Terrigenous of Inorganic Sediment ......... 56

3.2.1.1 Temporal Variability.......................................... 57

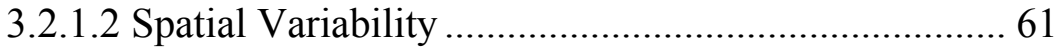

3.2.2 Introduction: Trap Terrigenous Sediment Accumulation.. 68

3.2.2.1 Temporal Variability............................................ 68

3.2.2.2 Spatial Variability ................................................ 72

3.2.3 Relationship between Terrigenous Accumulation Rates and

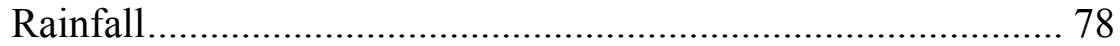

3.2.3.1 Rainfall-Based Regressions .................................. 78

3.2.3.2 Antecedent Precipitation Index (API)-Based

Regressions ..................................................................... 82

3.2.3.3 Rainfall-Based Compared with API-Based Regressions

3.2.4 Terrigenous Accumulation Pre- Compared with Post-

Restoration .................................................................. 88

3.2.4.1 Differences in Non- and Rain-Normalized Terrigenous

Accumulation Rates Pre- and Post-Restoration ........................ 89

3.2.4.2 Terrigenous Accumulation Rates during Equivalent

Storm Events Pre- and Post-Restoration.................................... 89

3.3 Wave Height .......................................................................... 95

3.3.1 Wave Height During Storm Events ............................... 95

3.3.2 Sampling Periods when Resuspension may have been a

Predominant Factor Controlling Terrigenous Sediment Trap

Accumulation ....................................................................... 97

3.3.3 Relationship between Terrigenous Sedimentation and Wave

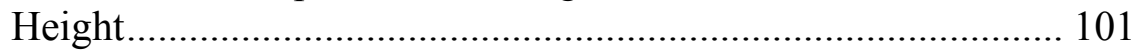

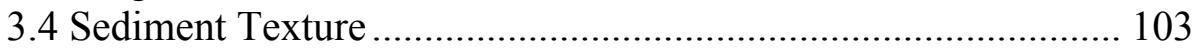

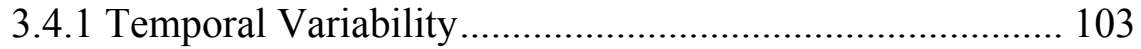

3.4.2 Spatial Variability ...................................................... 106

3.5 Total and Silt Accumulation Rates ....................................... 116

3.5.1 Introduction................................................................ 116

3.5.1.1 Temporal Variability: Total and Silt Accumulation Rates

3.5.1.2 Spatial Variability: Total Accumulation Rates ......... 122

3.5.1.3 Spatial Variability: Silt Accumulation Rates ............. 122 
Chapter 4: Discussion

4.1 Sources of Sediment .................................................................. 133

4.2 Processes Affecting Marine Sedimentation .............................. 135

4.2.1 Rainfall and Ephemeral Stream Activation ..................... 135

4.2.2 Effect of Watershed Development on Watershed-Marine

Transport Processes and Marine Sedimentation ........................ 138

4.2.3 Transport and Distribution of Terrigenous Sediments and

Carbonate Sediment Production ............................................... 142

4.2.4 Resuspension............................................................ 144

4.3 Sedimentation and Coral Stress .............................................. 149

4.4 Sediment Traps and a Monitoring Tool .................................. 153

4.5 Contribution to Management and Monitoring of Developed,

Tropical Watersheds and Adjacent Coral Reefs ....................... 155

Chapter 5: Conclusions ................................................................... 156

Literature Cited .............................................................................. 161

Appendix I: Table of Traps................................................................ 171

Appendix II: Sampling Periods ...................................................... 172

Appendix III: Terrigenous Accumulation Rates and Proportions of

Terrigenous Sediment .............................................................. 173

Appendix IV: Resuspension .......................................................... 177

Appendix V: Trap Sediment Texture .............................................. 178

Appendix VI: Benthic Data ......................................................... 191

Appendix VII: Trap Total and Silt Accumulation .................................... 204 


\section{LIST OF FIGURES}

Figure 2.1. Map of St. John showing location relative to Puerto Rico, the

general study location, National Park boundary, and Cruz Bay

Figure 2.2. General study locations of Coral and Lameshur Bays showing near-shore and offshore reef sampling sites and locations

Figure 2.3. Map of Coral Bay showing near-shore and offshore reef sampling sites and locations

Figure 2.4. Map of Lameshur Bay showing near-shore and offshore reef sampling sites and locations.

Figure 2.5. Picture of a sediment trap 30

Figure 2.6. Relationship between Influence (Weight \%) of a Given Rainfall Event in the Antecedent Precipitation Index (API) and Number of Days since the Rainfall Event Occurred 39

Figure 2.7. The Relationship between the Antecedent Precipitation Index (API) and Cumulative Daily Rainfall

Figure 3.1. Mean Cumulative Monthly Rainfall ( \pm SD) in Coral Bay during the Study Period (2007-2012) and Historically (1972-2012) 50

Figure 3.2. Mean Cumulative Monthly Rainfall ( \pm SD) in Coral Bay in MayNovember versus December-April (2007-2012) with Historical Means $(1972-2012)$

Figure 3.3. Cumulative Daily Rainfall, Cumulative Rainfall/Storms, and Mean Daily Rainfall/Sampling Period in Coral Bay, St. John (2007-2012) 55 
Figure 3.4. Proportions (\%) Terrigenous Sediment at all Locations and Mean Daily Rainfall/Sampling Period (2007-2012) 60

Figure 3.5. Study period Mean Terrigenous Proportions ( \pm SD \%) at all Shore and Reef Sites 64

Figure 3.6. Study Period Mean Terrigenous Proportions ( \pm SD \%) at all

Shore and Reef Locations 66

Figure 3.7. Terrigenous Sediment Accumulation at all Locations and Mean

Daily Rainfall (2007-2012) 71

Figure 3.8. Study Period Mean Terrigenous Accumulation (+ SD) at Shore (Right) and Reef (Left) Environments

Figure 3.9. Study Period Mean Terrigenous Accumulation (+ SD) at Shore and Reef Locations 76

Figure 3.10. R-Squared Values from Regressions Ran between Mean Daily Rainfall, Mean Rainfall Intensity, Maximum Daily Rainfall with Terrigenous Accumulation Rates under Various Rainfall Regimes 80

Figure 3.11. R-Squared Values from Regressions Ran between Mean Daily Rainfall, Mean Rainfall Intensity, Maximum Daily Rainfall with Terrigenous Accumulation Rates under Various API-based Regimes 83 Figure 3.12. Difference of Maximum R-squared Values: API Regime minus Rainfall Parameter R-squared Values ..... 86

Figure 3.13. Pre- and Post-Restoration Terrigenous Accumulation at all Shore Sites during Storm Pair One and Two 92 
Figure 3.14. Pre- and Post-Restoration Terrigenous Accumulation at all Reef Sites during Storm Pair One and Two 93

Figure 3.15. Maximum and Mean Wave Height during Major Storms and Named Tropical Storms and Hurricanes 96

Figure 3.16. Terrigenous Accumulation and Maximum Wave Height at all Locations (2008-2012) 99

Figure 3.17. Proportions of Terrigenous Sediment and Maximum Wave Height at all Locations (2008-2012) 100

Figure 3.18. \% Variability in Terrigenous Accumulation Explained by Maximum Wave Height

Figure 3.19. Mean Grain Size of Sediments $<1 \mathrm{~mm}$ at all Locations and Mean Daily Rainfall/Sampling Period (2009-2012)

Figure 3.20. Mean, Median, and Mode Grain Size of Trap Sediments (+ SD) at Shore and Reef Locations

Figure 3.21. Mean Percentage of Benthic Grains $>1 \mathrm{~mm}(+\mathrm{SD})$ at Developed and Undeveloped Shore and Reef Locations

Figure 3.22. Mean, Median, and Mode Grain Size of Benthic Sediments (+ SD) at Shore and Reef Locations

Figure 3.23. Total Accumulation at all Locations and Mean Daily Rainfall (2007-2012)

Figure 3.24. Silt Accumulation at all Locations and Mean Daily Rainfall (2007-2012) 
Figure 3.25. Percentage of Sampling Periods where Total and Silt Accumulation Levels were Exceeded.

Figure 3.26. Study Period Mean Total Sediment Accumulation (+ SD) at all

Sites 125

Figure 3.27. Study Period Mean Total Sediment Accumulation (+ SD) at all

Locations

Figure 3.28. Study Period Mean Silt Accumulation Rates (+ SD) at all Trap

Sites.

Figure 3.29. Study Period Mean Silt Accumulation Rates (+ SD) at all

Locations 


\section{LIST OF TABLES}

Table 2.1. Physical characteristics of St. John bays and watershed areas for this project.

Table 2.2. Sampling "locations" including the sediment trap "sites" comprising each location, the bays where sites were located, watershed development, site type, and watershed area. Sediment trap data collected from proximal "sites" with similar degree of development were grouped together as "locations"

Table 2.3. Data value regimes for rainfall parameters examined in this study

Table 3.1. Summary of all storm events during the $2007-12$ study period in order of greatest to least cumulative rainfall/storm.

Table 3.2. Mann-Whitney U summaries for "Terrigenous Sedimentation" section

Table 3.3. P-values for Kruskal-Wallis pairwise comparisons of proportions of terrigenous sediment (\%) means between all shore and reef sites 65

Table 3.4. P-values for Kruskal-Wallis pairwise comparisons of proportions of terrigenous sediment (\%) means between all shore and reef locations .... 67 Table 3.5. P-values for Kruskal-Wallis pairwise comparisons of terrigenous accumulation rate means between all shore and reef sites 75

Table 3.6. P-values for Kruskal-Wallis pairwise comparisons of terrigenous accumulation rate means between all shore and reef locations 
Table 3.7. The maximum $\%$ variance of terrigenous accumulation rates explained by mean daily rainfall, mean rainfall intensity, and maximum daily rainfall and respective p-values in rainfall-based regressions at each location

Table 3.8. The maximum $\%$ variance of terrigenous accumulation rates explained by mean daily rainfall, mean rainfall intensity, and maximum daily rainfall and respective p-values in API-based regressions at each location . 84 Table 3.9. Maximum regression coefficients produced for rainfall-based and API-based regressions for each rainfall parameter and location 87

Table 3.10. Two pairs of equivalent storms identified pre- and postrestoration and rainfall values 89

Table 3.11. Range of values for $\%$ reduction in TAR for post-restoration in shore and reef areas 94

Table 3.12. Mann-Whitney U summary for $\%$ benthic gravel

Table 3.13. P-values for Kruskal-Wallis pairwise comparisons of mean grain size of trap sediment in developed and minimally developed shore and reef areas

Table 3.14. P-values for Kruskal-Wallis pairwise comparisons of mean \% gravel of benthic sediments in developed and minimally developed shore and reef areas

Table 3.15. P-values for Kruskal-Wallis pairwise comparisons of mean grain size of benthic sediments in developed and minimally developed shore and reef areas 115 
Table 3.16. Mann-Whitney U summaries for "Total and Silt Accumulation" section

Table 3.17. P-values for Kruskal-Wallis pairwise comparisons of $\Sigma$ AR means between all sites. 126

Table 3.18. P-values for Kruskal-Wallis pairwise comparisons of $\Sigma$ AR means between all locations. 128 Table 3.19. P-values for Kruskal-Wallis pairwise comparisons of SAR means between all sites. 130

Table 3.20. P-values for Kruskal-Wallis pairwise comparisons of SAR means between all locations. 132 


\begin{abstract}
In the Caribbean, sedimentation has been identified as a serious threat to coral reef communities. Although land-based sediment delivery to coastal waters harboring coral reefs occurs under natural conditions, human activities in the watersheds above reefs increases the erosion and delivery of terrigenous sediment to the reefs. Delivery of terrigenous sediment into marine areas below developed watersheds affects sedimentation rates, alters the composition and texture of sediments that are suspended in the water column, and/or sediments that are deposited on the sea floor and on corals.

St. John, U.S. Virgin Islands is an ideal location to study the effects of rainfall and human development on sedimentation on coral reefs. From a management perspective, there is a need on St. John for studies that examine how watershed development and watershed restoration activities affect marine sedimentation. The island is surrounded by fringing coral reefs and over half the area $(56 \%)$ of the island's landmass is largely protected from development by the Virgin Islands National Park (VINP) or the Virgin Islands Coral Reef National Monument (CRNM). The presence of minimally developed watersheds within the VINP or the CRNM makes it possible to compare sedimentation in bays below adjacent developed and minimally developed watersheds simultaneously.

Building on previous sedimentation studies by our research group, the objectives of this project were to examine how marine sedimentation varied in eastern St. John as a function of: (a) different rainfall parameters and wave
\end{abstract}


activity over several seasons (4-5), (b) location with respect to shoreline runoff inputs and coral reefs, and (c) degree of watershed development.

Sediment traps (13) were deployed over $\sim 26$-day sampling periods in shore and offshore reef sites below developed and minimally developed watersheds over five rainy seasons between 2007-2012. Sediments collected in traps were analyzed to determine: (a) the proportion of terrigenous sediment $(\% \mathrm{~T})$; (b) total sediment accumulation rate ( $\mathrm{AR})$, terrigenous sediment accumulation rate (TAR), and silt accumulation rate (SAR) in $\mathrm{mg} / \mathrm{cm}^{2} / \mathrm{d}$; and (c) sediment grain size. Rainfall data collected from recording rain gauges in Coral Bay were used to determine mean daily rainfall, mean rainfall intensity, maximum daily rainfall, and an antecedent precipitation index (API) for each 26-day sampling period. Wave height data were collected from NOAA buoys near St. John or St. Croix (USVI). The relationships between TARs and parameters of rainfall (mean daily rainfall, mean rainfall intensity, and maximum daily rainfall) and wave height (mean, median and maximum) were tested using regression analyses.

The 2007 to 2012 study period included storm events characterized by a wide variety of total rainfall amounts and swell. Tropical Storm Otto during October of 2010 was the greatest rain-producing storm historically. One to two major storms (storms characterized by $100 \mathrm{~mm}$ or more of rainfall) occurred each year from 2007 - 2012, all of which occurred between May and December. Based on the cumulative rainfall per storm, Hurricane Earl (9/2010) only ranked $18^{\text {th }}$ but was notable due to the high wind and ocean swells produced. 
$\mathrm{TAR}$ and $\% \mathrm{~T}$ were normally greater during periods of greater rainfall and varied more with rainfall intensity and maximum daily rainfall than with mean rainfall intensity. At most sites, the greatest TARs were recorded during the sampling period when Tropical Storm Otto occurred. Because of the ephemeral nature of runoff on St. John, terrigenous sediment delivery only occurred during periods when there was enough rainfall to saturate the soil and produce saturation overland flow. Increased wave activity was sometimes associated with high rainfall, thus, sediment resuspension from the seafloor in addition to runoff from rainfall contributed to TAR during some rainfall/storm events. Resuspension caused by waves can lead to the entrapment of both terrigenous and carbonate grains, explaining why wave activity simultaneously increased TAR and lowered $\% \mathrm{~T}$, even during periods during both runoff and non runoff sampling periods. For example, resuspension during both Tropical Storm Otto (characterized by high runoff) and T.S. Earl (characterized by little to no runoff) produced \%Ts lower than the study period means. Some resuspension contributed to sediment accumulated in most traps during periods with moderate to low rainfall and wave activity.

$\% \mathrm{~T}$ and TAR were greatest nearest to the ephemeral stream outfalls, where most terrigenous sediments are presumed to be deposited following delivery to the bay. Because there is greater terrigenous sedimentation near shore and greater carbonate production offshore, mean grain sizes were normally finer near shore compared to at the offshore reef locations, as terrigenous grains are in general finer than carbonate grains. 
Consistent with (a) GIS-based modeling and watershed erosion studies at our study sites that predicted 3 to 10 times greater sediment delivery below developed compared with minimally developed watersheds, and (b) previous sediment trap studies, terrigenous sedimentation was on average approximately four times greater below developed compared with minimally developed watersheds. When API (a proxy for soil moisture) was considered in the regression model, rainfall better predicted TAR below the minimally developed but not the developed watershed. High density of exposed and compacted surfaces such as unpaved roads, where sediments are more easily eroded and where compaction of soil favors runoff over infiltration, may have contributed to greater terrigenous sedimentation overall below developed watersheds. Because there is greater terrigenous sediment below developed watersheds, mean grain size was normally (but not always) finer for sediment collected below developed compared with minimally developed watersheds.

Based on the comparisons between our total $(\Sigma \mathrm{AR})$ and silt accumulation rates (SARs) with published levels related to coral stress, corals near our study locations were most likely subjected to greater stress during (and immediately following) study periods of high rainfall, near shore, and below developed watersheds. SARs exceeding $4 \mathrm{mg} / \mathrm{cm}^{2} / \mathrm{d}$ were measured approximately twice as frequently ( $86 \%$ of sampling periods) at the shore sites with patch reefs below developed compared to the minimally developed watersheds ( $42 \%$ and $32 \%$ of sampling periods). Similarly, SARs exceeding $4 \mathrm{mg} / \mathrm{cm}^{2} / \mathrm{d}$ more commonly occurred at the offshore reef below the developed watershed ( $40 \%$ of sampling 
periods) than below the minimally developed watershed (11\% of sampling periods).

As building and human development continues along tropical and subtropical coastlines, the input of terrigenous sediment is likely to increase on coral reefs. The outcomes of this study have shown that sediment traps are an effective way to monitor general temporal and spatial patterns in terrigenous sedimentation. This study is the first marine sediment trap study to capture the natural variability in storms, rainfall, and wave activity over a study period longer than two years that also monitored distinct near shore and offshore areas below both developed and minimally developed watersheds simultaneously. Monitoring simultaneously across distinct areas over a long, 5-year study period made it possible to examine the relationship between terrigenous sedimentation, rainfall and wave activity statistically, and identify areas most likely to be subjected to the greatest sediment-related coral stress. The results of this study have generated potentially useful data related to watershed land management in tropical, coastal areas and will help inform future studies that will assess the effect of watershed restoration efforts on terrigenous sediment delivery to marine areas harboring coral reefs. 


\section{Chapter 1: Introduction}

\subsection{Scientific Problem and Research Objectives}

As building and human development activities continue along tropical and subtropical coastlines (Hernández- Delgado et al. 2012), the input of terrigenous (land-derived) sediment is likely to increase on coral reefs. In order to effectively manage watershed development and protect coral reef systems, it is necessary to understand the relationship between watershed development and coastal and reef sedimentation for individual watershed-reef systems. Particular points of interest include how marine terrigenous sediment accumulation and proportions, and sediment grain size will be affected under a range of watershed and climatic conditions.

Building on previous sedimentation studies by our research group (Gobbi 2009, Narwold 2009, Kolupski 2011, Gray et al. 2012), the objectives of this project are to examine how marine sedimentation varies in eastern St. John, US Virgin Islands as a function of: (a) different rainfall parameters and wave activity over several seasons (4-5), (b) variable locations with respect to shoreline runoff inputs and coral reefs, and (c) degree of watershed development.

Overall, the results of this project will shed light on the impact of watershed development on short-term (months to years) sedimentation near coral reefs. A better understanding of the long-term average sedimentary response to variable conditions in specific reef systems will provide important data to make general predictions on the effects of development on reef sedimentation for similar sites. These data will help watershed managers target the highest priority 
areas for restoration. Lessons learned may guide future watershed and reef management efforts in the face of increasing population, land use patterns, and climate change.

\subsection{Land-based (Terrigenous) Sedimentation}

In the Caribbean, sedimentation has been identified as a serious threat to coral reef communities (e.g. Rogers 1990, Torres and Morelock 2002, Pandolfi et al. 2003, Jeffery et al. 2005, Burke and Maidens 2004, Rogers et al. 2008, Bégin et al. 2014). Sediment may impact corals by physically blocking sunlight, smothering individual coral polyps, and limiting growth rate, fecundity, and recruitment (e.g. Rogers 1990, Fabricius 2005). The effect of sediment on corals depends on many factors, including sedimentation rate, composition (e.g., organic matter), and texture (i.e., grain size distribution) (Weber et al. 2006) as well as the tolerance level of individual coral species (Torres and Morelock 2002; Philipp and Fabricius 2003). Influxes of organic matter from land-derived (terrigenous) sediments can cause algal blooms, which block sunlight and may increase nutrient inputs, promoting growth of algae on the available substrate, which compete with corals for space. Sediment-derived particulate organic matter has been linked to increased coral stress compared with sandy sediments in one coral species (Weber et al. 2006). In addition, dissolved organic carbon may increase coral mortality by interacting with microbes on coral surfaces (Kuntz et al. 2005; Kline et al. 2006). Sediments of variable grain size can affect corals in different ways. Some coral species cannot remove fine-grained sediments as efficiently from their 
surfaces. For example, Weber et al. 2006 found that sandy grain-sized sediments were rejected three to four times more efficiently than silty sediments in $M$. peltiformis. Another study (Fabricius and Wolanski 2000) found an inverse relationship between grain rejection efficiency and sediment "stickiness", which is associated with grain size. On the other hand, coarse grains can be more abrading than fine grains (Anthony and Larcombe 2000). In Puerto Rico, the presence of silt lowered the net productivity of all coral species (Rogers 1977, 1983). It is not clear whether chronic or acute sedimentation events are more harmful overall to corals.

Although land-based sediment delivery to coastal waters harboring coral reefs occurs under natural conditions, human activities in the watersheds above reefs may increase erosion and delivery of terrigenous sediment to the reefs. This may occur as the result of vegetation removal, building of unpaved roads, and construction (e.g. Anderson 1994, UNEP 1994, Brooks et al. 2007, RamosScharrón and MacDonald 2005, 2007a, b, Larsen and Webb 2009, RamosScharrón 2010, Ramos-Scharrón et al. 2012). Accelerated delivery of terrigenous sediment into marine areas below developed watersheds affects sedimentation rates, composition and texture of sediment suspended in the water column and/or deposited on the sea floor and on corals. This has been documented extensively in the US Virgin Islands (Brooks et al. 2007, Gobbi 2009, Narwold 2009, Kolupski 2011, Gray et al. 2009, 2012), Hawaii (e.g. Ogston et al. 2004, Bothner et al. 2006, Calhoun et al. 2002, Draut et al. 2008, Storlazzi et al. 2009, etc), 
Venezuela (Bastidas et al. 1999), Micronesia (Golbuu et al. 2003), and Australia (Bartley et al. 2014), among other locations.

Fringing coral reefs in poorly flushed embayments surrounding steep islands may be especially vulnerable to exposure to land-based sedimentation because there is less energy to advect suspended sediments offshore, increasing the potential for deposition, which could lead to increased coral stress. Previous research on St. John, US Virgin Islands, a steep island surrounded by embayments with fringing coral reefs, demonstrated that erosion from developed watershed areas produce $300-900 \%$ more sediment relative to undisturbed watershed areas, and unpaved roads account for $>80 \%$ of these yields (Ramos-Scharrón and MacDonald 2007b; Ramos-Scharrón et al. 2014). Studies predicting total sediment delivery between developed and undeveloped watershed areas in St. John found three times greater total sediment delivery rates from developed compared to undeveloped areas $\left(31 \mathrm{Mg} / \mathrm{km}^{2} / \mathrm{yr}\right.$ [Ramos- Scharrón and Swanson 2012 vs. $10 \mathrm{Mg} / \mathrm{km}^{2} / \mathrm{yr}$ [Anderson and MacDonald 1998, respectively]). During some rainfall events, this eroded sediment will run off into the bays.

These studies of watershed erosion are supported by short-term (month to years) and long-term (decades to centuries) studies of marine sedimentation in St. John. In Coral Bay, St. John, USVI, a geologic study of marine sedimentation over the past decades and centuries revealed that long-term terrigenous accumulation rates increased by about 10 -fold since the 1960 's, coinciding with increased road building and the development of vacation homes and other touristrelated development. This study also showed that recent (last 60 years) marine 
terrigenous sedimentation due to development was even greater than during the planation era when the island was largely deforested to plant sugar cane fields and other cash and subsistence crops (Brooks et al. 2007). From 2009-2011, the rate of terrigenous sediment accumulation in bays below developed watersheds on St. John was calculated to be 6 times greater at the reef and up to 24 times greater near shore than below minimally developed watersheds (Gray et al. 2012).

\subsection{Findings of Previous Marine Sedimentation Studies}

Due to the potentially detrimental effects of sediment on corals, reef ecologists have been interested in monitoring sedimentation on reefs for many years using sediment traps. Though tube sediment traps have been used as a standard method for monitoring marine sedimentation in coral reef environments, there are limitations to this approach. Sediment traps cannot differentiate whether sediments are derived from runoff directly, resuspension, or by current advection. Sediment traps provide information about relative spatial and temporal differences in "gross sedimentation", or the total sum of sediments that are trapped in the sediment tubes from all processes and cannot measure "net" sedimentation, which is the measure only of how much sediment has been deposited on the seafloor and not been eroded (Storlazzi et al 2011). Both gross and net sedimentation are important in understanding the nature of sedimentrelated coral stress, and the proportion of each at any given time will vary with prevailing oceanographic conditions. More research to critically assess the use of 
sediment traps as a monitoring tool for land-based (terrigenous) sedimentation and sedimentation stress to corals is needed.

Various sedimentological processes have been explored on coral reefs using sediment traps, such as sediment budgets (Calhoun et al. 2002, Wolanski et al. 2005), the identification of mechanisms responsible for sediment movement on specific reefs (Calhoun et al. 2002, Ogston et al. 2004, Wolanksi et al. 2005, Draut et al. 2008, Storlazzi et al. 2009) and sediment resuspension (Baker et al. 1988, Prager et al. 1996, Gacia and Duarte 2001, Ogston et al 2004, Narwold 2009, Kolupski 2011). In addition, studies around the world using sediment traps have demonstrated that the rates of sediment accumulation and the response of corals to sedimentation vary geographically (e.g. Dodge et al. 1974, Rogers 1983, Cortés and Risk 1985, Nemeth and Nowlis 2001, Nugues and Roberts 2003, Field et al. 2008, Smith et al. 2008). Although a variety of processes such as currents, waves, and the activity of benthic organisms can contribute to sediment transport and resuspension, previous studies have shown that in some areas, waves are of primary importance (Calhoun et al. 2002, Ogston et al. 2004, You 2005, Bothner et al. 2006, Jordi et al. 2009).

Among the studies using sediment traps to characterize sediment processes, only a few have directly linked degree of watershed development to marine sedimentation rates. Nemeth and Nowlis (2001) evaluated the impacts of watershed development on marine sedimentation on St. Thomas, U.S. Virgin Islands over two seasons (1997-1999) (22 months on a reef below a watershed before, during and after construction in the watershed). Though they inferred the 
land-derived source texturally (by assuming all sediment $<75 \mu \mathrm{m}$ were terrigenous), they did not measure the chemical composition (siliceous vs. carbonate) of the sediment directly. Subsequent studies in the USVI (Rawling et al. 2010) demonstrated that sediment texture does not provide an accurate proxy of terrigenous sediment source.

Among the few sediment trap studies that have related their findings to watershed development or human activities, most sampled on gradients from the source of terrigenous input (stream) and found that sedimentation was greater nearer to the source of terrigenous sediment input (Bastidas et al. 1999, Nugues and Roberts 2004, Smith 2008). Only studies conducted that were part of this project in previous years (Gray et al. 2009, 2012) have compared sedimentation between developed and minimally developed watersheds simultaneously, which allows for establishing comparisons associated with variable environmental conditions. Previous studies also have not thoroughly explored how terrigenous sediment accumulation varied below watersheds with different degrees of development or physical characteristics (i.e. watershed area and relief). Furthermore, while some studies explored the relationship between rainfall and sedimentation (e.g. Nemeth and Nowlis 2001, Wolanksi 2009, Bothner et al. 2006), these studies were relatively short in duration (less than two years), which may not be long enough to sample the full range of natural variability of storms/rainfall events.

In summary, current literature has contributed to our knowledge about sediment-related coral stress, marine sediment dynamics, and in general, the role 
watershed development plays in increasing sedimentation in the marine environment. This study further builds upon the knowledge of watershed-marine sediment dynamics with a long-term, relatively short sampling interval study conducted below developed and minimally developed watersheds and shore and reef locations simultaneously. This study approach uniquely allows us to examine how marine sediment parameters vary over a range of environmental conditions and to examine factors that might explain the spatial patterns in sedimentation among our sampling locations.

\subsection{Research Questions}

St. John, U.S. Virgin Islands is an ideal location to study the effects of rainfall and human development on sedimentation on coral reefs. From a management perspective, there is a need on St. John for studies that examine how watershed development and restoration affect marine sedimentation (Coldren et al., 2013; Center for Watershed Protection, 2008). St. John has been a target for model watershed restoration approaches (refer to "Methods and Location" chapter for more details). Secondly, just over half (56\%) of the island's landmass with fringing reefs is largely protected from development (aside from some unpaved road networks and few structures) by the Virgin Islands National Park and Coral Reef National Monument, which makes it possible to directly compare reef sedimentation in bays below both developed and minimally developed watersheds. 
The specific research questions addressed in this thesis are the following:

1A. How does terrigenous sedimentation (\% terrigenous and terrigenous accumulation rates) vary:

i. temporally over a 4-5 year period in response to rainfall/storm events and wave activity? and

ii. spatially

1. between the shore and reef and

2. areas drained by developed vs. undeveloped watersheds?

$H_{O} 1 \mathrm{Ai}$. There will be no change in terrigenous sedimentation in response to rainfall.

$H_{i}$ lAi. Terrigenous sedimentation will increase during runoff-triggering rainfall/storm events.

$H_{O}$ 1Aii. There will be no difference between terrigenous sedimentation in near shore compared with offshore reef sites/locations, nor will there be any difference in sedimentation between sites/locations below developed versus minimally developed watersheds.

$H_{i}$ lAii. Terrigenous sedimentation will be greater in near shore compared with offshore reef sites/locations, and terrigenous sedimentation will be greater below developed versus minimally developed watersheds. 
1B. Is there a significant relationship between terrigenous accumulation rates and rainfall?

b. If so, how does this relationship differ among

i. locations, and

ii. different rainfall parameters (i.e., mean cumulative daily rainfall, mean rainfall intensity, maximum daily rainfall, and antecedent rainfall)

$H_{o} 1 B$. Terrigenous accumulation rates will not vary significantly with rainfall.

$H_{i} 1 B$. Terrigenous accumulation rates will vary significantly with rainfall.

$H_{o} 1 \mathrm{Bi}$. The correlation between terrigenous accumulation and rainfall will not differ among locations.

$H_{i} 1$ Bi.Terrigenous accumulation will correlate more strongly with rainfall a) at shore compared to reef locations b) where resuspension is minimal and c) in developed compared with minimally developed locations.

$H_{o} 1$ Bii. The correlation between terrigenous accumulation rates and rainfall will not differ among different rainfall parameters (mean daily rainfall, mean rainfall intensity, and maximum daily rainfall).

$H_{i}$ lBii.Terrigenous accumulation will correlate more strongly with mean rainfall intensity and maximum daily rainfall than mean daily rainfall. 
2. How does sediment texture vary:

a. over a 5-year period in response to rainfall/storm events? and

b. spatially

$i$. between the shore and reef and

ii. areas drained by developed vs. undeveloped watersheds?

$H_{o}$ 2. Sediment texture will not vary a) in response to rainfall, b) spatially between shore and reef areas or c) with respect to development.

$H_{i} 2 a$. Sediment grain size will decrease in response to rainfall and will be finer in shore compared with reef areas and below developed compared with minimally developed watersheds.

3. A. How do indicators of sediment stress to corals (total sediment accumulation rates and silt accumulation rates) vary

a. over a 5-6 year period and

b. spatially between developed and undeveloped areas?

B. What do these results suggest about the potential for sediment-induced coral stress at our sites near corals?

$H_{o}$ 3. Potential sediment stress to corals will not vary temporally over the 5-6 year study period and there will no difference in potential sediment stress to corals below developed compared with minimally developed watersheds. 
$H_{i} 3$. There will be greater potential sediment stress to corals during storms/high rainfall periods and below developed compared with minimally developed watersheds.

4. What do the results of this study suggest: about the impact of watershed development and restoration on terrigenous sedimentation and about the efficacy (and limitations) of using traditional sediment traps to measure temporal and spatial variation in terrigenous sedimentation?

\subsection{Significance of Study}

This long-term study will aid in establishing spatial and seasonal differences in contemporary sedimentological patterns among several locations around St. John and examine how these patterns change under a wide variety of rainfall/storm conditions. Data collected will aid managers to: a) understand how marine sediment dynamics differ spatially, seasonally and in response to rainfall; and b) target high risk/high need areas in watersheds and bays. Secondly, the marine sedimentation data provided in this study can help identify which coral reefs are most prone to potentially harmful sedimentation and under what conditions these reefs are prone to potential sedimentation stress. From these spatial differences in sediment accumulation rates, it can be inferred which subcatchments are contributing the most to marine sedimentation and thus which may be highest priority for restoration efforts. Because efforts and funds are often limited in tropical coastal regions it is important to identify the areas at greatest 
risk and in most need of limited restoration funds. The approach used in this study is broadly applicable to aid in proper management of tropical, coastal watershed development in general. 


\section{Chapter 2: Location and Methods}

\subsection{Study Site: St. John, U.S. Virgin Islands}

St. John, in the U.S. Virgin Islands is located $4 \mathrm{~km}$ east of St. Thomas and $60 \mathrm{~km}$ north of St. Croix. With a land area of about $48 \mathrm{~km}^{2}$, (roughly $13 \mathrm{~km}$ long and $4 \mathrm{~km}$ wide), it is the smallest of the three major US. Virgin Islands (Thomas and Devine 2005) (Figure 2.1), and as of 2010, had a population of around 4,500 (USVI BER 2010). The island is characterized by steep slopes ( $80 \%$ of island has slopes exceeding 30\%) (CH2M Hill Inc. 1979) and highly erodible soils (Rankin 2002).

The predominant winds affecting St. John are trade winds, which generally blow from the east during the winter and the southeast during the summer. These winds are strongest during the winter from December through February and blow at 11-21 knots $\left(\sim 20-40 \mathrm{~m} \mathrm{~s}^{-1}\right) 60 \%$ of the time (Towle et al. 1976). During these winter months, the Christmas Winds from the north also occur, leading to increased wave height in most bays (Wüst 1964). The two main ocean currents affecting St. John are the Antilles Current to the north in the Atlantic Ocean, which flows northwest (Rowe et al. 2010) and the Caribbean Current to the south in the Caribbean Sea, which flows west (Wüst 1964). Tides in St. John typically fluctuate by $\sim 0.2 \mathrm{~m}$ (Tide-forecast, 2014).

The climate of St. John is subtropical, with seasonal rainfall and episodic tropical storms/hurricanes. Precipitation ranges from $890-1400 \mathrm{~mm} \mathrm{yr}^{-1}$, and the majority of rainfall occurs from May to November (though June-August can be relatively dry), with a dry season from December through April (Weaver and 
Chinea-Rivera 1987, Reilly 1991). During the rainy season, large tropical storms and low-pressure systems pass over St. John. During some of these events, the ephemeral streams that characterize St. John are activated, and high rates of soil erosion lead to terrigenous sediment delivery to the bays (MacDonald et al. 1997, MacDonald et al. 2001, Ramos-Scharrón and MacDonald 2007a, b). There are no perennial streams on St. John, but ephemeral streams can run for days to (less commonly) weeks after intense storm events (MacDonald et al. 1997, 2001; Cosner 1972; personal observation).

\subsubsection{Coral Bay}

Coral Bay is on the eastern side of St. John (Figure 2.1). The hilly rural community of Coral Bay is built on the largest aggregation of watersheds draining into a single bay on St. John and is comprised of many bays/inlets. (Figure 2.2) The watershed areas of Coral Bay that were part of this study (the area of Coral Bay on the map shaded in either green or brown: Coral Harbor, Plantation Hill, and Coral Bay South Shore cover an area of approximately $10.1 \mathrm{~km}^{2}$, or $83 \%$ of the total land area draining towards Coral Bay $\left(12.2 \mathrm{~km}^{2}\right.$ ) (Figure 2.2). The watershed area draining directly into Coral Harbor is much larger than both Plantation Hill and Coral Bay South Shore watersheds, which are 4.5, 0.56, and $0.76 \mathrm{~km}^{2}$, respectively (Ramos-Scharrón, personal communication) (Table 2.1). The area draining into Coral Bay is comprised of eight sub-catchments that are each drained by at least one ephemeral stream (Figure 2.2). The mean slope of these sub-catchments is $\sim 30 \%$, and several areas exceed $35 \%$, including 
within the Plantation Hill and Coral Bay South Shore watershed areas (44 and $38 \%$, respectively) (Center for Watershed Protection 2008, Table 2.1). The community of Coral Bay has the second largest population on the island $(\sim 650$ persons [Schwing 2006]), exceeded only by Cruz Bay, the main port, on the western side of the island ( 2,700 persons [Schwing 2006]) (Figure 2.1). The unpaved road density in the developed parts of Coral Bay, including Coral Bay South Shore $(3.4 \mathrm{~km})$ and Coral Harbor $(2.6 \mathrm{~km})$ is greater than in minimally developed Plantation Hill (1.14 km), Little Lameshur (0.4 km) and Great Lameshur (1.0 km) (Table 2.1). For comparison, unpaved road density was similar to Coral Bay in developed watersheds Fish Bay $\left(3.7 \mathrm{~km} / \mathrm{km}^{2}\right)$ and Cinnamon Bay $(3.3$ km/km²) (Ramos- Scharrón and MacDonald 2007b. Development and numerous unpaved roads (Table 2.1), coupled with steep topography, highly erodible soils, and periodic, acute storm events, make Coral Bay a likely source for high levels of terrigenous sedimentation into the bay (WRI and NOAA, 2005, Brooks et al. 2007, Gray et al. 2012).

Marine habitats in Coral Bay are diverse and include mangrove communities, salt ponds, seagrass beds, coral reefs (many Acropora and Porites corals), and turtle nesting areas (Zitello et al. 2009, Friedlander et al. 2012). In most parts of the bay, microalgae biomass is characterized by abundant calcareous algae, particularly Halimeda spp. (Hill et al. 2014, personal observation). Coral Harbor is in the northernmost part of the bay (outlined by the brown watershed area labeled "Coral Harbor", Figure 2.2) and directly receives drainage from the largest watershed area through several ephemeral streams. The shoreline of the 
harbor is partially lined by mangroves, which likely trap sediments from the watershed. The benthos in Coral Bay Harbor is characterized by mostly very fine, dark terrigenous clays and some seagrass. This part of the bay also houses many live-aboard boats that may release waste into the harbor.

Just southwest of the harbor is the "Plantation Hill" watershed area (Figure 2.2), which is relatively undeveloped compared with other watershed areas in Coral Bay and therefore serves as the Coral Bay "reference" shore location. The benthos in the Plantation Hill marine area (also called Saunders Bay) is characterized by fine sands, seagrass, and some coral cover (Zitello et al. 2009, personal observation) (Figure 2.2).

The southernmost study location adjacent to Plantation is what is referred to in this study refer to as "Coral Bay South Shore" (Figure 2.2). This includes two sub-catchments draining the area above Calabash Boom and the Shipwreck restaurant into Johnson's Bay. The benthos of Coral Bay South Shore consists mostly of seagrass beds and limited coral (personal observation). In the middle of Coral Bay (see: “Coral Bay Reef”, Figure 2.2) are various patch reefs characterized by live hard corals and soft corals and sand channels (Figure 2.2). Towards the northern part of the bay, the reef structure has been described as consisting of a well-developed carbonate framework growing on bedrock with high coral diversity (Smith et al. 2011). Sponges and gorgonians are common at this site and epilithic and crustose coralline algae characterize the algal community (Smith et al. 2011). 


\subsubsection{Great and Little Lameshur Bays}

Most of the two watersheds draining into Great and Little Lameshur Bays are within the Virgin Islands National Park with the exception of a small private property near the ridgeline (Figure 2.2). The watershed characteristics of Great and Little Lameshur are very similar in degree of slope (20 and 22\%, respectively), vegetative cover, and degree of development (Table 2.1). Development within the bays is limited to the structures making up the Virgin Islands Environmental Resource Station (VIERS) in the Great Lameshur Bay watershed area, small ruins in Little Lameshur Bay, and about three miles total of partially paved roads (Table 2.1), some of which are near the coast and watershed crest. While there is natural drainage in the Little Lameshur watershed area, there is a large, man-made earthen but leaky retention pond above Great Lameshur Bay constructed in the 1950's (MacDonald et al. 1997). During periods of high rainfall, the pond fills with runoff. Some of this water drains out of a spring at VIERS headquarters and part drains slowly into Great Lameshur Bay, long after the rain event has ended (personal observation); however, this drainage is filtered through coarse alluvial deposits before reaching the bay, so it is likely that little sediment from the pond reaches Great Lameshur (Ramos-Scharrón and MacDonald 2007c) (Figure 2.2).

In all, there are two drainage ephemeral streams in Great Lameshur Bay; one in each of the northeastern (where the retention pond sometimes drains) and northwestern corners of the bay (Figure 2.2, the general location of retention pond is marked by a red circle). In Little Lameshur, there is one drainage ephemeral 
stream in the northwestern corner of the bay (Figure 2.2). The mean slope of Little and Great Lameshur watersheds are lower than that of Coral Bay in general at $\sim 20 \%$ (compared to $\sim 30 \%$ for all of Coral Bay) and there are fewer paved roads (Table 2.1).

The benthos of Lameshur Bay in near-shore areas is composed mostly fine to coarse sands and seagrass with terrigenous grains intermixed. There are mangroves in the northwestern edge of Great Lameshur Bay that are often fed by the ephemeral stream draining the Great Lameshur Bay watershed (Figure 2.2). Offshore, Tektite and Yawzi reefs, along the mouth of Great Lameshur Bay are well-studied fringing coral reefs (e.g. Edmunds and Witman 1991; Edmunds 2000, 2002, and 2007; Rogers and Miller 2006, Rogers 2008, Rogers et al. 2008). The benthos of offshore reef locations in Lameshur Bay is characterized by coarse sands composed mostly of carbonate biogenic sand and shell fragments (in contrast to Coral Bay Reef benthos, which is mostly Halimeda intermixed with fine sand). The benthos in the centers of Little and Great Lameshur Bays consist of mostly bare biogenic carbonate sand and patches of seagrass (personal observation) (Figure 2.2). 


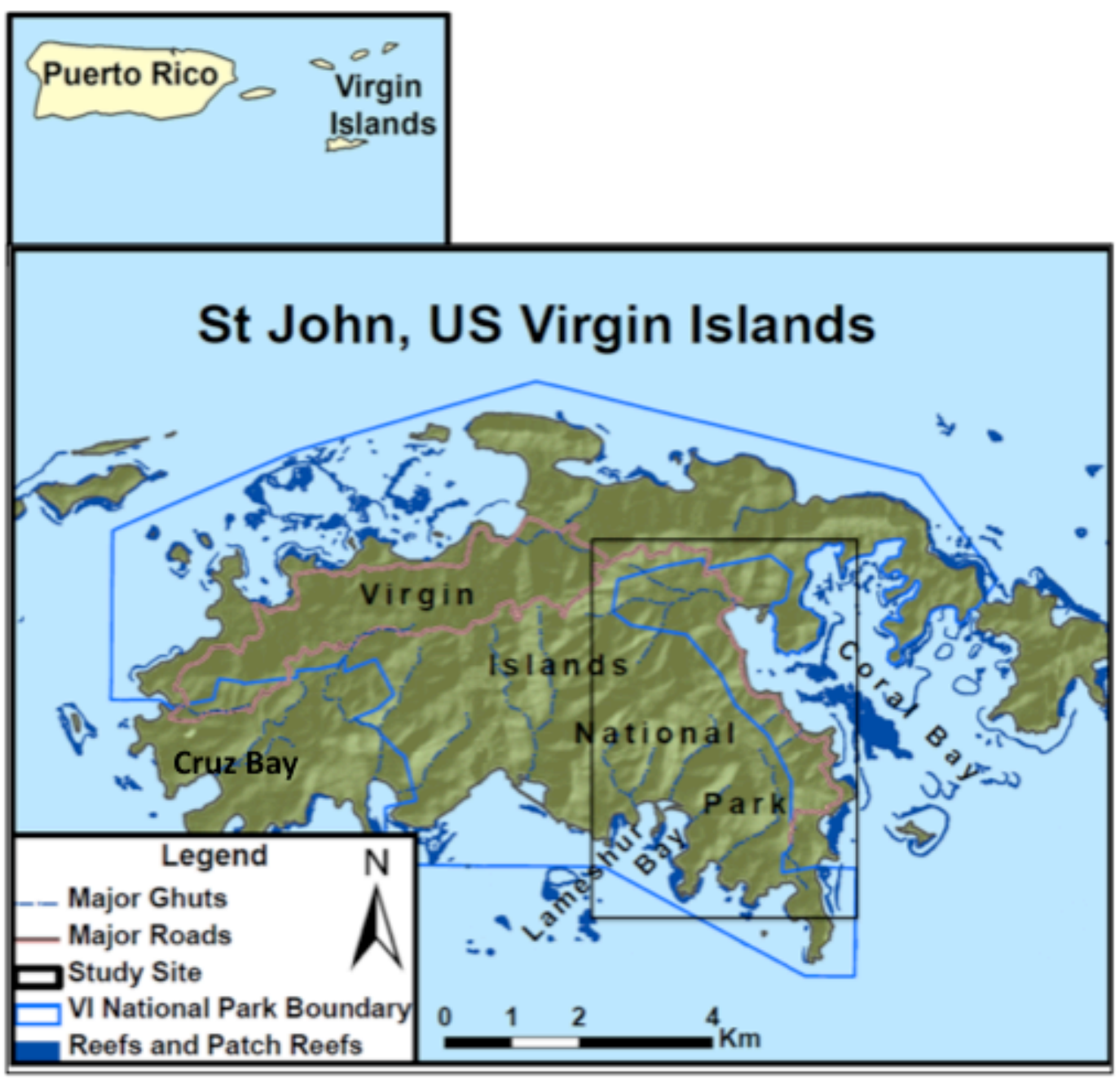

Figure 2.1 (Top) St. John, USVI in relation to Puerto Rico and the other U.S. Virgins Islands (St. John is the smallest, northeastern-most island shown). (Bottom) St. John with the National Park Boundary in blue and the general study location (in the black square, which is also the inset for Figure 2.2), showing the location of Lameshur and Coral Bay. Cruz Bay, the major town on the island, is marked on the eastern side of the island. 


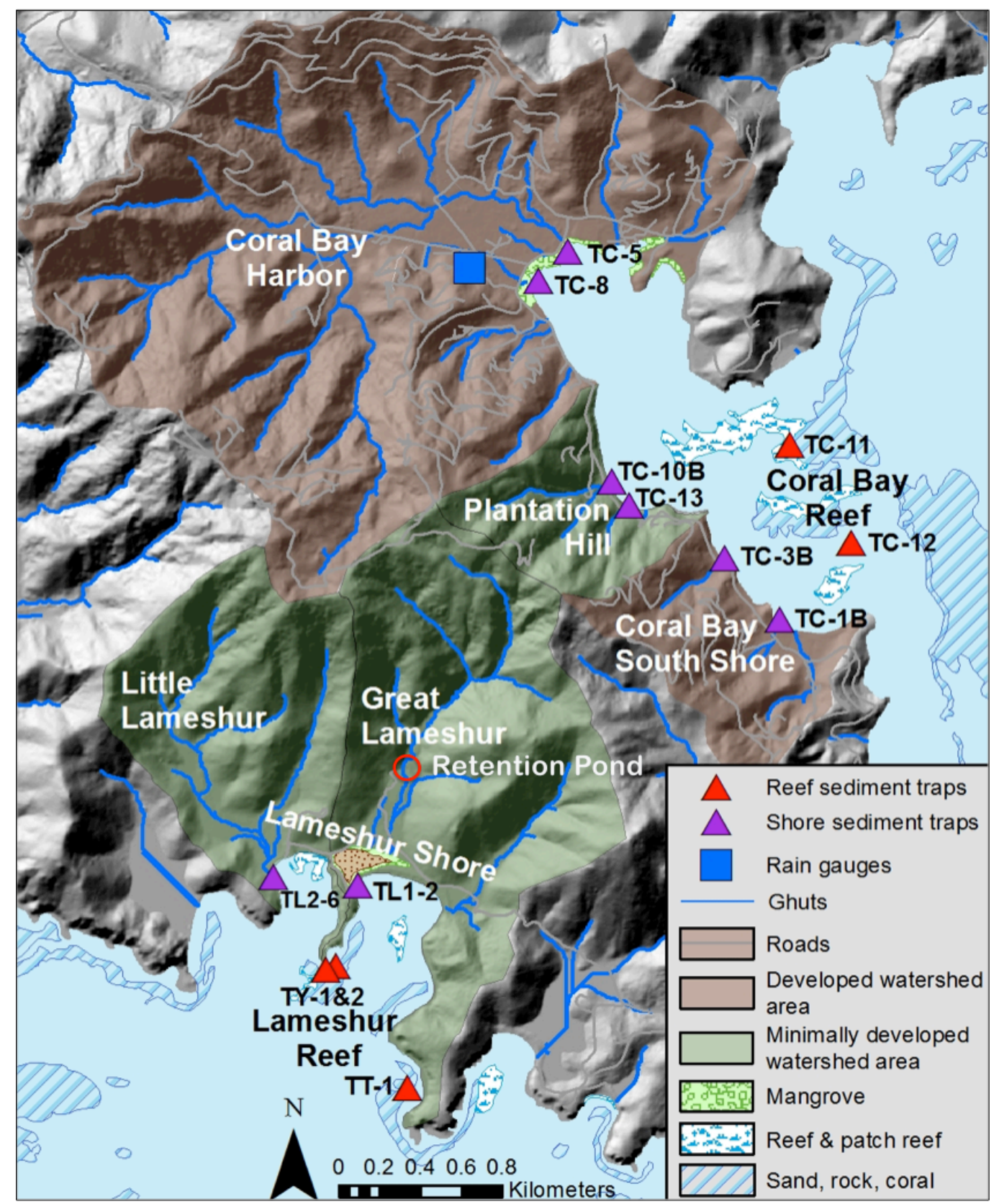

Figure 2.2. The general study locations (marked by the box in Figure 2.1) of Coral and Lameshur Bays showing near-shore (purple triangles) and offshore reef (red triangles) sampling sites and locations. Developed watershed areas are shaded in brown (Coral Bay Harbor and Coral Bay South Shore) and minimally developed watershed areas are in green (Plantation Hill and Lameshur Shore). The blue and gray lines in the watersheds represent the location of ephemeral streams and roads, respectively. The blue stippled areas with white background in the bays indicate where patch reefs are present; the blue, diagonal lined areas indicate the presence of sand, rock and coral (Zitello et al. 2009). The retention pond is marked in Lameshur by the red circle. Benthic substrate characteristics are indicated in the legend (Zitello et al. 2009). 
Table 2.1. Physical characteristics of St. John bays and watershed areas for this project (see Figures 2.1 and 2.2 for location and extent of watershed areas)(*Ramos-Scharrón unpublished, **Hubbard et al. 1987, ***McCreery 2007) (Table modified from Harrington, 2014).

\begin{tabular}{|c|c|c|c|c|c|}
\hline \multirow[b]{2}{*}{ Watershed Area } & \multicolumn{2}{|l|}{ Lameshur Bay } & \multicolumn{3}{|l|}{ Coral Bay } \\
\hline & Great Lameshu & Little Lameshur & Plantation Hill & Coral Bay South Shore & Coral Harbor \\
\hline Development & Minimal & Minimal & Minimal & High & High \\
\hline Drainage Area $\left(\mathrm{km}^{2}\right)^{*}$ & 2.4 & 1.9 & 0.56 & 0.76 & 4.5 \\
\hline Mean Slope (\%)** & 20 & 22 & 44 & 38 & 18 \\
\hline Unpaved Road Area (km)* & 2.5 & 0.72 & 0.64 & 2.6 & 11.5 \\
\hline Unpaved Road Density (km)* & 1 & 0.38 & 1.14 & 3.36 & 2.58 \\
\hline Watershed to Bay area ratio** & 6.5 & 10.3 & 4.1 & 4.1 & 15.5 \\
\hline \# Primary Ephemeral Streams & 2 & 1 & 2 & 2 & 1 \\
\hline Mean Bay Depth $(\mathrm{m})^{* * *}$ & 6.5 & & & 2.7 & 3.7 \\
\hline Bay Surface Area $(\mathrm{m} 2)^{* * *}$ & 960,000 & & & 110,000 & 690,000 \\
\hline Bay Volume $(\mathrm{m} 3)^{* * *}$ & $6,200,000$ & & & 310,00 & $2,600,000$ \\
\hline
\end{tabular}




\subsection{Field Methods}

\subsubsection{Sampling sites}

Sediments were collected in sediment traps at the benthic surface below ephemeral stream outfalls in near-shore areas (purple triangles: Figures 2.3 and 2.4), and in offshore reef environments (red triangles: Figures 2.3 and 2.4) starting in August of 2007 in Lameshur Bay and August 2008 in Coral Bay (though the majority of the sampling sites were set up in 2009). Sediment trap and benthic surface sampling sites targeted marine near-shore areas below two developed (Coral Bay and South Shore, shaded brown) and two minimally developed (Plantation Hill and Lameshur Bay, shaded green) watershed areas (Figures 2.3 and 2.4; Table 2.1). In addition to near-shore sites, there were offshore reef sampling sites in Coral Bay and in Lameshur Bay reefs (Figures 2.3 and 2.3; and Table 2.2).

Throughout the study, the word "site" is used to refer to specific sedimenttrap sampling sites (marked as triangles in Figures 2.2-4), and "location" refers to data pooled from 2 or 3 sites (multiple traps) in similar environments (i.e., near shore or offshore) and in proximity to each other (Table 2.2). In order to compare sampling sites in developed and minimally developed locations, we paired developed and reference locations based roughly on their relative watershed size and slope as well as their geographic orientation and shoreline features (such as presence or absence of mangroves) (Table 2.1; Figure 2.2). Paired reference/developed locations for this study are: Lameshur Bay Shore (reference)/Coral Bay Harbor (shore, developed watershed), Plantation Hill 
(shore) (reference)/Coral Bay South Shore (developed watershed), and Lameshur Bay reef /Coral Bay reef (Table 2.2, Figure 2.2).

Near-shore sampling sites below developed watershed areas included two sites in the "Coral Bay Harbor" location (TC-5 and TC-8) and two sites in "Coral Bay South Shore" location (TC-1B and TC-3B) (Table 2.2; Figure 2.3). Two sampling sites below the minimally developed "Plantation Hill" watershed area are grouped as the "Plantation Hill" location (TC-10B and TC-13) (Table 2.2; Figure 2.3). Near shore sediment traps deployed below ephemeral stream outfalls below the Great Lameshur (TL1-2) and Little Lameshur watershed areas (TL2-6; and TL1-2) are grouped as the "Lameshur Bay Shore" location, which are within the VI National Park and only minimally developed (Figure 2.4; Table 2.2).

Off-shore reef sites in Coral Bay included TC-11 and TC-12 (collectively, "Coral Bay Reef" location, Table 2.2), which are located in the middle of bay near patch reefs to the south and true reefs with well-developed carbonate framework to the north (Smith et al. 2011) (Figure 2.3). In Lameshur Bay, there were three reef sites at Yawzi (TY-1 and TY-2) and Tektite (TT-1) (collectively, "Lameshur Bay Reef" location, Table 2.2) (Figure 2.4). Yawzi Reef was off the headland between Great and Little Lameshur bays and Tektite Reef was located on the eastern wall of Great Lameshur bay, close to the mouth of the bay (Figure 2.4). Both reef locations contain fringing coral reefs (Rogers 2008). 
Table 2.2. Sampling "locations" including the sediment trap "sites" comprising each location, the bays where sites were located, watershed development, site type, and watershed area (Ramos- Scharrón unpublished). Sediment trap data collected from proximal "sites" with similar degree of development were grouped together as "locations".

\begin{tabular}{|l|l|l|l|l|l|}
\hline Location Name & Bay & Sediment Trap Site & Development & Site Type & Watershed Area $\mathbf{( k m}^{\mathbf{2}}$ ) \\
\hline Coral Bay Harbor & Coral & TC-5, TC-8 & yes & Shore & 4.5 \\
\hline Plantation Hill & Coral & TC-10B, TC-13 & no & Shore & 0.56 \\
\hline Coral South Shore & Coral & TC-1B, TC-3B & yes & Shore & 0.76 \\
\hline Coral Bay Reef & Coral & TC-11, TC-12 & yes & Reef & na \\
\hline Lameshur Shore & Lameshur & TL1-2, TL2-6 & no & Shore & 4.3 \\
\hline Lameshur Reef & Great Lameshur & TY-1, TY-2, TT-1 & no & Reef & na \\
\hline
\end{tabular}


In summary, for this study we present data from eight sediment trap sites in Coral Bay (six near-shore and two reef sites) from three "locations". In Lameshur Bay, there are five sediment traps, two of which comprise the "nearshore" environment (or hereafter called "Lameshur Shore" location) and the remaining three the "reef" environment (or hereafter called "Lameshur Reef" location) (Table 2.2). The depth of traps at shore sites ranged from 0.5 to $1.6 \mathrm{~m}$ (mean: $1.0 \mathrm{~m}$ ) and at reefs 6 to $11 \mathrm{~m}$ (mean: $7.7 \mathrm{~m}$ ) (Appendix I).

\subsubsection{Sediment Trap and Benthic Surface Sediments}

Each sediment trap consisted of four 8" PVC tubes with a height-todiameter ratio of 4:1. The height to diameter ratio was chosen for optimal trapping following previous studies (Gardner 1980a, b). The four PVC tubes were attached to a fence post that were either pounded directly into the seafloor or secured on a cement block that was placed on the seafloor. Sediment traps were mounted so the tops of the tubes were $60 \mathrm{~cm}$ above the seafloor (Figure 2.5).

From September to November 2007, sediment trap deployment periods (sampling periods) at Lameshur Bay (one shore [TL1-2] and two reef sites [TY-1 and TY-2]) were two weeks in duration. Remaining traps were not deployed until 2009 (TT-1) and 2010 (TL2-6). In Coral Bay, one trap (TC-5) used in this study was deployed in 2008, while others were deployed in 2009 (TC-1B, TC-3B, TC8, TC-10B, TC-11, TC-12) and 2010 (TC-13) (Appendix I). In Lameshur and Coral Bays, the duration of normal sediment trap deployment (i.e., not during the off-season) ranged from 8 to 32 and 9 to 31 days, respectively (Appendix II). 
Trap and benthic surface sediments were collected and processed approximately every 26 days starting in 2008 and 2009, respectively (mode deployment duration in both Lameshur and Coral Bay after 2008: 26 days; the mean was slightly greater at 27 days due to the fact that sampling periods that did not last for 26 days were typically greater rather than less than 26 days) (Appendix II). With a couple of exceptions, collection dates in Coral Bay were typically two days prior to collection dates in Lameshur Bays for processing and logistical purposes. 


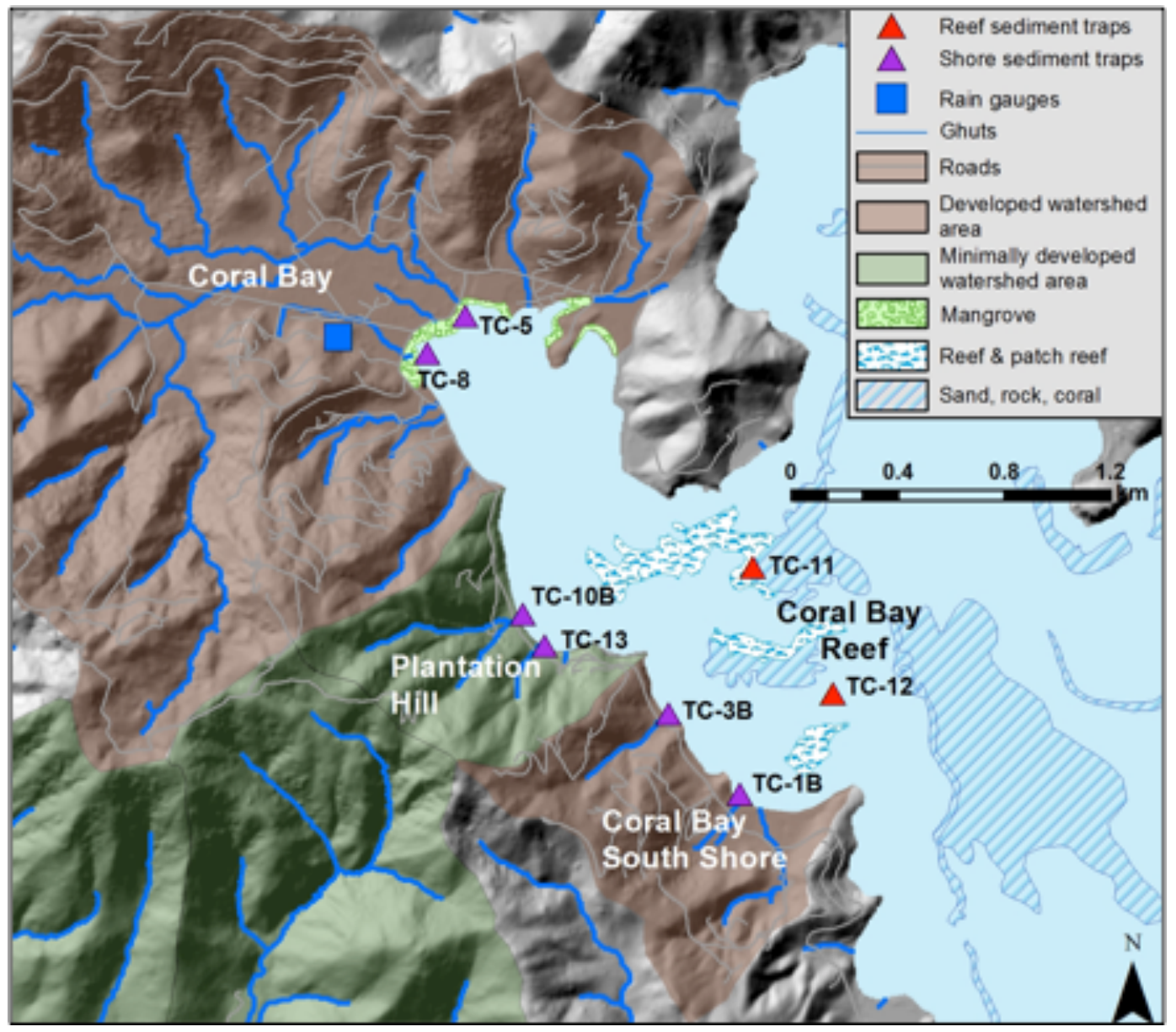

Figure 2.3. Map of Coral Bay showing near-shore (purple triangles) and offshore reef (red triangles) sampling sites and locations. Developed watershed areas are shaded in brown (Coral Bay Harbor and Coral Bay South Shore) and minimally developed watershed areas are in green (Plantation Hill). The blue stippled areas with white background in the bays indicate where patch reefs are present; the blue, diagonal lined areas indicate the presence of sand, rock and coral (Zitello et al. 2009). 


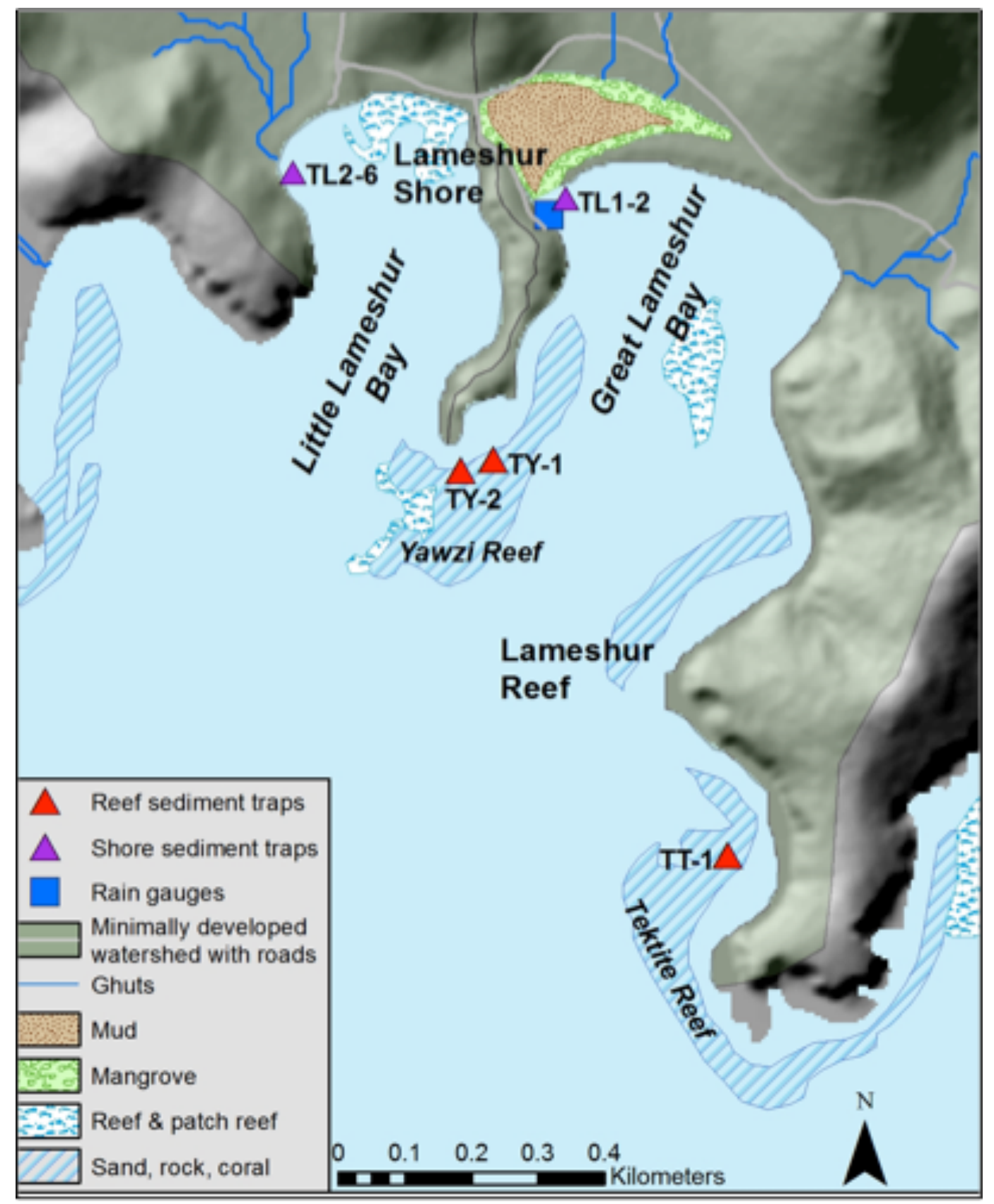

Figure 2.4. Map of Lameshur Bay showing near-shore (purple triangles) and offshore reef (red triangles) sampling sites and locations. The rain gauge used for this watershed area is indicated by the blue square. The green shading of the watershed area indicates that it is minimally developed. The blue stippled areas with white background in the water indicate where patch reefs are present; the nearby blue, diagonal lined areas indicate the presence of sand, rock and coral (Zitello et al. 2009). 


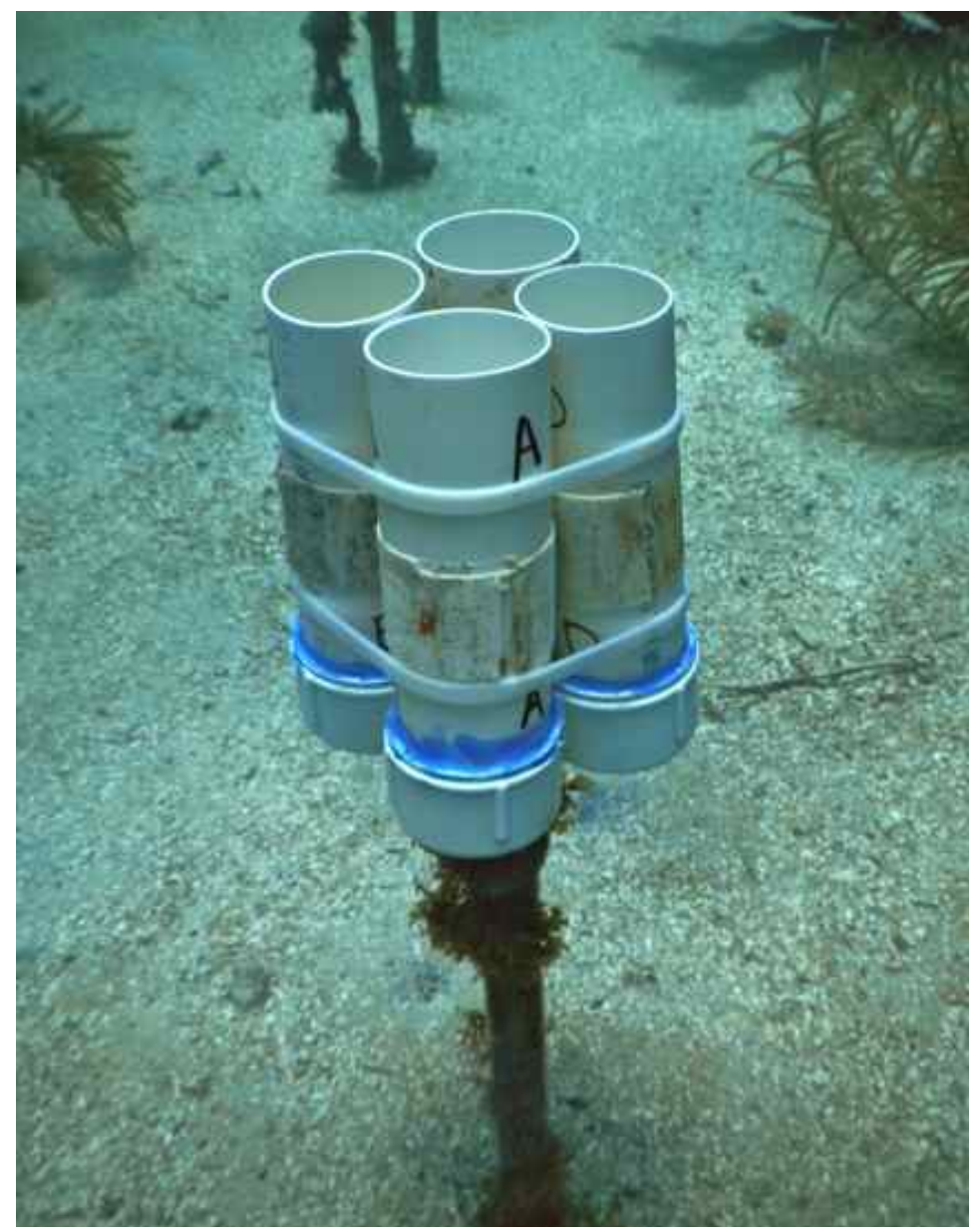

Figure 2.5. Example of one sediment trap which was built using a fence post as the mounting structure. The tops of tubes are open to collect sediment and are positioned $60 \mathrm{~cm}$ above the seafloor (Photo: Stephen Campbell). 


\subsubsection{Rainfall and Storms}

A high-resolution HOBO Pendant Data recording, tipping bucket rain gauge was installed on the VIERS laboratory roof near Great Lameshur Bay in September 2008 (Figure 2.3). In Coral Bay, rain data were collected by the Coral Bay Community Council at a long-term tipping bucket rain gauge and "Agave" rain gauge as indicated by the blue square in Figure 2.3 (the location of the gauges are in close proximity). In cases where there were gaps in the Agave rain gauge data, Lameshur Bay rain gauge data were used. In the Great and Little Lameshur Bay watershed areas, many major storm events were documented from 2008 through 2012 based on field assistant notes and photographs as well as follow-up research. When it was possible to observe some of the ephemeral streams during and following storms, the date and time when ephemeral streams began and stopped running were noted, and photographs were taken daily. Using rainfall data and newspaper and weather reports, storm events during the period of study were identified and described. "Storms" were defined as one or more consecutive days with $20 \mathrm{~mm}$ or more of cumulative rainfall per day; "major storms" were defined as one or consecutive days of $20 \mathrm{~mm}$ or more of cumulative rainfall per day that totaled $100 \mathrm{~mm}$ or more cumulative rainfall per storm.

\subsection{Lab Methods}

\subsubsection{Sediment Processing and Accumulation Rates}

Sediment collected within three of the four sediment trap tubes at each site were filtered through a pre-weighed $3 \mu \mathrm{m}$ filter and rinsed to remove salts, dried 
at $100{ }^{\circ} \mathrm{C}$ and weighed to the nearest $0.1 \mathrm{mg}$ using an analytical balance (Gobbi 2009, Gray et al. 2012). Sediment trap accumulation rates (in $\mathrm{mg} / \mathrm{cm}^{2} / \mathrm{d}$ ) were determined by dividing sediment mass by the length of time of accumulation (typically 26 days) and the internal area of the sediment trap tube $\left(21.2 \mathrm{~cm}^{2}\right.$ or

$\left.24.6 \mathrm{~cm}^{2}\right)$. The masses of the sediment in three tubes (A, B, and C) were averaged to find the mean trap accumulation rate (in $\mathrm{mg} / \mathrm{cm}^{2} / \mathrm{d}$ ) at each site for each sampling period. The fourth replicate trap sediment sample (tube D) was not filtered but was used for textural analysis and archived. Two replicates of the benthic samples were rinsed with fresh water and dried in the sun while the third replicate was frozen for further textural analysis and archived.

\subsubsection{Sediment Composition}

The relative composition ( $\%$ organic, $\%$ carbonate, and $\%$ terrigenous [siliceous]) of the sediment trap and benthic surface sediment samples was determined by Loss on Ignition (LOI) (Heiri et al. 2001). The organic fraction (burned at $550{ }^{\circ} \mathrm{C}$ ) and calcium carbonate fractions (calculated from the stoichiometric relationship with carbon dioxide lost during a subsequent $950{ }^{\circ} \mathrm{C}$ combustion) were subtracted from the total pre-combusted sediment mass to determine the residual siliceous or terrigenous mass (Maher, 1998).

This analysis was used as the basis for determining the proportion of terrigenous material (hereafter referred to as 'terrigenous \%). In order to calculate the terrigenous trap accumulation rates $\left(\mathrm{mg} / \mathrm{cm}^{2} / \mathrm{d}\right)$, the terrigenous $\%$ determined by LOI was multiplied by the total accumulation rate $\left(\mathrm{mg} / \mathrm{cm}^{2} / \mathrm{d}\right)$. Because 
factors such as bio-fouling and entrapment of marine organisms confounded the estimation of organic sediment accumulation, the organic fraction of sediment was excluded from the analysis and \% terrigenous of inorganic sediments was determined by the following formula:

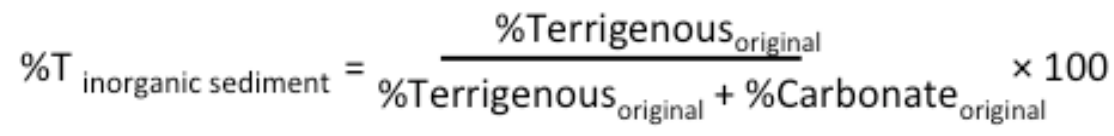

\subsubsection{Grain Size Analysis (texture) and Siltation Rates}

The unfiltered replicate (trap tube $\mathrm{D}$ and benthic replicate $\mathrm{C}$ ) was wet sieved through a $1000 \mu \mathrm{m}$ mesh to remove gravel and then the remaining sediment was scanned on a Beckman-Coulter LS200 Laser Particle Sorter (LPS) to determine sediment grain size distribution. The volume of the sieved gravel (> $1000 \mu \mathrm{m}$ ) was measured by volume displacement (Gobbi 2009, Kolupski 2011). The remaining, finer portion of the sample was then analyzed on the LPS, which measured mean, median and mode grain size and $\%$ silt + clay $(\%$ fraction less than $<75 \mu \mathrm{m})$. This silt + clay percentage $(\%<75 \mu \mathrm{m})$ was multiplied by the sediment trap accumulation rate to determine a trap accumulation rate for the clay + silt fraction of sediment (referred to in this study as "silt accumulation rate"). Even through the Wentworth grain size scale (Wentworth 1922) defines the boundary between silt and fine sand as $63 \mu \mathrm{m}$, for this study $75 \mu \mathrm{m}$ was chosen as the upper diameter of grain size used to determine the "siltation rate" because previous research had examined the ecological impact of grains $<75 \mu \mathrm{m}$ on coral condition (e.g., Smith et al. 2008). 


\subsection{Data Analysis}

\subsubsection{Statistical Analysis}

Statistical relationships among data were examined using the statistical programs SPSS and R. All data were tested for normality using the KolmogorovSmirnov test in SPSS, and the vast majority of data were not normal. All percentage data were arcsine-square root transformed, and all ratio and terrigenous accumulation data were log-transformed. In a few cases, data passed the Kolmogorov-Smirnov test after transformation, and in all cases, transformations brought data closer to normality. Thus, transformed data were used for all statistical analyses. All data were also tested for homogeneity of variance using a Levene's test. A Mann-Whitney U or Kruskal-Wallace was used to test for differences in means. A Kruskal-Wallace test with pairwise comparisons was used to test for differences in multiple mean values of $\% \mathrm{~T}$, TAR, $\Sigma A R$ and SAR. To prevent a Type I error, a Bonferroni correction was used to correct the alpha level in pairwise comparisons. Data to be analyzed by regression analysis were initially plotted on a scatter plot to check whether the distribution was linear. Several simple single linear regression models in R were then used to assess the relationship between parameters of rainfall (mean daily rainfall, mean rainfall intensity, maximum daily rainfall, antecedent precipitation index) and TAR. 


\subsubsection{Rainfall Data}

Several parameters of rainfall were calculated from the rain gauge data. Unless referring explicitly to storm events (for example, saying "cumulative rainfall/storm" or "mean daily rainfall/storm") or referring to the cumulative rainfall for one given day (i.e. “cumulative daily rainfall”), averaged rainfall parameters (i.e. "mean daily rainfall" and "mean rainfall intensity") refer to mean values of each $\sim 26$-day sampling period. Similarly, rainfall values identified as “maximum" (i.e. "maximum daily rainfall”) also refer to maximum values over each 26-day sediment trap sampling period. For example, "mean daily rainfall" was the cumulative rainfall over the course of a $\sim 26$-sampling period divided by the number of days in the period. "Maximum daily rainfall" referred to the cumulative rainfall value on the single day with the greatest cumulative daily rainfall value during the $\sim 26$-day sediment trap sampling period. Thus, for the sake of conciseness, "per sampling period" will be assumed for these rainfall parameters and will not be written out. When referring to storms, it will be explicitly stated. In summary, the following terms define rainfall parameters:

1) "Mean daily rainfall ( $\mathrm{mm} / \mathrm{d})$ ": the cumulative rainfall over a $~ 26$-day sampling period divided by the number of days in the period;

2) "Maximum daily rainfall (mm)": the greatest rainfall value measured on a single day during the sampling period; 
3) "Rainfall intensity $(\mathrm{mm} / \mathrm{hr})$ ": the mean 15 -minute interval intensity over the duration of one sampling period. More specifically, rainfall intensity was calculated for every 15 -minute interval within each sampling period $(\mathrm{mm} / 15 \mathrm{~min})$ and then the mean of these values was calculated. Then, to convert the units from "mm/15 min" into "mm/hr", the mean, 15-minute intensity values were multiplied by four.

4) "Cumulative Daily Rainfall (mm)": the total amount of rainfall on a given day;

5) "Cumulative rainfall/storm $(\mathrm{mm})$ ": the total amount of rainfall during a given storm;

6) "Mean daily rainfall/storm $(\mathrm{mm} / \mathrm{d})$ ": cumulative rainfall during a given storm divided by the storm duration in days;

7) "Mean cumulative monthly rainfall $(\mathrm{mm} / \mathrm{mo})$ ": the mean of cumulative monthly rainfall values over the study period or historically for a particular season or month. In the study, cumulative monthly rainfall is either averaged over the course of the same months (e.g. all January months historically and in the study period) or with respect to the historical and study period rainy (May-Nov) and dry (Dec-April) seasons. 
8) Maximum Sampling Period Antecedent Precipitation Index (API, cm) (Dunne and Leopold 1978) is the maximum API attained at any time during the $\sim 26$-day sampling period, including the API values updated within a given day by rainfall events; "Antecedent Precipitation Index" (API, cm), was defined as:

$\mathrm{I}_{\mathrm{t}}=\mathrm{I}_{0} \mathrm{k}^{\mathrm{t}}$

Where $I_{t}$ and $I_{0}$ were the values of the API on day $t$ and at the initial calculation period $(\mathrm{cm})$ at the beginning of the study period, respectively; $k$ is a constant set at 0.9 that indicates the rate of reduction of soil wetness; and $t$ represents the number of days since the last rainfall. The APIs on proceeding days were equal to: $I_{0}, I_{0} K, I_{0} K^{2}, I_{0} K^{3}$ (the original value of yesterday's API before events were added multiplied by 0.9 to the power of the number of days since last rainfall plus yesterday's cumulative rainfall), and so on (Dunne and Leopold 1978). If on successive days no rainfall occurred, a value of 1 was added to $t$ for each day. When rainfall occurred, the rainfall total was added to the index and $t$ was set back to zero.

For this analysis, rainfall was added to the index on a per event basis during a given day to give better than daily temporal resolution information about watershed saturation following rainfall events (then, the next day's API was calculated based on the original API that did not include event totals as described in the paragraph above). An "event total" in this sense was distinguished from other rainfall events if at least one hour of no rainfall separated the event from 
other occurrences of rainfall. Thus, API increases during a given day if there were rainfall events. The maximum API (including APIs with event totals) was then identified for each sampling period.

Because the API used in this analysis is updated continuously from the beginning of the dataset, all previous rainfall events in the study period to some degree impacted the API calculation. For example, between 29 and 30 days after a storm, only about $5 \%$ of the original weight of the storm is implicit in the API calculation, and by day 45 , less than $1 \%$, or essentially zero (Figure 2.6 ). Therefore, the influence of a previous storm on API decreased over time (Figure 2.6). The decaying characteristic of API generally indicated whether a period of time was dry or wet in terms of rainfall. Thus, the API provides useful information in determining whether soil moisture content is sufficient so that runoff could occur during a rainfall event. More generally, the API can also provide a sense of whether conditions have been predominately wet or dry over a given amount of time.

The relationship between the API and daily rainfall is highlighted in Figure 2.7. Because rainfall from previous days was used in calculating current APIs, there was a small lag in when API values "peaked" relative to daily rainfall. Therefore, API values can remain relatively high for days after significant rainfall even when little or no rainfall occurs on the proceeding days (Figure 2.7). This again is consistent with the fact that soil moisture increases/decreases depending on rainfall. 


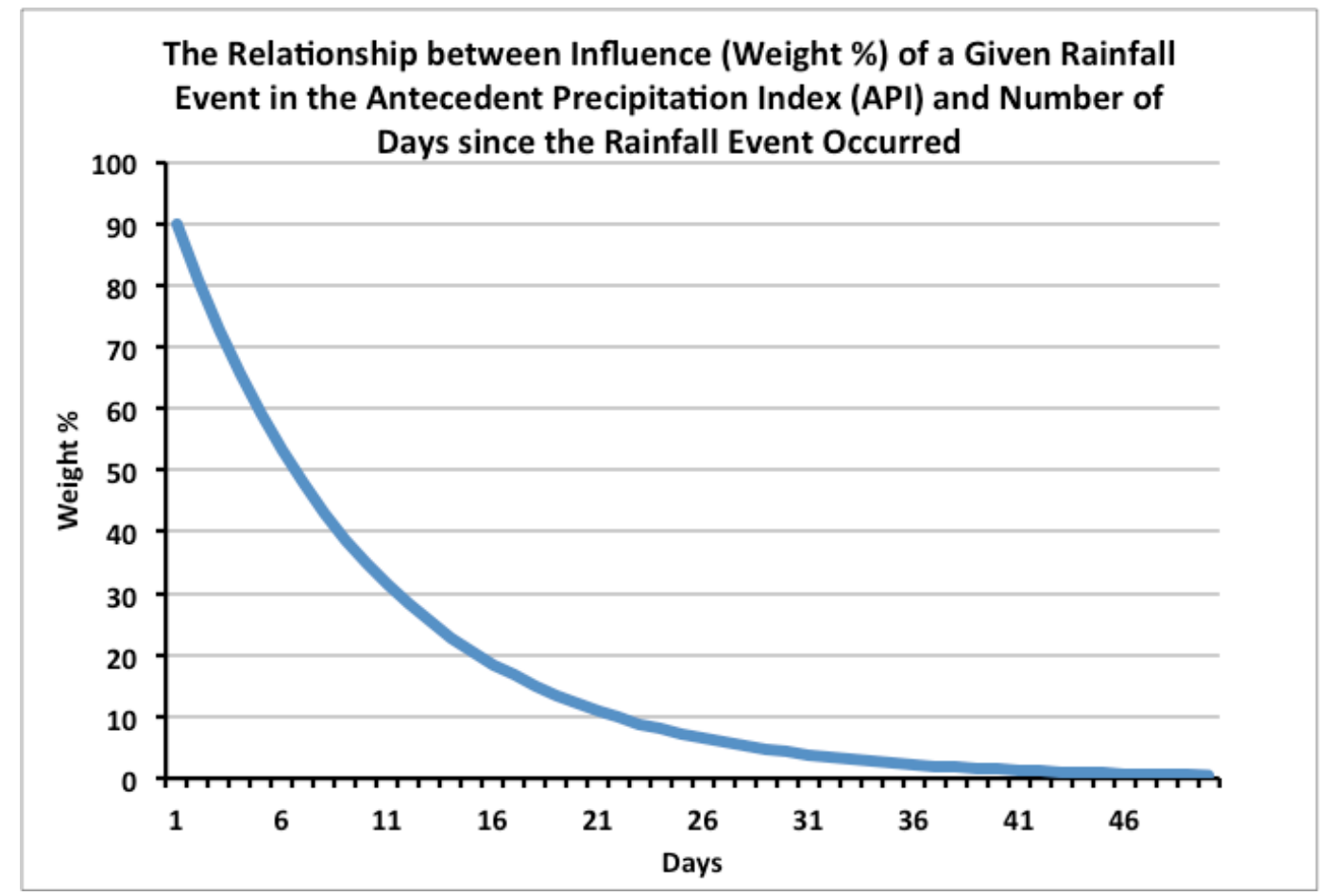

Figure 2.6. The relationship between the influence of a given rainfall event (shown as weight $\%$ of the original storm value, y-axis) in the API and the number of days since the rainfall event occurred (x-axis). 


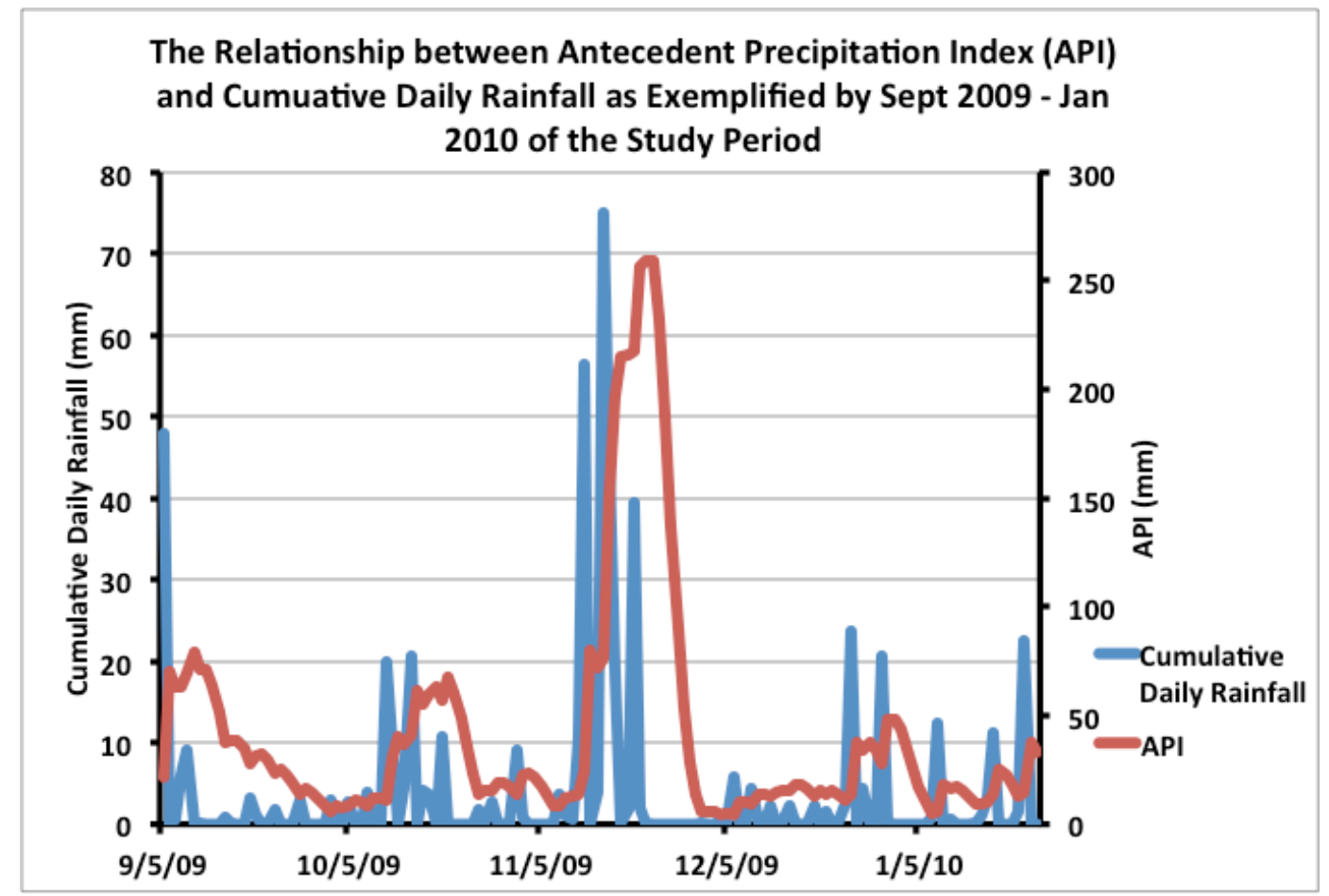

Figure 2.7. The relationship between cumulative daily rainfall (primary axis) and the API (secondary axis) as exemplified by a section of the study period. 
The values for each parameter of rainfall above were categorized into regimes with progressively greater values (and fewer data points). For example, mean daily rainfall data were categorized into: All periods, and periods where values were greater than: $1,2,3,4,5,6$ and $7 \mathrm{~mm} / \mathrm{d}$. Other rainfall parameters were similarly categorized based on increasing values and specific regimes and are outlined in Table 2.3. 
Table 2.3. Data value regimes for rainfall parameters examined in this study.

\begin{tabular}{|l|l|r|r|r|r|r|r|r|}
\hline Rainfall Parameter & \multicolumn{3}{|l|}{ Regimes } \\
\hline Mean Daily Rainfall (mm/d) & All Periods & 1 & 2 & 3 & 4 & 5 & 6 & 7 \\
\hline Rainfall Intensity (mm/hr) & All Periods & 0.04 & 0.08 & 0.1 & 0.15 & & & \\
\hline Maximum Daily Rainfall (mm) & All Periods & 0.2 & 0.4 & 0.8 & 1 & 1.2 & 2 & \\
\hline Maximum API (cm) & All Periods & 2.5 & 5 & 9 & 10 & 12 & & \\
\hline
\end{tabular}




\subsubsection{Relationship between Rainfall Characteristics and Terrigenous}

Sediment Accumulation

For each location, terrigenous accumulation data were categorized into groups with their respective rainfall parameter values based on the regimes outlined in Table 2.3 so that differences in R-squared values in regressions between terrigenous accumulation and rainfall parameters among the regimes could be examined. For the API analysis, maximum API itself was not the independent variable in the regression, but only used as the means for categorizing the data into regimes. After data were categorized by maximum API values (Table 2.3), then mean daily rainfall, rainfall intensity, and maximum daily rainfall were the independent variables used in the regressions. To standardize terrigenous accumulation data values from 2-3 sediment trap sites constituting one "location" (Table 2.2) for all regressions, values for one location were converted to z-scores around the mean and standard deviation of all data points within one regime. Then, these standardized terrigenous accumulation values were used in regressions. The regressions were graphed and followed a linear pattern. Thus, a simple linear regression model was used to determine statistical values (R-squared and p-values, regression coefficients) for all regressions in the statistics program R.

\subsubsection{Resuspension of Sediments}

A common method used to assess resuspension is by evaluating the similarity between benthic and trap sediments in terms of a particular sedimentological parameter, such as by similarity in sediment composition 
(Bloesch 1994). When resuspension occurs, the characteristics of trap sediments become more similar to bottom sediments since more bottom sediments (as opposed to new flux) will enter traps. For this project, sediment trap and nearby benthic sediments were assessed for resuspension by examining similarity of trap and nearby benthic sediments in terms of $\%$ terrigenous sediment and mean grain size for all sampling periods using the following equations:

$$
\frac{\% \mathrm{~T}_{\text {trap sediment }}}{\% \mathrm{~T}_{\text {bottom sediment }}}
$$

and

Mean Grain Size trap sediment $_{\text {. }}$

Mean Grain Size bottom sediment

The closer the values of these ratios are to one, the more similar trap and bottom sediments are in terms of $\% \mathrm{~T} /$ mean grain size, which could indicate greater resuspension than if the value is less similar to one.

\subsubsection{Pre- and Post-restoration Terrigenous Accumulation during Fall} Periods

In order to characterize how TARs in response to rainfall have changed with respect to restoration in Coral Bay, we compared TARs during the fall season (September - November) before (2007 - 7/2011) and after (8/2011$12 / 2012$ ) the completion of watershed restoration efforts in Coral Bay. Terrigenous accumulation rates at all trap sites $\left(\mathrm{mg} / \mathrm{cm}^{2} / \mathrm{d}\right)$ for all fall sampling 
periods (i.e. all September - November sampling periods) were first summarized. Then, mean terrigenous accumulation rates at each site were calculated for all fall periods prior to restoration $(9 / 10 / 08,9 / 30 / 08,10 / 22 / 08,11 / 13 / 08,9 / 2 / 09,9 / 16 / 09$, $10 / 12 / 09,11 / 7 / 09,8 / 20 / 10,9 / 15 / 10,10 / 11 / 10,11 / 8 / 10)$ and for fall periods postrestoration $(9 / 15 / 11,10 / 11 / 11,11 / 5 / 11,8 / 20 / 12,9 / 15 / 12,10 / 11 / 12,11 / 6 / 12)$. Statistical differences in pre- and post-restoration means were then examined at each site. This approach was repeated for only fall periods were there was high rainfall, which was determined as those fall periods with mean daily rain values $>$ $3 \mathrm{~mm} / \mathrm{d}$. This analysis in its entirety was also repeated so that terrigenous accumulation values were normalized by mean daily rainfall over sampling periods to get sedimentation rates in units of $\mathrm{mg} / \mathrm{cm}^{2} / \mathrm{mm}$.

2.4.6 Terrigenous Accumulation during Equivalent Storms Pre- and PostRestoration

As described in "Rainfall and Storms" above, "storms" were defined as one or more consecutive days with $20 \mathrm{~mm}$ or more of cumulative rainfall per day; "major storms" were defined as one or consecutive days of $20 \mathrm{~mm}$ or more of cumulative rainfall per day that totaled $100 \mathrm{~mm}$ or more cumulative rainfall per storm.

Equivalent storms pre- and post- mitigation were identified and paired under several criteria, which were duration (days), days between storms, cumulative rainfall/storm, mean daily rainfall/storm, mean daily rainfall, and season. Then, once these comparable pre- and -post- mitigation storms were 
paired, terrigenous accumulation values pre- and post- mitigation could be compared.

\subsubsection{Wave Height}

For August 2008 - November 2010 and June 2011 - December 2012, wave data were gathered from National Data Buoy Center buoy 41140 and 41052 , respectively. The 41140 buoy data were collected from Christiansted, St. Croix $\left(17^{\circ} 46^{\prime} 7^{\prime \prime} \mathrm{N}, 6^{\circ} 43^{\prime} 24^{\prime \prime} \mathrm{W}\right)$, which was disestablished in November 2010. Buoy 41052 was established south of St. John $\left(18^{\circ} 14^{\prime} 55^{\prime \prime}\right.$ N 64 $45^{\prime} 45^{\prime \prime}$ W) in April 2011 and was used for the remaining part of the study period.

The mean, median and maximum wave heights were summarized for each sampling period, and mean and maximum wave heights were summarized for all major storm events and named tropical depressions. The relationship between mean, median and maximum wave height and $\% \mathrm{~T}$ and $\mathrm{TAR}$ were examined for each location using a regression analysis. 


\section{Chapter 3: Results}

\subsection{Rainfall and Storms}

\subsubsection{Introduction}

Since storms can cause surface runoff in the watersheds (and thus lead to the delivery of terrigenous sediment to the marine environment), it is important to understand the sedimentological response to storms and the temporal patterns of their occurrences. In this section, rainfall during our 2007 to 2012 study period is compared to historical monthly and seasonal patterns (collected since 1972 from a historical rain gauge in Coral Bay).

The following rainfall parameters (defined in "Methods") were examined:

a) mean cumulative monthly rainfall (historic [from 1972-present] and during the study period [2007-2012]) (mm/mo);

b) mean cumulative monthly rainfall during the rainy (May-Nov) and dry (DecApril) seasons (mm/mo);

c) cumulative daily rainfall $(\mathrm{mm} / \mathrm{d})$;

d) cumulative rainfall/storm ( $\mathrm{mm} / \mathrm{storm})$;

e) mean daily rainfall/storm $(\mathrm{mm} / \mathrm{d})$; 
f) mean sampling period daily rainfall (“mean daily rainfall”) $(\mathrm{mm} / \mathrm{d})$;

g) maximum sampling period daily rainfall (“maximum daily rainfall”) (mm/d);

h) mean rainfall intensity/sampling period ("mean rainfall intensity") (mm/hr); and

i) maximum sampling period Antecedent Rainfall Index (“maximum API") (cm).

\subsubsection{Seasonal and Annual Means Compared with Historical Values}

Historically and during the study period, greater rainfall fell on St. John during the rainy season between May and November (73 and 62\% of annual rainfall, respectively) compared to during the dry season (Dec-April). Historically, November and September were the rainiest and January, February and March were the driest months (Figure 3.1). On average, the driest month during the study period was February (mean: $30 \pm 7 \mathrm{SD} \mathrm{mm} / \mathrm{mo}$ ) (Figure 3.1), and the rainiest months were October and November (mean: $207 \pm 151$ SD and $162 \pm$ $74 \mathrm{SD} \mathrm{mm} / \mathrm{mo}$, respectively). Mean monthly rainfall during the study period (mean: $112 \pm 84 \mathrm{SD} \mathrm{mm} / \mathrm{mo}$ ) was 15\% greater than the historical mean (mean: 97 $\pm 90 \mathrm{SD} \mathrm{mm} / \mathrm{mo}$ ).

The driest rainy seasons of the 2007-2012 study period were 2009 and $2012(12 \%$ [13 mm/mo] and 58\% [39 $\mathrm{mm} / \mathrm{mo}]$ less than historical means, respectively) and the wettest rainy seasons were 2010 and 2011 (41\% [80 
$\mathrm{mm} / \mathrm{mo}$ ] and $28 \%$ [ $45 \mathrm{~mm} / \mathrm{mo}$ ] greater than historical means, respectively) (Figure 3.2). The 2010 rainy season produced an exceptional amount of rainfall. In particular, T.S. Otto produced over $400 \mathrm{~mm}$ of rainfall in four days in October, breaking all historical storm cumulative rainfall records and was $115 \%$ greater than mean monthly rainfall for October during the study period (Figures 3.1 and $3.2)$.

In summary, historical and study period rainfall were highly variable. Study period mean cumulative monthly rainfall did not always closely mirror long-term historical means, but generally, expected seasonal trends were observed. 


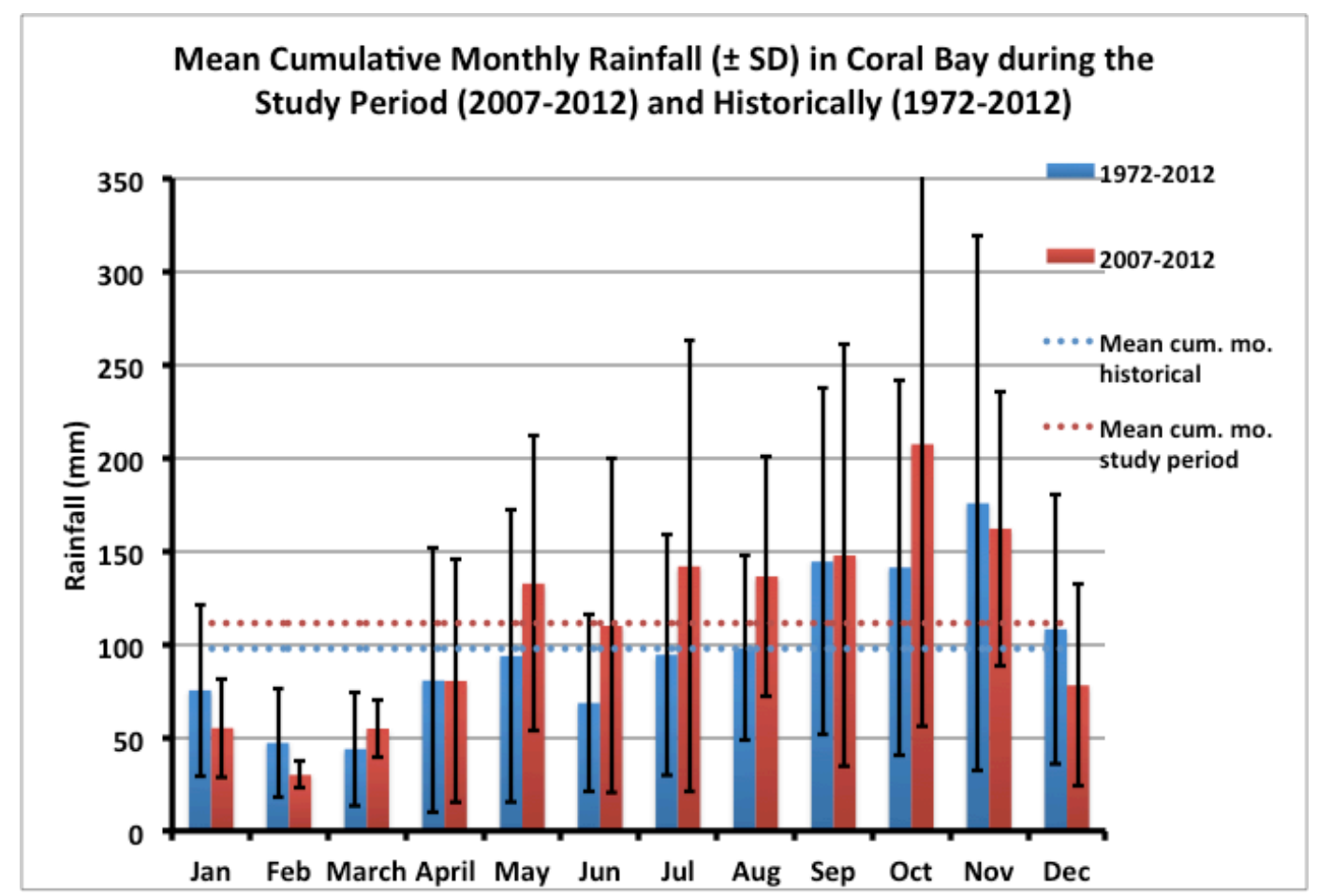

Figure 3.1. Mean cumulative monthly rainfall $( \pm \mathrm{SD})$ historically (1972-2012) and during the study period (2007-2012) collected from the Agave rain gauge in Coral Bay, St. John (Figure 1.2). Dotted lines indicate the mean cumulative monthly historical rainfall (blue) and mean cumulative monthly rainfall during the study period (red). 


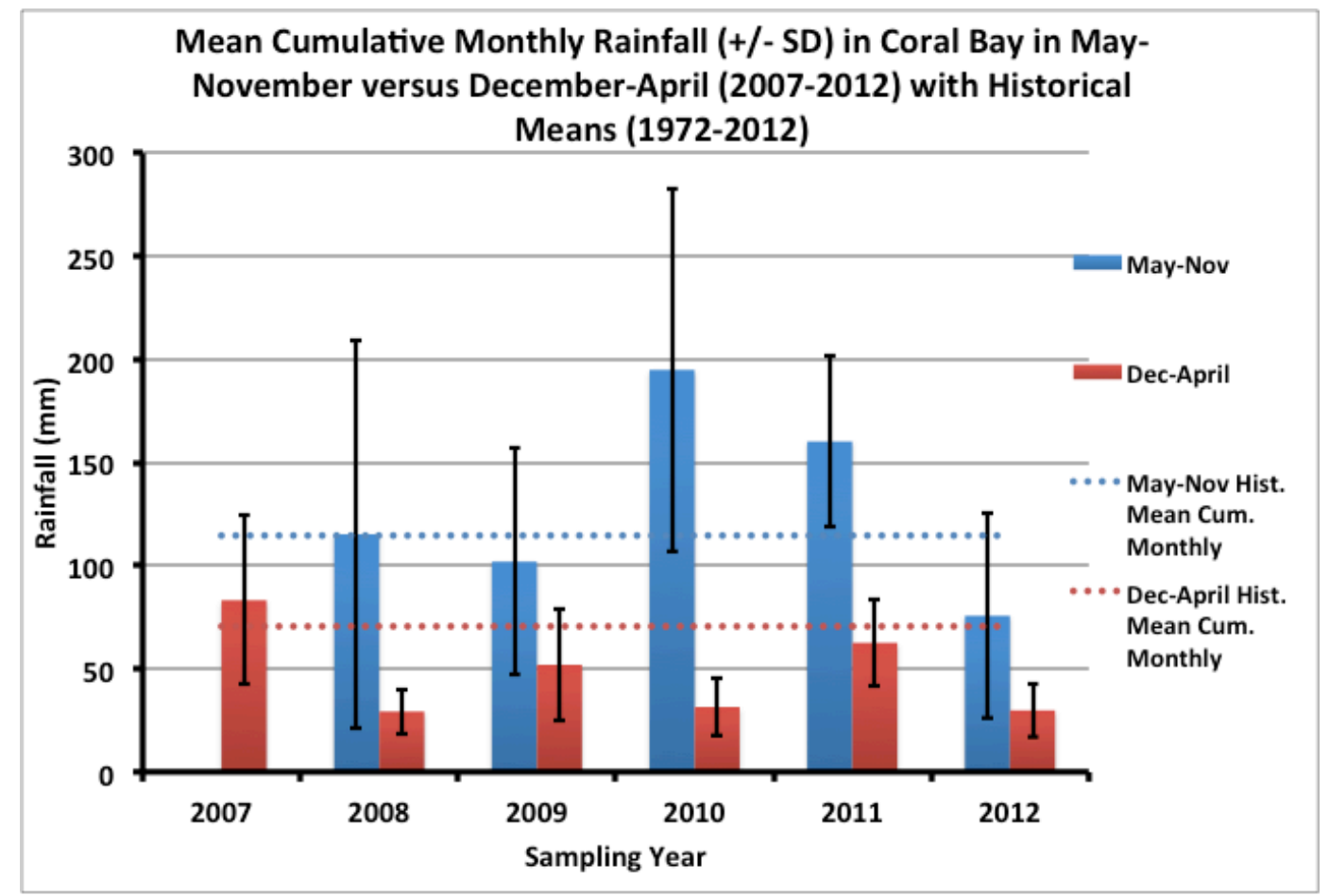

Figure 3.2. Mean cumulative monthly rainfall $( \pm \mathrm{SD})$ during the rainy (May to November) versus dry (December-April) season. Dotted lines indicate historical cumulative monthly means (from 1972 to 2012) for the same months. All data were collected from Agave rain gauge in Coral Bay, St. John (Figure 2.5). 


\subsubsection{Temporal Variability in Rainfall and Storms}

A total of 42 rainfall events were identified as "storms" during the period of study, which were defined as one or more consecutive days of at least $20 \mathrm{~mm} / \mathrm{d}$ of cumulative daily rainfall during the storm each day (Table 3.1, Figure 3.3). Of those 42 storms, 11 qualified as "major storms", where cumulative rainfall/storm exceeded $100 \mathrm{~mm} / \mathrm{storm}$. "Moderate Storms" were those where there were also one or more consecutive days of at least $20 \mathrm{~mm} / \mathrm{d}$ of rainfall, but with rainfall totaling less than $100 \mathrm{~mm} / \mathrm{storm}$ (Table 3.1). The five largest rain-producing storms are circled in Figure 3.3. All of the major storms during the study period occurred during the rainy season between May and November: four in October, two in November, and one each in May, June, July, August, and September. Except for 2012, when there was only one major storm, two major storms occurred each year from 2007 - 2012. These storms included T.S. Kyle and H. Omar (2008), T.S. Otto (2010), and T.S. Irene (2011) and other unnamed, high rainfall events. T.S. Otto was the greatest rain-producing storm historically and during the study period (cumulative rainfall/storm $=416 \mathrm{~mm} / \mathrm{storm}$ ) and was also the greatest in terms of mean daily rainfall/storm for multi-day storms (mean: 83 $\mathrm{mm} / \mathrm{d})$ (Table 3.1). Some hurricanes and tropical storms did not produce as much rainfall as many unnamed, high rainfall events associated with low-pressure systems. For example, Hurricane Earl, which brought high wind to St. John and turned Lameshur Bay a milky color after carbonate resuspension (personal observation), only produced $81 \mathrm{~mm} /$ storm of rain between $8 / 29 / 10-9 / 1 / 10$ and ranked $18^{\text {th }}$ of storms in terms of cumulative rainfall/storm (Table 3.1). T.S. 
Maria, Hanna, and Rafael brought rainfall to St. John while passing through the Caribbean, but these storms ranked at 31,32 , and last in terms of cumulative rainfall/storm (Table 3.1) on St. John. Two differences between major and moderate storm events were their duration (mean: 3.1 days for major compared vs. 1.5 days for moderate storms) and the mean daily rainfall/storm (mean: 57 $\mathrm{mm} / \mathrm{d}$ vs. $36 \mathrm{~mm} / \mathrm{d}$ for major vs. moderate storms). Cumulative daily rainfall and mean daily rainfall were variable (range: 0 to $216 \mathrm{~mm} / \mathrm{d}$ and 0.43 to $19.6 \mathrm{~mm} / \mathrm{d}$, respectively) throughout the study period (Figure 3.3). The greatest cumulative daily rainfall $(216 \mathrm{~mm} / \mathrm{d})$ and mean daily rainfall (20 mm/d) occurred during Tropical Storm Otto, on 10/6/10 (Figure 3.3). 
Table 3.1. Summary of all storm events during the 2007-12 study period in order of greatest to least cumulative rainfall/storm. Highlighted in pink are "major storms" ( $\geq 100 \mathrm{~mm}$ of cumulative rainfall/storm). Also shown are the start and end dates of the storms, their duration (d), and mean rainfall/d (mm/d).

\begin{tabular}{|c|c|c|c|c|c|}
\hline Start Date & End Date & Name & Duration (d) & Cum. Rain/storm (mm/storm) & Mean Rain/Day (mm/d) \\
\hline $10 / 5 / 10$ & $10 / 9 / 10$ & T.S. Otto & 5 & 415.54 & 83.11 \\
\hline $9 / 20 / 08$ & $9 / 24 / 08$ & T.S. Kyle & 5 & 182.12 & 36.42 \\
\hline $7 / 21 / 10$ & $7 / 23 / 10$ & & 3 & 177.29 & 59.10 \\
\hline $11 / 15 / 09$ & $11 / 17 / 09$ & & 3 & 144.27 & 48.09 \\
\hline $10 / 13 / 08$ & $10 / 16 / 08$ & H. Omar & 4 & 140.97 & 35.24 \\
\hline $10 / 6 / 07$ & $10 / 8 / 07$ & & 2 & 139.45 & 69.72 \\
\hline $10 / 26 / 07$ & $10 / 29 / 07$ & & 3 & 137.67 & 45.89 \\
\hline $5 / 5 / 09$ & $5 / 5 / 09$ & & 1 & 122.94 & 122.94 \\
\hline $6 / 6 / 11$ & $6 / 9 / 11$ & & 4 & 103.38 & 25.84 \\
\hline $11 / 20 / 12$ & $11 / 21 / 12$ & & 2 & 98.81 & 49.40 \\
\hline $8 / 21 / 11$ & $8 / 22 / 11$ & T.S. Irene & 2 & 98.04 & 49.02 \\
\hline $6 / 25 / 10$ & $6 / 28 / 10$ & & 3 & 94.49 & 31.50 \\
\hline $8 / 15 / 08$ & $8 / 15 / 08$ & & 1 & 93.98 & 93.98 \\
\hline $11 / 7 / 10$ & $11 / 8 / 10$ & & 2 & 93.73 & 46.86 \\
\hline $6 / 19 / 10$ & $6 / 21 / 10$ & & 3 & 86.36 & 28.79 \\
\hline $11 / 10 / 10$ & $11 / 12 / 10$ & & 3 & 84.07 & 28.02 \\
\hline $7 / 17 / 10$ & $7 / 19 / 10$ & & 3 & 83.57 & 27.86 \\
\hline $8 / 29 / 10$ & $9 / 1 / 10$ & H. Earl & 3 & 81.28 & 27.09 \\
\hline $5 / 8 / 10$ & $5 / 8 / 10$ & & 1 & 70.36 & 70.36 \\
\hline $5 / 20 / 11$ & $5 / 21 / 11$ & & 2 & 67.82 & 33.91 \\
\hline $10 / 12 / 09$ & $\mid 10 / 13 / 09$ & & 2 & 67.56 & 33.78 \\
\hline $9 / 19 / 10$ & $9 / 20 / 10$ & & 2 & 65.28 & 32.64 \\
\hline $7 / 2 / 11$ & 7/4/11 & & 3 & 62.48 & 20.83 \\
\hline $3 / 7 / 10$ & $3 / 7 / 10$ & & 1 & 60.96 & 60.96 \\
\hline $6 / 9 / 09$ & $6 / 9 / 09$ & & 1 & 57.15 & 57.15 \\
\hline $9 / 21 / 11$ & $9 / 21 / 11$ & & 1 & 55.37 & 55.37 \\
\hline $5 / 29 / 10$ & $5 / 29 / 10$ & & 1 & 50.29 & 50.29 \\
\hline $7 / 30 / 12$ & $7 / 31 / 12$ & & 2 & 49.78 & 24.89 \\
\hline $9 / 16 / 11$ & $9 / 16 / 11$ & T.S. Maria & 1 & 43.18 & 43.18 \\
\hline $8 / 31 / 08$ & $8 / 31 / 08$ & T.S. Hanna & 1 & 36.32 & 36.32 \\
\hline $11 / 15 / 11$ & $11 / 15 / 11$ & & 1 & 29.72 & 29.72 \\
\hline $12 / 25 / 09$ & $12 / 25 / 09$ & & 1 & 28.70 & 28.70 \\
\hline $12 / 31 / 09$ & $12 / 31 / 09$ & & 1 & 28.70 & 28.70 \\
\hline $11 / 19 / 07$ & $\mid 11 / 19 / 07$ & & 1 & 27.94 & 27.94 \\
\hline $9 / 30 / 11$ & $9 / 30 / 11$ & & 1 & 26.92 & 26.92 \\
\hline $9 / 16 / 08$ & $9 / 16 / 08$ & & 1 & 24.38 & 24.38 \\
\hline $12 / 6 / 11$ & $12 / 6 / 11$ & & 1 & 23.62 & 23.62 \\
\hline $9 / 13 / 10$ & $9 / 13 / 10$ & & 1 & 22.35 & 22.35 \\
\hline $9 / 13 / 08$ & $9 / 13 / 08$ & & 1 & 21.59 & 21.59 \\
\hline $5 / 18 / 11$ & $5 / 18 / 11$ & & 1 & 21.34 & 21.34 \\
\hline $10 / 14 / 12$ & $10 / 14 / 12$ & T.S. Rafael & 1 & 21.34 & 21.34 \\
\hline $9 / 4 / 08$ & $9 / 4 / 08$ & & 1 & 21.08 & 21.08 \\
\hline
\end{tabular}




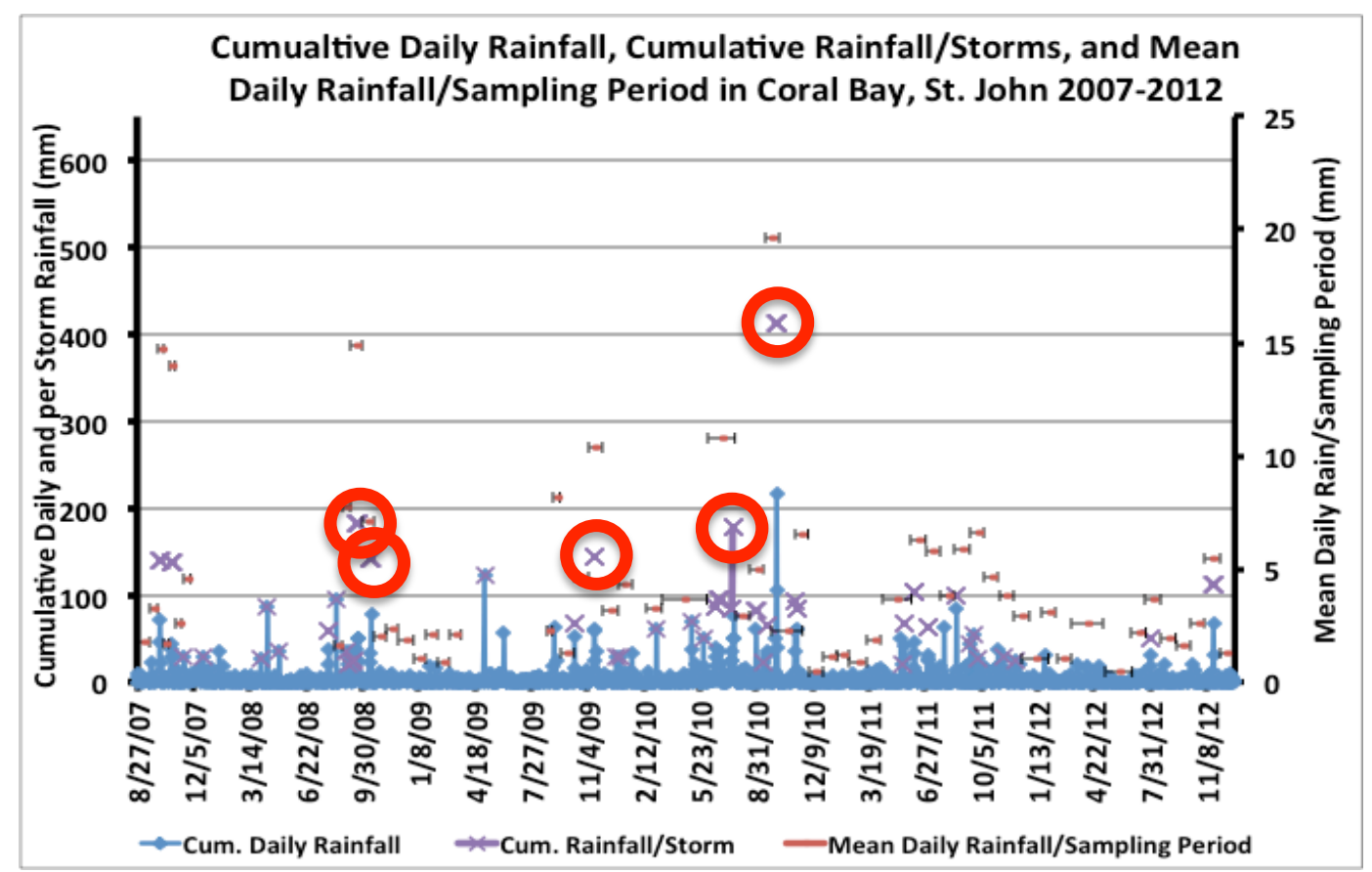

Figure 3.3. Cumulative daily rainfall (light blue lines), cumulative rainfall/storm (purple Xs) and mean daily rainfall (red dots with black bars, secondary axis) during each sampling period collected from Agave rain gauge in Coral Bay, St. John (Figure 2.5). The five storms with the greatest cumulative rain are circled in red (Table 3.1). T. S. Otto (10/5/10-10/9/10) produced over $400 \mathrm{~mm}$ of rain, more than twice as much as the second largest storm, a low-pressure system in 9/2008. 


\subsection{Terrigenous Sedimentation}

\subsubsection{Introduction: \% Terrigenous of Inorganic Sediment}

Because the proportion of terrigenous sediment $(\% \mathrm{~T})$ in the marine environment may vary temporally with rainfall and spatially with respect to shoreline inputs and watershed development, it is important to examine temporal and spatial patterns of $\% \mathrm{~T}$. The data presented in this section will address the $\% \mathrm{~T}$ Research Question 1A, which seeks to examine temporal variability of \% $\mathrm{T}$ in response to rainfall and spatial variability with respect to watershed development and shoreline runoff inputs. In this section, variation in proportion (\%) of terrigenous sediments (relative to the inorganic [carbonate + terrigenous] fraction) collected from sediment traps will be examined (Appendix III). The term "\%T" will be used to represent "\% terrigenous of inorganics", which is calculated after removing the $\%$ organic fraction from the sediment and adjusting " $\%$ terrigenous original $_{\text {" }}$ (the $\%$ terrigenous, where $\%$ terrigenous $+\%$ carbonate $+\%$ organic $=100 \%$ ) to:

$$
\% \mathrm{~T}_{\text {inorganic sediment }}=\frac{\% \text { Terrigenous }_{\text {original }}}{\% \mathrm{Terrigenous}_{\text {original }}+\% \text { Carbonate }_{\text {original }}} \times 100
$$

Temporal variability at shores and then reefs will be presented, followed by a presentation of spatial variability at shores and reefs. In Appendix IV, the similarity in $\% \mathrm{~T}$ between benthic and trap sediment are compared to evaluate the contribution of benthic sediment to trap accumulation as the result of resuspension. 


\subsubsection{Temporal Variability}

$\%$ Ts varied over the 5-6 year study period from 0 to $98 \%$ with the greatest range in $\% \mathrm{~T}$ recorded at the minimally developed shore and reef locations (Lameshur Shore: range: 13-65\%; max value 1.7 times mean; Lameshur Reef: range: $4-37 \%$; max value 2.2 times mean). $\% \mathrm{~T}$ did not appear to systematically increase or decrease through the study period (Figure 3.4). Generally most of our results supported the hypothesis that "\%Ts will increase in response to rainfall". Greater $\% \mathrm{Ts}$ at shore locations were sometimes associated with sampling periods with storms. For example, sampling periods 12/2/09 and 10/11/10 with major storms coincided with maximum $\% \mathrm{~T}$ at shore locations (Coral Harbor: 94\% for both sampling periods; Coral South Shore: 81 and 88\%, respectively; and Plantation Hill: 75 and 94\%, for the 12/2/09 and 10/11/10 periods respectively) (Figure 3.4).

For most sampling periods spatial variation in $\% \mathrm{~T}$ consistently followed the following pattern of decreasing \%T: Coral Harbor $>$ Coral South Shore $>$ Plantation Hill > Lameshur Shore. However, there were 7 out of 37 sampling periods when $\%$ Ts at Plantation Hill surpassed or were very similar to $\%$ Ts at Coral South Shore (storm: 12/2/09, 10/11/10, 11/8/10, 9/15/11; non-storm: 2/13/11, 12/29/11, 2/15/12) (Figure 3.4, Table 3.1). The greatest $\%$ Ts were recorded during the 10/11/10 (T.S. Otto) and the 11/8/10 storm sampling periods at Plantation Hill (93 and 78\%, respectively) when \%T at Plantation Hill was almost as high as at Coral Harbor (89 and 83\%, respectively) (Figure 3.4). During the 10/11/10 period, there was a landslide above Plantation Hill associated 
with rainfall from T.S. Otto. \%T remained elevated at Plantation Hill during the following $11 / 8 / 10$ period, even though mean daily rainfall was relatively low, and the sampling period captured only one moderate storm (Table 3.1, Figure 3.4). Lameshur Shore \%T surpassed \%T at Coral South Shore for two out of 37 sampling periods (storm: 9/15/11; non-storm: 2/15/12) (Figure 3.4, Table 3.1). At reef locations, \%Ts exceeding study period means were often associated with storms $(10 / 12 / 09,10 / 11 / 10,12 / 2 / 10,3 / 16 / 11,6 / 29 / 11,7 / 25 / 11)$ (Figure 3.4). \%Ts were greater at the developed than minimally developed reef location for about $90 \%$ of sampling periods (exceptions: 12/2/10, 4/11/11, 9/15/11, 9/15/12) (Figure 3.4).

Interestingly, in Lameshur Bay, storm sampling periods were sometimes associated with reduced terrigenous and greater carbonate proportions. For example, at Lameshur Shore and Reef, \%T less than the study period mean was measured during the sampling period with T.S. Otto $(10 / 11 / 10)$ but the study period maximum $\% \mathrm{~T}$ was measured during the following 11/8/10 storm period (65\%) (Figure 3.4). During the 9/15/10 period when Hurricane Earl produced intense wind and southerly swell but little rainfall, \% $\mathrm{T}$ at Lameshur Shore and Reef was recorded at the study period minimum value of 13 and $9 \%$, respectively. In contrast, at developed Coral Bay shore locations, all \%Ts were at or above study period mean values during the sampling periods with H. Earl and T.S. Otto (Figure 3.4).

In summary, the greatest \%Ts were usually (but not always) measured during sampling periods with storms, and during most periods the spatial pattern 
of $\% \mathrm{~T}$ among locations was consistent between sites. However, in some cases, storms were associated with lower \% $\%$ at Lameshur Shore and Reef and were sometimes associated with exceptions to the typical spatial pattern of $\% \mathrm{~T}$. 


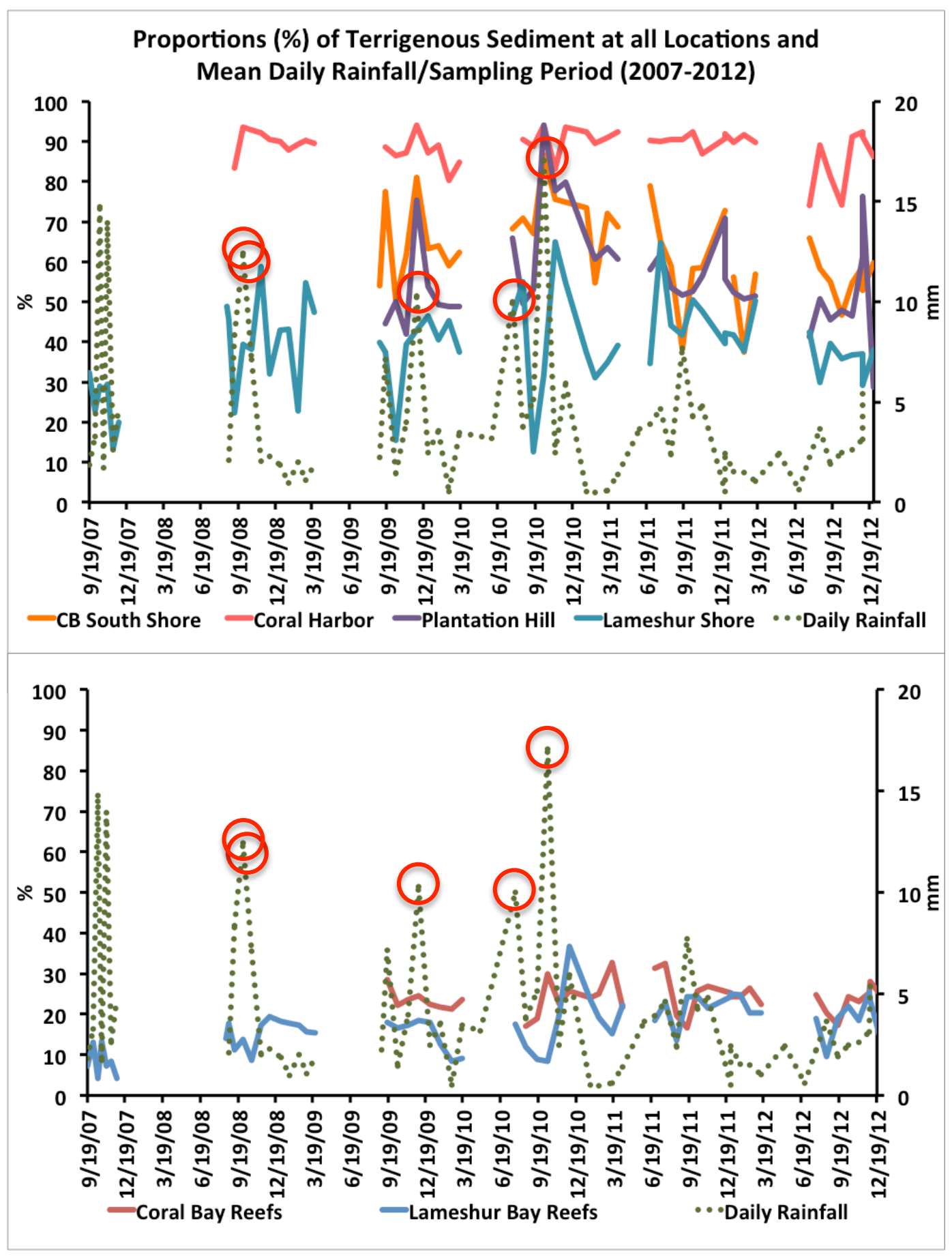

Figure 3.4. Study period \%T at developed and minimally developed shore and reef sites. Developed locations are represented by warm colors and minimally developed by cool colors. Mean daily rainfall by sampling period is shown as the green, hashed line in both panels and is plotted on the secondary y-axis. Red circles mark the five greatest storms in terms of cumulative rainfall/storm (Table 3.1). Line gaps represent time intervals when data were not collected. 


\subsubsection{Spatial Variability}

The study period mean $\% \mathrm{~T}$ at all sites ranged from $16 \pm 7 \mathrm{SD} \%$ to $90 \pm 6$ SD \% (Figure 3.5). The following results help determine whether the alternative hypothesis that "there would be greater $\% \mathrm{~T}$ in shore compared with reef sites/locations and below developed compared with minimally developed watersheds" was supported. Mean study period $\%$ Ts were significantly greater at shore (mean: $64 \pm 23$ SD \%) compared with reef sites (mean: $19 \pm 9$ SD \%) (Table 3.2, Ref. 1), and at developed (mean: $75 \pm 17 \mathrm{SD} \%$ ) compared to minimally developed shore sites (mean: $38 \pm 20 \mathrm{SD} \%$ ) (Table 3.2, Ref. 2).

For shore sites, study period mean $\% \mathrm{~T}$ were similar among developed Coral Harbor North (90 \pm 6 SD \%), Coral Harbor South ( $88 \pm 5$ SD \%), and Shipwreck (81 \pm 7 SD \%) (Figure 3.5) and study period mean \%Ts were not significantly different among these sites (Table 3.3). Of the developed shore sites, study period mean $\% \mathrm{~T}$ was greater at Coral Harbor North than at minimally developed Plantation Hill North and South (Figure 3.5). The study period mean $\% \mathrm{~T}$ at developed sites Shipwreck and Coral Harbor South were significantly greater than at developed Calabash and minimally developed Great and Little Lameshur Shore sites (Table 3.3).

By shore location, study period mean $\% \mathrm{~T}$ was greatest at Coral Harbor (study period mean: $89 \pm 5 \mathrm{SD} \%$ ), which was significantly greater than at Coral Bay South Shore (study period mean: $62 \pm 11$ SD \%), Plantation Hill (study period mean: $57 \pm 12$ SD \%), and Lameshur Shore (study period mean: $39 \pm 11$ SD \%) (Figure 3.6, Table 3.4). All pairwise differences in means between shore 
locations were significant except between Plantation Hill and Coral South Shore (Table 3.4).

Study period mean $\% \mathrm{~T}$ was significantly greater at Coral Reef North compared to all other reef sites except Tektite Reef, and there were no other significant differences between reef sites (Figure 3.5, Table 3.3). When data were grouped by location, study period mean $\%$ Ts were not significantly different between Coral Bay Reef and Lameshur Bay Reef (Figure 3.6, Table 3.4). 
Table 3.2. Mann-Whitney U summaries for "Terrigenous Sedimentation" section.

\begin{tabular}{|c|c|c|c|c|c|c|c|c|}
\hline Ref. \# & Parameter & Group 1 & Group 1 Mean \pm SD & Group 2 & Group 2 Mean \pm SD & Z-value & $\mathbf{N}$ & P-value \\
\hline 1 & $\% \mathrm{~T}$ & all shore sites & $64 \pm 23$ SD $\%$ & all reef sites & $19 \pm 9$ SD $\%$ & -4.765 & 229 & $<0.001$ \\
\hline 2 & $\% \mathrm{~T}$ & dev. shore sites & $75 \pm 17$ SD $\%$ & min. dev. shore sites & $38 \pm 20$ SD $\%$ & -12.84 & 328 & $<0.001$ \\
\hline 3 & TAR & all shore sites & $13 \pm 24 \mathrm{SD} \mathrm{mg} / \mathrm{cm}^{2} / \mathrm{d}$ & all reef sites & $1 \pm 3 \mathrm{SD} \mathrm{mg} / \mathrm{cm}^{2} / \mathrm{d}$ & -15.95 & 584 & $<0.001$ \\
\hline 4 & TAR & dev. shore sites & $21 \pm 30 \mathrm{SD} \mathrm{mg} / \mathrm{cm}^{2} / \mathrm{d}$ & min. dev. shore sites & $7 \pm 18 \mathrm{SD} \mathrm{mg} / \mathrm{cm}^{2} / \mathrm{d}$ & -9.368 & 179 & $<0.001$ \\
\hline 6 & TAR & $\begin{array}{c}\text { mean TAR at LL } \\
\text { Shore during } \\
\text { fall periods pre- } \\
\text { restoration }\end{array}$ & $25 \pm 27 \mathrm{SD} \mathrm{mg} / \mathrm{cm}^{2} / \mathrm{d}$ & $\begin{array}{l}\text { mean TAR at LL } \\
\text { Shore during fall } \\
\text { periods post- } \\
\text { restoration }\end{array}$ & $1 \pm 1 \mathrm{SD} \mathrm{mg} / \mathrm{cm}^{2} / \mathrm{d}$ & -2.378 & 12 & 0.02 \\
\hline
\end{tabular}


Study Period Mean Terrigenous Proportions ( \pm SD \%) at all Shore and Reef Sites
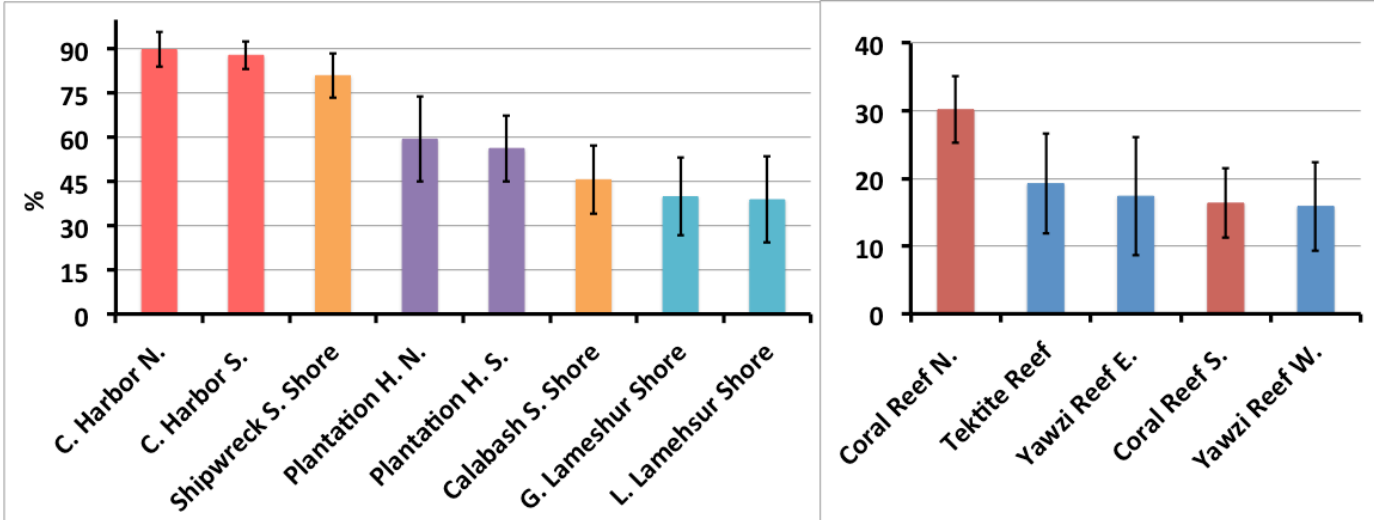

Figure 3.5. Study period mean $\% \mathrm{~T}( \pm \mathrm{SD} \%)$ at all shore (left panel) and reef (right panel) sites. Sites that are grouped as the same location refer to the same color, and warm colors are developed and cool colors are minimally developed sites. 
Table 3.3. P-values for Kruskal-Wallis pairwise comparisons of \%T means between all sites. The area shaded in purple represents shore to shore comparison, in blue shore to reef comparisons, and in pink reef-to-reef comparisons.

\begin{tabular}{|c|c|c|c|c|c|c|c|c|c|c|c|c|}
\hline & C.B. Harbor N. & C.B. Harbor S. & Shipwreck & P. Hill N. & P. Hill S. & Calabash & G.L. Shore & L.L. Shore & C.B. Reef N. & Tektite Reef & Yawzi Reef E. & C.B. Reef S. \\
\hline C.B. Harbor S. & 1.000 & & & & & & & & & & & \\
\hline Shipwreck & 1.000 & 1.000 & & & & & & & & & & \\
\hline P. Hill N. & 0.013 & 0.208 & 1.000 & & & & & & & & & \\
\hline P. Hill S. & 0.013 & 0.130 & 0.676 & 1.000 & & & & & & & & \\
\hline Calabash & $<0.001$ & 0.002 & 0.005 & 0.884 & 1.000 & & & & & & & \\
\hline G.L. Shore & $<0.001$ & $<0.001$ & $<0.001$ & 0.026 & 0.143 & 1.000 & & & & & & \\
\hline L.L. Shore & $<0.001$ & $<0.001$ & 0.001 & 0.078 & 0.286 & 1.000 & 1.000 & & & & & \\
\hline C.B. Reef N. & $<0.001$ & $<0.001$ & $<0.001$ & 0.001 & 0.003 & 0.169 & 1.000 & 1.000 & & & & \\
\hline Tektite Reef & $<0.001$ & $<0.001$ & $<0.001$ & $<0.001$ & $<0.001$ & $<0.001$ & 0.001 & 0.004 & 0.143 & & & \\
\hline Yawzi Reef E. & $<0.001$ & $<0.001$ & $<0.001$ & $<0.001$ & $<0.001$ & $<0.001$ & $<0.001$ & $<0.001$ & 0.006 & 1.000 & & \\
\hline C.B. Reef S. & $<0.001$ & $<0.001$ & $<0.001$ & $<0.001$ & $<0.001$ & $<0.001$ & $<0.001$ & 0.001 & 0.005 & 1.000 & 1.000 & \\
\hline Yawzi Reef W. & $<0.001$ & $<0.001$ & $<0.001$ & $<0.001$ & $<0.001$ & $<0.001$ & $<0.001$ & $<0.001$ & 0.002 & 1.000 & 1.000 & 1.000 \\
\hline
\end{tabular}




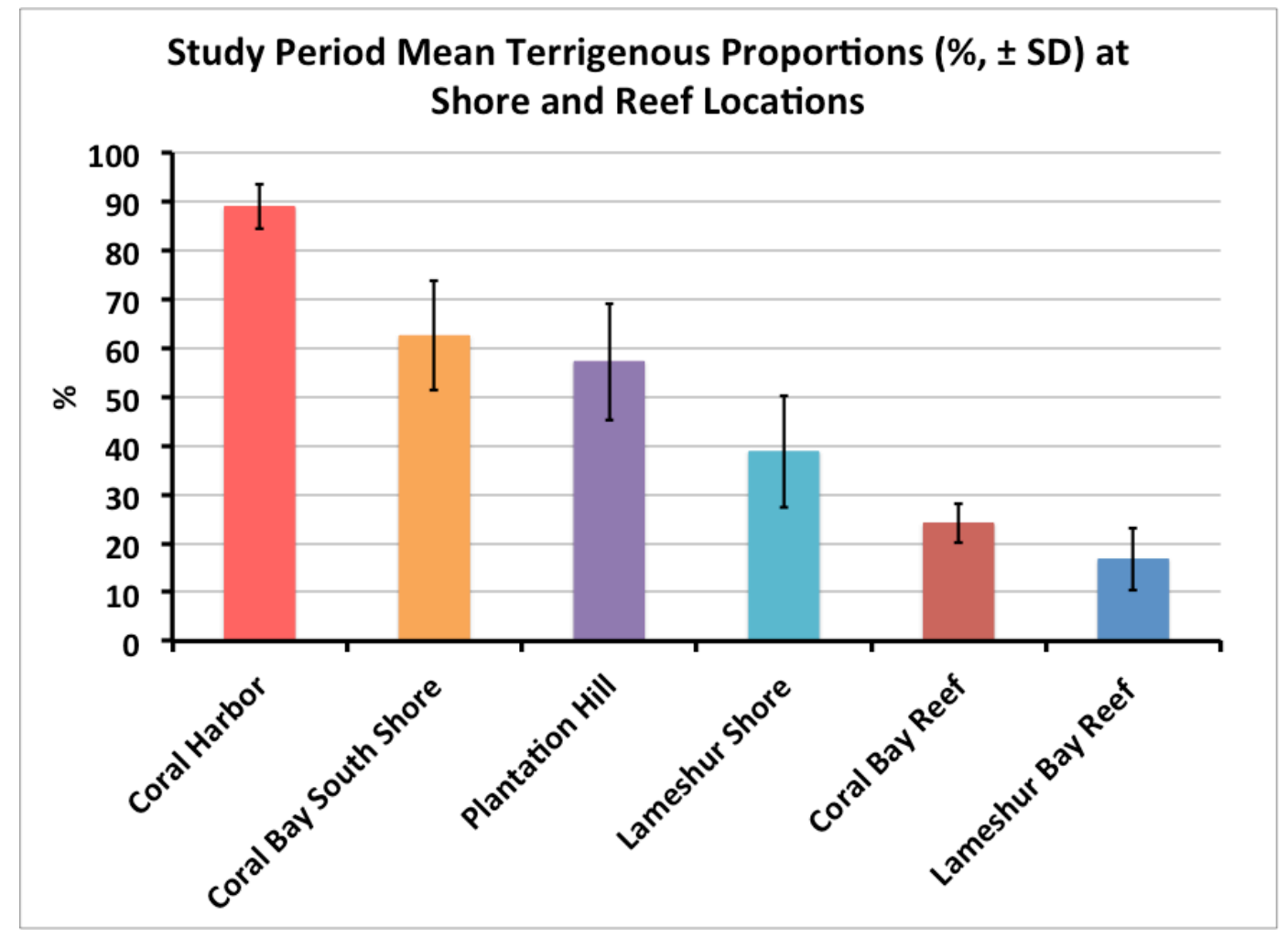

Figure 3.6. Study period mean $\% \mathrm{~T}( \pm \mathrm{SD} \%)$ at all shore and reef locations. Warm colors are developed and cool colors are minimally developed locations. 
Table 3.4. P-values for Kruskal-Wallis pairwise comparisons of \%T means between all shore and reef locations. The area shaded in purple represents shore to shore comparisons, in blue shore to reef comparisons, and in pink reef-to-reef comparisons.

\begin{tabular}{|l|l|l|l|l|l|}
\cline { 2 - 6 } \multicolumn{1}{c|}{} & C. Harbor & C. South Shore & P. Hill & L. Shore & C.B. Reef \\
\hline C. South Shore & $<0.001$ & & & & \\
\hline P. Hill & $<0.001$ & 1.000 & & & \\
\hline L. Shore & $<0.001$ & $<0.001$ & $<0.001$ & & \\
\hline C.B. Reef & $<0.001$ & $<0.001$ & $<0.001$ & $<0.001$ & \\
\hline L. Reef & $<0.001$ & $<0.001$ & $<0.001$ & $<0.001$ & 0.114 \\
\hline
\end{tabular}




\subsubsection{Introduction: Trap Terrigenous Sediment Accumulation}

Temporal and then spatial variability in the mean daily terrigenous accumulation rate $\left(\mathrm{mg} / \mathrm{cm}^{2} / \mathrm{d}\right)$ for each sampling period (TAR) (Appendix III) will be presented. TAR is calculated by multiplying the $\%$ terrigenous by the total sediment accumulation rate $\left(\mathrm{mg} / \mathrm{cm}^{2} / \mathrm{d}\right)$. The data presented in this section will help to address the TAR aspect of Research Question 1A, which seeks to examine temporal variability of TAR in response to rainfall and spatial variability with respect to watershed development and shoreline runoff inputs.

\subsubsection{Temporal Variability}

Though TAR varied greatly (range: 0 to $254 \mathrm{mg} / \mathrm{cm}^{2} / \mathrm{d}$ ), there were no clear temporal trends of increasing or decreasing TAR over the study period. The temporal variability in TAR was greater than for $\% \mathrm{~T}$. Similarly to the pattern observed for $\% \mathrm{~T}$, the greatest temporal variability in TAR was recorded at the minimally developed shore and reef locations (Lameshur Shore: range: 0 - 99 $\mathrm{mg} / \mathrm{cm}^{2} / \mathrm{d}$; max value 25.0 times mean; Lameshur Reef: range: 0 - 14; max value 15.6 times mean; Plantation Hill: range: $1-80 \mathrm{mg} / \mathrm{cm}^{2} / \mathrm{d}$ : max value 9.6 times mean) (Figure 3.7).

The hypothesis that "TAR would be greater during high rainfall" was supported except for during some periods of elevated TAR during low rainfall in 2012. Prior to 2012, above average TARs were usually measured during sampling periods when moderate or major* storms occurred $\left(10 / 22 / 08^{*}(\mathrm{H}\right.$. Omar), 12/2/09*, 10/11/10*, 11/8/10 and 9/15/11*) (Figure 3.7, Table 3.1). Three 
of $\operatorname{six}(10 / 22 / 08,12 / 2 / 09,10 / 11 / 10)$ of these sampling periods coincided with the top five major storms (Figure 3.7, Table 3.1). Unfortunately, for two sampling periods with top five storms, $9 / 20 / 08$, and $7 / 25 / 10$, sediment trap data were not collected at most sites. However, in 2012, there were several sampling periods with elevated TARs at some locations despite minimal rainfall (e.g. 9/15/12, 11/6/12, and 12/28/12) (Figure 3.7).

Although the typical spatial pattern of relative TARs among locations (i.e. decreasing TARs: Coral South Shore $>$ Coral Harbor $>$ Plantation Hill $>$ Lameshur Shore) were observed during most of the six sampling periods when elevated TAR coincided with rainfall, for two of these six sampling periods (10/11/10 and 11/8/10), the spatial pattern differed from the norm. For example, during the 10/11/10 (T.S. Otto) sampling period, TAR at Lameshur Shore exceeded that of all other shore locations $\left(99 \mathrm{mg} / \mathrm{cm}^{2} / \mathrm{d}\right.$ ) (Figure 3.7). During the 10/11/10 (T.S. Otto) and 11/8/10 (period following T.S. Otto), TAR at Plantation Hill ( 80 and $46 \mathrm{mg} / \mathrm{cm}^{2} / \mathrm{d}$, respectively) exceeded TAR at Coral Harbor (49 and $25 \mathrm{mg} / \mathrm{cm}^{2} / \mathrm{d}$, respectively) (Figure 3.7). TAR at Plantation Hill also exceeded rates measured at Coral South Shore during the 9/15/11 storm-sampling period.

TAR at Lameshur Reef was greatest (and surpassed rates at Coral Bay reefs) during the sampling periods when T.S. Otto $\left(10 / 11 / 10,14 \mathrm{mg} / \mathrm{cm}^{2} / \mathrm{d}\right)$ and H. Earl $\left(9 / 15 / 10,13 \mathrm{mg} / \mathrm{cm}^{2} / \mathrm{d}\right)$ passed over St. John. Though H. Earl brought little rain, it brought swell from the south and high levels of resuspension (personal observation). Maximum TAR was recorded at Coral Bay Reef during 
the $9 / 15 / 11$ sampling period (high rainfall) but also during the 9/15/12 (minimal rainfall) sampling period $\left(9 \mathrm{mg} / \mathrm{cm}^{2} / \mathrm{d}\right.$ for both sampling periods) (Figure 3.7$)$. In summary, similar to $\% \mathrm{~T}$, TARs varied greatly but did not appear to increase or decrease over time and were elevated during sampling periods with storms for most of the 2007-2011, but were also elevated during some periods despite low rainfall. 


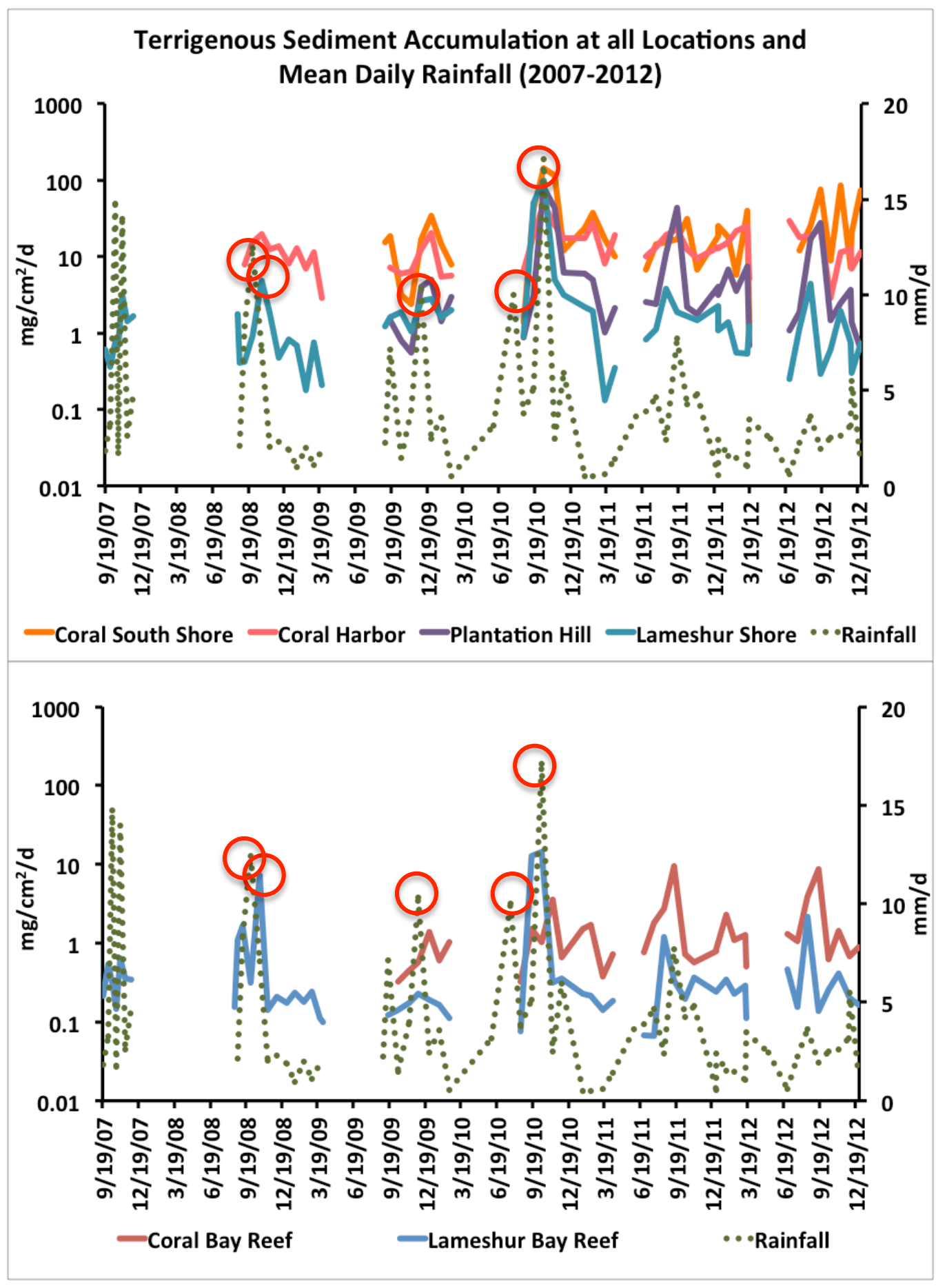

Figure 3.7. TARs at all shore (top panel) and reef (bottom panel) locations through the 2007-12 study period with the top five rain-producing storms circled in red (Table 3.1). Warm colors represent developed locations and cool colors represent minimally developed locations. Mean daily rainfall by sampling period is shown as the green, hashed line in both panels and is plotted on the secondary $y$-axis. The primary $y$-axis is plotted on a log scale. Line gaps represent time intervals when data were not collected. 


\subsubsection{Spatial Variability}

Study period mean TARs ranged from $1 \pm 2 \mathrm{SD} \mathrm{mg} / \mathrm{cm}^{2} / \mathrm{d}$ to $2 \pm 2 \mathrm{SD}$ $\mathrm{mg} / \mathrm{cm}^{2} / \mathrm{d}$ at the reefs and $5 \pm 57 \mathrm{SD}$ to $46 \pm 10 \mathrm{SD} \mathrm{mg} / \mathrm{cm}^{2} / \mathrm{d}$ at the shore sites. The data presented in this section address the alternative hypothesis that "TAR will be greater in shore compared with reef sites/locations and below developed compared with minimally developed watersheds". When all shore data were compared to reef data, mean TAR was significantly greater at shore (mean: $13 \pm$ $24 \mathrm{SD} \mathrm{mg} / \mathrm{cm}^{2} / \mathrm{d}$ ) than at reef sites (mean: $1 \pm 3 \mathrm{SD} \mathrm{mg} / \mathrm{cm}^{2} / \mathrm{d}$ ) (Table 3.2, Ref. 3). The study period mean TARs were significantly greater at developed (mean: $21 \pm$ $30 \mathrm{SD} \mathrm{mg} / \mathrm{cm}^{2} / \mathrm{d}$ ) than at minimally developed shores (mean: $6 \pm 17 \mathrm{SD}$ $\mathrm{mg} / \mathrm{cm}^{2} / \mathrm{d}$ ) by roughly a factor of three (Table 3.2 , Ref. 4).

The study period mean TAR at the site Shipwreck $\left(46 \pm 10 \mathrm{SD} \mathrm{mg} / \mathrm{cm}^{2} / \mathrm{d}\right)$ was three times greater than at the site with the second greatest study period mean, Coral Harbor South (mean: $15 \pm 9 \mathrm{SD} \mathrm{mg} / \mathrm{cm}^{2} / \mathrm{d}$ ) and 7.5 and 3.5 times greater than at Plantation North and Plantation South, respectively (Figure 3.8). However, of all these shore sites mentioned, study period mean TAR at Shipwreck was only found to be significantly greater than at Plantation Hill South (Table 3.5). The only other significant differences in mean TAR at shore sites were greater mean TAR at Plantation Hill North compared with Coral Harbor South and Coral Harbor North, and greater mean TAR at Plantation Hill South compared with Great Lameshur Shore (Table 3.5).

By shore location, study period mean TARs were greatest at Coral Bay South Shore $\left(28 \pm 43 \mathrm{SD} \mathrm{mg} / \mathrm{cm}^{2 /}\right.$ ), followed by Coral Harbor (14 $\pm 9 \mathrm{SD}$ 
$\mathrm{mg} / \mathrm{cm}^{2} / \mathrm{d}$ ) (Figure 3.9), and all pairwise comparisons between shore locations were significantly different with the exception of Coral South Shore compared to Coral Harbor (Table 3.6).

Study period mean TAR at all minimally developed (Lameshur) reef sites were significantly less than both Coral Bay Reef North and South, and there were no significant differences within Lameshur Reef sites nor between Coral Bay Reef North and South (Table 3.5). When reef sites were grouped by location, Coral Bay Reef was significantly greater than Lameshur Bay reef (Table 3.6). 
Study Period Mean Terrigenous Accumulation (+ SD) at Shore (Right) and Reef (Left) Environments

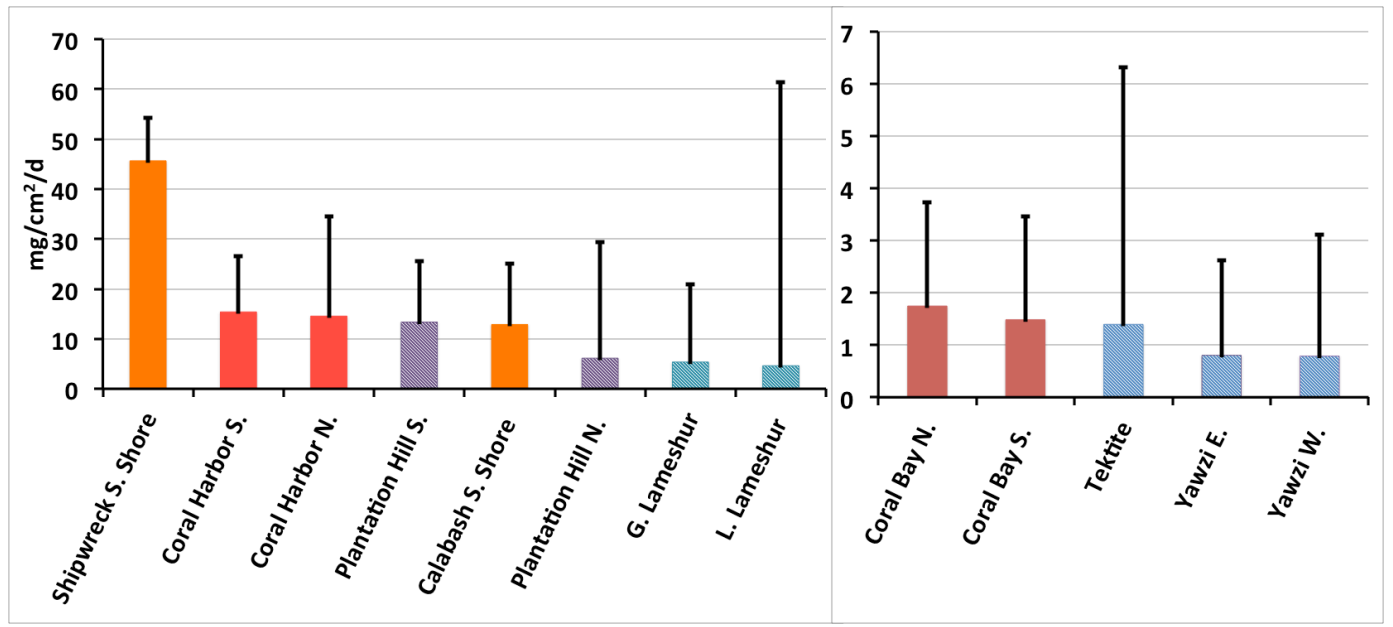

Figure 3.8. Study period mean TARs (+ SD) at shore (right) and reef (left) sites. Developed locations are represented by warm colors and minimally developed by cool colors. 
Table 3.5. P-values for Kruskal-Wallis pairwise comparisons of TAR means between all sites. The area shaded in purple represents shore to shore comparisons, in blue shore to reef comparisons, and in pink reef-to-reef comparisons.

\begin{tabular}{|c|c|c|c|c|c|c|c|c|c|c|c|c|}
\hline & Shipwreck & C. Harbor S. & C. Harbor $\mathbf{N}$. & P. Hill S. & Calabash & P. Hill N. & G.L. Shore & L.L. Shore & C. B. Reef $\mathrm{N}$. & C.B. Reef S. & Tektite Reef & Yawzi Reef E. \\
\hline C. Harbor S. & 1.000 & & & & & & & & & & & \\
\hline C. Harbor $\mathrm{N}$. & 1.000 & 1.000 & & & & & & & & & & \\
\hline P. Hill S. & 0.052 & 0.624 & 0.494 & & & & & & & & & \\
\hline Calabash & 0.338 & 1.000 & 1.000 & 1.000 & & & & & & & & \\
\hline P. Hill N. & $<0.001$ & 0,026 & 0.013 & 1.000 & 0.741 & & & & & & & \\
\hline G.L. Shore & $<0.001$ & $<0.001$ & $<0.001$ & 0.013 & $<0.001$ & 0.130 & & & & & & \\
\hline L.L. Shore & $<0.001$ & $<0.001$ & $<0.001$ & 0.182 & 0.013 & 1.000 & 1.000 & & & & & \\
\hline C. B. Reef N. & $<0.001$ & $<0.001$ & $<0.001$ & 0.052 & $<0.001$ & 1.000 & 1.000 & 1.000 & & & & \\
\hline C.B. Reef S. & $<0.001$ & $<0.001$ & $<0.001$ & 0.002 & $<0.001$ & 0.026 & 1.000 & 1.000 & 1.000 & & & \\
\hline Tektite Reef & $<0.001$ & $<0.001$ & $<0.001$ & $<0.001$ & $<0.001$ & $<0.001$ & $<0.001$ & $<0.001$ & $<0.001$ & 0.013 & & \\
\hline Yawzi Reef E. & $<0.001$ & $<0.001$ & $<0.001$ & $<0.001$ & $<0.001$ & $<0.001$ & $<0.001$ & $<0.001$ & $<0.001$ & 0.033 & 1.000 & \\
\hline Yawzi Reef W. & $<0.001$ & $<0.001$ & $<0.001$ & $<0.001$ & $<0.001$ & $<0.001$ & $<0.001$ & $<0.001$ & $<0.001$ & 0.026 & 1.000 & 1.000 \\
\hline
\end{tabular}




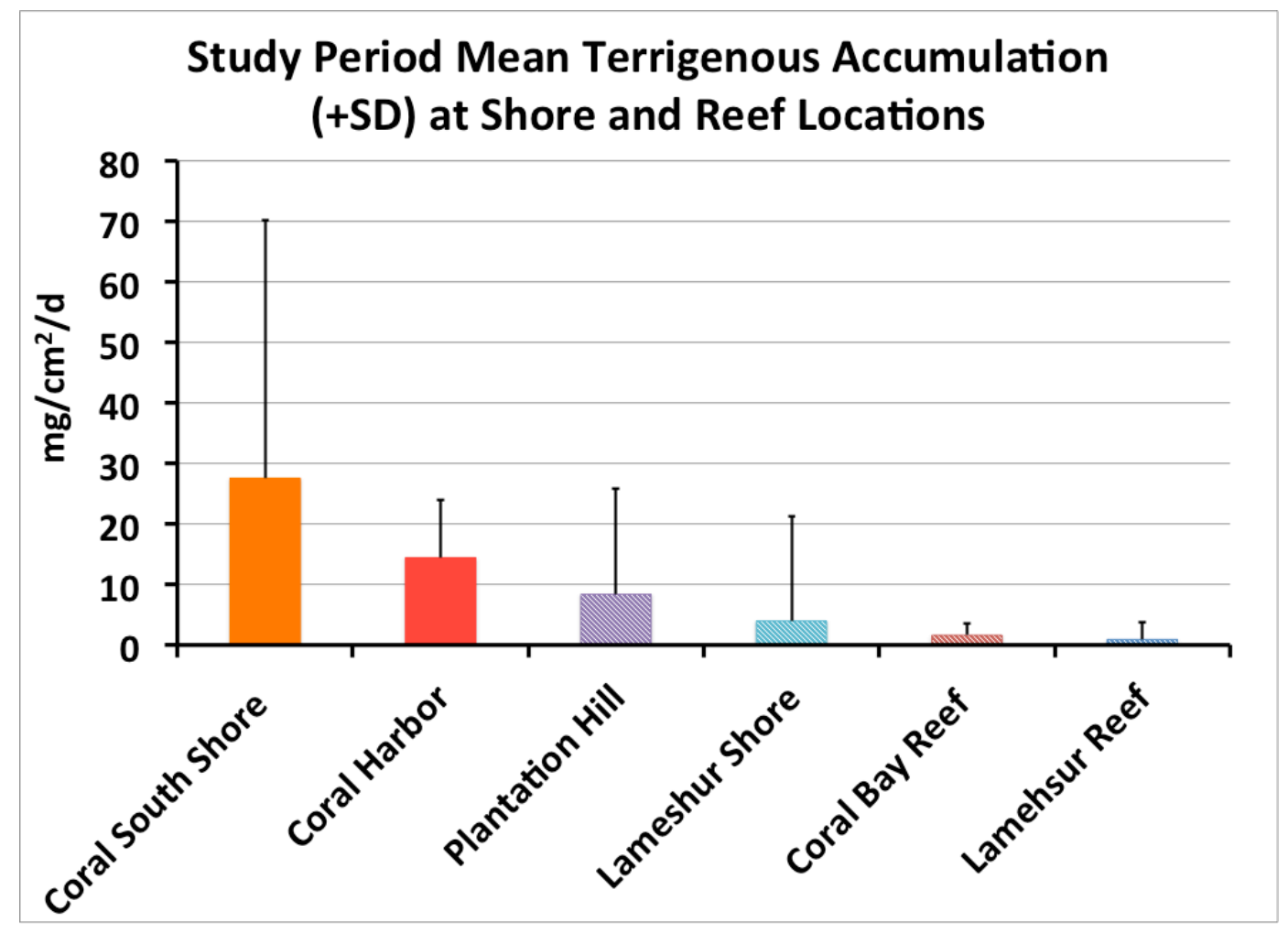

Figure 3.9. Study period mean TARs $(+\mathrm{SD})$ at all shore and reef locations. Developed locations are represented by warm colors and minimally developed by cool colors. 
Table 3.6. P-values for Kruskal-Wallis pairwise comparisons of TAR means between all locations. The area shaded in purple represents shore to shore comparisons, in blue shore to reef comparisons, and in pink reef-to-reef comparisons.

\begin{tabular}{|l|l|l|l|l|l|}
\cline { 2 - 6 } \multicolumn{1}{c|}{} & C. South Shore & C. Harbor & P. Hill & L. Shore & C.B. Reef \\
\hline C. Harbor & 1.000 & & & & \\
\hline P. Hill & 0.004 & 0.001 & & & \\
\hline L. Shore & $<0.001$ & $<0.001$ & 0.002 & & \\
\hline C.B. Reef & $<0.001$ & $<0.001$ & $<0.001$ & 1.000 & \\
\hline L. Reef & $<0.001$ & $<0.001$ & $<0.001$ & $<0.001$ & $<0.001$ \\
\hline
\end{tabular}


3.2.3 Relationship between Terrigenous Accumulation Rates and Rainfall

\subsubsection{Rainfall-based Regressions}

The data provided in this section address Research Question 1B, which seeks to examine the relationship between TAR and rainfall in more detail. More specifically, the data presented here help determine whether the following alternative hypotheses can be supported: "TAR will vary significantly with rainfall", "the correlation between TAR and rainfall will be greater near-shore and below developed watersheds", and "the correlation between TAR and rainfall will be stronger with mean rainfall intensity, and maximum daily rainfall than with mean daily rainfall." To examine the relationship between mean daily rainfall, mean rainfall intensity, and maximum daily rainfall and terrigenous accumulation rates (TARs), both with and without the consideration of the Antecedent Precipitation Index (API), a rainfall-based proxy for soil moisture, regressions were run between rainfall parameters and TAR. In this section, we present and compare rainfall-based regressions, which do or do not consider API for different locations (Refer to "Methods and Location" Table 2.3 for a detailed summary of value regimes used for all regressions).

Of the maximum $\%$ variance in TAR explained by regression models for each location, mean daily rainfall, mean rainfall intensity, and maximum daily rainfall explained $21-62 \%, 19-55 \%$ and $37-81 \%$ of the variability in TAR, respectively (Table 3.7). Overall, the $\%$ variance in TAR explained by mean daily rainfall, mean rainfall intensity, and maximum daily rainfall was greater for greater rainfall regimes and at shore compared with reef locations (Figure 3.10). 
Maximum daily rainfall and mean rainfall intensity generally correlated more strongly with TAR (Figure 3.10).

Of the shore locations, the $\%$ variance of TAR explained by mean daily rainfall, mean rainfall intensity, and maximum daily rainfall was lowest at Coral Bay South Shore (10-47\%) (Figure 3.10, Table 3.7) and was similar among Plantation Hill, Coral Harbor, and Lameshur Shore for mean rainfall intensity (55\%) (Figure 3.10, Table 3.7). The \% variance in TAR explained by mean and maximum daily rainfall at Plantation Hill and Coral Harbor was generally over 60 and $75 \%$, respectively, compared with around 30 and $50 \%$, respectively, at Lameshur Shore (Figure 3.10, Table 3.7).

There was not a significant relationship between mean daily rainfall, mean rainfall intensity, and maximum daily rainfall vs. TAR at Coral Bay Reef (Figure 3.10, Table 3.7). At Lameshur Bay Reef, $\%$ variance in TAR explained by mean daily rainfall, mean rainfall intensity, and maximum daily rainfall was lower than at most other shore locations (21-38\%) (Figure 3.10, Table 3.7). 
\% Variance in Terrigenous Accumulation Rates Explained by Mean Daily Rainfall, Mean Rainfall Intensity, and Maximum Daily Rainfall in RainfallBased Regressions

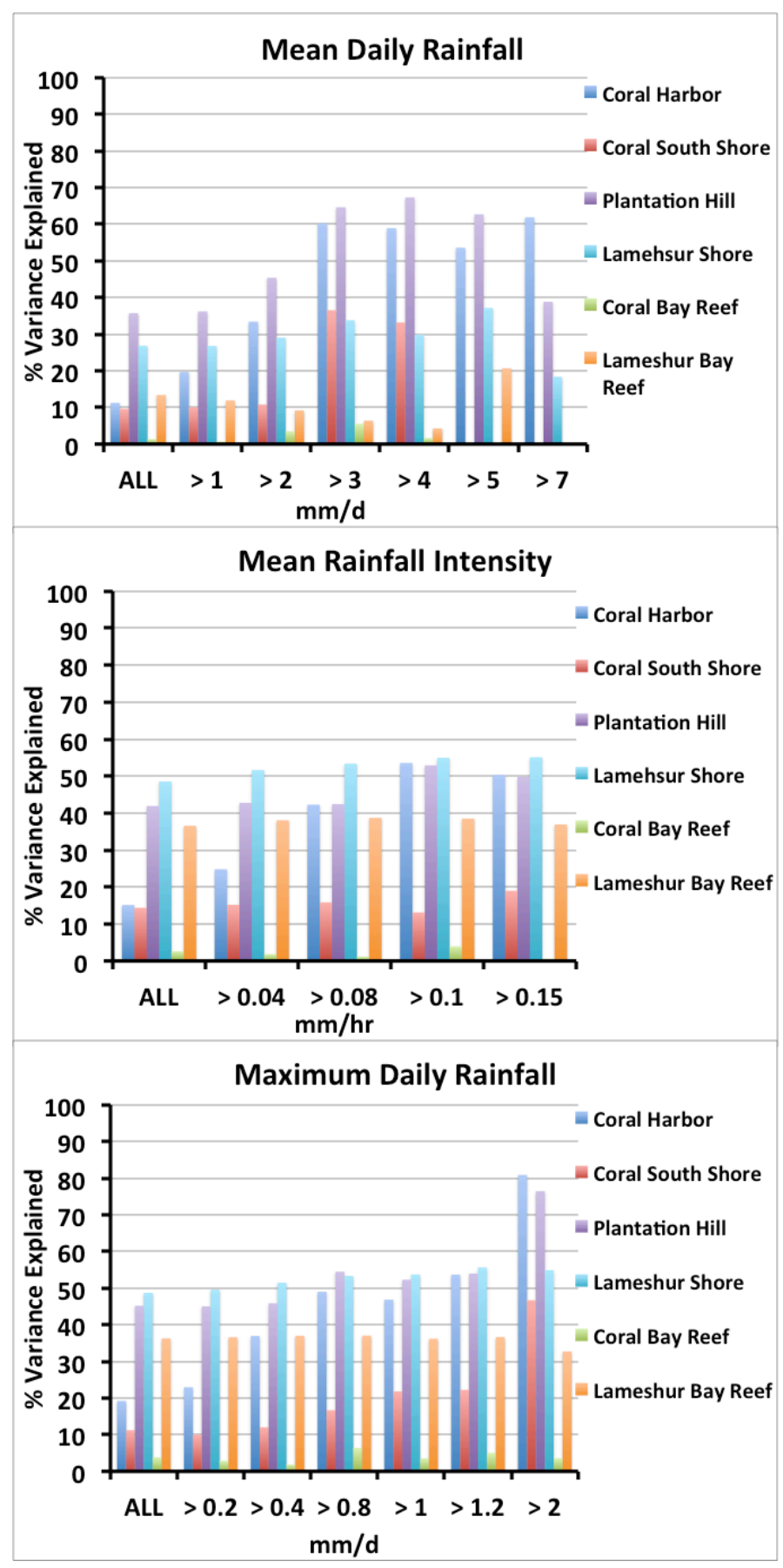

Figure 3.10. R-squared values (shown as \% variance in TAR) in mean daily rainfall, mean rainfall intensity, and maximum daily rainfall regressions in rainfall-based regressions. Each $\mathrm{x}$-axis notes the regime values for each different rainfall parameter. All Coral Bay Reef regressions were insignificant. 
Table 3.7. The maximum $\%$ variance of TAR explained by mean daily rainfall, mean rainfall intensity, and maximum daily rainfall and respective $p$-values in rainfall-based regressions at each location. Insignificant values are italicized.

\begin{tabular}{|l|r|r|r|r|r|r|}
\hline Location & Mean Daily Rainfall & p-value & Mean Rainfall Intensity & p-value & Maximum Daily Rainfall & p-value \\
\hline Coral Harbor & 62 & 0.01 & 53 & $<0.001$ & 81 & $<0.001$ \\
\hline Coral South Shore & 37 & $<0.001$ & 19 & 0.03 & 47 & 0.001 \\
\hline Coral Bay Reef & 21 & 0.2 & 4 & 0.25 & 6 & 0.09 \\
\hline Plantation Hill & 67 & $<0.001$ & 53 & $<0.001$ & 56 & $<0.001$ \\
\hline Lameshur Shore & 37 & $<0.001$ & 39 & $<0.001$ & $<0.001$ & $<0.001$ \\
\hline Lameshur Reef & 21 & 0.01 & 39 & $<0.001$ \\
\hline
\end{tabular}




\subsubsection{Antecedent Precipitation Index (API)-Based Regressions}

For the regressions that considered API, mean daily rainfall, mean rainfall intensity, and maximum daily rainfall explained up to $14-61 \%, 22-69 \%$, and $24-$ $77 \%$ of the variability in TARs at all locations, respectively (Table 3.8). At the shore locations, the correlation between mean daily rainfall, rainfall intensity, and maximum daily rainfall vs TARs was generally stronger for greater regimes compared with lesser rainfall regimes (Figure 3.11) (with the exception of Coral Bay South Shore, where correlations were not significant for the $>10$ and 12 regimes). At all locations, the greatest $\%$ variance in TAR was explained by maximum daily rainfall (Figure 3.11, Table 3.8).

The maximum $\%$ variance in TARs explained by mean daily rainfall (42$61 \%)$, mean rainfall intensity (52-69\%), and maximum daily rainfall (55-77\%) were similar at Lameshur Shore, Plantation Hill, and Coral Harbor, and Lameshur Reef (Table 3.8, Figure 3.11) and was lowest $(<20 \%)$ at Coral South Shore (Figure 3.11). There was not a significant relationship between mean daily rainfall, mean rainfall intensity, and maximum daily rainfall vs. TAR at Coral Bay Reef.

The mean $\%$ variance in TAR across all locations was $46 \%$ for maximum daily rainfall regressions compared with 36 and $42 \%$ for mean daily rainfall and mean rainfall intensity regressions, respectively. 
\% Variance in Terrigenous Accumulation Rates Explained by Mean Daily Rainfall, Mean Rainfall Intensity, and Maximum Daily Rainfall in APIBased Regressions

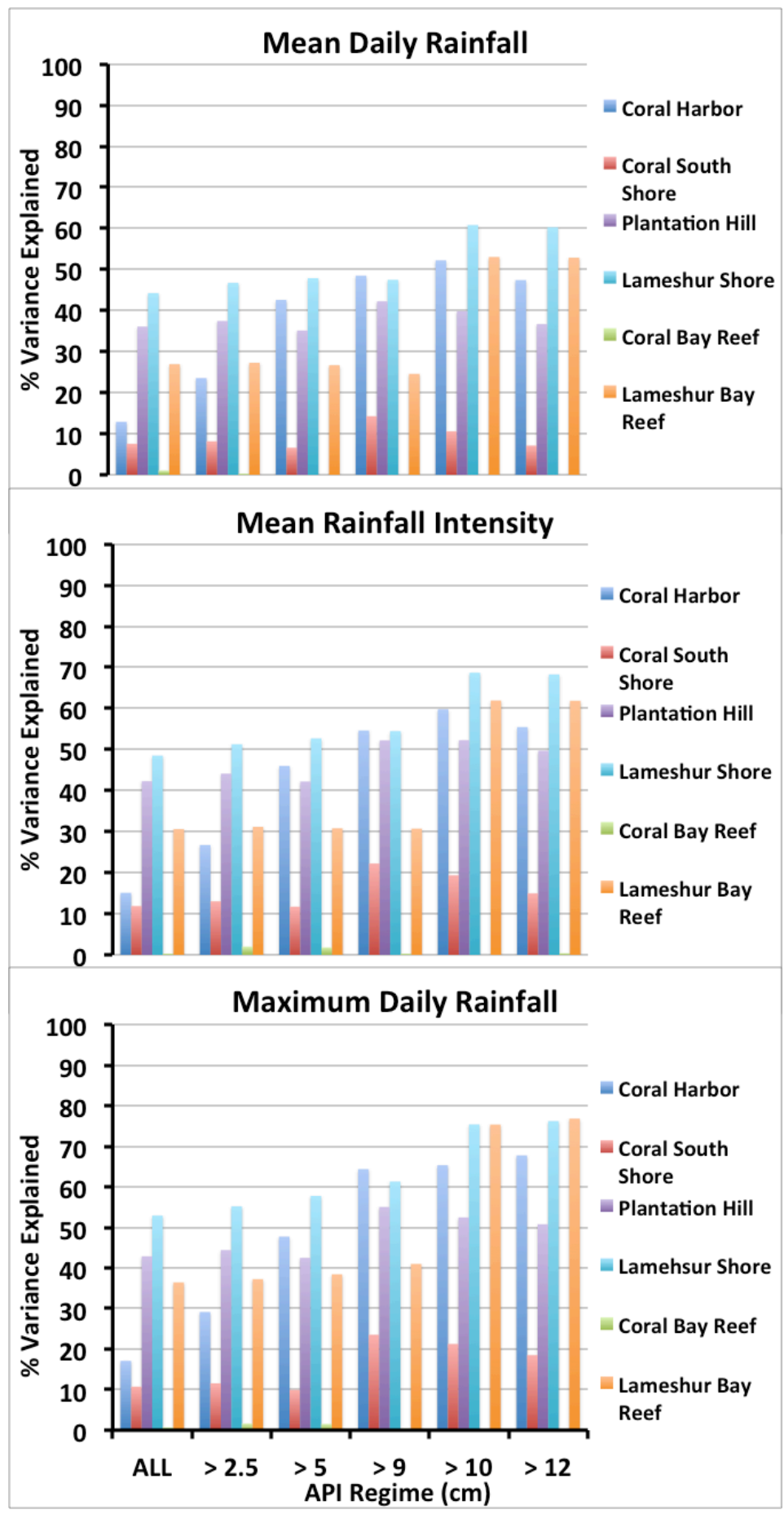

Figure 3.11. R-squared values (shown as \% variance in TAR) for mean daily rainfall, mean rainfall intensity, and maximum daily rainfall vs. TAR API-regime regressions at all locations. All Coral Bay Reef regressions were insignificant. 
Table 3.8. The maximum $\%$ variance in TAR explained by mean daily rainfall, mean rainfall intensity, and maximum daily rainfall and respective p-values in API-based regressions at each location. Insignificant values are italicized.

\begin{tabular}{|c|c|c|c|c|c|c|}
\hline Location & Mean Daily Rainfall API & p-value & Mean Rainfall Intensity API & p-value & Maximum Daily Rainfall API & p-value \\
\hline Coral Harbor & 52 & $<0.001$ & 60 & $<0.001$ & 68 & $<0.001$ \\
\hline Coral South Shore & 14 & 0.05 & 22 & 0.01 & 24 & 0.009 \\
\hline Coral Bay Reef & 1 & 0.98 & 2 & 0.33 & 2 & 0.35 \\
\hline Plantation Hill & 42 & $<0.001$ & 52 & $<0.001$ & 55 & $<0.001$ \\
\hline Lameshur Shore & 61 & $<0.001$ & 69 & $<0.001$ & 76 & $<0.001$ \\
\hline Lameshur Reef & 53 & $<0.001$ & 62 & $<0.001$ & 77 & $<0.001$ \\
\hline
\end{tabular}




\subsubsection{Rainfall-based Compared with API-based Regressions}

The $\%$ variance in TAR explained by mean rainfall intensity was greater for API regressions compared with rainfall-based regressions at all sites except at Plantation Hill. At Lameshur Shore and Reef, \% variance in TAR explained by mean rainfall intensity, mean daily rainfall and maximum daily rainfall were greater for API compared with rainfall-based regressions (Figure 3.12). In contrast, at locations in Coral Bay (including minimally developed Plantation Hill), \% variance in TAR explained by mean daily and maximum daily rainfall was greater for the rainfall-based regressions (Figure 3.12).

Overall, the rate change in TAR was greatest with respect to mean rainfall intensity for both rainfall and API-based regressions, and regression coefficients were generally around 5 in both models, compared with regression coefficients of 0.01-0.2 for mean daily rainfall and maximum daily rainfall regressions (Table 3.9).

In summary, TARs correlated more strongly with parameters of rainfall in Coral Bay for API-blind (absent) regressions (with the exception of mean rainfall intensity), but correlated more strongly for regressions that considered API in Lameshur Bay (Figure 3.12). For both the rainfall parameter and API-regime regressions, maximum regression coefficients were always greatest for mean rainfall intensity regressions (Table 3.9), and maximum daily rainfall tended to explain the greatest \% variance in TAR (Figures 3.10 and 11). 


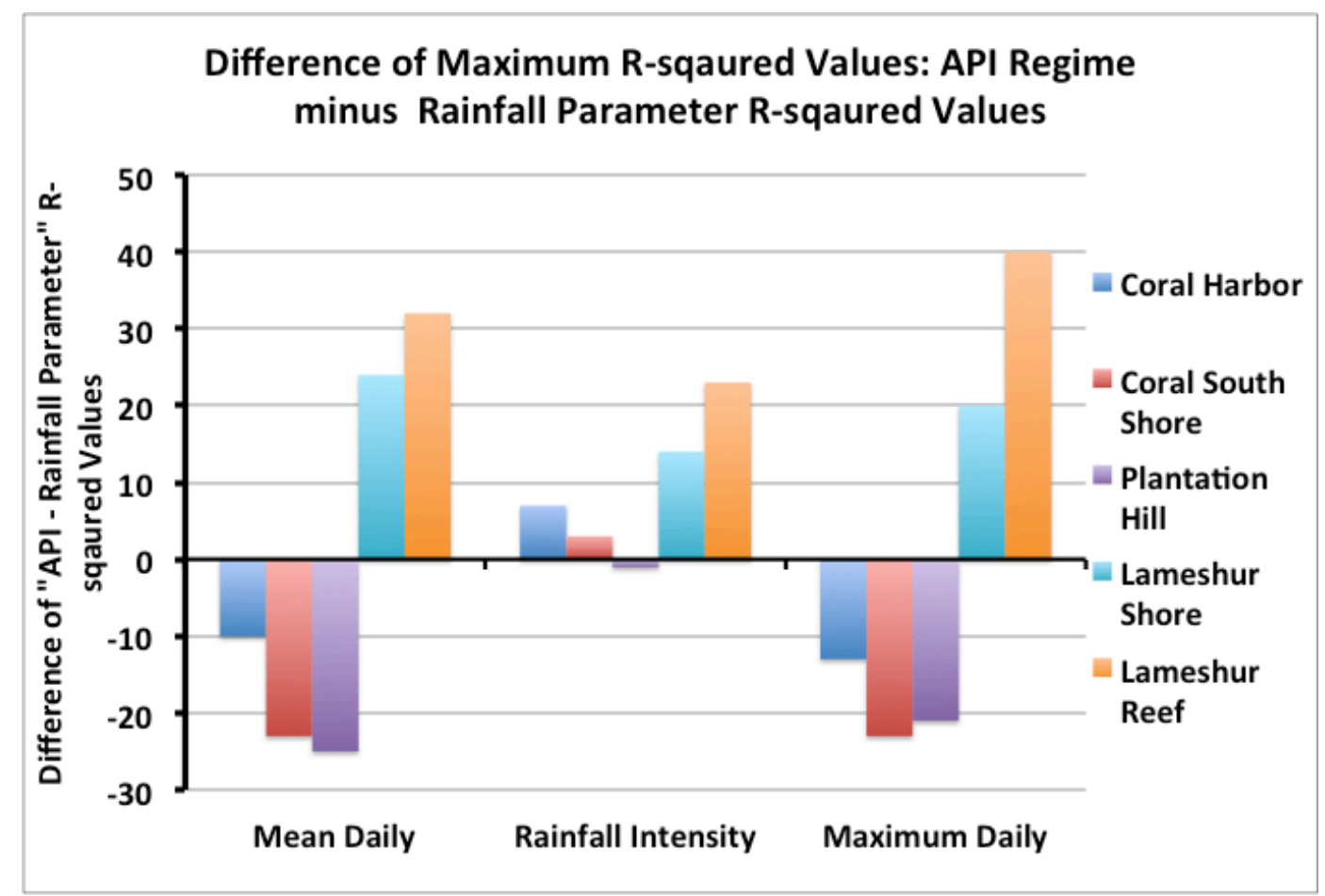

Figure 3.12. Differences in maximum R-squared values (shown as \% variance in TAR) between API and rainfall parameter-regime regressions. Values were calculated by subtracting rainfall parameter-regime r-squared values from APIregime r-squared values. Data from Coral Bay were not included as all data were insignificant. 
Table 3.9. Maximum regression coefficients produced for rainfall-based regressions and API-based regressions for each rainfall parameter and location. Data from Coral Bay were not included as all data were insignificant.

\begin{tabular}{|l|r|r|r|r|r|r|}
\cline { 2 - 7 } \multicolumn{1}{c|}{} & \multicolumn{3}{c|}{ Rainfall-Based } & \multicolumn{3}{c|}{ API-Based } \\
\cline { 2 - 7 } \multicolumn{1}{c|}{} & Mean D. Rain & Mean Rain. Intensity & Max. D. Rain & Mean D. Rain & Mean Rain. Intensity & Max. D. Rain \\
\hline C. Harbor & 0.20 & 5.09 & 0.52 & 0.19 & 4.78 & 0.01 \\
\hline C. S. Shore & 0.17 & 2.79 & 0.37 & 0.10 & 2.96 & 0.01 \\
\hline P. Hill & 0.21 & 5.09 & 0.53 & 0.19 & 5.04 & 0.02 \\
\hline L. Shore & 0.16 & 5.46 & 0.45 & 0.21 & 5.30 & 0.02 \\
\hline L. Reef & 0.11 & 4.95 & 0.41 & 0.17 & 4.50 & 0.02 \\
\hline
\end{tabular}




\subsubsection{Terrigenous Accumulation Pre- Compared with Post-Restoration}

In order to preliminarily examine how TAR may have changed with respect to watershed restoration in Coral Bay, in this section terrigenous accumulation rates (TAR) will be compared before and after the completion of the Coral Bay NOAA/ARRA watershed restoration projects. The pre-restoration period was prior to $7 / 2011$, and the post-restoration period spanned from 7/2011$12 / 2012$.

The restored sub-catchments were drained by ephemeral streams near our CB South Shore (TC-3B, TC-1B) and CB Harbor sites (TC-5, TC-8) Overall, it was predicted that watershed restoration such as the installation of sediment detention ponds, cemented road swales, and to a lesser degree, paving segments of roads would decrease overall sediment delivery in Coral Bay from 445 to 327 Mg/yr (\% reduction: 27\%) (Ramos- Scharrón and Swanson 2012). Because the Lameshur Bay watershed is our control site and did not undergo restoration, we predicted that there would be a greater reduction in TAR at our developed sites post-restoration relative to Lameshur Bay sites during the rainy fall season and during similar storms.

Pre- vs. post-restoration TAR are compared by examining a) mean TAR and rain-normalized TAR at each site pre- vs. post- restoration, and b) by identifying and comparing TAR during sampling periods pre- vs. post- restoration with "equivalent" storms. 


\subsubsection{Differences in Non- and Rain-Normalized Terrigenous}

Accumulation Rates Pre- and Post-Restoration

For all sites except Little Lameshur shore, post-restoration (7/201112/2012) mean TARs were not found to be significantly different from prerestoration (9/2008-7/2011) TARs for both the non-normalized and rainnormalized analyses, which included "all fall season periods" and "high rainfall, fall season" periods only". At Little Lameshur Shore, the mean TAR of eight post-restoration periods was significantly less than the mean pre-restoration TAR of four sampling periods for the non-normalized and rain-normalized "high rainfall fall" period analysis (Table 3.2, Ref. 6 for both). However, Little Lameshur was a control site, not a site where restoration took place.

\subsubsection{Terrigenous Accumulation Rates during Equivalent Storms}

Identified Pre- and Post-Restoration:

In order to compare TAR pre- vs. post- restoration during sampling periods, pairs of storms that shared similar characteristics were chosen from the pre- and the post- restoration periods. Two pairs of storms were identified as the best candidates for "equivalent" storm analysis (Table 3.10). Paired storms were chosen based on similarity in the duration in days, shared similar cumulative rainfall/storm (rainfall/storm), and storm rainfall/d (Table 3.10). However, for each pair, there was slightly greater mean daily rainfall during the post-restoration storm (Table 3.10). 
Table 3.10. Two pairs of equivalent storms identified pre- and post-restoration and rainfall values.

\begin{tabular}{|l|l|l|l|l|l|}
\cline { 3 - 6 } \multicolumn{2}{c|}{} & \multicolumn{2}{l|}{$\begin{array}{l}\text { Mean Daily } \\
\text { Beginning-End Date }\end{array}$} & $\begin{array}{l}\text { Cum. Rainfall/ } \\
\text { Rainfall }\end{array}$ & $\begin{array}{l}\text { Storm } \\
\text { Storm }\end{array}$ \\
\hline \multirow{2}{*}{ Pair One } & PRE & $12 / 25 / 09-12 / 25 / 09$ & 2.5 & 28.7 & 28.7 \\
\cline { 2 - 6 } & POST & $11 / 15 / 11-11 / 15 / 11$ & 3.1 & 29.7 & 29.7 \\
\hline \multirow{2}{*}{ Pair Two } & PRE & $11 / 7 / 10-11 / 8 / 10$ & 2.5 & 93.7 & 46.9 \\
\cline { 2 - 6 } & POST & $11 / 20 / 12-11 / 21 / 12$ & 5.5 & 98.8 & 49.4 \\
\hline
\end{tabular}


For all sites except the Lameshur reefs in storm pair one, the TARs during the post-restoration storm periods were lower than during pre-restoration periods (Figures 3.13 and 14) and in summary were $62-94 \%$ lower during post- than the pre-restoration periods (Table 3.11). Results at minimally developed reef sites were more variable. While there were post-restoration reductions at all minimally developed reef sites during storm pair two, post-restoration TAR was greater at all minimally developed reef sites during pair one (Figure 3.14). 


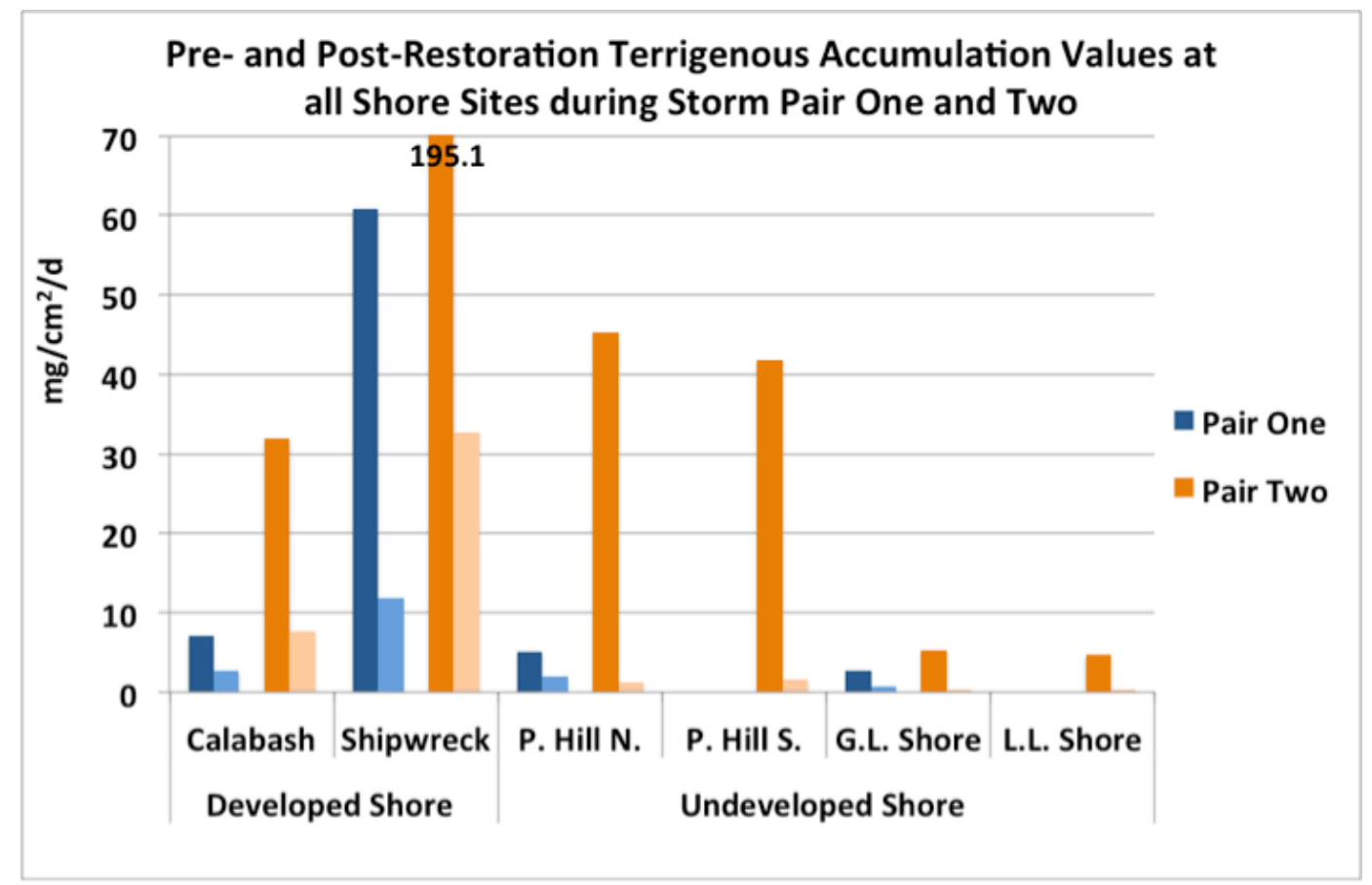

Figure 3.13. Pre- and post-restoration TARs at all shore sites during equivalent storm pairs. Storm pair one is shown in blue and pair two in orange. In both pairs, pre-restoration values are given first as the darker shade of each respective pair color. 


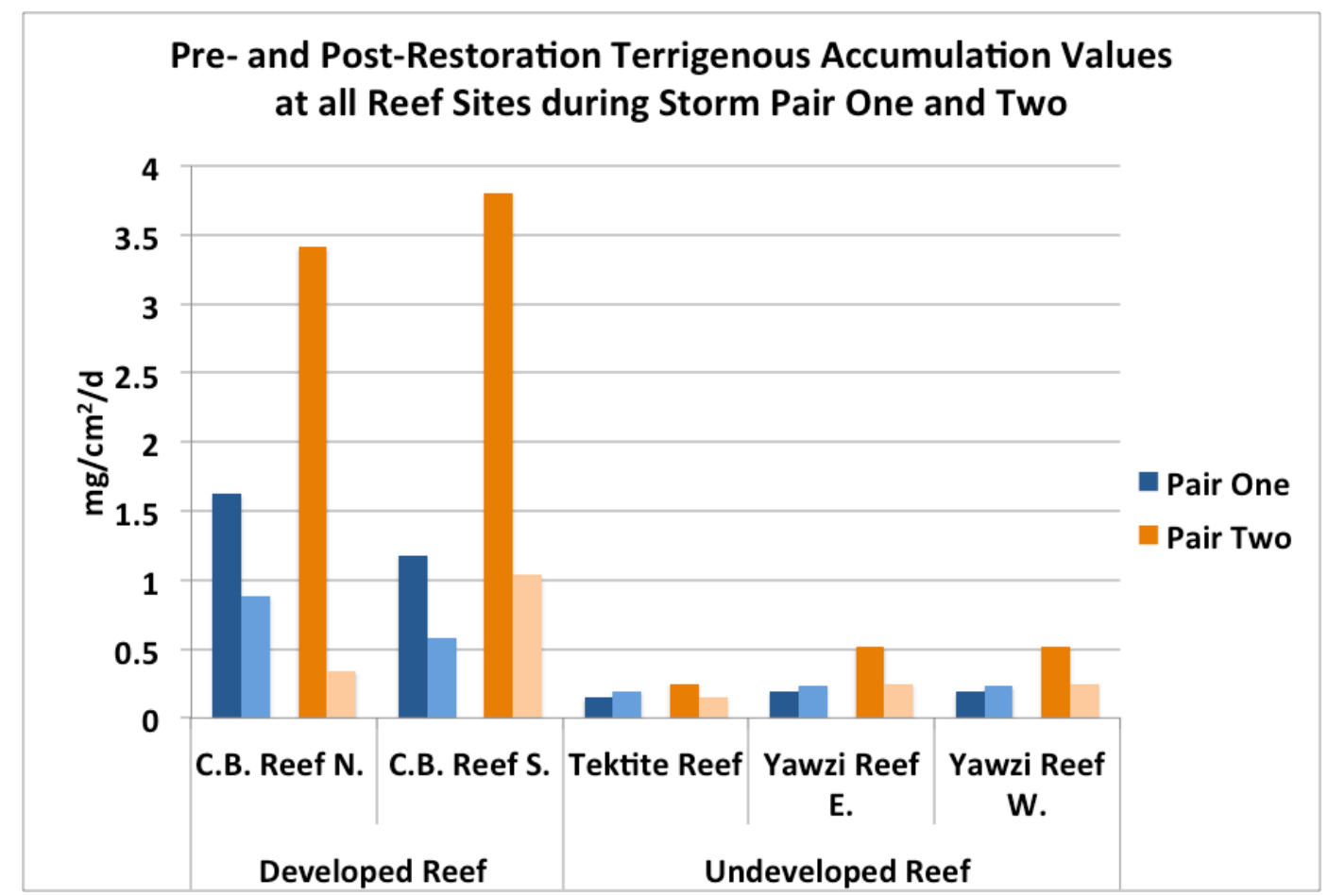

Figure 3.14. Pre- and post-restoration TARs at all reef sites during equivalent storm pairs. Storm pair one is shown in blue and pair two in orange. In both pairs, pre-restoration values are given first as the darker shade of each respective pair color. 
Table 3.11. Range of values for $\%$ reduction in TAR for post-restoration in shore and reef areas.

\begin{tabular}{|l|l|}
\hline Environment & \% Reduction \\
\hline Developed Shore & $62-81$ \\
\hline Developed Reef & $46-90$ \\
\hline Minimally Dev. Shore & $72-94$ \\
\hline Minimally Dev. Reef & $(-51)-32 \%$ \\
\hline
\end{tabular}




\section{$\underline{3.3 \text { Wave Height }}$}

In addition to rainfall and watershed characteristics, resuspension caused by wave activity is also an important process that affects the spatial and temporal variability in the quantity and proportions of sediment types (e.g., terrigenous and carbonate) that accumulate in sediment traps. In this section, temporal and spatial variability in wave height will be explored.

\subsubsection{Wave Height during Storm Events}

Maximum and mean wave height during major storms and tropical depressions exceeded the study period mean wave height during ten and six of the thirteen storms, respectively. The storm with the greatest maximum wave was Hurricane Omar (10/13/08-10/16/08) at 4.4 m, followed by Hurricane Earl $(8 / 29 / 10-9 / 1 / 10)$ at 2.97 (Figure 3.15). Two named storms, T.S. Irene (7/2/11) and T.S. Raphael ( 10/14/12) as well as one, unnamed high rainfall event (5/5/09) surpassed $1.5 \mathrm{~m}$ in maximum wave height. All other storms were similar in terms of wave height to the study period mean wave height (Figure 3.15). 


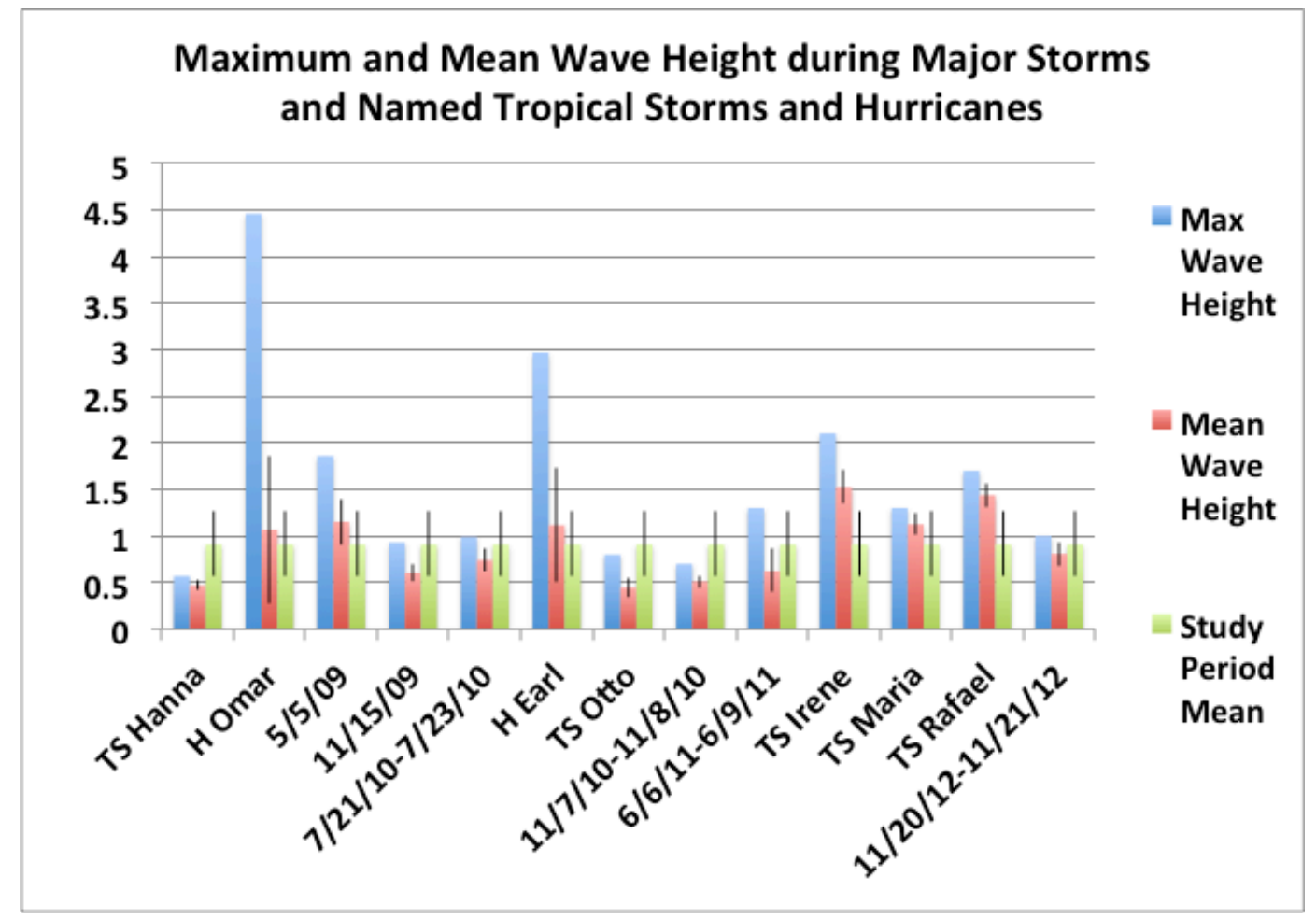

Figure 3.15. Maximum and mean wave height during major, unnamed storms (represented by the date of occurrence) and named tropical depressions compared with study period mean wave height. Error bars represent standard error. 
3.3.2 Sampling Periods when Resuspension may have been a Predominant Factor Controlling Terrigenous Sediment Trap Accumulation

We examined how $\% \mathrm{~T}$ and $\mathrm{TAR}$ varied with maximum wave height because waves may induce resuspension of benthic sediments and deposit sediment in the sediment traps and thus, along with rainfall/runoff affect \%Ts and TARs.

Throughout the study period, maximum wave height ranged from about 1 to $4.5 \mathrm{~m}$. In general, the greatest maximum wave heights occurred in the months of September and October months during the peak of hurricane season (Figure 3.16). We found that only TAR varied significantly with wave height and not $\% \mathrm{~T}$. However, though there was not a significant relationship, there were a few sampling periods when $\% \mathrm{~T}$ may have been reduced due to carbonate resuspension associated with resuspension of benthic carbonate sediment due to increased elevated wave activity.

There were two sampling periods in which there was exceptionally elevated wave height coupled with low mean daily rainfall: the $9 / 15 / 10$ period during which Hurricane Earl occurred, and the 9/15/12 period. In both cases, despite the fact that terrigenous sediment delivery likely did not occur during these periods, TARs were highly elevated at most locations (Figure 3.16). As was mentioned earlier, \% $\%$ at Lameshur Shore and Reef during Earl were at the lowest values of study period (13 and $9 \%$, respectively), likely due to carbonate resuspension as a result of high southerly wave activity. During the 9/15/12 
period, \% $\mathrm{T}$ was also low at Coral Bay in addition to Lameshur Bay locations (Figure 3.17). There were also sampling periods when both maximum wave height and rainfall were elevated (10/22/08, 10/11/10 and 9/15/11), during which TAR was elevated but $\% \mathrm{~T}$ was low, again, likely from resuspension and entrapment of carbonates (Figures 3.16 and 3.17).

For sampling periods when there was moderate wave activity (maximum wave height: $1-2 \mathrm{~m}$ ) but also minimal chance that terrigenous sediment delivery occurred (less than $5 \mathrm{~mm}$ of maximum daily rainfall: 10/12/09 and 2/19/10) (Figure 3.16), all terrigenous sediment accumulation in traps must have resulted from resuspension. During the 10/12/09 period, TARs at all locations ranged from 0.1 to $6 \mathrm{mg} / \mathrm{cm}^{2} / \mathrm{d}$ and during the $2 / 19 / 10$ from 0.1 to $8 \mathrm{mg} / \mathrm{cm}^{2} / \mathrm{d}$, indicating that there was some degree of terrigenous sediment accumulation in traps from resuspension at all locations. There were likely many other periods with greater maximum daily rainfall when terrigenous sediment delivery did not occur and thus where all terrigenous sediment accumulation in traps must have been attributable to resuspension. 


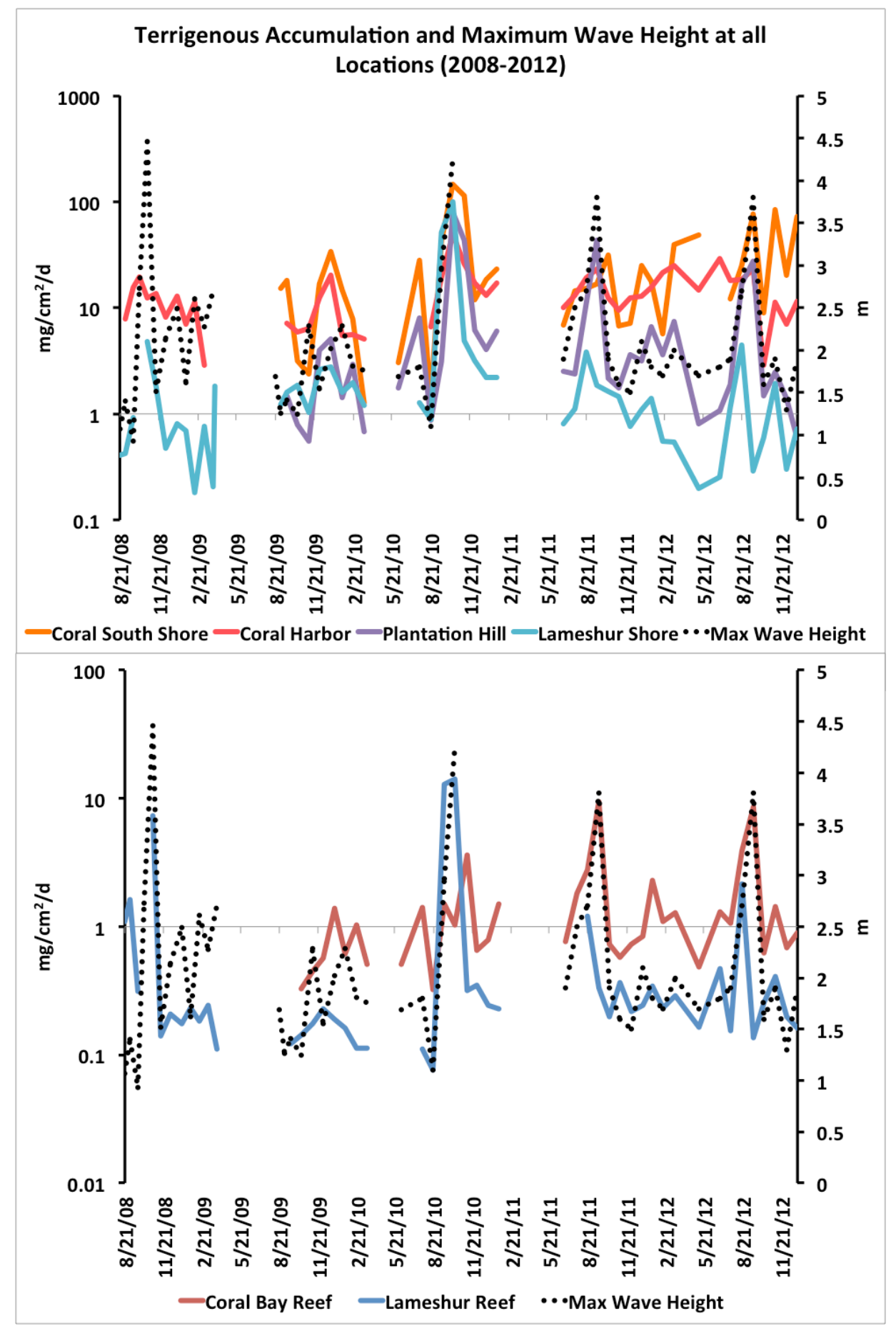

Figure 3.16. TARs (with line gaps when data were not collected) and maximum wave height at all locations. Shore locations are plotted in the top and reef locations in the bottom panels. Terrigenous accumulation rates are plotted on the primary y-axis and maximum wave height on the secondary y-axis and shown as the black, hashed line. 


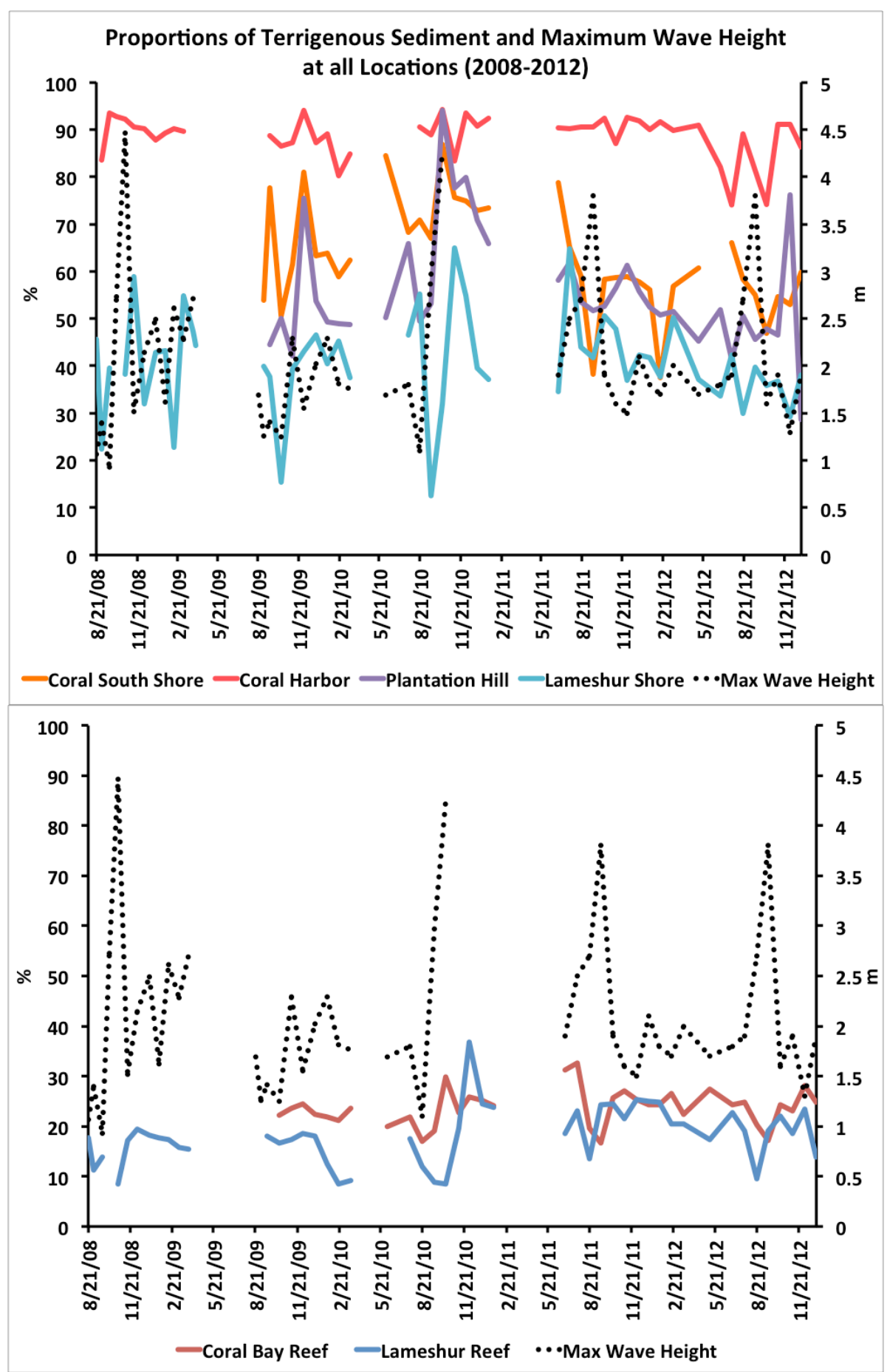

Figure 3.17. \%Ts (with line gaps when data were not collected) and maximum wave height at all locations. Shore locations are plotted in the top and reef locations in the bottom panels. \%Ts are plotted on the primary y-axis and maximum wave height on the secondary $y$-axis and shown as the black, hashed line. 
3.3.3 Relationship between Terrigenous Sedimentation and Wave Height

Of all regressions ran between mean, median, and maximum wave heights with \%Ts and TARs at all locations, only thos between maximum wave heights and TARs were significant. The \% variance in TAR explained by maximum wave height varied from 15 to $60 \%$ and was greatest at Coral Bay Reef $(60 \%)$ and Plantation Hill (57\%), lowest at Coral South Shore (15\%) and intermediate at Coral Harbor (27\%) and Lameshur Shore (23\%) and Lameshur Reef (28\%) (Figure 3.18). 


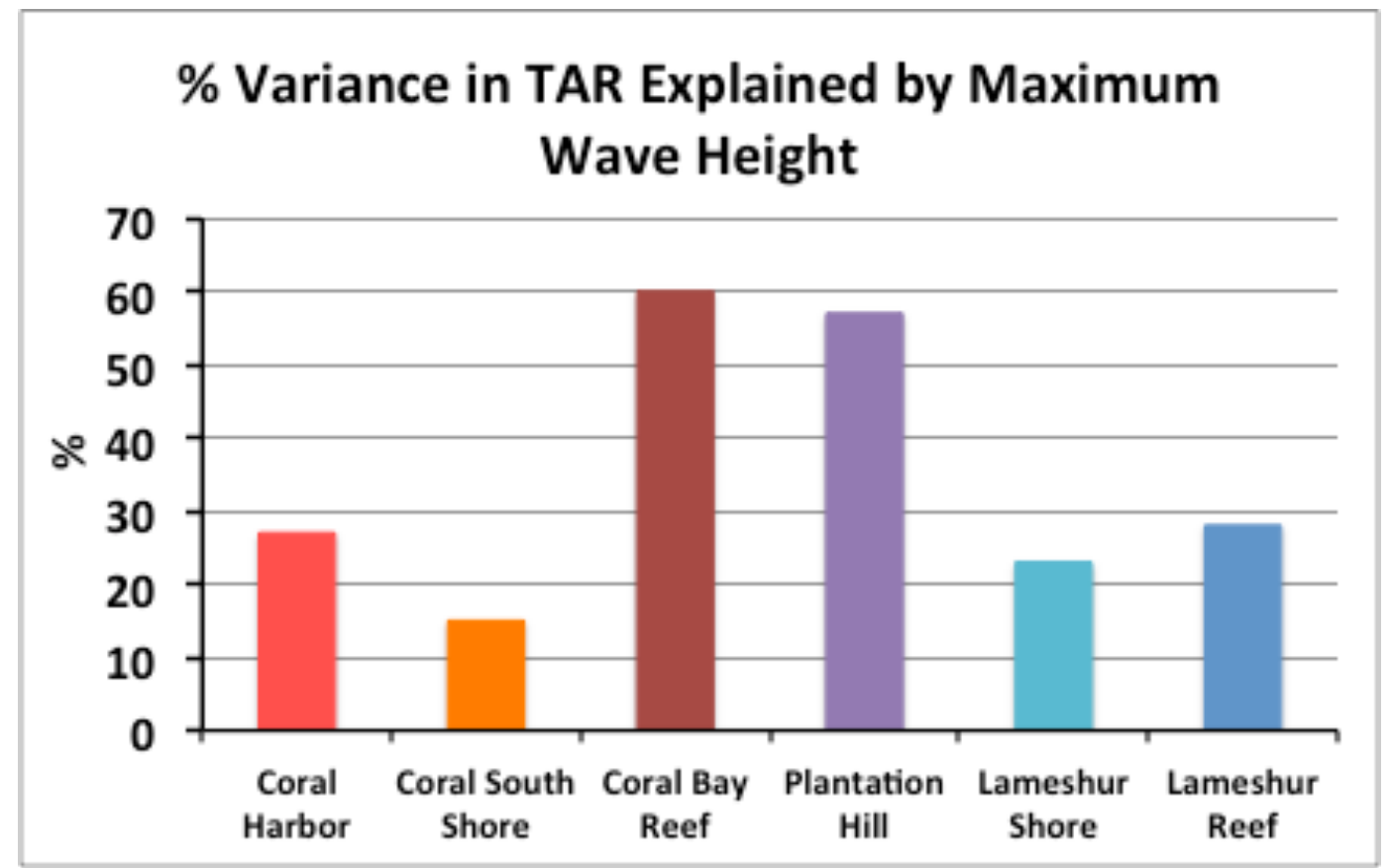

Figure 3.18. \% Variance in TAR explained by maximum wave height at all locations. Warm colors represent developed and cool colors represent minimally developed shores and reefs. 


\subsection{Sediment Texture}

In this section, variation in sediment texture data collected from sediment traps (Appendix V) and surrounding benthic areas (Appendix VI) will be examined to address Research Question 2, which seeks to examine temporal variation in texture with respect to rainfall and spatially with respect to watershed development and shoreline runoff inputs. First, the temporal variability in mean grain size of trap sediments will be addressed, followed by spatial variability in texture of trap and benthic sediments among and between shore and reefs areas. The purpose of this textural analysis was also in part to evaluate sediment resuspension. In Appendix IV, the textural similarity between benthic and trap sediment are compared to evaluate the contribution of benthic sediment to trap accumulation as the result of resuspension.

\subsubsection{Temporal Variability}

Trap sediment mean grain size varied throughout the study period from 36 $\mu \mathrm{m}$ (coarse silt) to $522 \mu \mathrm{m}$ (very coarse sand) (Figure 3.19). The greatest range in grain size was recorded in at Plantation Hill followed by the other minimally developed sites at Lameshur Reef and Shore. For the developed areas, the range in mean grain size was greatest at Coral Bay Reef, followed by Coral Bay Harbor, and Coral Bay South Shore. At Lameshur Bay, mean grain size generally varied consistently at the reef and shore prior to 2012 . However, there did not appear to be consistent temporal variability between locations at Coral Bay (Figure 3.19). 
Because terrigenous sediments often consist of fine silt and clay, one might expect deposition of land-derived terrigenous sediments during storm periods to contribute to lower mean grain size of sediments. However, there was not a consistent relationship between mean grain size and rainfall. For example, there were periods in Lameshur Bay when mean grain size was greater than the study period average during both low and high rainfall conditions (Figure 3.19). 


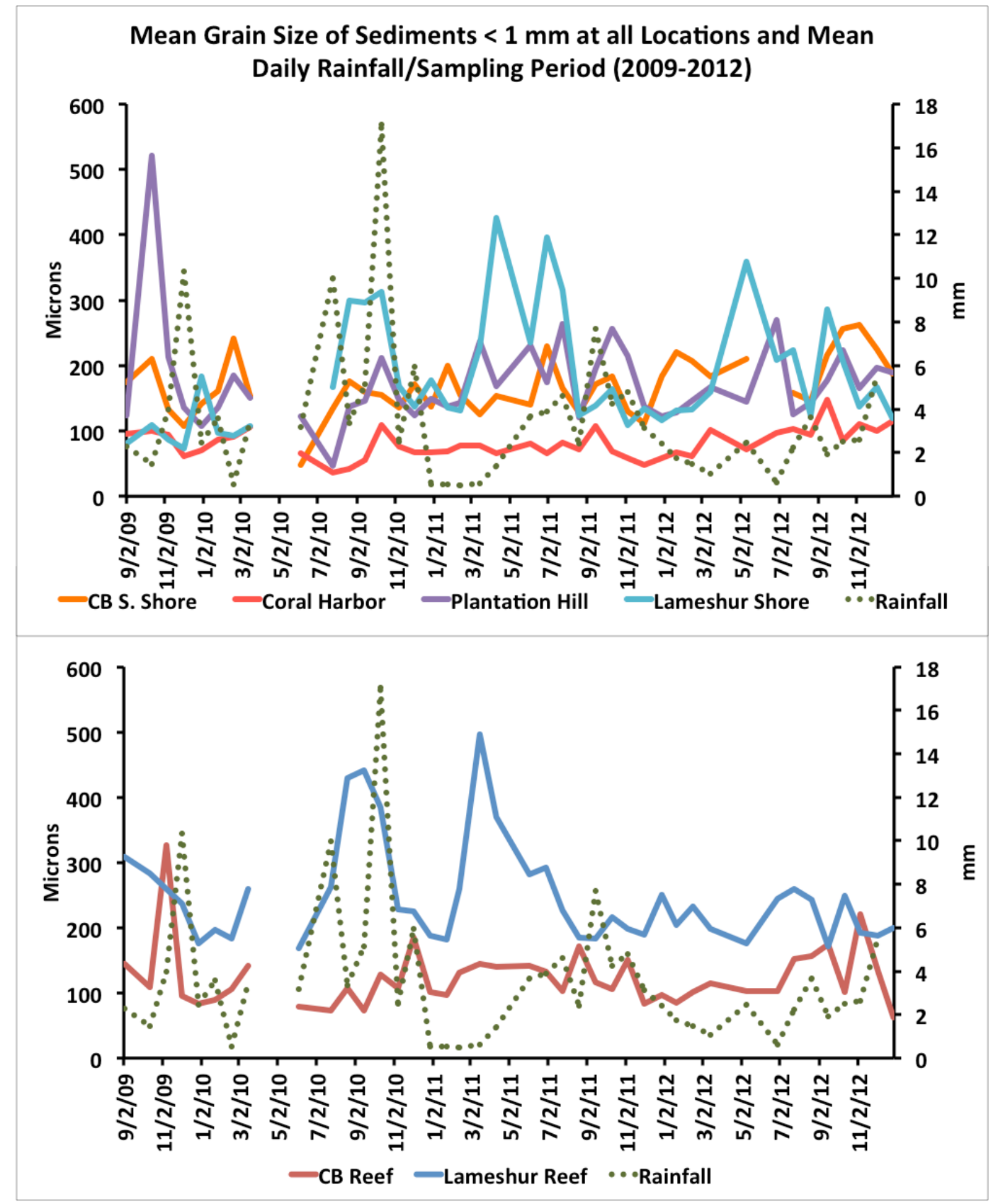

Figure 3.19. Study period mean grain sizes at shore (top panel) and reef (bottom panel) locations. Developed locations are represented by warm colors and minimally developed by cool colors. Mean daily rainfall by sampling period is shown as the green, hashed line in both panels and is plotted on the secondary yaxis. Line gaps represent time intervals when data were not collected. 


\subsubsection{Spatial Variability}

To evaluate sediment resuspension (Appendix IV), sediment texture of benthic sediments in addition to trap sediments was also examined. Gravel sized

(> $1 \mathrm{~mm}$ ) inorganic grains (e.g. coral skeletal material or shell fragments) were rarely found in the sediment trap sediments and any material $>1 \mathrm{~mm}$ typically consisted of organic material (such as sea-grass blades, algae, etc.). Therefore, the textural characteristics for the $<1 \mathrm{~mm}$ fraction of the trap sediments, which are measurable by LPS, provides an accurate measure of the whole-sediment texture.

Sediment trap sediments were finely skewed and on average ranged from silt to fine sand (Wentworth, 1922) (Figure 3.20). Trap sediments were coarsest on average at the minimally developed reef (mean: $248 \pm 91 \mathrm{SD} \mu \mathrm{m}$ [fine sand], median: $132 \pm 91 \mathrm{SD} \mu \mathrm{m}$ ) and shore (mean: $202 \pm 133 \mathrm{SD} \mu \mathrm{m}$ [fine sand], median: $101 \pm 102 \mathrm{SD} \mu \mathrm{m}$ ) and finest on average at developed areas (shores mean: $139 \pm 69 \mathrm{SD} \mu \mathrm{m}$ [fine sand], median: $71 \pm 36 \mathrm{SD} \mu \mathrm{m}$; reefs mean: $122 \pm 83$ $\mathrm{SD} \mu \mathrm{m}$ [very fine sand], median $54 \pm 48 \mathrm{SD} \mu \mathrm{m}$ ). In the developed areas, there was no significant difference between the shore and reef areas in trap sediment mean grain size (Table 3.13). However, sediment at the minimally developed areas was significantly coarser on average at the reefs than the shores (Table $3.13)$.

In contrast to the trap sediments, benthic sediment samples more commonly contained gravel-sized grains $(>1 \mathrm{~mm})$ with significantly greater mean proportions of benthic gravel at the reefs than shores (MWU test of all shore vs. 
all reef sites: $\mathrm{Z}=-12.892 ; \mathrm{N}=417$; $\mathrm{p}$-value $=<0.001$ ) (Figure 3.21). There was a significantly greater percentage of gravel-sized grains $(>1 \mathrm{~mm})$ at the minimally developed (mean: $38.1 \pm 21.5 \mathrm{SD} \%$ ) compared to developed (mean: $5.7 \pm 11.4 \mathrm{SD} \%$ ) shores (Table 3.14 ). Benthic gravel at the shore generally consisted of organic litter at developed sites and biogenic carbonates (Halimeda $>$ shell fragments $>$ coral fragments) at minimally developed sites. At the developed reefs, gravel consisted primarily of Halimeda followed by smaller quantities of shells, coral and echinoderm fragments and at minimally developed reefs, coral and shell fragments with rare Halimeda. There was not a significant difference in mean proportions of benthic gravel between developed and minimally developed reefs (Table 3.14).

When only considered the benthic sediments $<1 \mathrm{~mm}$, study period mean benthic sediments ranged from fine to coarse sand (Figure 3.22) and, in contrast to sediment trap sediments were positively (coarsely) skewed in all areas except the developed shore. Benthic sediments were coarsest on average at the minimally developed areas (minimally developed reef mean: $603 \pm 125 \mathrm{SD} \mu \mathrm{m}$ [coarse sand], median: $578 \pm 151 \mathrm{SD} \mu \mathrm{m}$; minimally developed shore: $384 \pm 119$ SD $\mu \mathrm{m}$ [medium sand], median: $323 \pm 139 \mu \mathrm{m})$ and were finest at the developed shore (mean: $160 \pm 54 \mathrm{SD} \mu \mathrm{m}$ [fine sand], median: $101 \pm 47 \mathrm{SD} \mu \mathrm{m})$ and reef areas (mean: $327 \pm 165$ SD $\mu \mathrm{m}$ [medium sand], median: $249 \pm 199 \mathrm{SD} \mu \mathrm{m}$ ) (Figure 3.22). The mean grain size of benthic sediments were significantly different among all areas except between the developed reed and minimally developed shore (Table 3.15). 
In summary, sediments were always coarser on average at the minimally developed compared with developed respective shores and reefs. 
Table 3.12. Mann-Whitney U summary for $\%$ benthic gravel.

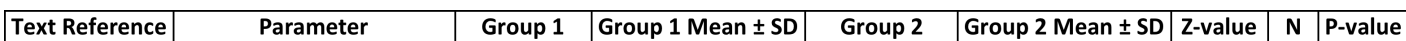

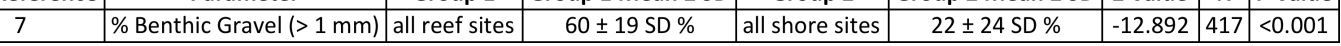




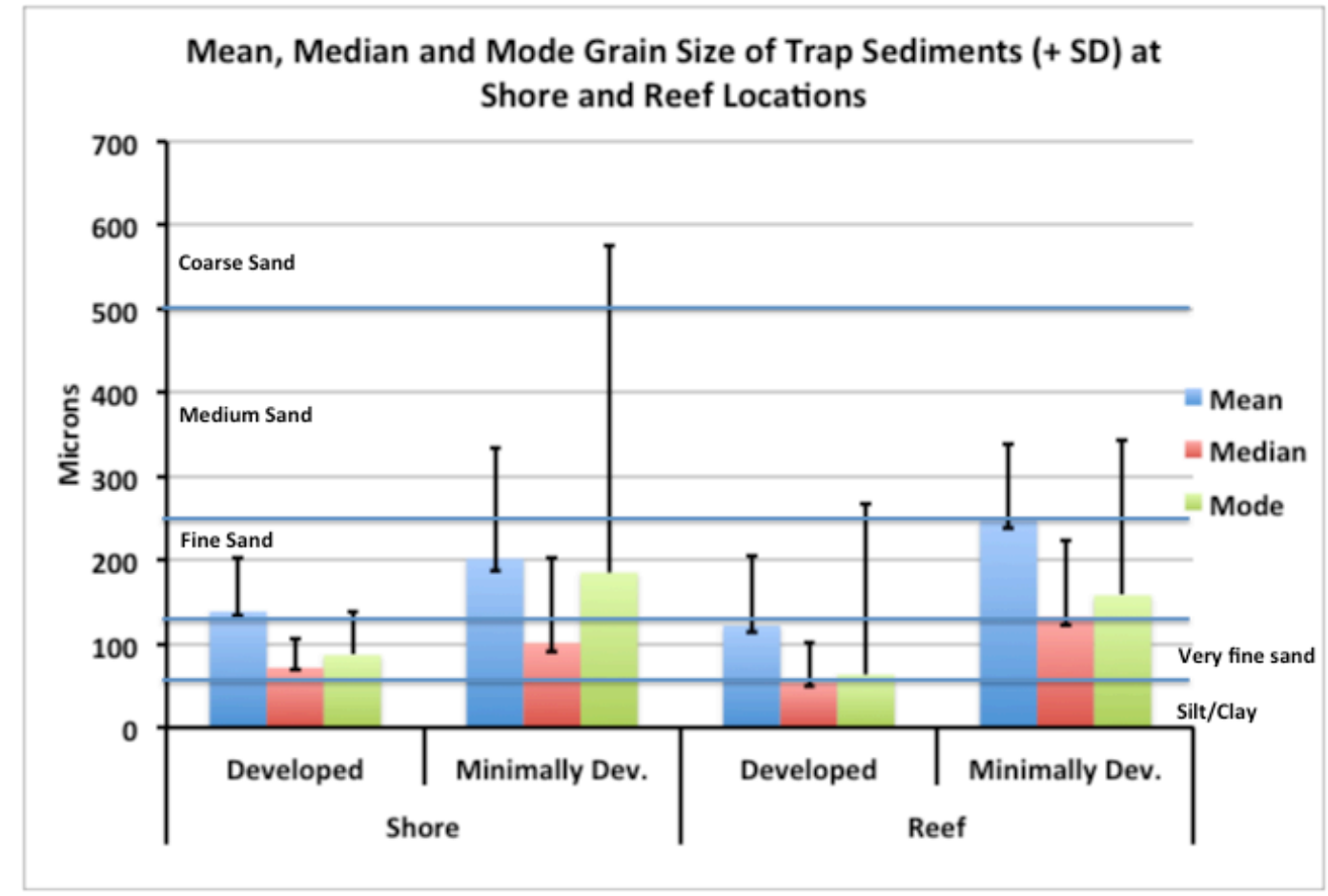

Figure 3.20. Mean, median and mode grain size (+ SD) in trap sediments at developed and minimally developed shore and reef areas. Blue, horizontal lines mark the grain size boundaries for Wentworth classification. 
Table 3.13. P-values for Kruskal-Wallis pairwise comparisons of mean grain size of trap sediments in developed and minimally developed shore and reef areas. The area shaded in purple represents shore to shore comparisons, in blue shore to reef comparisons, and in pink reef-to-reef comparisons.

\begin{tabular}{|l|l|l|l|}
\cline { 2 - 4 } \multicolumn{1}{c|}{} & Developed Shore & Min. Dev. Shore & Dev. Reef \\
\hline Min. Dev. Shore & $<0.001$ & & \\
\hline Developed Reef & 1.000 & $<0.001$ & \\
\hline Min. Dev. Reef & $<0.001$ & $<0.001$ & $<0.001$ \\
\hline
\end{tabular}




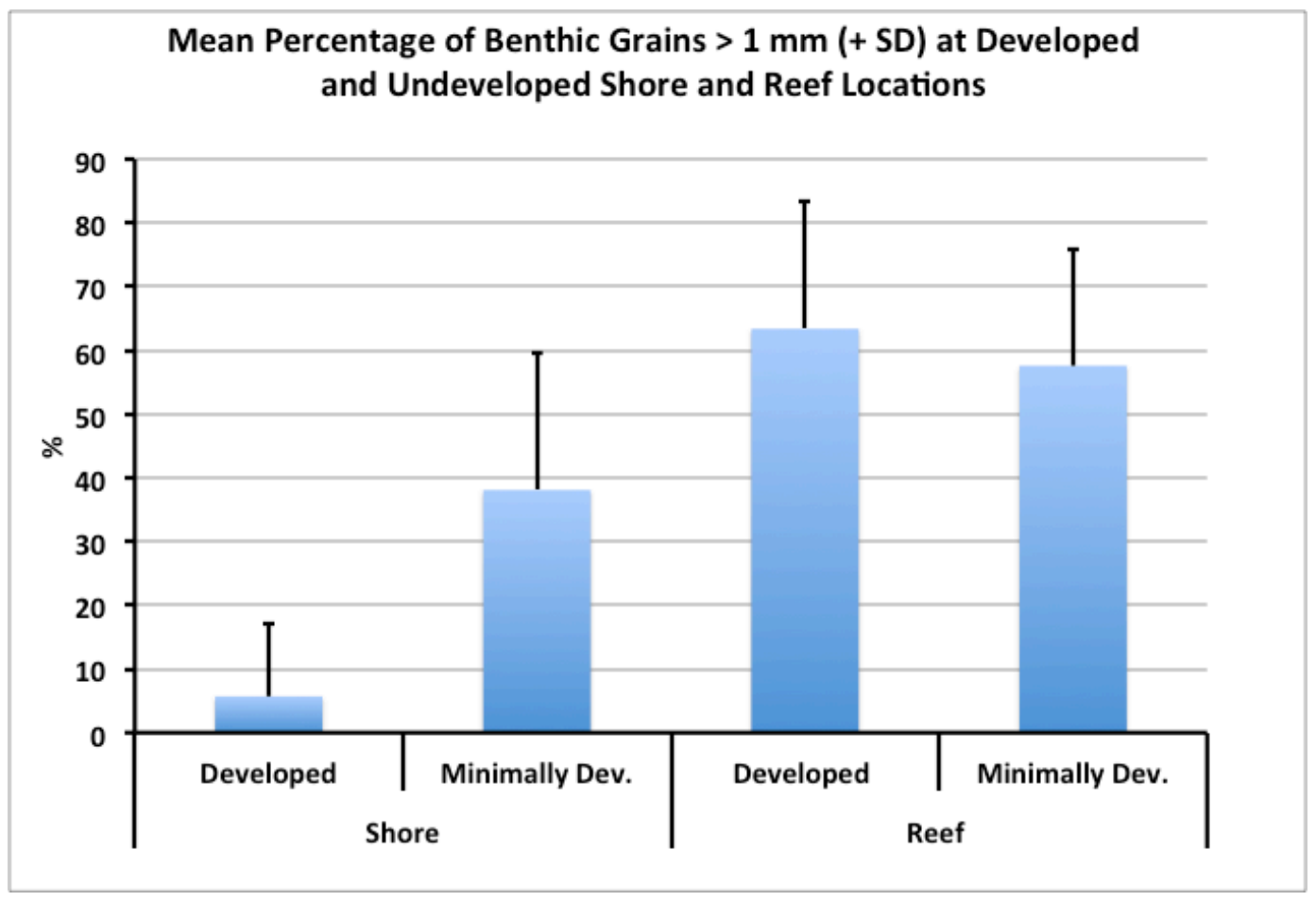

Figure 3.21. Mean percentage of benthic gravel $(\%>1 \mathrm{~mm},+\mathrm{SD})$ in benthic surface sediments at developed and minimally developed shore and reef areas. 
Table 3.14. P-values for Kruskal-Wallis pairwise comparisons mean \% gravel of benthic sediments in developed and minimally developed shore and reef areas. The area shaded in purple represents shore to shore comparisons, in blue shore to reef comparisons, and in pink reef-to-reef comparisons.

\begin{tabular}{|l|l|l|r|}
\cline { 2 - 4 } \multicolumn{1}{c|}{} & Dev. Shore & Min. Dev. Shore & Dev. Reef \\
\hline Min. Dev. Shore & $<0.001$ & & \\
\hline Dev. Reef & $<0.001$ & $<0.001$ & \\
\hline Min. Dev. Reef & $<0.001$ & $<0.001$ & 1.000 \\
\hline
\end{tabular}




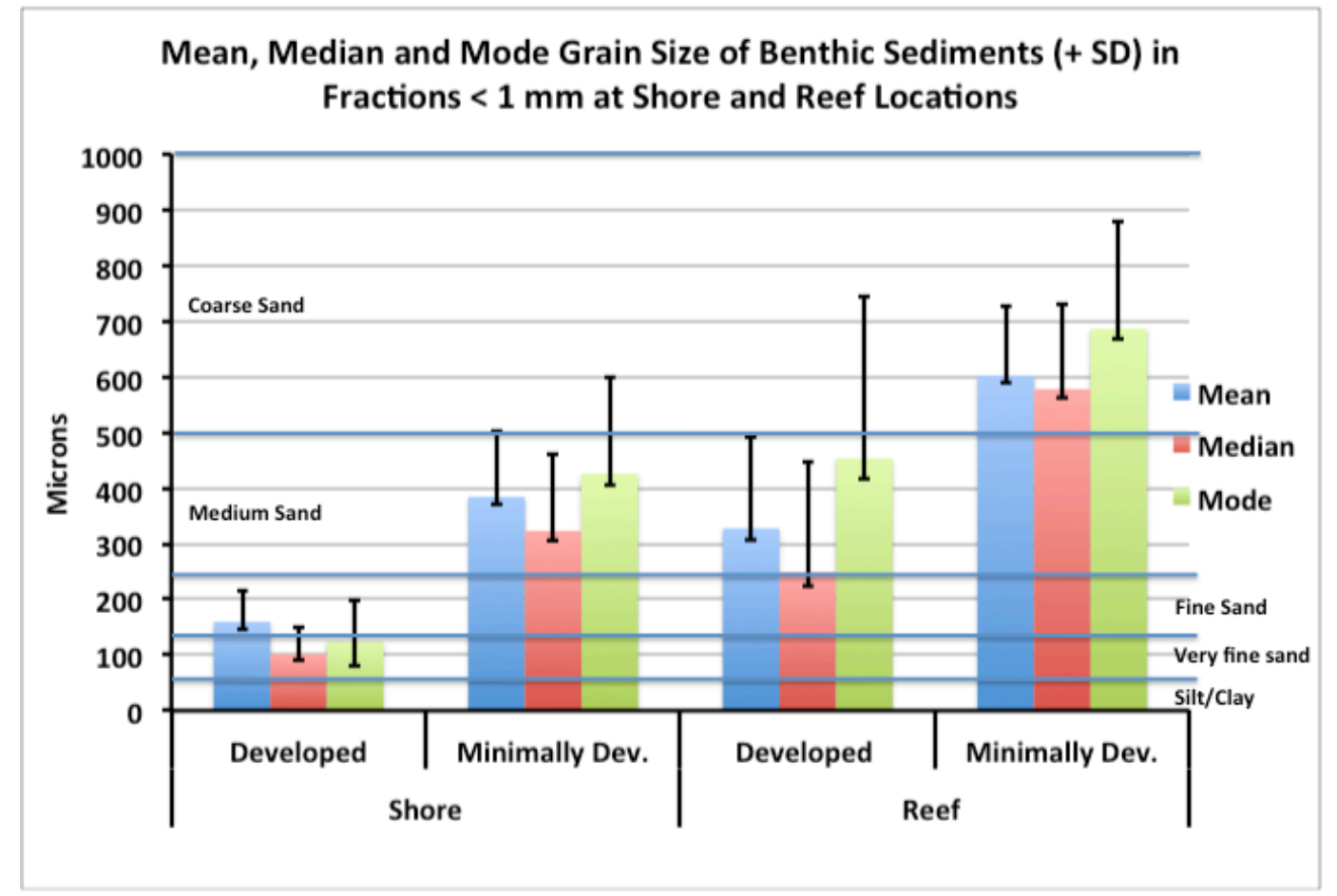

Figure 3.22. Mean, median and mode grain size (+ SD) in benthic sediments at developed and minimally developed shore and reef areas. Blue, horizontal lines mark the grain size boundaries for Wentworth classification. 
Table 3.15. P-values for Kruskal-Wallis pairwise comparisons of mean grain size of benthic sediments in developed and minimally developed shore and reef areas. The area shaded in purple represents shore to shore comparisons, in blue shore to reef comparisons, and in pink reef-to-reef comparisons.

\begin{tabular}{|l|l|l|l|}
\cline { 2 - 4 } \multicolumn{1}{c|}{} & Dev. Shore & Min. Dev. Shore & Dev. Reef \\
\hline Min. Dev. Shore & $<0.001$ & & \\
\hline Dev.Reef & $<0.001$ & 0.379 & \\
\hline Min. Dev. Reef & $<0.001$ & $<0.001$ & $<0.001$ \\
\hline
\end{tabular}




\subsection{Total and Silt Accumulation Rates}

\subsubsection{Introduction}

In this section, temporal and then spatial variation in total sediment accumulation rates $(\Sigma \mathrm{AR})$ and silt $(<75 \mu \mathrm{m})$ accumulation rates (SAR) (Appendix VII) will be summarized and compared to sedimentation rates which have been shown in the literature to induce different levels of stress to corals or affect coral reef condition. These comparisons will be made for reef locations and for shore locations where there are reefs or patch reefs (all locations except those in Coral Bay Harbor [TC-5, TC-8]). Previous studies have suggested that $\Sigma$ AR "sedimentation stress levels" of $50 \mathrm{mg} / \mathrm{cm}^{2} / \mathrm{d}$ may induce "severe to catastrophic" sediment stress [Pastorak and Bilyard, 1985]), and rates exceeding $100 \mathrm{mg} / \mathrm{cm}^{2} \mathrm{~d}$ have been shown capable of killing exposed coral tissue (Philipp and Fabricius, 2003). In addition, SARs have been correlated with coral impairment in the USVI (Henderson et al. 2013). For example, Henderson et al. (2013) found that for USVI coastal corals reefs with SARs of about $4 \mathrm{mg} / \mathrm{cm}^{2} / \mathrm{d}$, about half of the population of USVI coastal corals showed signs of bleaching and old partial mortality, and about $85 \%$ showed other signs of impairment. The data presented in this section will help to address Research Question 3, which examines how corals near our study sites might be affected by total sediment and silt accumulation stress. 


\subsubsection{Temporal Variability: Total and Silt Accumulation Rates}

The data presented here help address the alternative hypothesis that "there will be greater potential sediment stress to corals during storms/high rainfall periods" was supported by this study. The $\Sigma$ ARs and SARs followed similar temporal patterns to terrigenous accumulation rates (TARs) (Figure 3.7). $\Sigma$ AR and SARs were greatest in all developed locations for the majority of the study period and maximum during storm sampling periods $9 / 15 / 10,10 / 11 / 10$, and 9/15/11 (Table 3.1, Figures 3.23 and 3.24). During Hurricane Earl (9/15/10 period), there was low rainfall in St. John, but the $\Sigma$ AR and SAR in Lameshur Bay were the greatest of the study period. As will be discussed later, high southerly swell/wave activity during $\mathrm{H}$. Earl likely produced increased sediment resuspension. Like the patterns of TARs, elevated $\Sigma$ ARs and SARs during some non-storm sampling periods were measured in 2012 (e.g. 8/20/12, 9/15/12, 11/6/12, and 12/28/12) (Figures 3.23 and 3.24).

The hypothesis that "sediment stress to corals will be greater below developed compared with minimally developed watersheds" was supported by this study over most sampling periods. At the minimally developed Lameshur Shore location, mean daily $\Sigma$ ARs exceeded the $100 \mathrm{mg} / \mathrm{cm}^{2} / \mathrm{d}$ sedimentation stress level $3 \%(2 / 58)$ of the sampling periods (Figure 3.25$)$. At the minimally developed Plantation Shore location, mean daily $\Sigma$ ARs exceeded the 50, and 100 $\mathrm{mg} / \mathrm{cm}^{2} / \mathrm{d}$ sedimentation stress levels during $8 \%(4 / 50)$ and $2 \%(1 / 50)$ of sampling periods, respectively (Figure 3.25). By contrast, at the developed Coral Bay South Shore location where there are patch reefs, the mean daily $\Sigma$ AR exceeded the 50 , 
and $100 \mathrm{mg} / \mathrm{cm}^{2} / \mathrm{d}$ sedimentation stress levels during $27 \%$ (11/40) and $12 \%(5 / 40)$ of the sampling periods, respectively (Figure 3.25).

$\Sigma$ AR of $50 \mathrm{mg} / \mathrm{cm}^{2} / \mathrm{d}$ was exceeded at both Lameshur and Coral Bay Reef during $5 \%$ of sampling periods ( $3 / 58$ and 2/40 of periods, respectively). Though $\Sigma$ AR exceeded $100 \mathrm{mg} / \mathrm{cm}^{2} / \mathrm{d}$ during Hurricane Earl (9/15/10) and T.S. Otto $(10 / 11 / 10)$ (Figure 3.21 and 3.23) at Lameshur Bay Reef, there were no periods at Coral Bay Reef where $\Sigma A R$ exceeded $100 \mathrm{mg} / \mathrm{cm}^{2} / \mathrm{d}$ (Figure 3.25).

SARs exceeding $4 \mathrm{mg} / \mathrm{cm}^{2} / \mathrm{d}$ were measured approximately twice as frequently $(86 \%$ [31/36]) at the developed (Coral Bay South Shore) compared to the minimally developed Plantation Hill (42\% [15/36]) and [Lameshur Shore (32\% [10/31]) locations with patch reefs. Similarly, SARs exceeding $4 \mathrm{mg} / \mathrm{cm}^{2} / \mathrm{d}$ more commonly occurred at Coral Bay Reef (40\% [14/35]) than at Lameshur Bay Reef (11\% [4/35]) (Figure 3.25).

In summary, $\Sigma A R$ and SAR sedimentation stress levels were exceeded most often in developed compared with minimally developed locations and nearer to shore. 


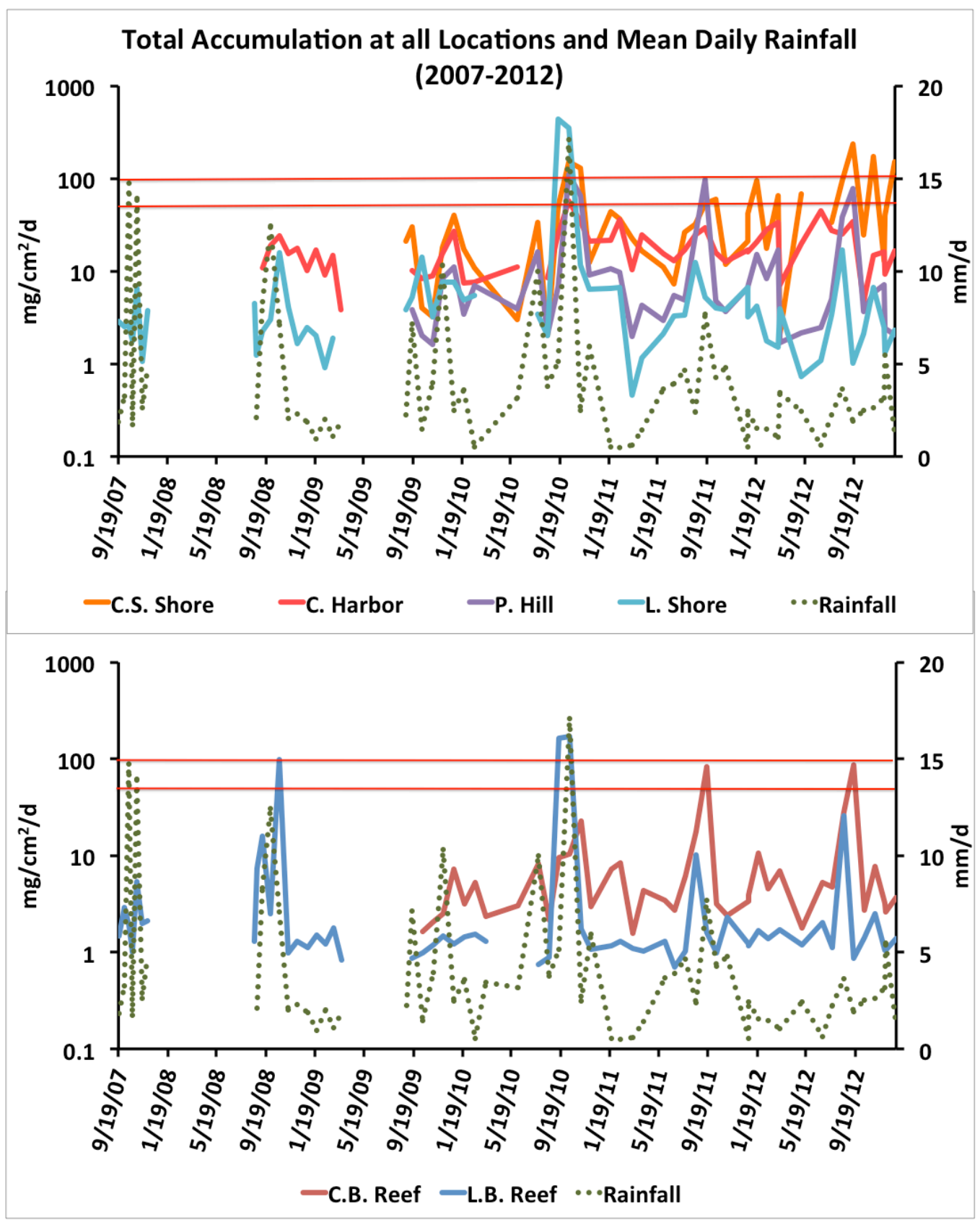

Figure 3.23. Study period total sediment accumulation at developed and minimally developed shore and reef sites. Developed locations are represented by warm colors and minimally developed by cool colors. Mean daily rainfall by sampling period is shown as the green, hashed line in both panels and is plotted on the secondary y-axis. Red lines mark the 50 (Pastorak and Bilyard, 1985) and $100 \mathrm{mg} / \mathrm{cm}^{2} / \mathrm{d}$ (Philipp and Fabricius, 1985) rates for sediment-related coral stress. Line gaps represent time intervals when data were not collected. 


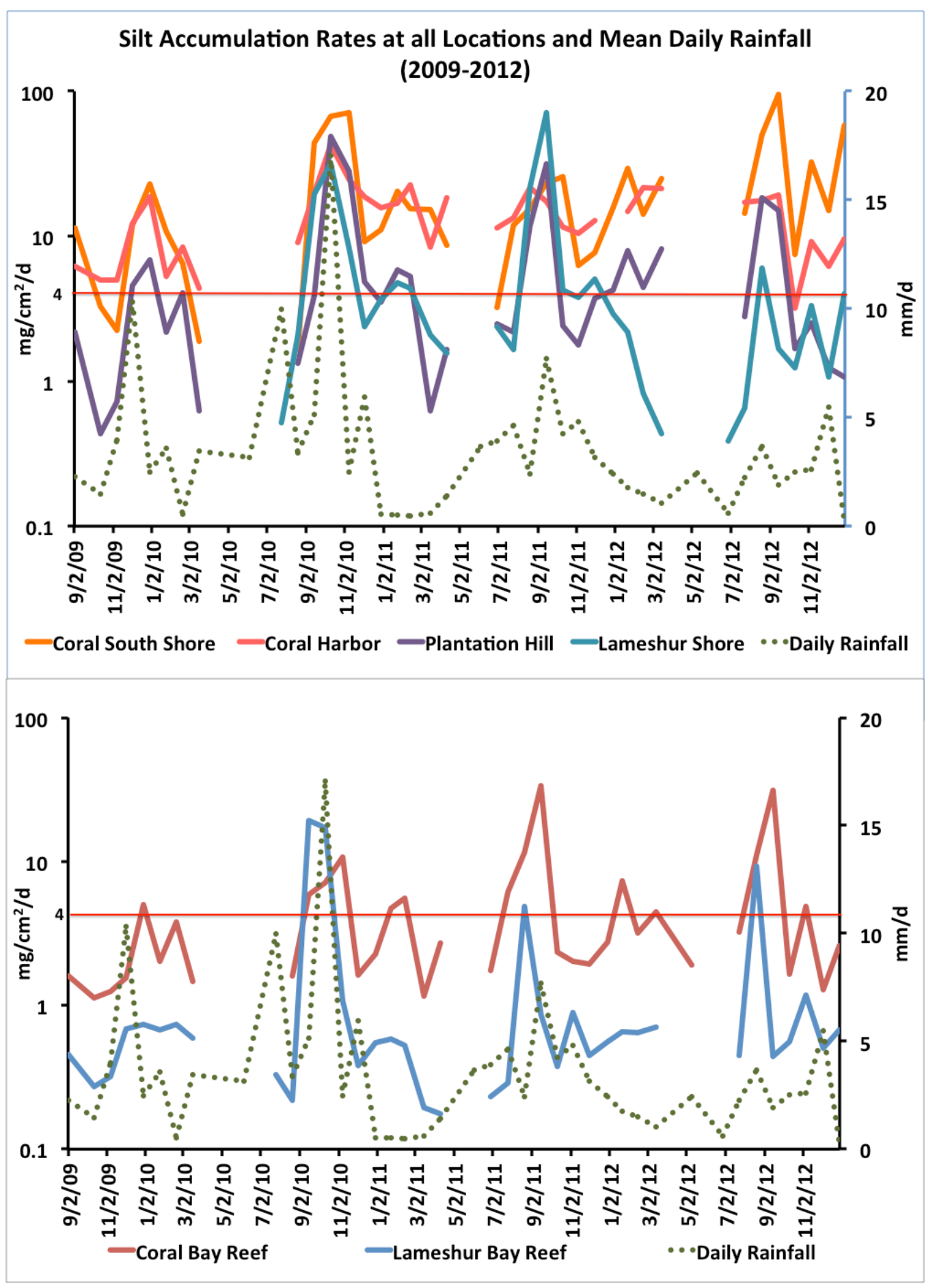

Figure 3.24. Study period silt accumulation at developed and minimally developed shore and reef sites. Developed locations are represented by warm colors and minimally developed by cool colors. Mean daily rainfall by sampling period is shown as the green, hashed line in both panels and is plotted on the secondary y-axis. Red lines mark the 4-mg/ $\mathrm{cm}^{2} / \mathrm{d}$ (Henderson et al. 2013) rates for sediment-related coral stress. Line gaps represent time intervals when data were not collected. 


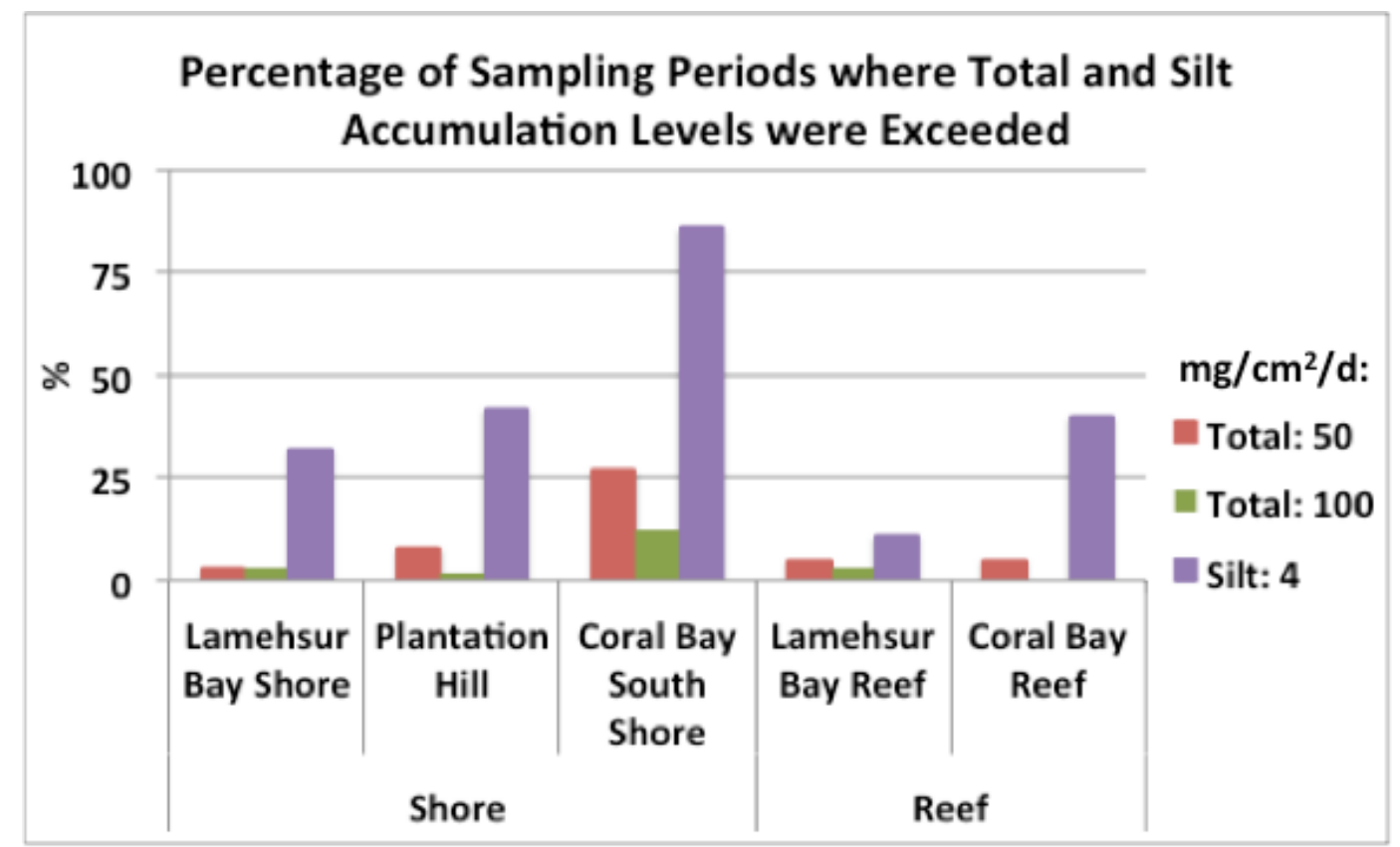

Figure 3.25. The percentage of sampling periods with coral stress-inducing $\Sigma A R s$ and SARs at all locations. 


\subsubsection{Spatial Variability: Total Accumulation Rates}

$\Sigma$ ARs overall were significantly greater at shore than at reef sites (Table 3.16, Ref. 8). Study period mean $\Sigma$ ARs at shore sites ranged from $11 \pm 17$ SD $\mathrm{mg} / \mathrm{cm}^{2} / \mathrm{d}$ to $56 \pm 63 \mathrm{SD} \mathrm{mg} / \mathrm{cm}^{2} / \mathrm{d}$ (Figure 3.26) and were significantly greater at developed (32 $\left.\pm 41 \mathrm{SD} \mathrm{mg} / \mathrm{cm}^{2} / \mathrm{d}\right)$ than at minimally developed shore sites $(19 \pm$ $68 \mathrm{SD} \mathrm{mg} / \mathrm{cm}^{2} / \mathrm{d}$ ) (Table 3.16, Ref. 9). Study period mean $\Sigma$ ARs were greater than the $50 \mathrm{mg} / \mathrm{cm}^{2} / \mathrm{d}$ ("severe" coral stress) threshold at one site (Shipwreck), at which the study period mean $\Sigma$ AR was significantly greater than at all minimally developed shore sites (Figure 3.26, Table 3.17). When the shore data were grouped by location, the mean $\Sigma$ ARs were significantly greater at Coral Bay South Shore (mean: $47 \pm 53 \mathrm{SD} \mathrm{mg} / \mathrm{cm}^{2} / \mathrm{d}$ ) than at all other shore locations except Coral Bay Harbor (Table 3.18).

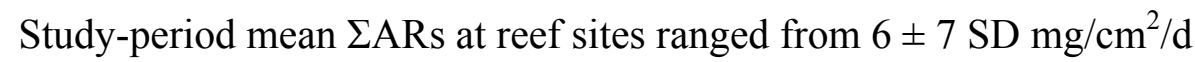
(Coral Bay Reef North) to $14 \pm \mathrm{SD} \mathrm{mg} / \mathrm{cm}^{2} / \mathrm{d}$ (Coral Reef South) (with intermediate means at Lameshur Reef sites). Study-period mean $\Sigma$ ARs for Coral Bay Reef South was significantly greater than all minimally developed reef sites (Table 3.17). When grouped by location, study period mean $\Sigma$ AR was significantly greater at Coral Bay Reef than Lameshur Bay Reef (Figure 3.27, Table 3.18).

\subsubsection{Spatial Variability: Silt Accumulation Rates}

SARs overall were significantly greater at shore than at the reefs (Table 3.16, Ref. 10). Study period mean SARs at shore sites ranged from $5 \pm 7 \mathrm{SD}$ 
(Plantation Hill North) to $25 \pm 27 \mathrm{SD} \mathrm{mg} / \mathrm{cm}^{2} / \mathrm{d}$ (Shipwreck), were significantly greater at developed $\left(17 \pm 18 \mathrm{SD} \mathrm{mg} / \mathrm{cm}^{2} / \mathrm{d}\right)$ than at minimally developed sites $(6$ $\pm 10 \mathrm{SD} \mathrm{mg} / \mathrm{cm}^{2} / \mathrm{d}$ ) (Table 3.16, Ref. 11) and exceeded the $4 \mathrm{mg} / \mathrm{cm}^{2} / \mathrm{d}$ sedimentation stress level at all shore sites (Figure 3.28). SARs at Shipwreck, Calabash, and Coral Harbor South and North were significantly greater than at Great and Little Lameshur Shore and Plantation Hill North (Table 3.19). By location, all shore locations were significantly different from one other with the exception of Coral Bay Harbor and Coral South Shore (Table 3.20).

At reef sites, study period mean SARs ranged from $2 \pm 5 \mathrm{SD} \mathrm{mg} / \mathrm{cm}^{2} / \mathrm{d}$ to $6 \pm 9 \mathrm{SD} \mathrm{mg} / \mathrm{cm}^{2} / \mathrm{d}$ and were significantly greater at the Coral Reef South and North than at minimally developed reef sites (Table 3.19). By reef location, study period mean SARs were significantly greater at Coral Bay Reef than Lameshur Bay Reef (Table 3.20). Study period mean SARs were greater than the 4 $\mathrm{mg} / \mathrm{cm}^{2} / \mathrm{d}$ sedimentation stress level at the developed reef and shore sites and locations (Figure 3.28 and 3.29).

In summary, like TARs, $\Sigma$ ARs and SARs were greater overall in shores compared with reefs and below developed compared with minimally developed sites/locations (Figures 3.26-29). Study period mean $\Sigma$ ARs and SARs suggested that coral sedimentation stress levels were surpassed regularly but generally more frequently at developed areas (Figures 3.26-29). At the developed reef location, 10 and $50 \mathrm{mg} / \mathrm{cm}^{2} / \mathrm{d} \Sigma$ AR sedimentation stress levels were exceeded during 20 and $5 \%$ of periods, respectively, and SAR sedimentation stress level were exceeded during $40 \%$ of sampling periods (Figure 3.25). 
Table 3.16. Mann-Whitney U summaries for "Total and Silt Accumulation" section.

\begin{tabular}{|c|c|c|c|c|c|c|c|c|}
\hline Ref. \# & Parameter & Group 1 & Group 1 Mean \pm SD & Group 2 & Group 2 Mean \pm SD & Z-value & $\mathbf{N}$ & P-value \\
\hline 8 & $\Sigma$ AR & all reef sites & $10 \pm 30 \mathrm{SD} \mathrm{mg} / \mathrm{cm}^{2} / \mathrm{d}$ & all shore sites & $25 \pm 57 \mathrm{SD} \mathrm{mg} / \mathrm{cm}^{2} / \mathrm{d}$ & -11.455 & 556 & $<0.001$ \\
\hline 9 & $\Sigma$ & dev. shore sites & $32 \pm 41 \mathrm{SD} \mathrm{mg} / \mathrm{cm}^{2} / \mathrm{d}$ & min. dev. shore sites & $19 \pm 68 \mathrm{SD} \mathrm{mg} / \mathrm{cm}^{2} / \mathrm{d}$ & -1 & 319 & 01 \\
\hline 10 & SAR & all shore sites & $12 \pm 17 \mathrm{SD} \mathrm{mg} / \mathrm{cm}^{2} / \mathrm{d}$ & all reef sites & $3 \pm 6 \mathrm{SD} \mathrm{mg} / \mathrm{cm}^{2} / \mathrm{d}$ & -10.735 & 455 & $<0.001$ \\
\hline 11 & SAR & dev. shore sites & $17 \pm 18 \mathrm{SD} \mathrm{mg} / \mathrm{cm}^{2} / \mathrm{d}$ & min. dev. shore sites & $6 \pm 10 \mathrm{SD} \mathrm{mg} / \mathrm{cm}^{2} / \mathrm{d}$ & -9.454 & 260 & $<0.001$ \\
\hline
\end{tabular}


Study Period Mean Total Sediment Accumulation (+ SD) at all Sites

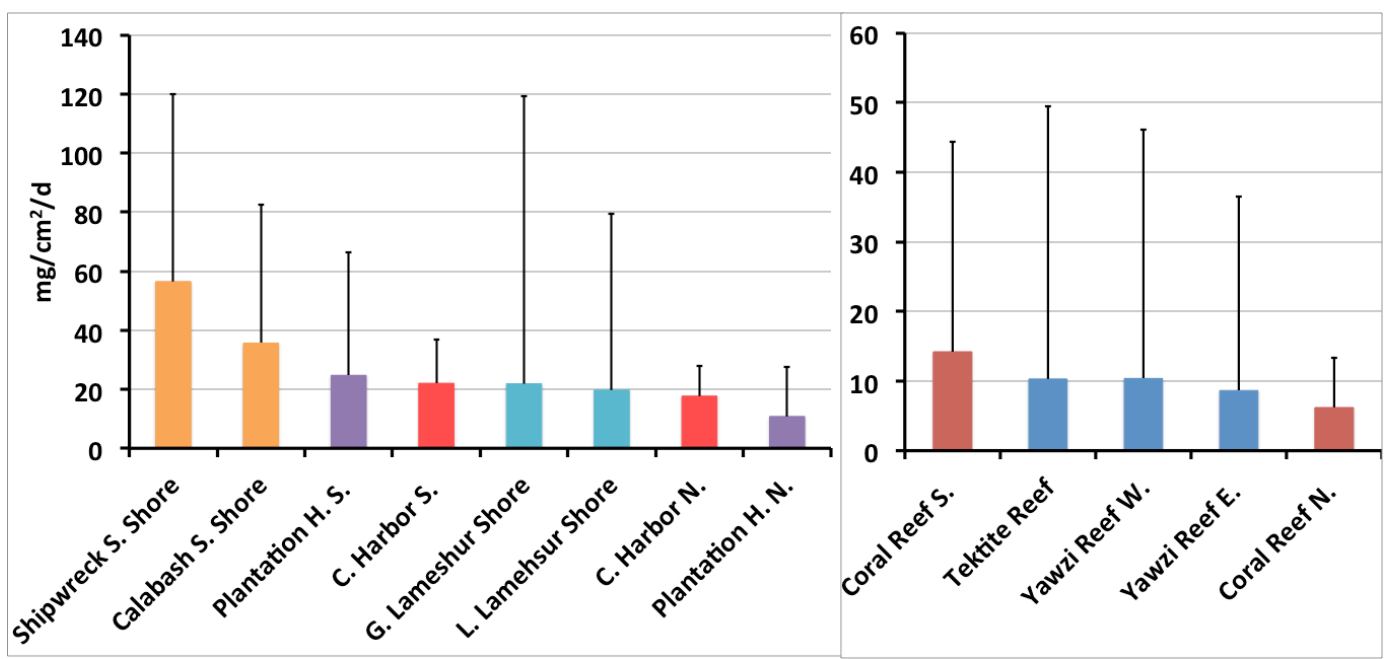

Figure 3.26. Study period mean $\Sigma$ ARs (+ SD) at all shore (left pane;) and reef (right panel) sites. Warm and cool colors represent developed and minimally developed sites, respectively. 
Table 3.17. P-values for Kruskal-Wallis pairwise comparisons of $\Sigma A R$ means between all sites. The area shaded in purple represents shore to shore comparisons, in blue shore to reef comparisons, and in pink reef-to-reef comparisons.

\begin{tabular}{|c|c|c|c|c|c|c|c|c|c|c|c|c|}
\hline & Shipwreck & Calabash & P. Hill S. & C. Harbor S. & G.L. Shore & L.L Shore & C. Harbor N. & P. Hill N. & C.B. Reef S. & Tektite Reef & Yawzi Reef W. & Yawzi Reef E. \\
\hline Calabash & 1.000 & & & & & & & & & & & \\
\hline P. Hill S. & 0.059 & 0.598 & & & & & & & & & & \\
\hline C. Harbor S. & 1.000 & 1.000 & 0.442 & & & & & & & & & \\
\hline G.L. Shore & $<0.001$ & $<0.001$ & 0.022 & $<0.001$ & & & & & & & & \\
\hline L.L Shore & $<0.001$ & $<0.001$ & 0.559 & $<0.001$ & 1.000 & & & & & & & \\
\hline C. Harbor N. & 1.000 & 1.000 & 0.494 & 1.000 & $<0.001$ & $<0.001$ & & & & & & \\
\hline P. Hill N. & 0.001 & 0.034 & 1.000 & 0.024 & 0.166 & 1.000 & 0.020 & & & & & \\
\hline C.B. Reef S. & $<0.001$ & 0.015 & 1.000 & 0.011 & 0.429 & 1.000 & 0.008 & 1.000 & & & & \\
\hline Tektite Reef & $<0.001$ & $<0.001$ & $<0.001$ & $<0.001$ & 0.003 & 0.001 & $<0.001$ & $<0.001$ & $<0.001$ & & & \\
\hline Yawzi Reef W. & $<0.001$ & $<0.001$ & $<0.001$ & $<0.001$ & 0.085 & 0.034 & $<0.001$ & $<0.001$ & $<0.001$ & 1.000 & & \\
\hline Yawzi Reef E. & $<0.001$ & $<0.001$ & $<0.001$ & $<0.001$ & 1.000 & 0.121 & $<0.001$ & $<0.001$ & $<0.001$ & 1.000 & 1.000 & \\
\hline C.B. Reef N. & $<0.001$ & 0.001 & 1.000 & \begin{tabular}{|l|}
$<0.001$ \\
\end{tabular} & 1.000 & 1.000 & $<0.001$ & 1.000 & 1.000 & $<0.001$ & $<0.001$ & 0.006 \\
\hline
\end{tabular}




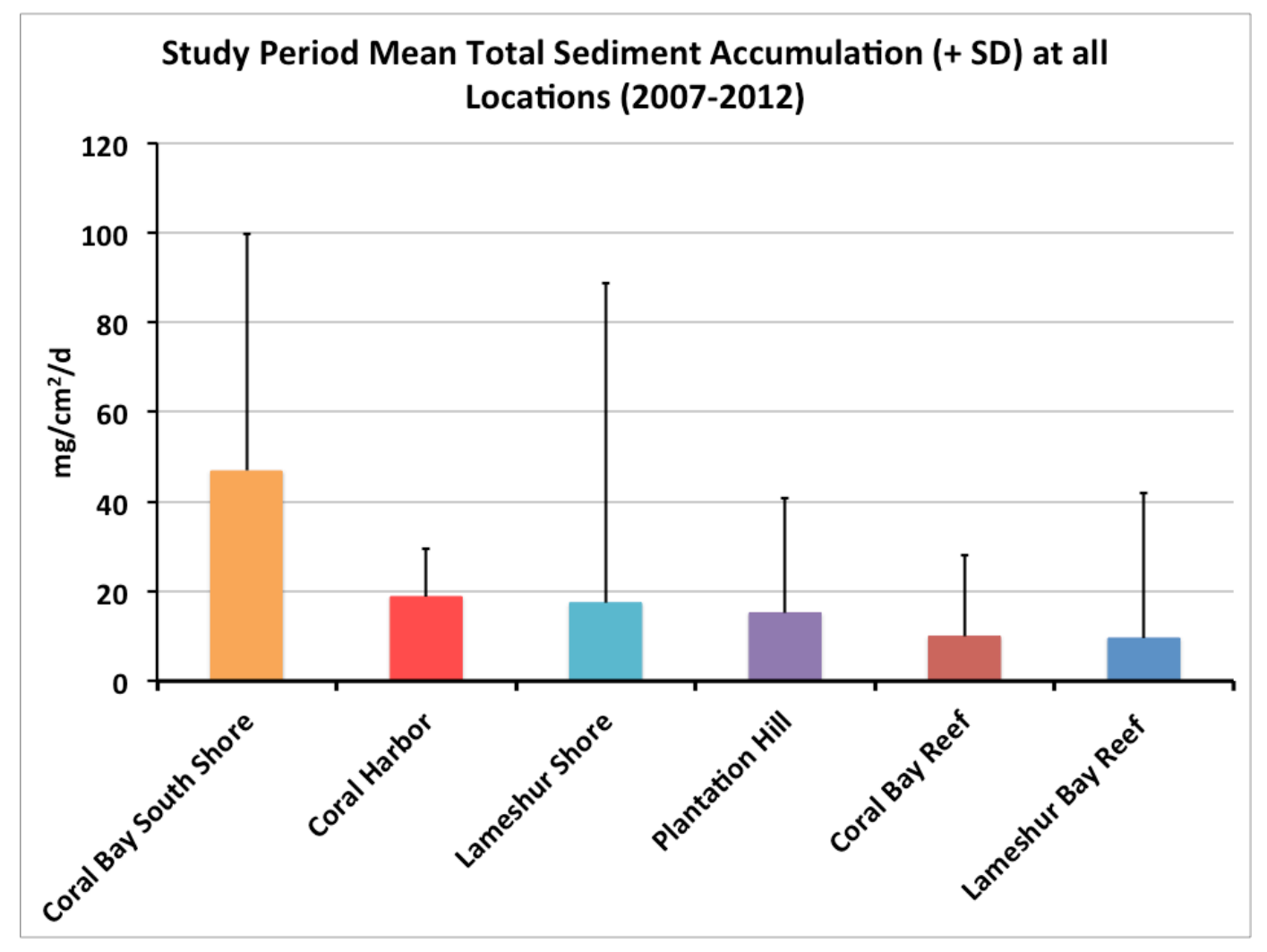

Figure 3.27. Study period mean $\Sigma$ ARs $(+\mathrm{SD})$ at all shore and reef locations. Warm and cool colors represent developed and minimally developed sites, respectively. 
Table 3.18. P-values for Kruskal-Wallis pairwise comparisons of $\Sigma A R$ means between all locations. The area shaded in purple represents shore to shore comparisons, in blue shore to reef comparisons, and in pink reef-to-reef comparisons.

\begin{tabular}{|l|l|l|l|l|l|}
\cline { 2 - 6 } \multicolumn{1}{c|}{} & C. South Shore & C. Harbor & L. Shore & P. Hill & C.B. Reef \\
\hline C. Harbor & 1.000 & & & & \\
\hline L. Shore & $<0.001$ & $<0.001$ & & & \\
\hline P. Hill & $<0.001$ & $<0.001$ & $<0.001$ & & \\
\hline C.B. Reef & $<0.001$ & $<0.001$ & 1.000 & $<0.001$ & \\
\hline L. Reef & $<0.001$ & $<0.001$ & $<0.001$ & $<0.001$ & $<0.001$ \\
\hline
\end{tabular}


Study Period Mean Silt Accumulation Rates (+ SD) at all Trap Sites

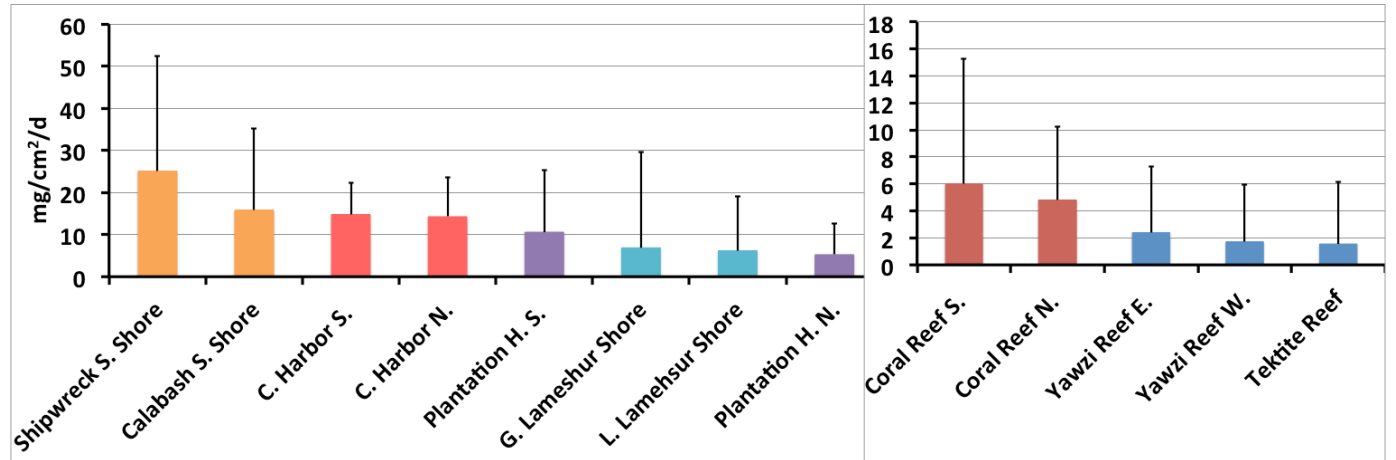

Figure 3.28. Study period mean SAR (+ SD) at all shore (left panel) and reef (right panel) sites. Warm and cool colors represent developed and minimally developed sites, respectively. 
Table 3.19. P-values for Kruskal-Wallis pairwise comparisons of SAR means between all sites. The area shaded in purple represents shore to shore comparisons, in blue shore to reef comparisons, and in pink reef-to-reef comparisons.

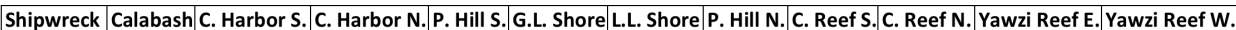

\begin{tabular}{|c|c|c|c|c|c|c|c|c|c|c|c|c|}
\hline & Shipwreck & Calabash & C. Harbor S. & C. Harbor $\mathbf{N}$. & P. Hill S. & G.L. Shore & L.L. Shore & P. Hill N. & C. Reef S. & C. Reef N. & Yawzi Reef E. & Yawzi Reef W. \\
\hline Calabash & 1.000 & & & & & & & & & & & \\
\hline C. Harbor S. & 1.000 & 1.000 & & & & & & & & & & \\
\hline C. Harbor $\mathbf{N}$. & 1.000 & 1.000 & 1.000 & & & & & & & & & \\
\hline P. Hill S. & 0.051 & 1.000 & 0.078 & 0.150 & & & & & & & & \\
\hline G.L. Shore & $<0.001$ & $<0.001$ & $<0.001$ & $<0.001$ & 0.208 & & & & & & & \\
\hline L.L. Shore & $<0.001$ & 0.006 & $<0.001$ & $<0.001$ & 0.793 & 1.000 & & & & & & \\
\hline P. Hill N. & $<0.001$ & 0.061 & $<0.001$ & 0.001 & 1.000 & 1.000 & 1.000 & & & & & \\
\hline C. Reef S. & $<0.001$ & 0.081 & $<0.001$ & 0.002 & 1.000 & 1.000 & 1.000 & 1.000 & & & & \\
\hline C. Reef N. & $<0.001$ & 0.122 & 0.001 & 0.003 & 1.000 & 1.000 & 1.000 & 1.000 & 1.000 & & & \\
\hline Yawzi Reef E. & $<0.001$ & $<0.001$ & $<0.001$ & $<0.001$ & $<0.001$ & 0.039 & 0.022 & $<0.001$ & $<0.001$ & $<0.001$ & & \\
\hline Yawzi Reef W. & $<0.001$ & $<0.001$ & $<0.001$ & $<0.001$ & $<0.001$ & 0.390 & 0.208 & 0.004 & 0.004 & 0.001 & 1.000 & \\
\hline Tektite Reef & $<0.001$ & $<0.001$ & $<0.001$ & $<0.001$ & $<0.001$ & 0.001 & $<0.001$ & $<0.001$ & $<0.001$ & $<0.001$ & 1.000 & 0.754 \\
\hline
\end{tabular}




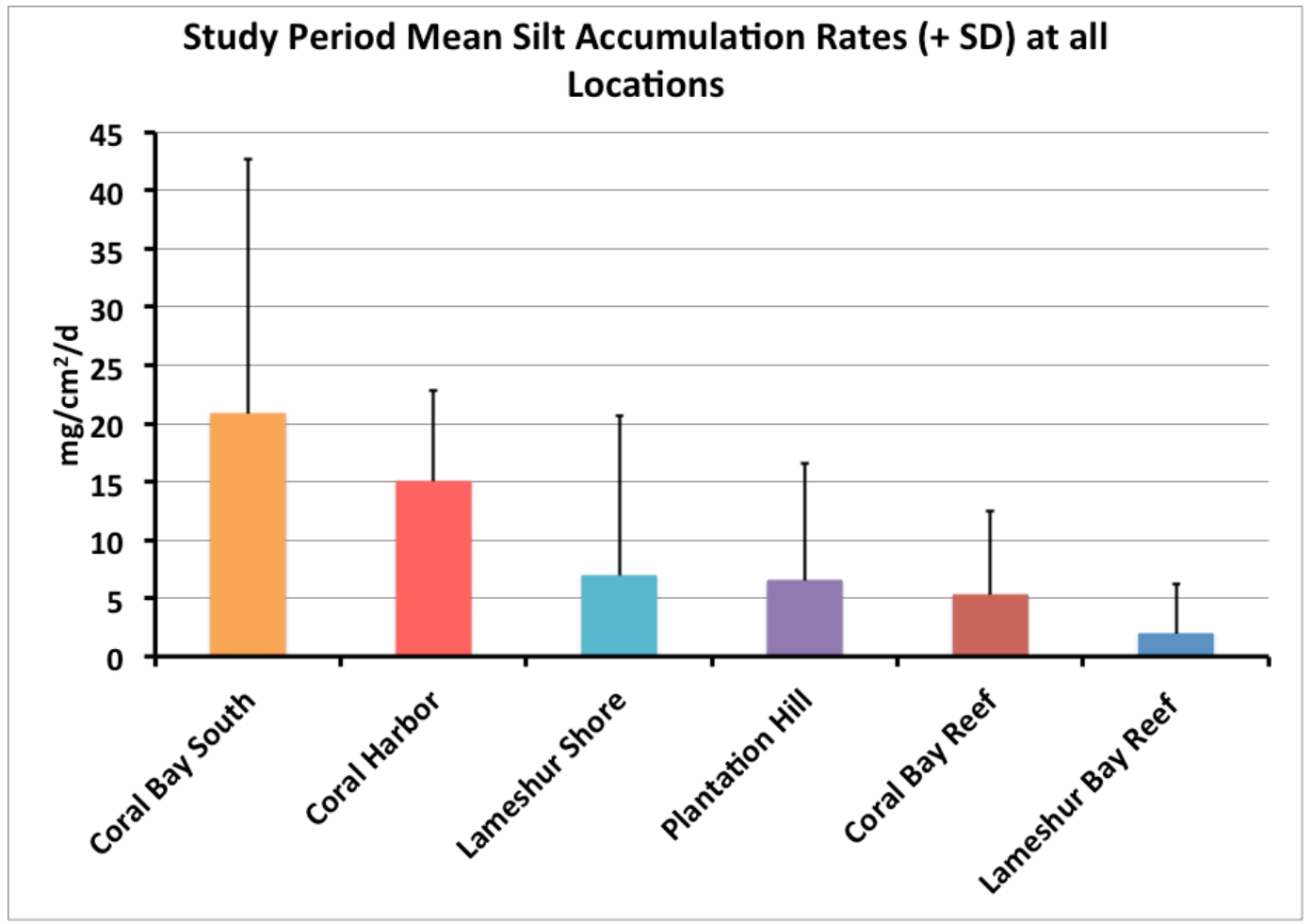

Figure 3.29. Study period mean SARs $(+\mathrm{SD})$ at all shore and reef locations. Warm and cool colors represent developed and minimally developed sites, respectively. 
Table 3.20. P-values for Kruskal-Wallis pairwise comparisons of SAR means between all locations. The area shaded in purple represents shore to shore comparisons, in blue shore to reef comparisons, and in pink reef-to-reef comparisons.

\begin{tabular}{|l|l|l|l|l|l|}
\cline { 2 - 6 } \multicolumn{1}{c|}{} & C. S. Shore & C. Harbor & P. Hill & L. Shore & C.B. Reef \\
\hline C. Harbor & 1.000 & & & & \\
\hline P. Hill & $<0.001$ & $<0.001$ & & & \\
\hline L. Shore & $<0.001$ & $<0.001$ & 0.140 & & \\
\hline C.B. Reef & $<0.001$ & $<0.001$ & 1.000 & 0.366 & \\
\hline L. Reef & $<0.001$ & $<0.001$ & $<0.001$ & $<0.001$ & $<0.001$ \\
\hline
\end{tabular}




\section{Chapter 4: Discussion}

\subsection{Sources of Sediment}

Marine sediments around St. John are composed of organic, carbonate, and terrigenous materials. Organic sediment may originate from both terrestrial and marine environments and can come from variety of sources, such as leaf litter, plant and animal waste, and phytoplankton. On eastern St. John, where the lithology is predominantly composed of igneous and metamorphic rocks (Rankin, 2002), carbonate sediments are derived exclusively from the marine environment.

Windblown, allocthonous sediments in the Caribbean include dust originating from Africa (Prospero, 1970) and volcanic dust particularly from the volcano Soufrière Hills on the island of Montserrat, which is about $300 \mathrm{~km}$ southeast of St. John, as well as from contributions from regional waste incineration. Of the sources of windblown sediments, African dust comprises the greatest volume (Kumar et al. 2014). Griffin et al. (2001) reported maximum surface deposition rates of $0.0001 \mathrm{mg} / \mathrm{cm}^{2} / \mathrm{d}\left(100 \mu \mathrm{g} / \mathrm{m}^{2} / \mathrm{d} / \mathrm{dust}\right.$ event $)$ on St. John during the largest dust event in 23 years. These maximum dust deposition rates are therefore 1000 to 1 million times less than the TARs $\left(0.1-100 \mathrm{mg} / \mathrm{cm}^{2} / \mathrm{d}\right)$ measured at our sites, suggesting that windblown sediment is not a significant source of sediment in our sediment traps.

The eroded soils and bedrock of St. John provide a significant source of terrigenous sediment to surrounding coastal areas. Terrigenous sediments are eroded from disturbed surfaces such as unpaved roads and overthrown trees, and by surface erosion on undisturbed soil surfaces, predominantly from stream banks 
(Ramos-Scharrón and MacDonald, 2007a \& b). Of the sources of sediment from disturbed areas, unpaved roads produce sediment at very high rates with estimates ranging from 12 to $580 \mathrm{Mg} / \mathrm{ha} / \mathrm{yr}$ depending on slope, time since the road was last graded, and degree of abandonment (Ramos-Scharrón and MacDonald, 2005, 2007a). For sources in undisturbed areas, stream banks display the highest mean erosion rate at $100 \mathrm{Mg} / \mathrm{ha} / \mathrm{yr}$ (Ramos-Scharrón and MacDonald, 2007a).

Eroded sediments are then transported from watersheds to the coastal bays in runoff through ephemeral streams. Though larger pebbles and boulders may be transported down the ephemeral streams during large storm events, finer silt and clay-sized terrigenous sediments are presumed to be more easily transported throughout the bay. Sediments from unpaved roads and exposed soil surfaces, which erode from developed watershed areas, tend to be fine-grained (silt and clay). Fine-grained sediments are particularly detrimental to corals (Nugues and Roberts 2003, Weber et al. 2006) (discussed in section "Sedimentation and Coral Stress" below). Consistent with greater area and density of unpaved roads in developed watersheds, our data showed that trap and benthic sediments are finest on average below developed watershed areas. Therefore, the results described here show that land development may affect the texture of sediments deposited in the marine environment where coral reefs may be located.

Sediment texture is related to the source of sediments (i.e. terrigenous versus carbonate). Carbonate sediments are composed of the calcium carbonate skeletal remains of corals and other reef organisms. The majority of marine carbonate grains at our study sites are generally coarser-grained on average than 
terrigenous sediments because they have not undergone as much breakdown by weathering or extensive bioerosion because they presumably have remained close to their source. Though it has been demonstrated at our study sites that both terrigenous and carbonate grains are present in all grain size fractions (Rawlings et al., 2010), in general, benthic sediments collected at our locations that were composed mostly of carbonate materials were characterized by greater mean grain size than sediments composed mostly of terrigenous grains.

\subsection{Processes Affecting Marine Sedimentation}

Marine sedimentation processes are complex and are affected by a variety of factors, including runoff/sediment-producing processes on land, rainfall characteristics, and marine transport processes. In addition, differences in carbonate production among locations leads to spatial variability in the proportion of terrigenous sediments within bays observed in this study. Further, resuspension resulting from wave activity affects trap accumulation temporally and spatially and can sometimes cause sedimentation during periods of low rainfall, which weakens the statistical relationship between rainfall and terrigenous sedimentation.

\subsubsection{Rainfall and Ephemeral Stream Activation}

St. John watersheds are drained exclusively by ephemeral, as opposed to perennial, streams. There is very little capacity for stream networks to store sediment, thus streams on St. John are very efficient at delivering sediment to 
coastal waters (MacDonald et al. 1997, Ramos-Scharrón and MacDonald 2007c).

Because rainfall is needed to activate the ephemeral streams, terrigenous sediment runoff on St. John only occurs over periods of hours to weeks during and after sufficient rainfall (MacDonald et al. 1997, Ramos-Scharrón and MacDonald 2007c). In St. John, soils are believed to hold at least $50 \mathrm{~mm}$ (2 in) of rain before runoff beings. When moisture content is lower than $50 \mathrm{~mm}$, the soil traps moisture, which is then later transpired by vegetation instead of activating streams (Cosner 1972). In order for the streams to become activated and for runoff to deliver terrigenous sediments to the marine environment, specific conditions, such as at least $50 \mathrm{~mm}(2 \mathrm{in})$ of total rainfall with sufficient intensity and pre-existing soil moisture must be met (MacDonald et al. 1997, Ramos-Scharrón and MacDonald 2007a \& c). In zero-order undisturbed areas, sediment is only produced during storms with at least $60 \mathrm{~mm}$ of rainfall (Ramos-Scharrón and MacDonald, 2007a). The need for sufficient rainfall in order for runoff to occur explains why the relationship between rainfall and TARs was stronger during sampling periods with greatest mean daily rainfall, mean rainfall intensity, and maximum daily rainfall at most locations.

Previous work has suggested that certain rainfall intensities (particular to pre-existing soil moisture conditions, total rainfall, and watershed characteristics such as slope and vegetative cover) must be obtained to generate erosion and overland flow (Ramos-Scharrón and MacDonald 2005, Wischmeier and Smith, 1978). In this study, rainfall intensity and maximum daily rainfall were stronger predictors of TARs than mean daily rainfall (total rainfall). Maximum daily 
rainfall is related to rainfall intensity because it is a measure of maximum rainfall over a shorter time (day) than the total rainfall parameter, which represents a 26day average. The 26-day intervals, over which mean daily rainfall was averaged, were significantly longer than the typical storm/ephemeral runoff duration of a few hours to days. Therefore, it was not surprising that mean daily rainfall (average \% variance) in TAR: $45 \pm 18 \mathrm{SD} \%$ ) did not correlate as strongly with TARs as did maximum (49 $\pm 17 \mathrm{SD} \%)$ or rainfall intensity $(60 \pm 19 \mathrm{SD} \%)$.

While we expected to observe a correlation between rainfall and terrigenous sedimentation, we did not predict that mean sediment grain size would vary with rainfall. At most of our study sites, the accumulated trap sediment included components of terrigenous, carbonate and organic sediment, all of which contributed to mean grain size. It was not analytically possible to isolate and measure the texture of each of these components. Therefore, it was not surprising then that we didn't find a strong relationship between rainfall and mean grain size.

In summary, because there are only ephemeral streams on St. John, runoff only occurs during and immediately after rainfall. Therefore, it was expected that the correlation between rainfall and terrigenous sedimentation would be significant. However, sufficient total rainfall, rainfall intensity, and soil moisture are needed for sediment delivery to occur, which explains why the relationship between rainfall and terrigenous sedimentation is stronger when we considered only sampling periods with greater rainfall (rainfall regimes) and potentially greater soil moisture (higher API regimes). Further, because certain rainfall intensities are needed to dislodge sediment particles and generate erosion (Ramos- 
Scharrón and MacDonald, 2005), mean rainfall intensity and maximum daily rainfall in general better correlated with TARs than mean daily rainfall. The general processes described here apply to both developed and minimally developed watersheds, but as will be discussed in the next section, watershed development, such as the presence of unpaved roads and exposed surfaces, may affect the minimal rainfall amount, intensity, and soil moisture needed to generate runoff and sediment erosion and at the watershed scale.

\subsubsection{Effect of Watershed Development on Watershed-Marine Transport} Processes and Marine Sedimentation

Watershed studies in St. John (Anderson 1994, Ramos-Scharrón and MacDonald 2005, 2007a, b, Ramos-Scharrón et al. 2012) and elsewhere (Larsen and Webb 2009) have demonstrated that land development increases terrigenous sediment erosion. GIS-based modeling studies evaluated how watershed sediment erosion varied between different sources such as tree throw, stream banks, and unpaved road segments, among other factors on St. John (RamosScharrón and MacDonald 2007b). On St. John, watershed-scale sediment yields from areas with unpaved roads were estimated to be up to nine times higher sediment than mostly undisturbed watersheds (Ramos-Scharrón and MacDonald 2007b). Unpaved roads were shown to account for over $80 \%$ of sediment delivery to the marine environment (Ramos-Scharrón and MacDonald 2007c). Sediment delivery below the specific developed watersheds of our study (Coral Bay, Coral Bay South Shore) were modeled to be 3 to 10 times greater compared 
to comparable, minimally developed watersheds (Lameshur Bay, Plantation Hill, respectively) (Ramos-Scharrón, pers. comm.).

The findings of these GIS-based modeling and watershed erosion studies that sediment delivery to the marine environment is 3 to 10 times greater below developed watersheds is consistent with the findings of Brooks et al., 2007, who linked long-term increases in terrigenous sedimentation in Coral Bay Harbor to watershed development. Using sediment cores collected in Coral Bay, they examined changes in the relative rate of marine terrigenous sediment deposition through the late Holocene. Brooks et al. (2007) measured an order of magnitude increase in the linear rate of terrigenous accumulation (thickness of sediment layer deposited per unit time) in marine sediment cores in Coral Bay from the 1950 's to present, which was consistent with dramatic rise in road building and watershed development during that period. Terrigenous sediment deposition was most pronounced near the two main drainages in Coral Harbor.

Consistent with watershed modeling and core studies, as well as with previous sediment trap results (2008-2011) (Kolupski 2011, Gray et al. 2012), the data presented here demonstrated that terrigenous sedimentation was significantly greater below developed watersheds compared to those that are minimally developed. Interestingly, the ratio of TARs between developed and similar, minimally developed subcatchments ranged from 2.7 to 5.1 with a mean of 4 . Our findings that mean TARs were approximately four times greater below developed compared with minimally developed subcatchments at our study sites were within range of watershed model sediment delivery predictions of 3-10 
times for the same pairs of developed/minimally developed subcatchments in St. John (Ramos-Scharrón, pers. comm.). The consistence of developed/minimally developed ratios for both marine TAR and watershed modeling approaches support that sediment traps are capable of providing a first-order record of relative differences in terrigenous sedimentation between developed and minimally developed areas over a long time ( $\sim 5$ year) period, despite the confounding processes that affect sediment trap-based measurements of TAR such as resuspension.

Though our finding that terrigenous sedimentation was greater below developed watersheds was not new for St. John and was consistent with previous watershed modeling efforts (e.g., St. John: Anderson 1994, Ramos-Scharrón and MacDonald 2005, 2007a, b, Ramos-Scharrón et al. 2012; Puerto Rico: Larsen and Webb 2009), sediment trap (Kolupski 2011, Gray et al. 2012), and sediment core (Brooks et al., 2007) studies, our data did provide new insights about how development may affect the relationship between rainfall and TARs when soil moisture conditions are considered (such as in the API calculation).

For example, rainfall better predicted TARs below the minimally developed watershed when API was considered in the regression model, but not when API was considered in the regression model for the developed watershed. The prevalence of unpaved roads in developed watersheds may explain why consideration of API did not improve the predictive power of rainfall to TAR in the regression model for the developed watershed. Because there are more unpaved roads in developed watersheds with compacted surfaces and poor 
infiltration rates, sediment may be eroded even when soil moisture is low (Ramos-Scharrón and MacDonald 2007b). For example, on unpaved roads, runoff is produced by only $2.5-5 \%$ of rainfall needed for runoff needed at the watershed scale (Ramos-Scharrón et al. 2014). Although runoff (and thus presumably delivery) varies significantly with antecedent soil moisture in developed watershed areas, runoff response to rainfall is highly variable (RamosScharrón and MacDonald, 2007a). On parking lots and unpaved roads, runoff can be originated by less than $1 \mathrm{~cm}$ of rainfall during storms (MacDonald et al. 1997), regardless of watershed soil moisture conditions. In contrast, in the minimally developed watersheds with intact vegetation and few exposed soil surfaces, vegetation binds loose sediment, preventing erosion, and rainfall is more likely to infiltrate instead of running off until a certain level of soil moisture has been reached. Thus, in minimally developed watershed areas like Lameshur Bay, greater soil moisture is likely needed to generate terrigenous sediment delivery to the bay. The wide wetland and interruptions to the natural flow of ephemeral streams by the retention pond also contribute to the fact that greater soil moistures are needed to initiate runoff in Lameshur Bay. Our study supported that more soil moisture was needed to initiate runoff in Lameshur Bay because 14-40\% more variability in TAR was explained by rainfall at the minimally developed Lameshur Bay Shore and Reef when API was considered in all rainfall regressions. By contrast (excluding mean rainfall intensity regressions, in which there was little difference in $\%$ variability in TAR with/without API consideration), 10 to $25 \%$ more variability in TAR was explained by rainfall at all 
Coral Bay locations when API was not considered for two of the three regressions (mean daily rainfall and maximum daily rainfall regressions).

Overall, this study supports that greater terrigenous sedimentation occurs below developed compared to minimally developed watersheds and less rainfall and soil moisture are needed to generate erosion of terrigenous sediments from developed compared to minimally developed watersheds. This difference in watershed erosion/runoff production is translated into measurements of terrigenous sedimentation in the marine environment.

\subsubsection{Transport and Distribution of Terrigenous Sediments and Carbonate}

Sediment Production

In addition to rainfall and watershed development, proximity to shore is an important factor that affects the composition and texture (mean grain size) of marine sediments. When terrigenous sediments are delivered to the marine environment, they will be deposited near the ephemeral stream outfall if the water energy (waves and currents) in the marine environment is less than required to keep them in suspension. Therefore, $\% \mathrm{~T}$ and $\mathrm{TAR}$ should be greater nearer the shoreline (ephemeral stream outfall). The water energy required to keep sediments in suspension is related to grain size such that coarser terrigenous sediments will be deposited near the ephemeral stream outfall while finer grains may remain in suspension (or be resuspended when wave energy increases) and be advected by marine currents away from the ephemeral stream outfall towards the offshore reefs. However, depending on the amount of rainfall and the nature 
of ocean currents associated with a particular storm, transport of terrigenous sediments from the ephemeral stream outfall to the reefs may not occur during the storm.

Distance from the ephemeral stream outfall may explain why the only location where there was not a significant relationship between rainfall and TAR was at the furthest offshore location, Coral Bay Reef. At Coral Bay Reef, sediment resuspension, rather than primary deposition following rainfall/runoff was likely largely responsible for most variability in TAR, because maximum wave height explained variability in TAR while rainfall did not. At Coral Bay reef, maximum wave height correlated significantly with TAR and explained $60 \%$ of the variability in TAR, further supporting that TAR at Coral Bay reef resulted from resuspension rather than terrigenous runoff (rainfall).

Offshore reef locations are farther from sources of terrigenous sediments, but in addition, carbonate sediment production associated with coral reef growth and erosion also affects sedimentation differently than near-shore where there are less carbonate sources. The magnitude of carbonate production is sufficient to dilute terrigenous sediment input. For example, in Hanalei Bay, Hawaii, the estimated carbonate production at an offshore reef $\left(3890 \mathrm{~m}^{3} / \mathrm{yr}\right)$ was 1.6 times greater than the estimated terrigenous sediment delivery $\left(2490 \mathrm{~m}^{3} / \mathrm{yr}\right)($ Calhoun et al. 2002). For this study in St. John, carbonate sediments comprised greater than $50 \%$ of trap sediments at every reef site during every period $(n=237)$. Study period mean $\%$ Ts for developed and minimally developed reef locations were only $25 \%$ and $17 \%$, respectively, which is consistent with Calhoun et al. (2002) in 
that there is greater carbonate content compared with terrigenous sediments offshore than near shore. Greater carbonate production on the offshore coral reefs may account for the lower \%Ts (due to dilution of terrigenous sediments by carbonate grains), and the generally coarser grain sizes (due to the input coarse carbonate bioclasts) we measured in our coral reef sediment traps.

Our results demonstrated consistently and significantly greater terrigenous sedimentation and finer benthic and trap mean grain size near shore compared with offshore reef locations at Lameshur and Coral Bay (with the exception of trap sediment at Coral Bay shore locations vs. Coral Bay Reef), which is generally consistent with other reef studies (Hubbard et al. 1987, Schrimm et al. 2004, Kennedy et al. 2002, Calhoun et al. 2002, Brooks et al. 2007, Calhoun and Field 2008). Based on sediment trap and benthic sediment collections at our study site in 2007-9, Kolupski (2011) also found greater terrigenous sedimentation (and finer mean grain size) near shore compared with offshore sites.

\subsubsection{Resuspension}

Results from this study demonstrated that rainfall, watershed development, and proximity to shore and coral reefs affect the composition, spatial and temporal distribution, and texture of marine sediments. However, an important process that affects the spatial distribution sediments on the seafloor and accumulation of sediments in traps, and temporal variability of trapped sediments (TARs, \% Ts, and sediment texture) in St. John is resuspension of benthic 
sediments from the seafloor associated with hydraulic energy from waves, tides, and currents.

Theoretically, sediment resuspension generally occurs when the forces of moving water are greater than the frictional and gravitational forces keeping sediment particles on the seafloor (Middleton and Southard 1984), but biological adhesion between particles and bed roughness also affect erosion from the seafloor (Self et al. 1989). Once sediment particles have been resuspended, whether a particle settles again is determined by the difference between the settling velocity of the particle and the energy of the water (Middleton and Southard, 1984).

Resuspension varies temporally in response to changes in water energy. For example, in Molokai, Hawaii, sediment accumulation rates were over 1000 times greater during storm events than during non-storm events primarily due to resuspension associated with increased wave activity (Bothner et al. 2006). At our study locations, there was a significant relationship between maximum wave height at offshore NOAA buoys and TARs, and maximum wave height explained $15-60 \%$ variability in TARs at our locations. This confirms that wave action is an important factor of marine sedimentation processes at our study sites.

When terrigenous sediment runoff does not occur, resuspension accounts for all terrigenous sediment accumulation in traps. For example, the 9/15/10 period during Hurricane Earl and the 9/15/12 sampling period both were characterized by relatively low rainfall but high maximum wave height (note: Hurricane Earl qualified as a "storm event" in terms of rainfall, but no runoff 
occurred during this storm at our sites [personal observation]). Despite little to no runoff during these periods, elevated TARs were measured at all shore and reef locations. However, \%Ts were simultaneously low during these periods, likely due to high carbonate resuspension. Because there was no runoff during Earl, Lameshur Bay progressed from clear to a distinct milky color from carbonate resuspension during the storm (personal observation). Because the waves and swell associated with Hurricane Earl came from the south there was more wave activity (and resuspension) in Lameshur Bay (open to the south) compared with Coral Bay (personal observation), which is protected from southerly swell due to orientation (Figure 2.3). Sediments collected in the Coral Bay traps were not characterized by a notable decrease $\% \mathrm{~T}$ during the sampling period during which H. Earl passed. This example illustrates how the orientation of storm-waves could affect spatial variability in wave-induced resuspension and impact sedimentation on reefs with different geographic orientations differently.

Further evidence for the importance of resuspension as a process affecting sediment trap accumulation was that terrigenous sediment accumulation was measured during at least two sampling periods (10/12/09 and 2/19/10) where maximum wave height was low/moderate and maximum daily rainfall was low (less than $5 \mathrm{~mm}$ ). Our data support that resuspension contributes to TARs during most sampling periods. We observed at least minimal terrigenous sediment accumulation at most locations during all periods despite lack of runoff or particularly high wave activity. 
When resuspension increases concurrently with rainfall during storms, which is common because rainfall is often associated with wind and increased wave energy, the expected relationship of greater $\%$ Ts due to runoff-derived terrigenous sediment delivery may not be observed. While resuspension and runoff during these storms would together contribute to greater TARs, resuspension of carbonate sediments from the seafloor could lower \%Ts, as this is the primary mechanism by which carbonate sediments may enter sediment traps. Tropical Storm Otto in October 2010 was an example of a storm that was characterized by exceptionally high rainfall (a storm of approximately $400 \mathrm{~mm}$ over five consecutive days, which broke historical records in St. John) and terrigenous sediment delivery, high maximum wave height, the greatest TARs measured during the study period for most locations, and low \%Ts at the Lameshur locations. Like Hurricane Earl, swell from T.S. Otto came from the south, which impacted Lameshur Bay more than Coral Bay. However, despite historic amounts of rainfall and runoff during T.S. Otto, \%Ts were lower than the study period mean at Lameshur Shore and Reef, though TARs were simultaneously very high. In contrast, $\% \mathrm{~T}$ remained similar to the study period mean in Coral Bay, suggesting less contribution of wave-induced resuspension of carbonates in Coral Bay compared to Lameshur Bay during T.S. Otto. Thus, the data we collected during T.S. Otto provided an example of how resuspension could alter the expected relationship between rainfall and \%Ts in Lameshur Bay despite exceptional terrigenous sediment delivery and TARs. 
The potential for resuspension also varies spatially because individual sites are differently exposed to waves and tides and are characterized by different mean grain sizes (which affect their potential for resuspension). Spatial differences in resuspension may explain why the relationship between rainfall and TAR was weakest at Coral South Shore compared to all other shore locations. In contrast, at Coral Harbor, where resuspension likely occurs less often due to its protection from strong waves, currents, and surge by mangroves and a peninsula, the correlation between rainfall and TAR was among the strongest of all locations.

The maximum current velocity is lowest at Coral Harbor $(0.28 \mathrm{~m} / \mathrm{s})$ of all locations during the fall (Stephen Campbell, unpublished data). Mean grain size of benthic sediments in Coral Harbor is approximately $0.08 \mathrm{~mm}$, which requires a velocity of approximately $0.30 \mathrm{~m} / \mathrm{sec}$ to erode from the seafloor (Self et al. 1989); thus, our measurements of current velocity at Coral Harbor suggest that resuspension of grains of mean size may not occur often. In contrast, Coral South Shore is the least protected from current and wave activity. The greatest maximum current velocity $(0.50 \mathrm{~m} / \mathrm{s})$ of all locations was measured at Coral South Shore (Stephen Campbell, unpublished data). At Coral South Shore, the mean grain size of benthic grains is approximately $0.15 \mathrm{~mm}$, which requires a current velocity of $0.25 \mathrm{~m} / \mathrm{sec}$ to erode (Self et al. 1989); thus, grains of mean size (and larger) will tend to be resuspended under maximum measured current velocities at Coral South Shore. The observation that resuspension was 
potentially greater at Coral South Shore compared to other shoreline sites was noted by Kolupski (2011) based on sediment trap studies in 2008-09.

In summary, terrigenous sediments are initially made available for primary deposition via runoff from land, and carbonate sediments are made available by biogenic production in the marine environment. When and where newly introduced sediment particles settle depend on the size of the particles, mechanisms responsible for runoff and sediment delivery, and hydrodynamic forces associated with ocean waves. Resuspension of sediments varies temporally with season and storms, and spatially with water energy and benthic texture. When runoff of terrigenous sediments does not occur, resuspension accounts for all terrigenous sediment accumulation in traps. The data showed that resuspension likely occurs to some degree even when wave activity is moderate to low. Because storms are often associated with increased wave activity, resuspension is often greater during storms. Thus, resuspension together with runoff determine terrigenous sediment accumulation in traps and sediment traps generally overestimate terrigenous sediment flux as a result of resuspension.

\subsection{Sedimentation and Coral Stress}

In addition to describing how sedimentation varies temporally and spatially as a result of rainfall, watershed land use, carbonate production, sediment transport and resuspension, one objective of this study was to explore how sedimentation might impact coral condition. All developed and minimally developed shore and reef locations (except Coral Bay Harbor) are near live corals 
(isolated colonies, patch reefs, and true reefs, [personal observation]). Though we did not measure the ecological condition of corals near our sites directly, independent studies have linked values of $\Sigma \mathrm{AR}$ to coral condition and stress. For example, $\Sigma$ ARs greater than $50 \mathrm{mg} / \mathrm{cm}^{2} / \mathrm{d}$ were associated with "severe to catastrophic" sediment stress (Pastorak and Bilyard, 1985) and $\Sigma$ ARs greater than $100 \mathrm{mg} / \mathrm{cm}^{2} / \mathrm{d}$ were shown to kill exposed coral tissue (Philipp and Fabricius, 2003). However, these values should be related to corals at our study sites with caution because these experiments were conducted on different coral species with varying abilities to adapt to sedimentation (Torres and Morelock 2002; Philipp and Fabricius 2003). In addition, even though general "sediment stress thresholds" for specific sediment accumulation rates have been defined, some studies have demonstrated the ability of corals to thrive in areas with chronically high turbidity and sedimentation (Albert et al. 2015).

It has been suggested that silt $(<75 \mathrm{um})$ produces greater negative effects on coral health than coarser sediments (e.g., Nugues and Roberts 2003, Weber et al. 2006). Studies on St. John and elsewhere in the USVI have further demonstrated that consideration of SAR is more important than $\Sigma$ AR to coral condition matrices (Smith et al. 2008; Henderson et al. 2013). Henderson et al. (2013) linked greater SAR to coral degradation and reduced coral cover in St. John and elsewhere in the USVI. For example, in areas with mean SARs of approximately $4 \mathrm{mg} / \mathrm{cm}^{2} / \mathrm{d}$, \% cover of $M$. annularis was approximately $10 \%$ compared to approximately $20 \%$ and $30 \%$ cover in areas where SAR was 2 and 1 $\mathrm{mg} / \mathrm{cm}^{2} / \mathrm{d}$, respectively (Smith et al. 2008; Henderson et al., 2013). In addition, 
when SARs were around $4 \mathrm{mg} / \mathrm{cm}^{2} / \mathrm{d}$, half or more of coral populations showed signs of bleaching, old partial mortality, and impairment in the Virgin Islands (Henderson et al. 2013). Comparisons between SAR data from our study sites and coral stress data from Henderson et al. (2013) are appropriate and meaningful because their studies of the detrimental effects of SARs were conducted near our study location and for similar coral species.

Given the sediment stress levels described, corals at our study sites may be under the greatest stress during periods of high rainfall, near shore, and below developed watersheds. Like TARs and \%Ts, study period mean total and SARs were greater during periods with greater rainfall, at shore compared to reef locations and in developed compared with minimally developed locations. Patterns of variability in SAR were similar to the patterns of variability in $\Sigma$ AR. This is not surprising because SAR is calculated by multiplying $\Sigma$ AR by $\%$ silt and therefore is based both on $\Sigma \mathrm{AR}$ as well as grain size.

Sampling periods where SARs were over $4 \mathrm{mg} / \mathrm{cm}^{2} / \mathrm{d}$ (a level that caused bleaching, old partial mortality, and impairment to over half the corals in the USVI, [Henderson et al., 2013]) were more common at Coral South Shore (86\%) and Coral Bay Reef (40\%) than in minimally developed locations Lameshur Shore and Reef (39\% and 11\%, respectively). For $\Sigma A R$, the 50 and $100 \mathrm{mg} / \mathrm{cm}^{2} / \mathrm{d}$ levels for "severe-catastrophic" (Pastorak and Bilyard, 1985) and lethal (Philipp and Fabricius, 2003) coral stress generally followed the same pattern as SARs but were surpassed far less frequently. 
Although the frequency of sediment-related stress was lower in Lameshur Bay compared with Coral Bay Reefs, $\Sigma$ AR surpassed the $100 \mathrm{mg} / \mathrm{cm}^{2} / \mathrm{d}$ level twice at Lameshur Bay Reef (but never at Coral Bay Reef) during the unusual 2010 fall rainy season and most likely due to large contributions from sediment resuspension. As discussed above, H. Earl (9/15/10) and, T.S. Otto (10/11/10) impacted St. John by producing southerly waves and produced greater $\Sigma \mathrm{AR}$ at Lameshur Bay compared with Coral Bay Reef during the study period (see discussion above). Although extremely high rates of sedimentation were measured during the fall of 2010, no clear reductions in cover of scleractinian corals as a result of 2010 were found at Lameshur reef, though coral recruitment was reduced in 2011 (Edmunds and Gray 2014). Reduced coral recruitment in 2011 cannot be directly attributed to high rainfall in 2010 because coral recruitment can be variable from year to year and recruitment between 2009-2011 (Edmunds and Gray, 2014) was still above median values of coral recruitment (Glassom et al., 2004; Smith, 1992). While it cannot be unequivocally concluded that heavy rainfall in fall 2010 led to reduced coral recruitment given the variable nature of recruitment year to year, increases in the abundance of suspension feeders observed the following year suggests that reduced recruitment at Lameshur reef was significant enough to cause an ecological shift favoring suspension feeders over coral cover (Edmunds and Gray 2014).

In summary, $\Sigma$ ARs and SARs measured in shore and reef locations suggest that coral stress is greater during times of high rainfall, at near shore sites, and below developed watersheds. At all developed and minimally developed 
locations, both total and silt accumulation rates were greater during most storm events in association with runoff and/or greater resuspension. Because development has been shown to increase total and silt accumulation, the results of this study suggest that development is contributing to coral reef stress in St. John. Similarly to what was documented in regional studies examining sediment-related coral stress in the Virgin Islands (e.g., Smith et al. 2008, Henderson et al. 2014), corals at our specific study locations are characterized by partial mortality and bleaching, which could in part be related to sediment stress.

\subsection{Sediment Traps as a Monitoring Tool}

The outcomes of this study have shown that sediment traps are an effective way to measure temporal and spatial patterns in sedimentation and to identify potential periods and locations where sedimentation is at levels that may induce stress to corals. While sediment traps are great tools for measuring major relative patterns in sedimentation through space and time, it still is unclear whether watershed restoration measures lower the amount of terrigenous sediment delivery to the marine environment. More information about the contribution of resuspension to trapped sediments is needed along with the monitoring of shoreline runoff, currents, wind, waves as well as water turbidity and sediment deposition. Also, because factors such as watershed soil moisture conditions can lead to different levels of runoff in otherwise similar storms, there is the need to collect concurrent watershed/marine data during storms in order to directly link 
watershed processes to marine sedimentation, and ultimately, evaluate the effects of restoration.

With a longer sediment monitoring study period now extending through the 2014 season (Gray et al., 2014), future studies and the availability of additional seasons of post-restoration data may provide sufficient data to measure the effect of the ARRA watershed restoration projects on terrigenous sedimentation in Coral Bay by comparing TARs during equivalent pairs of storms occurring pre- and post-restoration.

To test this approach, a simple analysis was conducted that compared terrigenous sedimentation in two storm pairs (one pre- vs. one post-restoration) with similar duration, season and rainfall characteristics. This storm comparison showed reductions in terrigenous sedimentation below the restored catchments post-restoration. However, the sample size was too small to make any conclusive and statistically significant interpretations. The study period for this thesis project ended in 2012, but this approach to test the effectiveness of the watershed restoration in reducing marine terrigenous sedimentation may be expanded to include more "equivalent storm" pairs now that two more years of postrestoration monitoring data are available. With a greater sample size, the effects of restoration may be better detected and may help address the primary objective of the USVI Sedimentation Program, which is to evaluate the effects of restoration on terrigenous sedimentation in Coral Bay. 


\subsection{Contribution to Management and Monitoring of Developed, Tropical}

Watersheds and Adjacent Coral Reefs

This is the first coral reef sediment trap study that we are aware of to capture the natural variability in storms and rainfall over a study period longer than two years while also monitoring distinct areas with different degrees of watershed development simultaneously. The large dataset allowed us to examine the relationship between terrigenous sedimentation and rainfall statistically using different parameters of rainfall. Monitoring distinct shoreline and reef environments simultaneously throughout the study provided data to test how the relationship between rainfall and terrigenous sedimentation varied with respect to variable shoreline environment, distance from shore, and development.

Monitoring simultaneously across several distinct areas also allowed evaluation of how potential sedimentation stress to corals varied temporally and spatially. This information could be used to allocate limited resources for restoration to areas with the highest need.

As coastal development continues along tropical coastlines, the input of sediment is likely to increase on coral reefs. In order to effectively manage watershed development and protect coral reef systems, it is necessary to understand the relationship between watershed development and the processes that control coastal and reef sedimentation for individual watershed-reef systems, and the effect of watershed and climatic conditions on marine terrigenous sedimentation. 


\section{Chapter 5: Conclusions}

The goals of this study were to: 1) examine how marine sedimentation varied temporally in St. John as a function of rainfall and wave activity, and 2) spatially with respect to shoreline runoff inputs and watershed development. Sediments collected in sediment traps deployed over five hurricane seasons (2007-2012) were analyzed to determine $\Sigma$ ARs, TARs, SARs, \%Ts, and grain size. These sedimentary matrices were then compared with rainfall and regional wave activity.

1) Terrigenous sedimentation was greater during periods of greater rainfall, particularly during periods characterized by high mean rainfall intensity and maximum daily rainfall. Streams are ephemeral on St. John and runoff of terrigenous sediments from land cannot occur unless the streams are activated by rainfall. Certain rainfall intensities are necessary to generate sediment erosion and overland flow of sediment runoff into the marine environment.

2) The statistical relationship between terrigenous sedimentation and rainfall varied spatially. 1) There were greater TARs and a stronger statistical relationship between rainfall and TARs at shore compared to reef sites. 2) Rainfall better predicted TARs below the minimally developed watershed when API (a proxy for soil moisture) was considered in the regression model, but not when API was considered in the regression model for the developed watershed. This is likely because runoff can occur during periods of relatively low soil moisture on 
exposed and compacted surfaces such as unpaved roads found in developed watersheds (Ramos-Scharrón and MacDonald 2007b).

Like previous watershed erosion modeling studies in St. John that predicted three to ten times greater terrigenous sediment delivery to the marine environment from developed watersheds (Ramos-Scharrón, pers. comm.), we found consistently greater rates of terrigenous sedimentation below developed watersheds. The magnitude of mean spatial differences in TAR (mean ratio of developed to minimally developed TAR: 4) was also generally consistent with modeling studies. As has been supported by previous studies, it is likely that the major source of excess terrigenous sediment is loose sediment on numerous unpaved road networks in the developed watersheds.

Because there is greater terrigenous sediment below developed watersheds and near-shore, mean grain size was typically (but not always) finer below developed compared with minimally developed watersheds and near-shore compared with offshore reef locations. At offshore reef locations, production of generally coarse-grained carbonate bioclasts contributed to greater mean sediment grain size.

3) Maximum wave height during major storms and tropical depressions exceeded study period mean wave height during ten out of thirteen storms and in addition to rainfall, likely contributed to terrigenous sediment accumulation via increased resuspension from the seafloor. TARs were greater during periods with high maximum wave height, even when rainfall was relatively low. Terrigenous 
sediment accumulated in traps even during periods of low rainfall and wave activity, suggesting that resuspension contributed to TAR during most periods.

Regardless of whether sampling periods were characterized by high rainfall, high wave activity was associated with low $\% \mathrm{~T}$, likely from the resuspension of carbonate sediments from the seafloor. Resuspension was the primary process by which generally coarse-grained bioclasts enter traps, so it was not surprising that increased wave activity (and thus, resuspension) was associated with greater $\%$ carbonate and thus lowered $\% \mathrm{~T}$ in traps.

4) Based on the comparisons between our total and silt accumulation rates with published levels related to coral stress, corals near our study locations were most likely subjected to greater stress during (and immediately following) periods of high rainfall, near-shore, and below developed watersheds. SARs exceeding 4 $\mathrm{mg} / \mathrm{cm}^{2} / \mathrm{d}$ were measured approximately twice as frequently $(86 \%$ of sampling periods) at the developed (Coral Bay South Shore) compared to the minimally developed Plantation Hill (42\% of sampling periods) and Lameshur Shore (32\% of sampling periods) locations with patch reefs. Similarly, SARs exceeding 4 $\mathrm{mg} / \mathrm{cm}^{2} / \mathrm{d}$ more commonly occurred at Coral Bay Reef ( $40 \%$ of sampling periods) than at Lameshur Bay Reef (11\% of sampling periods).

5) The outcomes of this study have shown that sediment traps are an effective way to monitor general temporal and spatial patterns of variability in terrigenous sedimentation and to identify potential periods and locations where 
sedimentation is at levels that may induce stress to corals. However, more information about the contribution of oceanographic (currents, wind, and waves) processes to resuspension, as well as the specific watershed processes that lead to sediment delivery are needed to complement sediment trap data.

As building and human development activities continue along tropical coastlines, the input of terrigenous sediment is likely to increase on coral reefs. This project is the first marine sediment trap study we are aware of a) to capture the natural variability in storms, rainfall, and resuspension over a study period longer than two years and b) to monitor distinct near shore and offshore areas below both developed and minimally developed watersheds simultaneously. The relatively long, 5-year dataset made it possible to examine the relationships between terrigenous sedimentation, rainfall and wave activity statistically. Because capitol and resources for restoration are limited on St. John, information about spatial variability of coral stress could be used to concentrate watershed restoration efforts to areas with the highest need. Specifically, corals near the southernmost portion of Coral Bay are likely under the greatest sedimentation stress. While the results from this project demonstrated that sediment traps are effective at monitoring temporal and spatial trends in sedimentation, due to the contributing factors of resuspension and the short (one season) post-restoration study period, it was not possible to detect smaller, more subtle changes in sedimentation that could have been associated with reductions in sediment delivery related to the 2011 ARRA restoration efforts. Future studies will build upon our findings, better link watershed and marine sedimentation processes, and 
utilize a longer post-restoration dataset to measure the effect of restoration on marine sedimentation. 


\section{Literature Cited}

Albert, S., P.L. Fisher, B. Gibbes, and A. Grinham. 2015. Corals persisting in naturally turbid waters adjacent to a pristine catchment in Solomon Islands. Marine Pollution Bulletin 94, 299-306.

Anderson, D.M. 1994. Analysis and modeling of erosion hazards and sediment delivery on St. John, U.S. Virgin Islands. Master's thesis. Colorado State University: Colorado, USA.

Anderson, D.M., L.E., MacDonald. 1998. Modeling road surface sediment production using a vector geographic information system. Earth Surface Processes and Landforms 23, 95-107.

Anthony, K.R.N., and P. Larcombe. 2000. Coral reefs in turbid waters: sedimentinduced stresses in corals and likely mechanisms of adaptation. Proceedings of the $9^{\text {th }}$ International Coral Reef Symposium.

Baker, E.T., H.B. Milburn, and D.A. Tennant. 1988. Field assessment of sediment trap efficiency under varying flow conditions. Journal of Marine Research 46: $573-592$

Bartley, R., Z.T. Bainbridge, S.E.,Lewis, F.J. Kroon S.N. Wilkinson, J.E. Brodie, and D. M. Silburn.2014. Relating sediment impacts on coral reefs to watershed sources, processes and management: A review. Science of the Total Environment, 468, 1138-1153.

Bathurst, R.G.C. 1975. Carbonate Sediments and their Diagenesis. Developments in Sedimentology (12). 2nd enlarged ed. Amsterdam: Elsevier Scientific Publishing Company. 658 pp.

Bastidas, C., D. Bone, and E.M. Garcia. 1999. Sedimentation rates and metal content of sediments in a Venezuelan coral reef. Marine Pollution Bulletin 38(1): 16-24.

Bloesch, J., A review of methods used to measure sediment resuspension. 1994. Hydrobiolgia 284: 13-44.

Bégin, C., G. Brooks, R.A. Larson, S. Dragićević, C.E. Ramos Scharrón, and I.M. Côté. 2014. Increased sediment loads over coral reefs in Saint Lucia in relation to land use change in contributing watersheds. Ocean and Coastal Management 95: 35-45.

Bothner, M.H., R.L. Reynolds, M.A. Casso, C.D. Storlazzi, and M.E. Field. 2006. Quantity, composition, and source of sediment collected in sediment traps 
along the fringing coral reef off Molokai, Hawaii. Marine Pollution Bulletin 52(9): 1034-1047.

Brooks, G. R., R. A. Larson, N. T. Edgar, R. H. Pierce, D. Wetzel, C. W. Holmes and M. Henry. 2004. Holocene Depositional History in Two Florida Gulf Coast Estuaries: Tampa Bay and Charlotte Harbor. Geological Society of America Abstracts with Programs, 36:301.

Brooks, G.R., B. Devine, R.A. Larson, and B.P. Rood. 2007. Sedimentary development of Coral Bay, St. John, USVI: a shift from natural to anthropogenic influences. Caribbean Journal of Science 43(2): 226-243.

Brooks, G.R., R.A Larson, B. Devine. 2008. Sediment input and accumulation rates: USVI Phase I Report: Coral Bay, St. John. Tetra Tech, Inc.

Burke, L. and J. Maidens. 2004. Reefs at risk in the Caribbean. World Resource Institute Report, $80 \mathrm{pp}$.

Calhoun, R.S., C.H. Fletcher, J.N. Harney. 2002. A budget of marine and terrigenous sediments, Hanalei Bay, Kauai, Hawaiian Islands. Sedimentary Geology,150: $61-87$.

Calhoun, R.S. and M.E. Field. 2008. Sand composition and transport history on a fringing coral reef, Molokai, Hawaii. Journal of Coastal Research 24(5): 1151-1160.

CBCC. 2014. Coral Bay Community Council, Inc. http://www.coralbaycommunitycouncil.org/Waterpdfs/Coral_Bay_Waters hed_Management_Plan_final.pdf

Center for Watershed Protection. 2008. Coral Bay watershed management plan: a pilot project for watershed planning in the USVI. Report submitted to NOAA Coral Reef Program and USVI DPNR.

CH2M Hill Inc. 1979. A sediment reduction program. Report submitted to the Department of Conservation and Cultural Affairs, Government of the U.S. Virgin Islands.

Coldren, S.L., P.C. Reed, and S.C. Gray. 2013. A model of science-driven, community-based efforts to mitigate watershed erosion and land-based sedimentation to coral reefs in Coral Bay, US Virgin Islands, Biennial Conference of the Coastal and Estuarine Research Foundation, $3^{\text {rd }}-7^{\text {th }}$ November, 2013, San Diego, CA.

Cornaglia, P. 1889. On Beaches. Fisher, J.S. and R. Dolan 1977. Beach Processes and Coastal Hydrodynamics. Stroudsbourg, Pennsylvania: Dowden, Hutchinson and Ross, Inc., pp 11-26. 
Cortés, J.N. and M.J. Risk. 1985. A reef under siltation stress: Cahuita, Costa Rica. Bulletin of Marine Science 36(2): 339-356.

Cosner, L. J. 1972. Water in St. John, US Virgin Islands. US Geological Survey Open-File Rep. 72-78, San Juan, Puerto Rico, 46 pp.

Draut, A.E., M.H. Bothner, M.E. Field, R.I. Reynolds, S.A. Cochran, J.B. Logan, C.D. Storlazzi, and C.J. Berg. 2008. Supply and dispersal of flood sediment from a steep, tropical watershed: Hanalei Bay, Kauai, Hawaii, USA. Geological Society of America Bulletin 121(3/4): 574-585

Dodge, R.E., R.C. Aller, and J. Thomson. 1974. Coral growth related to resuspension of bottom sediments. Nature 247: 574-577.

Dunne, T. 1978. Water in Environmental Planning. Macmilla, 818 pp.

Edmunds, P.J. and J.D. Witman. 1991. Effect of Hurricane Hugo on the primary framework of a reef along the south shore of St. John, USVI. Marine Ecology Progress Series 78: 201-204.

Edmunds, P.J. 2000. Patterns in the distribution of juvenile corals and coral reef community structure in St. John, US Virgin Islands. Marine EcologyProgress Series 202: 113-124.

Edmunds, P.J. 2002. Long-term dynamics of coral reefs in St. John, US Virgin Islands. Coral Reefs 21(4): 357-367.

Edmunds, P.J. 2007. Evidence for a decadal-scale decline in the growth rates of juvenile scleractinian corals. Marine Ecology-Progress Series 341: 1-13.

Edmunds, P.J., and S.C. Gray. 2014. The effects of storms, heavy rain, and sedimentation on the shallow coral reefs of St. John, US Virgin Islands. Hydrobiologia 734: 143-158.

Fabricius, K.E. 2005. Effects of terrestrial runoff on the ecology of corals and coral reefs: review and synthesis. Marine Pollution Bulletin 50(2): 125146.

Field, M.E., S.A. Cochran, J.B. Logan, and C.D. Storlazzi. 2008. The coral reef of south Moloka'i, Hawai'i - portrait of a sediment-threatened reef. USGS Scientific Investigations Report 2007-5101.

Friedlander A.M., C.F.G. Jeffery, S.D. Hile, and S.J. Pittman. 2012. Coral reef ecosystems of St. John, U.S. Virgin Islands: Spatial and temporal patterns in fish and benthic communities (2001-2009). NOAA Technical Memorandum 152. Silver Spring. MD. 
Gacia E. and Duarte C.M. 2001. Sediment Retention by a Mediterranean Posidonia oceanica Meadow: The Balance between Deposition and Resuspension. Estuarine, Coastal and Shelf Science 52, 505-514.

Gardner, T.A. 1980a. Field assessment of sediment traps. Journal of Marine Research 38: 41-52.

Gardner, T.A. 1980b. Sediment trap dynamics and calibration: a laboratory evaluation. Journal of Marine Research 38: 17-39.

Glassom, D., D. Zakai, and N. E. Chadwick-Furman. 2004. Coral recruitment: a spatio-temporal analysis along the coastline of Eilat, northern Red Sea. Marine Biology 144: 641-651.

Gobbi, K.L. 2009. Inorganic sediment source, flux, and composition within bays in St. John, USVI. Master's thesis. University of San Diego: California, USA.

Golbuu, Y., Victor, S., Wolanksi, E., and Richmond, R. H. 2003. Trapping of fine sediment in a semi-enclosed bay, Palau, Micronesia. Estuarine, Coastal and Shelf Science 57, 941-949.

Gray, S.C., Gobbi, K.L., and Narwold, P.V. 2009. Comparision of sedimentation in bays and reefs below developed versus undeveloped watershed on St. John, US Virgin Islands. Proceedings of the 11th International Coral Reef Symposium.

Gray, S.C., W. Sears, W., M. L. Kolupski, Z.C. Hastings, N.W. Przyuski, M.D. Fox, and A. DeGrood. 2012. Factors affecting land-based sedimentation in coastal bays, US Virgin Islands. Proceedings of the $12^{\text {th }}$ International Coral Reef Symposium.

Gray, S. C., W. Sears, S. Campbell, C.E. Ramos-Scharrón, H. Hirsh, T. Barnes, and J. Whinney. 2014. Monitoring approaches to assess the impact of watershed development and restoration on land-based sedimentation in the US Virgin Islands: lessons learned. American Geophysical Union, Fall Meeting, Dec. $15^{\text {th }}-19^{\text {th }}, 2014$, San Francisco, CA.

Griffin, D.W., V.H. Garrison, J.R. Herman, E.A. Shinn. 2001. African desert dust in the Caribbean atmosphere: microbiology and public health.

Aerobiologia 17 203-213.

Harney, J.N., and C.H. Fletcher. 2003. A budget of carbonate framework and sediment production, Kailua Bay, Oahu, Hawaii. Journal of Sedimentary Research 73(6), 856-868. 
Harrington, R.J. 2014. Impact of Development on Ridge to Reef Transport of Terrestrial Elements in St. John, U.S. Virgin Islands. (Masters thesis, Universtiy of San Diego).

Heiss, W.M., A.M. Smith, and P.K. Probert. 2013. Influence of the small intertidal seagrass Zostera novazelandica on linear water flow and sediment texture. New Zealand Journal of Marine and Freshwater Research 34: 689-694.

Henderson LM, T.B. Smith, M. Taylor, and R.S. Nemeth. 2013. Sedimentation patterns of coral health across large gradients of human pressure in the US Virgin Islands. $36 \mathrm{t}^{\mathrm{h}}$ Association of the Marine Laboratories Scientific Meeting, Jun $17^{\text {th }}-21^{\text {st }}$, 2013, Rio Ochos, Jamaica,.

Heiri, O., A.F. Lotter, and G. Lemcke. 2001. Loss on ignition as a method for estimating organic and carbonate content in sediments: reproducibility and comparability of results. Journal of Paleolimnology 25(1): 101-110.

Hernández- Delgado, E.A., C.E. Ramos-Scharrón, C.R. Guerrero-Pérez. M.A. Lucking, R. Laureano, P.A. Méndez-Lázaro, and J.O. Meléndez-Díaz.. 2012. Long-Term Impacts of Non-Sustainable Tourism and Urban Development in Small Tropical Islands Coastal Habitats in a Changing Climate: Lessons Learned from Puerto Rico, Visions for Global Tourism Industry - Creating and Sustaining Competitive Strategies, Dr. Murat Kasimoglu (Ed.), ISBN: 978-953-51-0520-6, InTech, DOI: $10.5772 / 38140$.

Hill, Ronald L., J.C. Doerr, and K.G. Ferran. 2014. Monitoring coral reef changes associated with Erosion Mitigation Projects in Fish Bay and Coral Bay, St. John, USVI. NOAA Technical Memorandum NOS NCCOS 178, Ch. 3.

Hubbard, D.K., J.D. Stump, and B. Carter. 1987. Sedimentation and reef development in Hawksnest, Fish and Reef Bays, St. John, U.S. Virgin Islands. In: Virgin Islands Resource Management Cooperative. Biosphere Research Reserve Report, No. 21, 99 pp.

Jordi, A., G. Basterretxea, and D.P. Wang. 2009. Evidence of sediment resuspension by island trapped waves. Geophysical Research Letters 36.

Kennedy, D.M., C.D. Woodroffe, B.G. Jones, M.E. Dickson, and C.V.G.Phipps. 2002. Carbonate sedimentation on subtropical shelves around Lord Howe Island and Balls Pyramd, Southwest Pacific. Marine Geology, 188: 333 349. 
Kline, D. I., N. M. Kuntz, M. Brietbart, N. Knowlton, and F. Rohwer. 2006. Role of elevated organic carbon levels and microbial activity in coral mortality. Marine Ecology Progress Series 314:119-125

Kolupski, M.L. 2011. Sedimentation in coastal bays with coral reef: Impacts of watershed development, St. John, USVI. Master's Thesis, University of San Diego.

Kuntz, N. M., D. Kline, S. A. Sandin, and F. Rohwer. 2005. Pathologies and mortality rates caused by organic carbon and nutrient stressors in three Caribbean coral species. Marine Ecology Progress Series 294: 173-180.

Larsen, M.C., and R. M. T. Webb. 2009. Potential Effects of Runoff, Fluvial Sediment, and Nutrient Discharges on the Coral Reefs of Puerto Rico. Journal Of Coastal Research 25(1): 189-208.

MacDonald, L.H., D.M. Anderson, and W.E. Dietrich. 1997. Paradise threatened: land use and erosion on St. John, US Virgin Islands. Environmental Management 21(6): 851-863.

MacDonald, L.H., R.W. Sampson, and D.M. Anderson. 2001. Runoff and road erosion at the plot and road segment scales, St. John, US Virgin Islands. Earth Surface Processes and Landforms 26, 251-272.

Maher, L.J. 1998. Automating the dreary measurements for loss-on-ignition. INQUA Sub-Commission on Data-Handling Methods. Newsletter 18: 3.

McCreery, H.F. 2007. The effect of anthropogenic development on sediment loading to bays on St. John, U.S. Virgin Islands. Master's thesis. Massachusetts Institute of Technology: Maine, USA.

Middleton, G.V., and J.V. Southard, 1984. Mechanics of Sediment Movement, second edition. Society of Economic Paleontologists and Mineralogists, University of California $401 \mathrm{pp}$.

Narwold, P.V. 2009. Organic composition of sediment in two bays with fringing coral reefs in St. John, U.S. Virgin Islands. Master's thesis. University of San Diego: Calfornia, USA.

Nemeth, R.S. and J.S. Nowlis. 2001. Monitoring the effects of land development on the near-shore reef environment of St. Thomas, USVI. Bulletin of Marine Science 69(2): 759-775.

Nugues, M.M. and C.M. Roberts. 2003. Coral mortality and interaction with algae in relation to sedimentation. Coral Reefs 22(4): 507-516. 
Ogston, A.S., C.D. Storlazzi, M.E. Field, and M.K. Presto. 2004. Sediment resuspension and transport patterns on a fringing reef flat, Molokai, Hawaii. Coral Reefs 23(4): 559-569.

Pandolfi, J.M., R.H. Bradbury, E. Sala, T.P. Hughes, K.A. Bjorndal, R.G. Cooke, D. McArdle, L. McClenachan, M.J.H. Newman, G. Paredes, R.R. Warner, and J.B.C. 2003. Global trajectories of the long-term decline of coral reef ecosystems. Science 301(5635): 955-958.

Pastorok, R.A. and G.R. Bilyard. 1985. Effects of sewage pollution on coral-reef communities. Marine Ecology Progress Series 21: 175-189.

Philipp, E. and K. Fabricius. 2003. Photophysiological stress in scleractinian corals in response to short-term sedimentation. Journal of Experimental Marine Biology and Ecology 287(1): 57-78.

Prager E.J., J.B. Southard, and E.R. Vivoni-Gallart. 1996. Experiments on the entrainment threshold of well-sorted and poorly sorted carbonate sands. Sedimentology, 43: 33-40.

Ramos-Scharrón, C.E. and L.H. MacDonald. 2005. Measurement and prediction of sediment production from unpaved roads, St John, US Virgin Islands. Earth Surface Processes and Landforms 30(10): 1283-1304.

Ramos-Scharrón, C.E. and L.H. MacDonald. 2007a. Measurement and prediction of natural and anthropogenic sediment sources, St. John, US Virgin Islands. Catena 71(2): 250-266.

Ramos-Scharrón, C.E. and L.H. MacDonald. 2007b. Runoff and suspended sediment yields from an unpaved road segment, St. John, US Virgin Islands. Hydrological Processes 21(1): 35-50.

Ramos-Scharrón, C.E. and L.H. MacDonald. 2007c. Development and application of a GIS-based sediment budget model. Journal of Environmental Management 84: 157-172.

Ramos- Scharrón, C.E. 2010. Sediment production from unpaved roads in a tropical setting - southwestern Puerto Rico. Catena 82: 146-158.

Ramos-Scharrón C.E., J.M. Amador, and E.A. Hernández-Delgado. 2012. An Interdisciplinary Erosion Mitigation Approach for Coral Reef Protection A Case Study from the Eastern Caribbean. Marine Ecosystems, ISBN: 978-953-51-0176-5, InTech

Ramos- Scharrón, C.E. and B. Swanson. 2012. Assessment of the Effectiveness of Watershed Stablization Practices in Reducing Sediment Yields Rates into Coral Bay, St. John, USVI. USVI Coastal Habitat Restoration Through 
Watershed Stablization Project. NOAA-ARRA: 2009-2012 Terrestrial Monitoring Component.

Ramos-Scharrón, C.E., S. Gray, W. Sears, G. Brooks, and R. Larson. 2014. Assessing the short- and long-term effects of land developed on sediment delivery to marine ecosystems of the USVI. American Geophysical Union, Fall Meeting, Dec. $15^{\text {th }}-19^{\text {th }}, 2014$, San Francisco, CA.

Rawling, D.W., M.D. Fox, and S.C. Gray. 2010. Can sediment texture be used as a proxy to measure terrigenous (land-derived) sediment flux on coral reefs? $91^{\text {st }}$ Annual Western Society of Naturalists Meeting, Nov. $11^{\text {th }}-14^{\text {th }}$, 2010, San Diego, CA.

Rankin, D.W. 2002. Geology of St. John, U.S. Virgin Islands. U.S. Geological Survey Professional Paper 1631, 39 pp.

Reilly, A.E. 1991. The effects of Hurricane Hugo in three tropical forests in the U.S. Virgin Islands. Biotropica 23(4a): 414-419.

Rogers, C.S. 1977. The response of a coral reef to sedimentation. PhD dissertation. University of Florida: Florida, USA.

Rogers, C.S. 1983. Sublethal and lethal effects of sediments applied to common Caribbean reef corals in the field. Marine Pollution Bulletin 14(10): 378382.

Rogers, C.S. 1990. Response of coral reefs and reef organisms to sedimentation. Marine Ecology Progress Series 62: 185-202.

Rogers, C.S. and J. Miller. 2006. Permanent 'phase shifts' or reversible declines in coral cover? Lack of recovery of two coral reefs in St. John, US Virgin Islands. Marine Ecology-Progress Series 306: 103-114.

Rogers, C. S., J. Miller, E. M. Muller, P. Edmunds, R. S. Nemeth, J. P. Beets,, ... and Voss, J. D. 2008. Ecology of coral reefs in the US Virgin Islands. In Coral Reefs of the USA. Springer Netherlands pp. 303-373.

Rowe, E., A.J. Mariano, and E.H. Ryan. 2010. "The Antilles Current". Ocean Surface Currents. http://oceancurrents.rsmas.miami.edu/atlantic/antilles.html.

Schrimm, M., R. Buscail, and M. Adjeroud. 2004. Spatial variability of the biogeochemical composition of surface sediments in an insular coral reef ecosystem: Moorea, French Polynesia. Estuarine, Coastal and Shelf Science, 60: $515-528$. 
Schwing, P. 2006. Regional climatology and anthropogenic impacts on coastal sedimentation patterns: St. John, USVI. (Senior Thesis, Eckerd College).

Self, R.F.L., A.R.M. Nowell, and P.A. Jumars. 1989. Factors controlling critical shears for deposition and erosion of individual grains. Marine Geology 86: 181-199.

Smith, S. R. 1992. Patterns of coral recruitment and post-settlement mortality on Bermuda's reefs: comparisons to Caribbean and Pacific reefs. American Zoologist 32: 663-673.

Smith, T.B., R.S. Nemeth, J. Blondeau, J.M. Calnan, E. Kadison, and S. Herzlieb. 2008. Assessing coral reef health across onshore to offshore stress gradients in the US Virgin Islands. Marine Pollution Bulletin 56(12): 1983-1991.

Smith, T.B., E. Kadison, L. Henderson, M.E. Brandt, J. Gyory, M. Kammann, V. Wright, and R.S. Nemeth. 2011. The United States Virgin Islands Territorial Coral Reef Monitoring Program. Year 11 Annual Report. Version $1243 \mathrm{pp}$

Storlazzi, C.D., M.E. Field, M.H. Bothner, M.K. Presto, and A.E. Draut. 2009. Sedimentation processes in a coral reef embayment: Hanalei Bay, Kauai. Marine Geology 264(3-4): 140-151.

Storlazzi, C.D., M.E. Field, and M.H. Bothner. 2011. The use (and misuse) of sediment traps in coral reef environments: Theory, observations, and suggested protocols. Coral Reefs 30: 23-38.

Thomas, T. and B. Devine. 2005. Island Peak to Coral Reef: A Field Guide to the Plant and Marine Communities of the Virgin Islands. UVI Press, Virgin Islands, $214 \mathrm{pp}$.

Tide-Forecast. 2014. Meteo365.com Ltd. http://www.tideforecast.com/locations/Lameshur-Bay-Saint-Johns-VirginIslands/tides/latest

Torres, J. L., and J. Morelock. 2002. Effect of terrigenous sediment influx on coral cover and linear extension rates of three Caribbean massive coral species. Caribbean Journal of Science 38: 222-229.

Towle, E., D. Grigg, and W. Rainey. 1976. Marine Environments of the Virgin Islands. Technical Supplement No. 1, Prepared for U.S. Virgin Islands Planning Office, St. Thomas.

UNEP. 1994. Guidelines for sediment control practices in the insular Caribbean. CEP Technical Report No. 32. UNEP Caribbean Programme, Kingston. 
USVI BER. 2010. United States Virgin Islands Bureau of Economic Resources. www.usviber.org

Weaver, P.L. J. D. Chinea-Rivera. 1987. A phytosociological study of Cinnamon Bay Watershed, St. John, U.S. Virgin Islands. Caribbean Journal of Science 23:318-336.

Weber, M., C. Lott, and K.E. Fabricius. 2006. Sedimentation stress in a scleractinian coral exposed to terrestrial and marine sediments with contrasting physical, organic and geochemical properties. Journal of Experimental Marine Biology and Ecology 336(1): 18-32.

Wentworth, C.K. 1922. A scale of grade and class terms for clastic sediments. The Journal of Geology 30(5): 377-392.

Wischmeier, W.H. and D.D. Smith. 1978. Predicting rainfall erosion losses - a guide to conservation planning. U.S. Department of Agriculture, Agriculture Handbook No. 537.

Wolanski, E., K. Fabricius, S. Spagnol, and R. Brinkman. 2005. Fine sediment budget on an inner-shelf coral-fringed island, Great Barrier Reef of Australia. Estuarine, Coastal and Shelf Science 65(1-2): 153-158.

WRI and NOAA. 2005. Land-based sources of threat to coral reefs in the US Virgin Islands. Washington, D.C.

Wüst, G. 1964. Stratification and Circulation in the Antillean-Caribbean Basins. Palisades, NY. 201 pp.

You, Z.J. 2005. Fine sediment resuspension dynamics in a large semi-enclosed bay. Ocean Engineering 32(16): 1982-1993.

Zitello, A.G., L.J. Bauer, T.A. Battista, P.W. Mueller, M.S. Kendall and M.E. Monaco. 2009. Shallow-Water Benthic Habitats of St. John, U.S. Virgin Islands. NOAA Technical Memorandum NOS NCCOS 96. Silver Spring, MD. 53 pp. 
Appendix I. Table of sediment traps, deployment year, location, and depth.

\begin{tabular}{|c|c|c|c|c|c|}
\hline Site & Deployment Year & Latitude & Longitude & Environment (*Undeveloped) & Depth (m) \\
\hline \multicolumn{6}{|c|}{ Lameshur Bay } \\
\hline TL1-2 & 2007 & 18.31872 & 64.72413 & Shore* & 0.5 \\
\hline TY-1 & 2007 & 18.31517 & 64.7252 & Reef* & 6.1 \\
\hline TY-2 & 2007 & 18.31502 & 64.72567 & Reef* & 7.6 \\
\hline TT-1 & 2009 & 18.30975 & 64.72192 & Reef* & 7 \\
\hline TL2-6 & 2010 & 18.3191 & 64.72802 & Shore* & 1.35 \\
\hline \multicolumn{6}{|c|}{ Coral Bay } \\
\hline TC-1B & 2009 & 18.33025 & 64.70453 & Shore & 1 \\
\hline $\mathrm{TC}-3 \mathrm{~B}$ & 2009 & 18.333 & 64.70706667 & Shore & 1.6 \\
\hline TC-5 & 2009 & 18.3465833 & 64.71415 & Shore & 0.6 \\
\hline TC-8 & 2008 & 18.3453333 & 64.71551667 & Shore & 0.6 \\
\hline TC-10B & 2009 & 18.33645 & 64.71221667 & Shore* & 1.3 \\
\hline TC-13 & 2010 & 18.3353667 & 64.71145 & Shore* & 1 \\
\hline TC-11 & 2009 & 18.3379667 & 64.70401667 & Reef & 7 \\
\hline TC-12 & 2009 & 18.3336333 & 64.7012 & Reef & 11 \\
\hline
\end{tabular}


Appendix II. Study period sampling periods with duration and deployment dates.

\begin{tabular}{|c|c|c|c|}
\hline Lameshur Dates & Duration (Days) & Coral Bay Dates & Duration (Days) \\
\hline $8 / 27 / 2007-9 / 19 / 2007$ & 22 & & \\
\hline $9 / 19 / 2007-10 / 3 / 2007$ & 14 & & \\
\hline $10 / 3 / 2007-10 / 14 / 2007$ & 11 & & \\
\hline $10 / 14 / 2007-10 / 23 / 2007$ & 9 & & \\
\hline $10 / 23 / 2007-11 / 3 / 2007$ & 11 & & \\
\hline $8 / 13 / 2008-8 / 21 / 2008$ & 8 & & \\
\hline $8 / 21 / 2008-9 / 2 / 2008$ & 13 & $8 / 18 / 2008-8 / 27 / 2008$ & 9 \\
\hline 9/2/2008-9/20/2008 & 18 & $8 / 27 / 2008-9 / 10 / 2008$ & 14 \\
\hline $9 / 20 / 2008-10 / 5 / 2008$ & 15 & $9 / 10 / 2008-9 / 30 / 2008$ & 20 \\
\hline $10 / 5 / 2008-10 / 25 / 2008$ & 20 & $9 / 30 / 2008-10 / 22 / 2008$ & 22 \\
\hline $10 / 25 / 2008-11 / 14 / 2008$ & 20 & $10 / 22 / 2008-11 / 13 / 2008$ & 22 \\
\hline $11 / 14 / 2008-12 / 6 / 2008$ & 22 & $11 / 13 / 2008-12 / 5 / 2008$ & 22 \\
\hline $12 / 6 / 2008-1 / 2 / 2009$ & 27 & $12 / 5 / 2008-12 / 31 / 2008$ & 26 \\
\hline $1 / 2 / 2009-1 / 23 / 2009$ & 21 & $12 / 31 / 2008-1 / 21 / 2009$ & 21 \\
\hline $1 / 23 / 2009-2 / 12 / 2009$ & 20 & $1 / 21 / 2009-2 / 13 / 2009$ & 23 \\
\hline $2 / 12 / 2009-3 / 6 / 2009$ & 22 & $2 / 13 / 2009-3 / 4 / 2009$ & 19 \\
\hline $3 / 6 / 2009-3 / 27 / 2009$ & 21 & $3 / 4 / 2009-3 / 25 / 2009$ & 21 \\
\hline $8 / 13 / 2009-8 / 21 / 2009$ & 8 & & \\
\hline $8 / 21 / 2009-9 / 2 / 2009$ & 12 & $8 / 22 / 2009-9 / 2 / 2009$ & 11 \\
\hline $8 / 24 / 2009-9 / 18 / 2009$ & 26 & 9/2/2009-9/16/2009 & 25 \\
\hline 9/18/2009-10/14/2009 & 25 & $9 / 16 / 2009-10 / 12 / 2009$ & 26 \\
\hline $10 / 14 / 2009-11 / 8 / 2009$ & 25 & $10 / 12 / 2009-11 / 7 / 2009$ & 26 \\
\hline $11 / 8 / 2009-12 / 3 / 2009$ & 25 & $11 / 7 / 2009-12 / 2 / 2009$ & 25 \\
\hline $12 / 3 / 2009-12 / 30 / 2009$ & 27 & $12 / 2 / 2009-12 / 29 / 2009$ & 27 \\
\hline $12 / 30 / 2009-1 / 25 / 2010$ & 24 & $12 / 29 / 2009-1 / 24 / 2010$ & 26 \\
\hline $1 / 25 / 2010-2 / 20 / 2010$ & 26 & $1 / 24 / 2010-2 / 19 / 2010$ & 26 \\
\hline $2 / 20 / 2010-3 / 19 / 2010$ & 27 & $2 / 19 / 2009-3 / 17 / 2010$ & 26 \\
\hline $8 / 7 / 2010-8 / 23 / 2010$ & 32 & $8 / 5 / 2010-8 / 20 / 2010$ & 17 \\
\hline $8 / 23 / 2010-9 / 18 / 2010$ & 26 & $8 / 20 / 2010-9 / 15 / 2010$ & 26 \\
\hline 9/18/2010-10/13/2010 & 25 & $9 / 15 / 2010-10 / 11 / 2010$ & 26 \\
\hline $10 / 13 / 2010-11 / 13 / 2010$ & 31 & $10 / 11 / 2010-11 / 8 / 2010$ & 28 \\
\hline $11 / 13 / 2010-12 / 4 / 2010$ & 21 & $11 / 8 / 2010-12 / 2 / 2010$ & 24 \\
\hline $12 / 4 / 2010-12 / 31 / 2010$ & 27 & $12 / 2 / 2010-12 / 29 / 2010$ & 27 \\
\hline $12 / 31 / 2010-1 / 25 / 2011$ & 24 & $12 / 29 / 2010-1 / 23 / 2011$ & 25 \\
\hline $1 / 25 / 2011-2 / 15 / 2011$ & 21 & $1 / 23 / 2011-2 / 13 / 2011$ & 21 \\
\hline $2 / 15 / 2011-3 / 18 / 2011$ & 31 & $2 / 13 / 2011-3 / 16 / 2011$ & 31 \\
\hline $3 / 18 / 2011-4 / 13 / 2011$ & 26 & $3 / 16 / 2011-4 / 11 / 2011$ & 26 \\
\hline $6 / 5 / 2011-7 / 1 / 2011$ & 26 & $6 / 3 / 2011-6 / 29 / 2011$ & 26 \\
\hline $7 / 1 / 2011-7 / 27 / 2011$ & 26 & $6 / 29 / 2011-7 / 25 / 2011$ & 26 \\
\hline $7 / 27 / 2011-8 / 26 / 2011$ & 30 & $7 / 25 / 2011-8 / 20 / 2011$ & 26 \\
\hline $8 / 26 / 2011-9 / 17 / 2011$ & 21 & $8 / 20 / 2011-9 / 15 / 2011$ & 26 \\
\hline 9/17/2011-10/13/2011 & 27 & 9/15/2011-10/11/2011 & 26 \\
\hline 10/13/2011-11/7/2011 & 25 & 10/11/2011-11/5/2011 & 25 \\
\hline $11 / 7 / 2011-12 / 3 / 2011$ & 26 & $11 / 5 / 2011-12 / 1 / 2011$ & 26 \\
\hline $12 / 3 / 2011-12 / 31 / 2011$ & 28 & $12 / 1 / 2011-12 / 29 / 2011$ & 28 \\
\hline $12 / 31 / 2011-1 / 24 / 2012$ & 24 & $12 / 29 / 2011-1 / 21 / 12$ & 23 \\
\hline $1 / 24 / 2012-2 / 18 / 2012$ & 25 & $1 / 21 / 12-2 / 15 / 12$ & 25 \\
\hline $2 / 18 / 2012-3 / 16 / 2012$ & 27 & $2 / 15 / 12-3 / 14 / 12$ & 28 \\
\hline $6 / 30 / 2012-7 / 26 / 2012$ & 26 & $6 / 28 / 12-7 / 24 / 12$ & 26 \\
\hline $7 / 26 / 2012-8 / 26 / 2012$ & 32 & $7 / 24 / 12-8 / 20 / 12$ & 27 \\
\hline $8 / 26 / 12-9 / 17 / 2012$ & 21 & $8 / 20 / 12-9 / 15 / 12$ & 26 \\
\hline 9/17/2012-10/13/2012 & 26 & $9 / 15 / 12-10 / 11 / 12$ & 26 \\
\hline $10 / 13 / 12-11 / 8 / 12$ & 26 & $10 / 11 / 12-11 / 6 / 12$ & 26 \\
\hline $11 / 8 / 12-12 / 2 / 12$ & 27 & $11 / 6 / 12-12 / 3 / 12$ & 27 \\
\hline $12 / 2 / 12-12 / 29 / 12$ & 28 & $12 / 3 / 12-12 / 28 / 12$ & 28 \\
\hline
\end{tabular}


Appendix III. \% Inorganic terrigenous sediments (\%T) at Coral Bay sites.

\begin{tabular}{|c|c|c|c|c|c|c|c|c|}
\hline \multirow[t]{2}{*}{ Sampling Date } & \multicolumn{4}{|c|}{ Developed Shore (\%T) } & \multicolumn{2}{|c|}{ Minimally Developed Shore (\%T) } & \multicolumn{2}{|c|}{\begin{tabular}{|l} 
Developed Reef (\%T) \\
\end{tabular}} \\
\hline & TC-1B & TC-3B & TC-5 & TC-8 & TC-10B & TC-13 & TC-11 & TC-12 \\
\hline $9 / 10 / 08$ & & & 83.5 & & & & & \\
\hline $9 / 30 / 08$ & & & 93.5 & & & & & \\
\hline $10 / 22 / 08$ & & & 92.8 & & & & & \\
\hline $11 / 13 / 08$ & & & 92.1 & & & & & \\
\hline $12 / 5 / 08$ & & & 90.5 & & & & & \\
\hline $12 / 31 / 08$ & & & 90.1 & & & & & \\
\hline $1 / 21 / 09$ & & & 87.8 & & & & & \\
\hline $2 / 13 / 09$ & & & 89.3 & & & & & \\
\hline $3 / 4 / 09$ & & & 90.2 & & & & & \\
\hline $3 / 25 / 09$ & & & 89.6 & & & & & \\
\hline $9 / 2 / 09$ & 35.5 & 72.4 & & & & & & \\
\hline $9 / 16 / 09$ & & 77.6 & 92.6 & 84.8 & 44.5 & & 28.5 & \\
\hline $10 / 12 / 09$ & 20.9 & 80.3 & 88.8 & 84.1 & 50.0 & & 27.3 & 17.1 \\
\hline $11 / 7 / 09$ & 43.4 & 79.7 & 87.6 & 86.9 & 42.1 & & 29.4 & 17.8 \\
\hline $12 / 2 / 09$ & 67.9 & 94.1 & 94.9 & 93.4 & 75.4 & & 29.8 & 19.2 \\
\hline $12 / 29 / 09$ & 43.8 & \begin{tabular}{|l|}
82.7 \\
\end{tabular} & 89.0 & 85.5 & 53.8 & & 29.4 & 15.2 \\
\hline $1 / 24 / 10$ & 43.6 & \begin{tabular}{|l|}
84.2 \\
\end{tabular} & 87.6 & 90.3 & 49.2 & & 26.5 & 17.1 \\
\hline $2 / 19 / 10$ & 43.4 & \begin{tabular}{|l|}
74.4 \\
\end{tabular} & 88.9 & 71.6 & 48.9 & & 27.1 & 15.3 \\
\hline $3 / 17 / 10$ & 42.2 & 82.6 & 85.1 & 84.6 & 48.8 & & 28.0 & 19.1 \\
\hline $6 / 5 / 10$ & & \begin{tabular}{|l|}
84.4 \\
\end{tabular} & \begin{tabular}{|l|}
91.4 \\
\end{tabular} & 85.8 & 50.2 & & 26.1 & 13.8 \\
\hline $7 / 25 / 10$ & 47.3 & \begin{tabular}{|l|}
89.2 \\
\end{tabular} & & & 65.8 & & 29.8 & 13.9 \\
\hline $8 / 20 / 10$ & 50.9 & 90.9 & 92.5 & 88.4 & 39.7 & 59.4 & 17.5 & 16.6 \\
\hline $9 / 15 / 10$ & \begin{tabular}{ll|}
46.9 \\
\end{tabular} & \begin{tabular}{|l|}
87.1 \\
\end{tabular} & 90.7 & 87.1 & 54.0 & 52.3 & 25.0 & 13.0 \\
\hline $10 / 11 / 10$ & 80.9 & \begin{tabular}{|l|}
92.6 \\
\end{tabular} & 96.5 & 91.8 & 94.7 & 93.2 & 29.9 & \\
\hline $11 / 8 / 10$ & $\begin{array}{ll}59.7 \\
\end{array}$ & \begin{tabular}{|l|}
91.6 \\
\end{tabular} & 92.0 & 74.6 & 82.6 & 72.6 & 33.6 & 11.8 \\
\hline $12 / 2 / 10$ & 60.3 & \begin{tabular}{|l|}
89.5 \\
\end{tabular} & 95.3 & 91.7 & 81.8 & 77.7 & 35.2 & 16.3 \\
\hline $12 / 29 / 11$ & 56.1 & \begin{tabular}{|l|}
89.6 \\
\end{tabular} & 90.8 & \begin{tabular}{|l|}
90.7 \\
\end{tabular} & 75.4 & 66.3 & 30.4 & 19.9 \\
\hline $1 / 23 / 11$ & 57.3 & \begin{tabular}{|l|}
89.6 \\
\end{tabular} & 93.3 & 91.3 & 71.4 & 60.2 & 31.3 & 16.8 \\
\hline $2 / 13 / 11$ & 54.9 & & 90.6 & 88.7 & 66.4 & 54.8 & 33.5 & 16.3 \\
\hline $3 / 16 / 11$ & 55.4 & \begin{tabular}{|l|}
88.9 \\
\end{tabular} & 93.5 & 88.5 & 67.7 & 59.2 & 47.9 & 17.5 \\
\hline $4 / 11 / 11$ & 55.4 & \begin{tabular}{|l|}
82.2 \\
\end{tabular} & 93.2 & 91.5 & 66.2 & 55.2 & 32.0 & 11.4 \\
\hline $6 / 3 / 11$ & & 82.0 & 92.0 & 90.9 & 57.5 & 53.9 & 31.9 & 8.8 \\
\hline $6 / 29 / 11$ & & \begin{tabular}{|l|}
78.8 \\
\end{tabular} & 91.5 & 89.2 & 64.1 & 52.2 & 31.2 & \\
\hline $7 / 25 / 11$ & 50.8 & \begin{tabular}{|l|}
79.5 \\
\end{tabular} & 90.2 & 90.1 & 58.5 & 65.0 & 32.6 & \\
\hline $8 / 20 / 11$ & 45.0 & \begin{tabular}{|l|}
73.2 \\
\end{tabular} & 90.7 & 90.3 & 57.8 & 49.1 & 28.4 & 10.8 \\
\hline $9 / 15 / 11$ & 38.3 & & \begin{tabular}{|l|}
91.3 \\
\end{tabular} & 89.8 & 54.6 & 48.6 & 24.3 & 9.1 \\
\hline $10 / 11 / 11$ & 41.3 & \begin{tabular}{|l|}
75.3 \\
\end{tabular} & 94.3 & 90.5 & 49.9 & 55.4 & 32.1 & 19.4 \\
\hline $11 / 5 / 11$ & 43.5 & \begin{tabular}{|l|}
73.9 \\
\end{tabular} & 91.8 & 82.2 & 59.8 & 53.1 & 34.4 & 19.6 \\
\hline $12 / 1 / 12$ & 43.9 & \begin{tabular}{|l|}
73.8 \\
\end{tabular} & 94.0 & 91.0 & 62.1 & 60.2 & 30.6 & 20.0 \\
\hline $12 / 29 / 11$ & 40.2 & \begin{tabular}{|l|}
75.2 \\
\end{tabular} & 93.1 & 90.6 & 57.5 & 53.9 & 32.5 & 16.1 \\
\hline $1 / 21 / 12$ & \begin{tabular}{ll|}
39.7 \\
\end{tabular} & \begin{tabular}{|l|}
72.5 \\
\end{tabular} & 91.2 & 88.6 & 53.8 & 51.1 & 32.2 & 16.3 \\
\hline $2 / 15 / 12$ & 37.5 & & 91.2 & 91.9 & 52.9 & 48.5 & 35.2 & 17.9 \\
\hline $3 / 14 / 12$ & 38.6 & \begin{tabular}{|l|}
75.2 \\
\end{tabular} & 90.6 & 89.1 & 53.5 & 49.3 & 28.6 & 16.1 \\
\hline $5 / 10 / 12$ & 39.5 & \begin{tabular}{|l|}
82.0 \\
\end{tabular} & 90.5 & 91.2 & 48.2 & 42.1 & 34.8 & 20.0 \\
\hline $6 / 28 / 12$ & & & 88.5 & 75.8 & 51.8 & & 32.6 & 15.9 \\
\hline $7 / 24 / 12$ & \begin{tabular}{ll|}
44.8 \\
\end{tabular} & \begin{tabular}{|l|}
87.2 \\
\end{tabular} & 86.8 & 87.8 & 34.0 & 48.7 & 30.1 & 19.5 \\
\hline $8 / 20 / 12$ & 32.5 & \begin{tabular}{|l|}
84.0 \\
\end{tabular} & 90.8 & 87.5 & 54.1 & 47.2 & 30.6 & 9.9 \\
\hline $9 / 15 / 12$ & 37.2 & 72.9 & 81.4 & & 48.3 & 43.0 & 28.3 & 6.2 \\
\hline $10 / 11 / 12$ & 26.5 & \begin{tabular}{|l|}
67.1 \\
\end{tabular} & 74.1 & & 48.4 & 47.2 & 32.5 & 16.0 \\
\hline $11 / 6 / 12$ & 36.7 & 72.6 & 91.1 & & 53.0 & 40.0 & 31.3 & 14.9 \\
\hline $12 / 3 / 12$ & 33.7 & \begin{tabular}{|l|}
72.1 \\
\end{tabular} & 91.1 & & 55.8 & 54.7 & 19.0 & 37.3 \\
\hline $12 / 28 / 12$ & 32.5 & \begin{tabular}{|l|}
69.7 \\
\end{tabular} & \begin{tabular}{|l|}
90.5 \\
\end{tabular} & 82.1 & 37.8 & 19.4 & 33.3 & 16.5 \\
\hline
\end{tabular}


Appendix III (cont.). \% Inorganic terrigenous sediments (\%T) at Lameshur Bay sites.

\begin{tabular}{|c|c|c|c|c|c|}
\hline Sampling Date & Minimally [ & Shore (\%T) & Minima & velop & ef (\%T) \\
\hline & TL1-2 & TL2-6 & TY-1 & TY-2 & $\pi-1$ \\
\hline $9 / 19 / 07$ & 32.2 & & 6.4 & 8.3 & \\
\hline $10 / 3 / 07$ & 22.9 & & 19.3 & 7.0 & \\
\hline $10 / 14 / 07$ & 29.0 & & 4.9 & 3.7 & \\
\hline $10 / 23 / 07$ & 28.0 & & 20.9 & 5.5 & \\
\hline $11 / 3 / 07$ & 29.3 & & 6.4 & 8.2 & \\
\hline $11 / 16 / 07$ & 13.4 & & 4.2 & 12.5 & \\
\hline $11 / 30 / 07$ & 20.0 & & 3.7 & 4.7 & \\
\hline $8 / 21 / 08$ & 48.8 & & 18.1 & 9.9 & \\
\hline $8 / 27 / 08$ & 45.6 & & 18.5 & 16.9 & \\
\hline $9 / 10 / 08$ & 22.4 & & 12.1 & 10.3 & \\
\hline $9 / 30 / 08$ & 39.5 & & 13.3 & 14.4 & \\
\hline $10 / 22 / 08$ & 38.3 & & 9.5 & 7.6 & \\
\hline $11 / 13 / 08$ & 58.8 & & 17.8 & 16.6 & \\
\hline $12 / 5 / 08$ & 32.1 & & 19.0 & 19.7 & \\
\hline $12 / 31 / 08$ & 42.9 & & 17.7 & 18.7 & \\
\hline $1 / 21 / 09$ & 43.2 & & 18.1 & 17.3 & \\
\hline $2 / 13 / 09$ & 22.8 & & 16.9 & 17.9 & \\
\hline $3 / 4 / 09$ & 54.8 & & 14.9 & 16.7 & \\
\hline $3 / 25 / 09$ & 47.3 & & 17.5 & 13.3 & \\
\hline $9 / 2 / 09$ & 39.9 & & & & \\
\hline $9 / 16 / 09$ & 37.6 & & 15.9 & 16.8 & 21.2 \\
\hline $10 / 12 / 09$ & 15.4 & & 20.6 & 17.6 & 11.5 \\
\hline $11 / 7 / 09$ & 39.4 & & 12.3 & 18.5 & 21.3 \\
\hline $12 / 2 / 09$ & 43.0 & & 16.0 & 18.9 & 20.6 \\
\hline $12 / 29 / 09$ & 46.5 & & 17.6 & 17.2 & 19.2 \\
\hline $1 / 24 / 10$ & 40.5 & & 16.3 & 11.4 & 9.9 \\
\hline $2 / 19 / 10$ & 45.2 & & 6.3 & 10.5 & 8.6 \\
\hline $3 / 17 / 10$ & 37.5 & & 12.0 & 14.7 & 0.9 \\
\hline $7 / 25 / 10$ & 46.5 & & 17.6 & 16.4 & 18.6 \\
\hline $8 / 20 / 10$ & 48.3 & 61.9 & & 19.9 & 4.0 \\
\hline $9 / 15 / 10$ & 11.9 & 13.2 & 6.3 & 4.9 & 15.5 \\
\hline $10 / 11 / 10$ & 28.9 & 34.9 & 7.5 & 6.6 & 11.3 \\
\hline $11 / 8 / 10$ & 37.9 & 92.1 & 22.8 & 14.4 & 21.6 \\
\hline $12 / 2 / 10$ & 59.5 & 50.3 & 61.1 & 20.5 & 28.8 \\
\hline $12 / 29 / 11$ & 35.9 & 43.3 & 24.0 & 25.0 & 24.2 \\
\hline $1 / 23 / 11$ & 30.5 & 43.9 & 23.8 & 24.0 & 23.3 \\
\hline $2 / 13 / 11$ & 23.3 & 38.8 & 20.7 & 17.5 & \\
\hline $3 / 16 / 11$ & 35.5 & 34.2 & 22.0 & 11.0 & 12.7 \\
\hline $4 / 11 / 11$ & 44.8 & 33.5 & 20.5 & 23.8 & 22.7 \\
\hline $6 / 3 / 11$ & 33.9 & 31.5 & 14.2 & 17.1 & 17.6 \\
\hline $6 / 29 / 11$ & 41.5 & 27.7 & 16.5 & 3.3 & 35.7 \\
\hline $7 / 25 / 11$ & 90.5 & 39.1 & 23.0 & & \\
\hline $8 / 20 / 11$ & 58.5 & 29.6 & 13.5 & 10.9 & 16.2 \\
\hline $9 / 15 / 11$ & 49.6 & 34.0 & 24.5 & 23.5 & 24.6 \\
\hline $10 / 11 / 11$ & 46.3 & 54.8 & 29.0 & 19.5 & 24.7 \\
\hline $11 / 5 / 11$ & 55.7 & 39.9 & 27.8 & 25.8 & 10.9 \\
\hline $12 / 1 / 12$ & 36.0 & 37.9 & 24.6 & 26.2 & 25.3 \\
\hline $12 / 29 / 11$ & 46.3 & 38.2 & 23.4 & 26.8 & 24.6 \\
\hline $1 / 21 / 12$ & 47.8 & 35.7 & 25.1 & 23.2 & 26.1 \\
\hline $2 / 15 / 12$ & 41.8 & 33.6 & 15.6 & 19.3 & 26.3 \\
\hline $3 / 14 / 12$ & 48.0 & 52.3 & 16.5 & 21.4 & 23.4 \\
\hline $5 / 10 / 12$ & 37.3 & 37.0 & 14.5 & 25.9 & 11.5 \\
\hline $6 / 28 / 12$ & 45.8 & 21.5 & 30.9 & 17.8 & 19.4 \\
\hline $7 / 24 / 12$ & 55.7 & 29.0 & 12.5 & 23.1 & 21.4 \\
\hline $8 / 20 / 12$ & 36.6 & 23.4 & 7.7 & 7.8 & 13.0 \\
\hline $9 / 15 / 12$ & 41.9 & 37.5 & 15.5 & 18.8 & 23.1 \\
\hline $10 / 11 / 12$ & 39.4 & 32.4 & 21.0 & 23.8 & 21.4 \\
\hline $11 / 6 / 12$ & 43.1 & 30.4 & 18.4 & 19.1 & 17.9 \\
\hline $12 / 3 / 12$ & 31.9 & 26.7 & 21.2 & 25.3 & 23.6 \\
\hline $12 / 28 / 12$ & 45.9 & 30.2 & 11.4 & 20.6 & 9.7 \\
\hline
\end{tabular}


Appendix III (cont.). Terrigenous sediment accumulation rates (TAR, $\mathrm{mg} / \mathrm{cm}^{2} / \mathrm{d}$ ) at Coral Bay sites.

\begin{tabular}{|c|c|c|c|c|c|c|c|c|}
\hline \multirow[t]{2}{*}{ Sampling Date } & \multicolumn{4}{|c|}{ Developed Shore (TAR) } & \multicolumn{2}{|c|}{ Minimally Developed Shore (TAR) } & \multicolumn{2}{|c|}{ Developed Reef (TAR) } \\
\hline & TC-1B & \begin{tabular}{|l|} 
TC-3B \\
\end{tabular} & TC-5 & TC-8 & TC-10B & TC-13 & TC-11 & TC-12 \\
\hline $9 / 10 / 08$ & & & 7.8 & & & & & \\
\hline $9 / 30 / 08$ & & & 15.5 & & & & & \\
\hline $10 / 22 / 08$ & & & 19.5 & & & & & \\
\hline $11 / 13 / 08$ & & & 12.3 & & & & & \\
\hline $12 / 5 / 08$ & & & 13.7 & & & & & \\
\hline $12 / 31 / 08$ & & & 8.1 & & & & & \\
\hline $1 / 21 / 09$ & & & 12.8 & & & & & \\
\hline $2 / 13 / 09$ & & & 7.0 & & & & & \\
\hline $3 / 4 / 09$ & & & 11.3 & & & & & \\
\hline $3 / 25 / 09$ & & & 2.9 & & & & & \\
\hline $9 / 2 / 09$ & 4.5 & 26.0 & & & & & & \\
\hline $9 / 16 / 09$ & & 30.3 & 6.6 & 7.8 & 1.5 & & & \\
\hline $10 / 12 / 09$ & 0.4 & 6.0 & 4.3 & 7.6 & 0.8 & & 0.4 & 0.3 \\
\hline $11 / 7 / 09$ & 0.8 & 3.9 & 3.7 & 9.0 & 0.6 & & 0.6 & 0.3 \\
\hline $12 / 2 / 09$ & 2.7 & 31.0 & 13.2 & 11.6 & 4.0 & & 0.8 & 0.4 \\
\hline $12 / 29 / 09$ & 7.1 & 60.8 & 20.2 & & 5.0 & & 1.6 & 1.2 \\
\hline $1 / 24 / 10$ & 2.8 & 26.5 & 5.3 & 5.7 & 1.4 & & 0.8 & 0.5 \\
\hline $2 / 19 / 10$ & 3.7 & 11.9 & 9.8 & 1.3 & 3.0 & & 1.3 & 0.8 \\
\hline $3 / 17 / 10$ & 0.9 & 1.7 & 3.8 & 6.4 & 0.7 & & 0.6 & 0.4 \\
\hline $6 / 5 / 10$ & & 3.0 & 6.3 & 9.8 & 1.8 & & 0.6 & 0.4 \\
\hline $7 / 25 / 10$ & 7.8 & 47.9 & & & 8.0 & & 1.4 & 1.4 \\
\hline $8 / 20 / 10$ & 0.8 & 2.0 & 12.4 & 0.9 & & 1.2 & 0.4 & 0.3 \\
\hline $9 / 15 / 10$ & 9.0 & 76.2 & 21.8 & 16.2 & 1.9 & 4.4 & 1.5 & 1.5 \\
\hline $10 / 11 / 10$ & 36.1 & \begin{tabular}{|l|}
253.6 \\
\end{tabular} & 49.8 & 48.9 & 61.8 & 98.4 & 2.1 & \\
\hline $11 / 8 / 10$ & 32.0 & \begin{tabular}{|l|}
195.1 \\
\end{tabular} & 34.5 & 17.4 & 45.3 & 41.8 & 3.4 & 3.8 \\
\hline $12 / 2 / 10$ & 0.9 & 23.1 & 12.4 & 22.0 & 6.9 & 5.5 & 0.8 & 0.5 \\
\hline $12 / 29 / 10$ & 5.1 & 32.1 & 13.3 & 13.1 & 4.1 & 4.0 & 1.1 & 0.5 \\
\hline $1 / 23 / 11$ & 14.4 & 57.0 & 21.8 & 12.5 & 6.3 & 5.7 & 1.7 & 1.3 \\
\hline $2 / 13 / 11$ & 17.1 & & 28.6 & 26.4 & 4.2 & 5.8 & 1.8 & 1.6 \\
\hline $3 / 16 / 11$ & 3.9 & 29.6 & 7.9 & 8.1 & 1.0 & 1.0 & 0.4 & 0.3 \\
\hline $4 / 11 / 11$ & 7.6 & 12.6 & \begin{tabular}{|l|}
18.4 \\
\end{tabular} & 20.0 & 2.0 & 2.3 & 0.8 & 0.6 \\
\hline $6 / 3 / 11$ & & 8.3 & 11.8 & 12.1 & 1.7 & 1.1 & 0.8 & 0.3 \\
\hline $6 / 29 / 11$ & & 6.8 & 12.8 & 7.2 & 2.1 & 3.0 & 0.8 & \\
\hline $7 / 25 / 11$ & 12.4 & 16.3 & \begin{tabular}{|l|}
13.2 \\
\end{tabular} & 13.2 & 4.4 & 0.4 & 1.8 & \\
\hline $8 / 20 / 11$ & 14.9 & 15.6 & 19.7 & 18.3 & 7.7 & 14.3 & 3.2 & 2.3 \\
\hline $9 / 15 / 11$ & 16.7 & & 24.2 & 21.8 & 22.1 & 64.5 & 7.4 & 11.4 \\
\hline $10 / 13 / 11$ & 11.8 & 51.2 & 11.1 & 13.6 & 1.2 & 3.2 & 0.9 & 0.6 \\
\hline $11 / 5 / 11$ & 2.2 & 11.2 & 9.7 & 9.3 & 1.6 & 1.9 & 0.7 & 0.4 \\
\hline $12 / 1 / 11$ & 2.6 & 11.8 & 13.6 & 11.4 & 2.0 & 5.3 & 0.9 & 0.6 \\
\hline $12 / 29 / 11$ & 5.2 & 45.2 & 12.8 & & 3.0 & 3.3 & 1.0 & 0.6 \\
\hline $1 / 21 / 12$ & 17.8 & 85.3 & 15.9 & 15.1 & 3.9 & 9.4 & 3.0 & 1.6 \\
\hline $2 / 15 / 12$ & 5.7 & & 20.8 & 22.2 & 2.7 & 4.5 & 1.5 & 0.7 \\
\hline $3 / 14 / 12$ & 13.3 & 64.8 & 12.1 & 37.9 & 5.9 & 8.9 & 1.1 & 1.4 \\
\hline $7 / 24 / 12$ & 12.1 & & 7.5 & 28.8 & 0.8 & 3.0 & 1.3 & 0.8 \\
\hline $8 / 20 / 12$ & 25.0 & & 14.8 & 21.9 & 8.5 & 25.0 & 3.9 & 4.0 \\
\hline $9 / 15 / 12$ & 76.3 & & 23.4 & & 8.6 & 53.3 & 9.0 & 8.2 \\
\hline $10 / 11 / 12$ & 6.0 & 11.8 & 2.9 & & 1.5 & 1.4 & 0.9 & 0.3 \\
\hline $11 / 5 / 12$ & 46.6 & \begin{tabular}{|l|}
122.3 \\
\end{tabular} & \begin{tabular}{|l|}
2.5 \\
11.3
\end{tabular} & & 3.8 & 1.2 & 1.6 & 1.3 \\
\hline $12 / 3 / 12$ & 7.7 & 32.7 & 7.0 & & 1.2 & 1.6 & 0.3 & 1.0 \\
\hline $12 / 28 / 12$ & 31.5 & \begin{tabular}{|l|}
113.6 \\
\end{tabular} & 9.3 & 13.5 & 1.0 & 0.2 & 1.4 & 0.4 \\
\hline
\end{tabular}


Appendix III (cont.). Terrigenous sediment accumulation rates (TAR, $\mathrm{mg} / \mathrm{cm}^{2} / \mathrm{d}$ ) at Coral Bay sites.

\begin{tabular}{|c|c|c|c|c|c|}
\hline Sampling Date & Minimally D & Shore (TAR) & Minima & elop & f (TAR) \\
\hline & TL1-2 & TL2-6 & TY-1 & TY-2 & TT-1 \\
\hline $9 / 19 / 07$ & 0.6 & & 0.2 & 0.2 & \\
\hline $10 / 3 / 07$ & 0.4 & & 0.5 & 0.6 & \\
\hline $10 / 14 / 07$ & 0.7 & & 0.3 & 0.3 & \\
\hline $10 / 23 / 07$ & 0.7 & & 0.1 & 0.2 & \\
\hline $11 / 3 / 07$ & 3.1 & & 0.6 & 0.7 & \\
\hline $11 / 16 / 17$ & 1.4 & & 0.4 & 0.4 & \\
\hline $11 / 30 / 07$ & 1.7 & & 0.4 & 0.3 & \\
\hline $8 / 21 / 08$ & 1.7 & & 0.2 & 0.1 & \\
\hline $8 / 27 / 08$ & 0.4 & & 0.3 & 1.9 & \\
\hline 9/10/08 & 0.4 & & 1.7 & 1.6 & \\
\hline $9 / 30 / 08$ & 0.9 & & 0.3 & 0.3 & \\
\hline $10 / 22 / 08$ & 4.8 & & 7.6 & 7.0 & \\
\hline $11 / 13 / 08$ & 1.8 & & 0.1 & 0.1 & \\
\hline $12 / 5 / 08$ & 0.5 & & 0.2 & 0.2 & \\
\hline $12 / 31 / 08$ & 0.8 & & 0.2 & 0.2 & \\
\hline $1 / 21 / 09$ & 0.7 & & 0.3 & 0.2 & \\
\hline $2 / 13 / 09$ & 0.2 & & 0.2 & 0.2 & \\
\hline $3 / 4 / 09$ & 0.8 & & 0.3 & 0.2 & \\
\hline $3 / 25 / 09$ & 0.2 & & 0.1 & 0.1 & \\
\hline $8 / 21 / 09$ & 1.8 & & 0.2 & 0.0 & 0.1 \\
\hline $9 / 2 / 09$ & 1.2 & & & & \\
\hline $9 / 16 / 09$ & 1.6 & & 0.1 & 0.2 & 0.1 \\
\hline $10 / 12 / 09$ & 1.9 & & 0.2 & 0.2 & 0.1 \\
\hline $11 / 7 / 09$ & 1.0 & & 0.1 & 0.2 & 0.2 \\
\hline $12 / 2 / 09$ & 2.6 & & 0.2 & 0.3 & 0.2 \\
\hline $12 / 29 / 09$ & 2.8 & & 0.2 & 0.2 & 0.1 \\
\hline $1 / 24 / 10$ & 1.6 & & 0.2 & 0.2 & 0.1 \\
\hline $2 / 19 / 10$ & 2.0 & & 0.1 & 0.1 & 0.1 \\
\hline $3 / 17 / 10$ & 1.2 & & 0.2 & 0.2 & 0.0 \\
\hline $7 / 25 / 10$ & 1.3 & & 0.1 & 0.1 & 0.1 \\
\hline $8 / 20 / 10$ & 0.5 & 1.3 & & 0.1 & 0.0 \\
\hline $9 / 15 / 10$ & 66.8 & 35.5 & 7.5 & 10.3 & 20.7 \\
\hline $10 / 11 / 10$ & 140.5 & 58.0 & 11.2 & 9.0 & 22.6 \\
\hline $11 / 8 / 10$ & 5.2 & 4.6 & 0.5 & 0.2 & 0.2 \\
\hline $12 / 2 / 10$ & 4.7 & 1.7 & 0.7 & 0.1 & 0.3 \\
\hline $12 / 29 / 10$ & 2.3 & 2.1 & 0.4 & 0.1 & 0.3 \\
\hline $1 / 23 / 11$ & 1.1 & 3.3 & 0.3 & 0.2 & 0.2 \\
\hline $2 / 13 / 11$ & 1.0 & 2.9 & 0.2 & 0.2 & \\
\hline $3 / 16 / 11$ & 0.1 & 0.2 & 0.2 & 0.1 & 0.1 \\
\hline $4 / 11 / 11$ & 0.2 & 0.5 & 0.2 & 0.1 & 0.2 \\
\hline $6 / 3 / 11$ & 0.1 & 1.0 & 0.2 & 0.2 & 0.1 \\
\hline $6 / 29 / 11$ & 0.2 & 1.4 & 0.1 & 0.0 & 0.0 \\
\hline $7 / 25 / 11$ & 0.2 & 2.0 & 0.2 & 0.0 & 0.0 \\
\hline $8 / 20 / 11$ & 2.8 & 4.8 & 1.3 & 1.3 & 1.1 \\
\hline $9 / 15 / 11$ & 2.2 & 1.5 & 0.4 & 0.3 & 0.3 \\
\hline $10 / 13 / 11$ & 1.5 & 1.8 & 0.3 & 0.2 & 0.2 \\
\hline $11 / 5 / 11$ & 1.8 & 1.2 & 0.4 & 0.4 & 0.3 \\
\hline $12 / 1 / 11$ & 0.8 & 0.7 & 0.2 & 0.2 & 0.2 \\
\hline $12 / 29 / 11$ & 1.1 & 1.1 & 0.2 & 0.3 & 0.2 \\
\hline $1 / 21 / 12$ & 1.5 & 1.3 & 0.3 & 0.4 & 0.3 \\
\hline $2 / 15 / 12$ & 0.7 & 0.4 & 0.2 & 0.3 & 0.3 \\
\hline $3 / 14 / 12$ & 0.6 & 0.5 & 0.2 & 0.4 & 0.3 \\
\hline $7 / 24 / 12$ & 1.7 & 0.6 & 0.1 & 0.3 & 0.1 \\
\hline $8 / 20 / 12$ & 5.9 & 2.9 & 1.8 & 2.7 & 2.0 \\
\hline $9 / 15 / 12$ & 0.4 & 0.2 & 0.2 & 0.1 & 0.1 \\
\hline $10 / 11 / 12$ & 0.7 & 0.5 & 0.3 & 0.3 & 0.2 \\
\hline $11 / 5 / 12$ & 1.7 & 2.1 & 0.5 & 0.3 & 0.4 \\
\hline $12 / 3 / 12$ & 0.3 & 0.3 & 0.2 & 0.2 & 0.1 \\
\hline $12 / 28 / 12$ & 0.9 & 0.6 & 0.2 & 0.2 & 0.1 \\
\hline
\end{tabular}


Appendix IV. Resuspension of Sediments

One approach that has been used to evaluate the contribution of sediment resuspension to sediment trap accumulation is to compare sediment similarity in terms of a particular sedimentological parameter between trap and benthic sediments (Bloesch 1994). This approach assumes that the process of sediment resuspension will transfer benthic sediment from the sea floor into the sediment traps. Therefore, greater resuspension should produce greater similarity between trap and benthic sediments. In this section, similarities between benthic and trap sediment $(\% \mathrm{~T})$ and mean grain sizes will be discussed and compared between sampling periods.

\% Terrigenous Trap to Bottom Sediment Ratios: Low vs. High Rain/Nonstorm vs. Storm Periods

Significant differences between mean ratios ( $\% \mathrm{~T}$ of trap sediments $/ \% \mathrm{~T}$ of benthic sediments) during sampling periods with high $(>3 \mathrm{~mm} / \mathrm{d})$ vs. low $(<3$ $\mathrm{mm} / \mathrm{d}$ ) rainfall were only found at two sites: Plantation Hill North and Coral Bay Reef North. At Plantation Hill North, a trap below a watershed with minimal development in Coral Bay, the mean "low rain" and "high rain" ratios were 1.14 and 1.41, respectively (One-way ANOVA: $d f=35 ; \mathrm{F}=4.611$; $\mathrm{p}$-value: 0.039 ). Thus, trap and bottom sediments were found to be most similar during periods with low rainfall at Plantation Hill North. At Coral Bay Reef North, a reef site in Coral Bay, mean trap/bottom ratios during "low rain" and "high rain" were 5.62 and 3.49, respectively (One-way ANOVA: $\mathrm{df}=35 ; \mathrm{F}=10.557$; $\mathrm{p}$-value $=0.003$ ), indicating that sediments were most similar during high rainfall conditions.

Only at one site Plantation Hill North, were there significant differences in ratios when storm periods were compared with non-storm periods. Mean ratios during non-storm and storms periods were 1.14 and 1.42, respectively (One-way ANOVA: $\mathrm{df}=35 ; \mathrm{F}=6.041$; $\mathrm{p}$-value: 0.019$)$. Thus, trap and bottom sediments were found to be most similar during periods with no storms.

Mean Grain Size Trap to Bottom Ratios: Low Rain vs. High Rain/Nonstorm vs. Storm Periods

For most sites, mean grain size was coarser in bottom sediments than in trap sediments during both low and high rainfall sampling periods and storm and non-storm periods. However, at TC-1B and TC-3B (collectively, Coral South Shore), mean grain sizes were coarser in trap sediments during low rain scenarios, and during both storm and non-storm periods. At the majority of sites, trap and bottom mean grain sizes were most similar during periods with high rainfall and periods that contained storms (exceptions: TC-5 and TC-10B: most similar during low rainfall; TC-10B, TL2-6, TL1-2, and TT-1 were most similar during nonstorms). However, no significant differences in mean ratios in low versus high rain and storm vs. non-storm scenarios were found. 
Appendix V. Mean, median, and mode grain size $[\mu \mathrm{m}]$ of sediment trap sediment and $\%$ trap sediment less than $75 \mu \mathrm{m}$ at TC-1B.

\begin{tabular}{|c|c|c|c|c|c|c|}
\hline Sample Name & Date Collected & Mean (um) & S.D. (um) & Median (um) & Mode (um) & $<75$ um (\%) \\
\hline TC-1B & $9 / 2 / 2009$ & 161.8 & 197.8 & 101.0 & 168.9 & 40.6 \\
\hline TC-1B & $10 / 12 / 2009$ & 330.5 & 416.3 & 158.3 & 168.9 & 31.6 \\
\hline TC-1B & $11 / 7 / 2009$ & 146.7 & 196.7 & 78.8 & 105.9 & 48.5 \\
\hline TC-1B & $12 / 2 / 2009$ & 123.7 & 188.7 & 55.8 & 66.5 & 59.2 \\
\hline TC-1B & $12 / 29 / 2009$ & 102.9 & 120.4 & 63.4 & 66.5 & 55.8 \\
\hline TC-1B & $1 / 24 / 2009$ & 151.4 & 303.9 & 59.5 & 60.5 & 58.2 \\
\hline TC-1B & $2 / 19 / 2009$ & 223.3 & 395.4 & 73.3 & 66.5 & 50.8 \\
\hline TC-1B & $3 / 17 / 2010$ & 183.5 & 294.1 & 68.4 & 66.5 & 52.6 \\
\hline TC-1B & $8 / 20 / 2010$ & 134.4 & 231.6 & 51.3 & 60.5 & 61.2 \\
\hline TC-1B & $10 / 11 / 2010$ & 115.8 & 150.9 & 65.5 & 80.1 & 54.3 \\
\hline TC-1B & $11 / 8 / 2010$ & 142.4 & 174.5 & 82.9 & 168.9 & 47.4 \\
\hline TC-1B & $12 / 2 / 2010$ & 130.9 & 198.4 & 62.2 & 60.5 & 55.7 \\
\hline TC-1B & $12 / 29 / 2010$ & 118.9 & 179.2 & 62.4 & 66.5 & 56.4 \\
\hline TC-1B & $1 / 23 / 2011$ & 143.1 & 188.2 & 78.4 & 168.9 & 48.8 \\
\hline TC-1B & $2 / 13 / 2011$ & 155.3 & 158.1 & 106.4 & 203.5 & 40.5 \\
\hline TC-1B & $3 / 16 / 2011$ & 160.1 & 212.5 & 83.6 & 185.4 & 47.5 \\
\hline TC-1B & $4 / 11 / 2011$ & 137.0 & 185.6 & 71.3 & 153.8 & 51.4 \\
\hline TC-1B & $6 / 29 / 2011$ & 180.9 & 233.6 & 95.3 & 116.3 & 42.7 \\
\hline TC-1B & $7 / 25 / 2011$ & 150.3 & 175.9 & 99.3 & 153.8 & 40.5 \\
\hline TC-1B & $8 / 20 / 2011$ & 125.9 & 179.0 & 64.2 & 80.1 & 54.7 \\
\hline TC-1B & $9 / 15 / 2011$ & 172.1 & 223.6 & 93.0 & 153.8 & 43.7 \\
\hline TC-1B & $10 / 11 / 2011$ & 161.6 & 201.7 & 97.8 & 168.9 & 42.2 \\
\hline TC-1B & $11 / 5 / 2011$ & 140.4 & 185.1 & 76.2 & 72.9 & 49.5 \\
\hline TC-1B & $12 / 1 / 2011$ & 112.2 & 162.6 & 59.7 & 80.1 & 57.1 \\
\hline TC-1B & $12 / 29 / 2011$ & 147.0 & 184.2 & 84.7 & 105.9 & 46.1 \\
\hline TC-1B & $1 / 21 / 2012$ & 175.5 & 201.4 & 110.5 & 185.4 & 38.0 \\
\hline TC-1B & $2 / 15 / 2012$ & 157.0 & 203.6 & 85.2 & 72.9 & 45.9 \\
\hline TC-1B & $3 / 14 / 2012$ & 144.3 & 185.2 & 79.4 & 72.9 & 48.2 \\
\hline TC-1B & $7 / 24 / 2012$ & 192.5 & 258.0 & 96.8 & 168.9 & 42.7 \\
\hline TC-1B & $8 / 20 / 2012$ & 127.3 & 175.2 & 68.0 & 80.1 & 53.2 \\
\hline TC-1B & $9 / 15 / 2012$ & 175.8 & 230.1 & 100.0 & 116.3 & 40.4 \\
\hline TC-1B & $10 / 11 / 2012$ & 258.5 & 302.5 & 152.1 & 168.9 & 28.7 \\
\hline TC-1B & $11 / 6 / 2012$ & 212.1 & 256.9 & 124.1 & 153.8 & 34.2 \\
\hline TC-1B & $12 / 3 / 2012$ & 252.7 & 304.5 & 140.0 & 223.4 & 33.6 \\
\hline TC-1B & $12 / 28 / 2012$ & 203.4 & 273.2 & 106.5 & 140.1 & 39.1 \\
\hline & & & & & & \\
\hline
\end{tabular}


Appendix V (cont.). Mean, median, and mode grain size $[\mu \mathrm{m}]$ of sediment trap sediment and $\%$ trap sediment less than $75 \mu \mathrm{m}$ at TC-3B.

\begin{tabular}{|c|c|c|c|c|c|c|}
\hline Sample Name & Date Collected & Mean (um) & S.D. (um) & Median (um) & Mode (um) & $<75$ um (\%) \\
\hline TC-3B & $9 / 2 / 2009$ & 186.0 & 253.8 & 89.6 & 80.1 & 42.5 \\
\hline TC-3B & $10 / 12 / 2009$ & 91.0 & 152.0 & 32.5 & 28.7 & 72.2 \\
\hline TC-3B & $11 / 7 / 2009$ & 120.1 & 184.9 & 45.6 & 28.7 & 61.0 \\
\hline TC-3B & $12 / 2 / 2009$ & 90.2 & 138.5 & 47.9 & 60.5 & 66.6 \\
\hline TC-3B & $12 / 29 / 2009$ & 180.0 & 293.2 & 76.5 & 72.9 & 49.2 \\
\hline TC-3B & $1 / 24 / 2010$ & 169.5 & 208.2 & 89.3 & 66.5 & 44.7 \\
\hline TC-3B & $2 / 19 / 2010$ & 260.6 & 405.9 & 74.8 & 66.5 & 50.1 \\
\hline TC-3B & $3 / 17 / 2010$ & 122.1 & 195.6 & 44.8 & 28.7 & 61.6 \\
\hline TC-3B & $8 / 20 / 2010$ & 216.4 & 370.9 & 67.7 & 168.9 & 52.5 \\
\hline TC-3B & $9 / 15 / 2010$ & 159.4 & 198.7 & 87.3 & 72.9 & 43.7 \\
\hline TC-3B & $10 / 11 / 2010$ & 194.5 & 247.0 & 103.5 & 80.1 & 37.4 \\
\hline TC-3B & $11 / 8 / 2010$ & 128.8 & 154.3 & 80.2 & 72.9 & 46.2 \\
\hline TC-3B & $12 / 2 / 2010$ & 211.6 & 370.4 & 66.3 & 66.5 & 54.1 \\
\hline TC-3B & $12 / 29 / 2010$ & 154.6 & 192.9 & 82.9 & 72.9 & 46.7 \\
\hline TC-3B & $1 / 23 / 2011$ & 256.0 & 298.3 & 158.7 & 223.4 & 31.9 \\
\hline TC-3B & $3 / 16 / 2011$ & 90.0 & 166.4 & 25.3 & 26.2 & 74.2 \\
\hline TC-3B & $4 / 11 / 2011$ & 168.8 & 237.1 & 66.2 & 203.5 & 52.6 \\
\hline TC-3B & $6 / 29 / 2011$ & 277.7 & 371.4 & 101.9 & 72.9 & 42.2 \\
\hline TC-3B & $7 / 25 / 2011$ & 181.2 & 283.2 & 71.7 & 66.5 & 51.8 \\
\hline TC-3B & $8 / 20 / 2011$ & 130.2 & 196.6 & 70.8 & 87.9 & 52.3 \\
\hline TC-3B & $10 / 11 / 2011$ & 204.4 & 263.3 & 104.7 & 203.5 & 42.5 \\
\hline TC-3B & $11 / 5 / 2011$ & 118.6 & 153.6 & 68.8 & 72.9 & 53.8 \\
\hline TC-3B & $12 / 1 / 2011$ & 110.9 & 185.4 & 49.2 & 66.5 & 62.4 \\
\hline TC-3B & $12 / 29 / 2011$ & 218.7 & 249.5 & 124.7 & 80.1 & 34.4 \\
\hline TC-3B & $1 / 21 / 2012$ & 264.2 & 280.9 & 159.6 & 72.9 & 27.9 \\
\hline TC-3B & $2 / 15 / 2012$ & 257.2 & 290.0 & 150.2 & 72.9 & 29.6 \\
\hline TC-3B & $3 / 14 / 2012$ & 223.0 & 254.3 & 116.5 & 80.1 & 33.5 \\
\hline TC-3B & $10 / 11 / 2012$ & 253.0 & 297.5 & 135.0 & 87.9 & 32.0 \\
\hline TC-3B & $11 / 6 / 2012$ & 312.9 & 345.1 & 189.3 & 245.2 & 5.6 \\
\hline TC-3B & $12 / 3 / 2012$ & 196.3 & 260.4 & 105.4 & 140.1 & 39.3 \\
\hline TC-3B & $12 / 28 / 2012$ & 173.5 & 213.9 & 98.6 & 87.9 & 37.5 \\
\hline & & & & & & \\
\hline
\end{tabular}


Appendix V (cont.). Mean, median, and mode grain size $[\mu \mathrm{m}]$ of sediment trap sediment and $\%$ trap sediment less than $75 \mu \mathrm{m}$ at TC-5.

\begin{tabular}{|c|c|c|c|c|c|c|}
\hline Sample Name & Date Collected & Mean (um) & S.D. (um) & Median (um) & Mode (um) & $<75$ um (\%) \\
\hline TC-5 & $9 / 16 / 2009$ & 99.2 & 162.0 & 50.8 & 80.1 & 62.5 \\
\hline TC-5 & $10 / 12 / 2009$ & 97.0 & 147.5 & 50.8 & 72.9 & 63.6 \\
\hline TC-5 & $11 / 7 / 2009$ & 103.9 & 159.5 & 54.3 & 72.9 & 61.9 \\
\hline TC-5 & $12 / 2 / 2009$ & 56.2 & 86.8 & 26.4 & 28.7 & 79.7 \\
\hline TC-5 & $12 / 29 / 2009$ & 73.2 & 134.3 & 32.4 & 28.7 & 73.9 \\
\hline TC-5 & $1 / 24 / 2010$ & 46.5 & 51.4 & 28.6 & 28.7 & 80.2 \\
\hline TC-5 & $2 / 19 / 2010$ & 87.9 & 193.6 & 39.0 & 72.9 & 69.9 \\
\hline TC-5 & $3 / 17 / 2010$ & 114.4 & 227.6 & 44.1 & 80.1 & 66.4 \\
\hline TC-5 & $8 / 20 / 2010$ & 40.0 & 51.9 & 19.6 & 26.2 & 84.1 \\
\hline TC-5 & $9 / 15 / 2010$ & 62.2 & 91.4 & 30.7 & 28.7 & 75.5 \\
\hline TC-5 & $10 / 11 / 2010$ & 68.7 & 89.7 & 33.0 & 28.7 & 71.4 \\
\hline TC-5 & $11 / 8 / 2010$ & 78.6 & 116.9 & 36.1 & 60.5 & 71.0 \\
\hline TC-5 & $12 / 2 / 2010$ & 42.1 & 51.1 & 23.6 & 28.7 & 82.9 \\
\hline TC-5 & $12 / 29 / 2010$ & 86.1 & 225.8 & 24.9 & 28.7 & 81.4 \\
\hline TC-5 & $1 / 23 / 2011$ & 77.0 & 155.9 & 30.8 & 28.7 & 75.0 \\
\hline TC-5 & $2 / 13 / 2011$ & 75.4 & 127.5 & 35.9 & 72.9 & 71.4 \\
\hline TC-5 & $3 / 16 / 2011$ & 66.8 & 124.7 & 30.1 & 28.7 & 75.9 \\
\hline TC-5 & $4 / 11 / 2011$ & 66.2 & 118.8 & 28.4 & 28.7 & 76.8 \\
\hline TC-5 & $6 / 29 / 2011$ & 65.4 & 117.0 & 27.5 & 28.7 & 77.3 \\
\hline TC-5 & $7 / 25 / 2011$ & 113.2 & 201.9 & 52.9 & 72.9 & 61.2 \\
\hline TC-5 & $8 / 20 / 2011$ & 68.7 & 133.2 & 24.1 & 28.7 & 78.6 \\
\hline TC-5 & $9 / 15 / 2011$ & 93.5 & 158.9 & 34.9 & 66.5 & 68.1 \\
\hline TC-5 & $10 / 11 / 2011$ & 71.7 & 118.6 & 34.3 & 80.1 & 70.7 \\
\hline TC-5 & $11 / 5 / 2011$ & 62.8 & 79.6 & 43.5 & 80.1 & 69.2 \\
\hline TC-5 & $12 / 1 / 2011$ & 39.8 & 49.6 & 21.1 & 28.7 & 82.5 \\
\hline TC-5 & $1 / 21 / 2012$ & 76.1 & 107.1 & 39.2 & 80.1 & 67.1 \\
\hline TC-5 & $2 / 15 / 2012$ & 64.0 & 105.0 & 26.5 & 28.7 & 75.3 \\
\hline TC-5 & $3 / 14 / 2012$ & 103.7 & 172.4 & 41.7 & 72.9 & 64.4 \\
\hline TC-5 & $7 / 24 / 2012$ & 67.5 & 113.3 & 32.2 & 28.7 & 74.2 \\
\hline TC-5 & $8 / 20 / 2012$ & 77.7 & 152.9 & 29.2 & 28.7 & 75.4 \\
\hline TC-5 & $9 / 15 / 2012$ & 147.0 & 220.0 & 57.4 & 72.9 & 56.1 \\
\hline TC-5 & $10 / 11 / 2012$ & 85.0 & 140.9 & 44.6 & 66.4 & 67.6 \\
\hline TC-5 & $11 / 6 / 2012$ & 109.8 & 183.5 & 50.5 & 66.4 & 62.6 \\
\hline TC-5 & $12 / 3 / 2012$ & 99.8 & 206.8 & 41.3 & 66.4 & 67.5 \\
\hline TC-5 & $12 / 28 / 2012$ & 73.0 & 117.2 & 37.6 & 66.4 & 70.4 \\
\hline & & & & & & \\
\hline
\end{tabular}


Appendix V (cont.). Mean, median, and mode grain size [ $\mu \mathrm{m}]$ of sediment trap sediment and $\%$ trap sediment less than $75 \mu \mathrm{m}$ at TC-8.

\begin{tabular}{|c|c|c|c|c|c|c|}
\hline Sample Name & Date Collected & Mean (um) & S.D. (um) & Median (um) & Mode (um) & $<75$ um (\%) \\
\hline TC-8 & $9 / 16 / 2009$ & 92.0 & 142.0 & 50.3 & 72.9 & 63.8 \\
\hline TC-8 & $10 / 12 / 2009$ & 102.7 & 160.2 & 59.3 & 80.1 & 59.4 \\
\hline TC-8 & $11 / 7 / 2009$ & 84.7 & 127.6 & 49.6 & 72.9 & 65.5 \\
\hline TC-8 & $12 / 2 / 2009$ & 67.5 & 113.0 & 32.5 & 72.9 & 74.8 \\
\hline TC-8 & $12 / 29 / 2009$ & 68.2 & 99.2 & 38.4 & 72.9 & 71.8 \\
\hline TC-8 & $1 / 24 / 2010$ & 125.9 & 201.3 & 62.9 & 80.1 & 56.6 \\
\hline TC-8 & $2 / 19 / 2010$ & 94.6 & 120.2 & 61.4 & 80.1 & 57.7 \\
\hline TC-8 & $3 / 17 / 2010$ & 96.1 & 135.2 & 61.1 & 80.1 & 58.5 \\
\hline TC-8 & $8 / 20 / 2010$ & 44.2 & 53.8 & 24.5 & 28.7 & 82.2 \\
\hline TC-8 & $9 / 15 / 2010$ & 48.8 & 60.6 & 29.5 & 31.5 & 80.0 \\
\hline TC-8 & $10 / 11 / 2010$ & 148.6 & 210.4 & 60.5 & 66.5 & 55.4 \\
\hline TC-8 & $11 / 8 / 2010$ & 72.4 & 123.1 & 29.1 & 28.7 & 75.2 \\
\hline TC-8 & $12 / 2 / 2010$ & 92.4 & 224.2 & 24.9 & 26.2 & 77.2 \\
\hline TC-8 & $12 / 29 / 2010$ & 49.8 & 84.6 & 28.8 & 31.5 & 82.5 \\
\hline TC-8 & $1 / 23 / 2011$ & 59.1 & 125.7 & 22.8 & 28.7 & 81.8 \\
\hline TC-8 & $2 / 13 / 2011$ & 79.9 & 113.2 & 41.1 & 72.9 & 66.7 \\
\hline TC-8 & $3 / 16 / 2011$ & 89.1 & 164.8 & 34.3 & 28.7 & 70.9 \\
\hline TC-8 & $4 / 11 / 2011$ & 65.2 & 110.9 & 29.6 & 28.7 & 74.9 \\
\hline TC-8 & $6 / 29 / 2011$ & 66.4 & 117.7 & 29.1 & 28.7 & 76.1 \\
\hline TC-8 & $7 / 25 / 2011$ & 51.5 & 86.2 & 23.9 & 28.7 & 81.3 \\
\hline TC-8 & $8 / 26 / 2011$ & 75.5 & 136.8 & 24.9 & 28.7 & 76.8 \\
\hline TC-8 & $9 / 15 / 2011$ & 119.9 & 192.7 & 51.0 & 72.9 & 60.6 \\
\hline TC-8 & $10 / 11 / 2011$ & 66.0 & 106.2 & 29.0 & 28.7 & 74.4 \\
\hline TC-8 & $11 / 5 / 2011$ & 55.0 & 76.0 & 30.6 & 28.7 & 77.0 \\
\hline TC-8 & $12 / 1 / 2011$ & 55.8 & 97.7 & 26.2 & 28.7 & 79.0 \\
\hline TC-8 & $12 / 29 / 2011$ & 58.8 & 98.0 & 29.2 & 80.1 & 76.3 \\
\hline TC-8 & $1 / 21 / 2012$ & 57.7 & 93.7 & 28.4 & 28.7 & 77.1 \\
\hline TC-8 & $2 / 15 / 2012$ & 58.1 & 98.2 & 25.8 & 28.7 & 78.4 \\
\hline TC-8 & $3 / 14 / 2012$ & 98.5 & 152.8 & 42.8 & 80.1 & 63.6 \\
\hline TC-8 & $7 / 24 / 2012$ & 137.4 & 212.3 & 59.2 & 66.5 & 57.6 \\
\hline TC-8 & $8 / 20 / 2012$ & 109.7 & 185.6 & 43.7 & 60.5 & 65.7 \\
\hline TC-8 & $12 / 28 / 2012$ & 157.3 & 220.8 & 74.8 & 72.9 & 50.1 \\
\hline
\end{tabular}


Appendix V (cont.). Mean, median, and mode grain size $[\mu \mathrm{m}]$ of sediment trap sediment and $\%$ trap sediment less than $75 \mu \mathrm{m}$ at TC-10B.

\begin{tabular}{|c|c|c|c|c|c|c|}
\hline Sample Name & Date Collected & Mean (um) & S.D. (um) & Median (um) & Mode (um) & $<75$ um (\%) \\
\hline TC-10B & $9 / 16 / 2009$ & 123.9 & 191.1 & 55.9 & 60.5 & 58.6 \\
\hline TC-10B & $10 / 12 / 2009$ & 521.7 & 541.9 & 314.7 & 1197.0 & 27.6 \\
\hline TC-10B & $11 / 7 / 2009$ & 213.0 & 301.1 & 83.2 & 60.5 & 47.6 \\
\hline TC-10B & $12 / 2 / 2009$ & 135.1 & 191.3 & 66.7 & 72.9 & 53.6 \\
\hline TC-10B & $12 / 29 / 2009$ & 106.8 & 166.2 & 53.8 & 60.5 & 62.2 \\
\hline TC-10B & $1 / 24 / 2010$ & 135.4 & 248.0 & 46.9 & 60.5 & 63.5 \\
\hline TC-10B & $2 / 19 / 2010$ & 184.5 & 334.6 & 61.2 & 66.5 & 56.1 \\
\hline TC-10B & $3 / 17 / 2010$ & 150.3 & 155.5 & 103.1 & 96.5 & 34.5 \\
\hline TC-10B & $8 / 20 / 2010$ & 159.6 & 292.8 & 48.5 & 60.5 & 61.8 \\
\hline TC-10B & $9 / 15 / 2010$ & 151.1 & 251.8 & 53.2 & 60.5 & 59.2 \\
\hline TC-10B & $10 / 11 / 2010$ & 242.0 & 359.8 & 104.7 & 203.5 & 43.0 \\
\hline TC-10B & $11 / 8 / 2010$ & 137.6 & 197.8 & 63.1 & 72.9 & 54.6 \\
\hline TC-10B & $12 / 2 / 2010$ & 125.9 & 183.7 & 60.6 & 66.5 & 56.7 \\
\hline TC-10B & $12 / 29 / 2010$ & 135.5 & 214.9 & 56.6 & 66.5 & 58.4 \\
\hline TC-10B & $1 / 23 / 2011$ & 125.2 & 179.1 & 61.8 & 72.9 & 56.0 \\
\hline TC-10B & $2 / 13 / 2011$ & 128.2 & 175.1 & 61.4 & 66.5 & 55.7 \\
\hline TC-10B & $3 / 16 / 2011$ & 246.8 & 293.1 & 148.6 & 185.4 & 30.7 \\
\hline TC-10B & $4 / 11 / 2011$ & 168.5 & 232.5 & 78.6 & 80.1 & 48.6 \\
\hline TC-10B & $6 / 29 / 2011$ & 188.6 & 264.8 & 86.7 & 87.9 & 45.7 \\
\hline TC-10B & $7 / 25 / 2011$ & 129.7 & 192.2 & 65.0 & 72.9 & 54.6 \\
\hline TC-10B & $8 / 20 / 2011$ & 114.9 & 175.3 & 52.3 & 66.5 & 60.6 \\
\hline TC-10B & $9 / 15 / 2011$ & 185.2 & 332.6 & 66.6 & 105.9 & 53.3 \\
\hline TC-10B & $10 / 11 / 2011$ & 283.5 & 366.0 & 121.0 & 203.5 & 40.3 \\
\hline TC-10B & $11 / 5 / 2011$ & 301.6 & 398.5 & 120.2 & 72.9 & 40.1 \\
\hline TC-10B & $12 / 1 / 2011$ & 151.9 & 232.1 & 58.7 & 66.5 & 56.3 \\
\hline TC-10B & $12 / 29 / 2011$ & 106.7 & 170.9 & 48.5 & 60.5 & 63.2 \\
\hline TC-10B & $1 / 21 / 2012$ & 110.6 & 156.2 & 46.3 & 60.5 & 61.9 \\
\hline TC-10B & $2 / 15 / 2012$ & 122.2 & 201.7 & 47.7 & 60.5 & 62.2 \\
\hline TC-10B & $3 / 14 / 2012$ & 155.4 & 220.8 & 65.9 & 66.5 & 53.4 \\
\hline TC-10B & $7 / 24 / 2012$ & 90.0 & 148.6 & 39.8 & 60.5 & 68.4 \\
\hline TC-10B & $8 / 20 / 2012$ & 115.4 & 179.9 & 52.6 & 66.5 & 60.7 \\
\hline TC-10B & $9 / 15 / 2012$ & 109.4 & 161.2 & 62.7 & 105.9 & 55.6 \\
\hline TC-10B & $10 / 11 / 2012$ & 265.5 & 382.8 & 101.3 & 116.3 & 42.9 \\
\hline TC-10B & $11 / 6 / 2012$ & 177.2 & 228.4 & 99.8 & 140.1 & 40.7 \\
\hline TC-10B & $12 / 3 / 2012$ & 211.8 & 340.1 & 72.9 & 60.5 & 51.0 \\
\hline TC-10B & $12 / 28 / 2012$ & 237.8 & 350.4 & 72.7 & 60.5 & 51.0 \\
\hline
\end{tabular}


Appendix V (cont.). Mean, median, and mode grain size $[\mu \mathrm{m}]$ of sediment trap sediment and $\%$ trap sediment less than $75 \mu \mathrm{m}$ at TC-11.

\begin{tabular}{|c|c|c|c|c|c|c|}
\hline Sample Name & Date Collected & Mean (um) & S.D. (um) & Median (um) & Mode (um) & $<75$ um (\%) \\
\hline TC-11 & $9 / 16 / 2009$ & 143.9 & 207.1 & 68.3 & 66.5 & 53.0 \\
\hline TC-11 & $10 / 12 / 2009$ & 63.4 & 105.0 & 31.0 & 31.5 & 78.1 \\
\hline TC-11 & $11 / 7 / 2009$ & 77.7 & 126.6 & 31.8 & 31.5 & 75.3 \\
\hline TC-11 & $12 / 2 / 2009$ & 72.1 & 134.2 & 27.2 & 28.7 & 79.9 \\
\hline TC-11 & $12 / 29 / 2009$ & 42.4 & 49.8 & 27.0 & 31.5 & 84.7 \\
\hline TC-11 & $1 / 24 / 2010$ & 59.0 & 105.2 & 31.5 & 34.6 & 81.5 \\
\hline TC-11 & $2 / 19 / 2010$ & 44.5 & 57.9 & 24.1 & 28.7 & 83.2 \\
\hline TC-11 & $3 / 17 / 2010$ & 85.6 & 177.3 & 28.7 & 28.7 & 76.2 \\
\hline TC-11 & $8 / 20 / 2010$ & 89.7 & 162.7 & 31.1 & 28.7 & 73.5 \\
\hline TC-11 & $9 / 15 / 2010$ & 41.1 & 49.0 & 24.9 & 28.7 & 84.4 \\
\hline TC-11 & $10 / 11 / 2010$ & 43.2 & 66.4 & 24.2 & 28.7 & 83.9 \\
\hline TC-11 & $11 / 8 / 2010$ & 42.9 & 64.0 & 23.7 & 28.7 & 84.9 \\
\hline TC-11 & $12 / 2 / 2010$ & 239.4 & 412.3 & 64.8 & 66.5 & 54.2 \\
\hline TC-11 & $12 / 29 / 2010$ & 74.6 & 133.4 & 35.3 & 34.6 & 75.4 \\
\hline TC-11 & $1 / 23 / 2011$ & 65.0 & 108.3 & 32.0 & 31.5 & 76.2 \\
\hline TC-11 & $2 / 13 / 2011$ & 77.5 & 139.7 & 35.1 & 31.5 & 73.8 \\
\hline TC-11 & $3 / 16 / 2011$ & 163.1 & 258.6 & 59.6 & 60.5 & 55.7 \\
\hline TC-11 & $4 / 11 / 2011$ & 98.8 & 178.6 & 35.7 & 31.5 & 71.0 \\
\hline TC-11 & $6 / 29 / 2011$ & 140.2 & 246.9 & 52.3 & 60.5 & 60.5 \\
\hline TC-11 & $7 / 25 / 2011$ & 96.7 & 183.9 & 35.8 & 31.5 & 71.1 \\
\hline TC-11 & $8 / 26 / 2011$ & 72.3 & 147.2 & 22.8 & 28.7 & 79.9 \\
\hline TC-11 & $9 / 15 / 2011$ & 91.4 & 148.9 & 31.9 & 28.7 & 69.5 \\
\hline TC-11 & $10 / 11 / 2011$ & 69.6 & 131.6 & 27.7 & 28.7 & 78.2 \\
\hline TC-11 & $11 / 5 / 2011$ & 61.3 & 109.8 & 27.7 & 28.7 & 78.4 \\
\hline TC-11 & $12 / 1 / 2011$ & 71.7 & 139.7 & 26.6 & 28.7 & 77.5 \\
\hline TC-11 & $12 / 29 / 2011$ & 75.2 & 136.3 & 34.2 & 31.5 & 74.7 \\
\hline TC-11 & $1 / 21 / 2012$ & 48.9 & 66.2 & 28.4 & 31.5 & 81.0 \\
\hline TC-11 & $2 / 15 / 2012$ & 66.8 & 117.1 & 31.3 & 31.5 & 75.7 \\
\hline TC-11 & $3 / 14 / 2012$ & 45.5 & 66.9 & 21.2 & 28.7 & 81.8 \\
\hline TC-11 & $5 / 10 / 2012$ & 90.5 & 163.5 & 39.7 & 55.1 & 69.8 \\
\hline TC-11 & $7 / 24 / 2012$ & 65.5 & 123.9 & 31.6 & 31.5 & 77.9 \\
\hline TC-11 & $8 / 20 / 2012$ & 46.8 & 85.1 & 24.4 & 28.7 & 84.7 \\
\hline TC-11 & $9 / 15 / 2012$ & 60.2 & 92.0 & 27.6 & 28.7 & 77.0 \\
\hline TC-11 & $10 / 11 / 2012$ & 69.2 & 117.8 & 32.6 & 31.5 & 76.4 \\
\hline TC-11 & $11 / 6 / 2012$ & 109.3 & 212.1 & 33.3 & 28.7 & 70.9 \\
\hline TC-11 & $12 / 3 / 2012$ & 121.2 & 204.7 & 40.3 & 28.7 & 65.2 \\
\hline TC-11 & $12 / 28 / 2012$ & 62.3 & 125.9 & 28.1 & 28.7 & 80.4 \\
\hline
\end{tabular}


Appendix V (cont.). Mean, median, and mode grain size $[\mu \mathrm{m}]$ of sediment trap sediment and $\%$ trap sediment less than $75 \mu \mathrm{m}$ at TC-12.

\begin{tabular}{|c|c|c|c|c|c|c|}
\hline Sample Name & Date Collected & Mean (um) & S.D. (um) & Median (um) & Mode (um) & $<75$ um (\%) \\
\hline TC-12 & $10 / 12 / 2009$ & 145.4 & 213.4 & 68.6 & 72.9 & 53.0 \\
\hline TC-12 & $11 / 7 / 2009$ & 155.2 & 235.0 & 69.1 & 73.9 & 52.6 \\
\hline TC-12 & $12 / 2 / 2009$ & 574.4 & 606.9 & 287.1 & 1739.0 & 33.2 \\
\hline TC-12 & $12 / 29 / 2009$ & 119.6 & 223.3 & 34.3 & 28.7 & 69.9 \\
\hline TC-12 & $1 / 24 / 2010$ & 124.8 & 210.6 & 55.9 & 66.5 & 60.3 \\
\hline TC-12 & $2 / 19 / 2010$ & 120.4 & 200.1 & 52.4 & 66.5 & 61.3 \\
\hline TC-12 & $3 / 17 / 2010$ & 167.1 & 267.6 & 64.9 & 66.5 & 54.5 \\
\hline TC-12 & $8 / 20 / 2010$ & 106.3 & 179.7 & 40.6 & 31.5 & 67.5 \\
\hline TC-12 & $9 / 15 / 2010$ & 124.1 & 161.9 & 71.3 & 168.9 & 51.2 \\
\hline TC-12 & $10 / 11 / 2010$ & 105.3 & 168.2 & 46.1 & 66.5 & 62.6 \\
\hline TC-12 & $11 / 8 / 2010$ & 212.1 & 276.2 & 138.2 & 203.5 & 35.7 \\
\hline TC-12 & $12 / 2 / 2010$ & 171.8 & 349.4 & 35.6 & 28.7 & 69.4 \\
\hline TC-12 & $12 / 29 / 2010$ & 130.7 & 198.8 & 59.7 & 66.5 & 57.4 \\
\hline TC-12 & $1 / 23 / 2011$ & 127.2 & 199.5 & 53.7 & 80.1 & 58.8 \\
\hline TC-12 & $2 / 13 / 2011$ & 129.1 & 222.8 & 46.5 & 60.5 & 64.1 \\
\hline TC-12 & $3 / 16 / 2011$ & 183.7 & 311.9 & 50.7 & 31.5 & 59.7 \\
\hline TC-12 & $4 / 11 / 2011$ & 126.4 & 236.2 & 36.2 & 28.7 & 67.7 \\
\hline TC-12 & $6 / 29 / 2011$ & 163.5 & 239.5 & 69.9 & 66.5 & 52.0 \\
\hline TC-12 & $7 / 25 / 2011$ & 123.8 & 221.3 & 43.6 & 66.5 & 64.2 \\
\hline TC-12 & $8 / 20 / 2011$ & 108.5 & 184.6 & 29.0 & 28.7 & 68.0 \\
\hline TC-12 & $9 / 15 / 2011$ & 269.7 & 286.8 & 198.0 & 245.2 & 33.0 \\
\hline TC-12 & $10 / 11 / 2011$ & 141.8 & 223.6 & 56.3 & 66.5 & 58.3 \\
\hline TC-12 & $11 / 5 / 2011$ & 140.4 & 225.0 & 56.7 & 66.5 & 58.4 \\
\hline TC-12 & $12 / 1 / 2011$ & 239.0 & 327.9 & 95.1 & 72.9 & 43.0 \\
\hline TC-12 & $12 / 29 / 2011$ & 95.6 & 163.4 & 40.5 & 60.5 & 67.2 \\
\hline TC-12 & $1 / 21 / 2012$ & 117.6 & 183.9 & 54.2 & 72.9 & 59.0 \\
\hline TC-12 & $2 / 15 / 2012$ & 119.6 & 202.7 & 48.9 & 66.5 & 62.6 \\
\hline TC-12 & $3 / 14 / 2012$ & 135.5 & 208.8 & 60.1 & 87.9 & 55.9 \\
\hline TC-12 & $7 / 24 / 2012$ & 132.6 & 221.5 & 56.7 & 72.9 & 59.1 \\
\hline TC-12 & $8 / 20 / 2012$ & 239.0 & 224.8 & 189.9 & 223.4 & 23.6 \\
\hline TC-12 & $9 / 15 / 2012$ & 265.8 & 255.7 & 211.6 & 245.2 & 25.9 \\
\hline TC-12 & $10 / 11 / 2012$ & 288.9 & 377.1 & 131.2 & 116.3 & 35.5 \\
\hline TC-12 & $11 / 6 / 2012$ & 132.5 & 213.0 & 56.7 & 60.5 & 58.0 \\
\hline TC-12 & $12 / 2 / 2012$ & 331.7 & 451.5 & 124.4 & 72.9 & 39.6 \\
\hline TC-12 & $12 / 28 / 2012$ & 146.4 & 229.3 & 63.8 & 66.4 & 54.7 \\
\hline & & & & & & \\
\hline
\end{tabular}


Appendix V (cont.). Mean, median, and mode grain size $[\mu \mathrm{m}]$ of sediment trap sediment and $\%$ trap sediment less than $75 \mu \mathrm{m}$ at TC-13.

\begin{tabular}{|c|c|c|c|c|c|c|}
\hline Sample Name & Date Collected & Mean (um) & S.D. (um) & Median (um) & Mode (um) & $<75$ um (\%) \\
\hline TC-13 & $8 / 20 / 2010$ & 113.8 & 175.6 & 48.0 & 60.5 & 62.3 \\
\hline TC-13 & $9 / 15 / 2010$ & 141.7 & 205.5 & 67.5 & 66.5 & 53.2 \\
\hline TC-13 & $10 / 11 / 2010$ & 182.0 & 241.9 & 86.2 & 203.5 & 47.1 \\
\hline TC-13 & $11 / 8 / 2010$ & 158.6 & 211.1 & 81.5 & 87.9 & 47.5 \\
\hline TC-13 & $12 / 2 / 2010$ & 122.6 & 189.5 & 56.6 & 72.9 & 58.7 \\
\hline TC-13 & $12 / 29 / 2010$ & 161.2 & 218.7 & 74.9 & 72.9 & 50.0 \\
\hline TC-13 & $1 / 23 / 2011$ & 150.6 & 219.2 & 69.1 & 80.1 & 52.5 \\
\hline TC-13 & $2 / 13 / 2011$ & 158.2 & 225.7 & 73.8 & 80.1 & 50.5 \\
\hline TC-13 & $3 / 16 / 2011$ & 226.3 & 261.1 & 136.5 & 203.5 & 34.1 \\
\hline TC-13 & $6 / 29 / 2011$ & 159.1 & 228.6 & 74.3 & 72.9 & 50.3 \\
\hline TC-13 & $7 / 25 / 2011$ & 396.8 & 453.1 & 195.0 & 185.4 & 26.5 \\
\hline TC-13 & $8 / 20 / 2011$ & 127.5 & 174.8 & 71.5 & 105.9 & 51.5 \\
\hline TC-13 & $9 / 15 / 2011$ & 206.0 & 206.5 & 150.3 & 185.4 & 29.5 \\
\hline TC-13 & $10 / 11 / 2011$ & 229.2 & 305.7 & 101.7 & 203.5 & 43.2 \\
\hline TC-13 & $11 / 5 / 2011$ & 128.9 & 184.2 & 64.9 & 72.9 & 54.5 \\
\hline TC-13 & $12 / 1 / 2011$ & 122.5 & 198.3 & 51.5 & 66.5 & 60.7 \\
\hline TC-13 & $12 / 29 / 2011$ & 138.2 & 206.5 & 60.4 & 66.5 & 56.2 \\
\hline TC-13 & $1 / 21 / 2012$ & 145.8 & 191.4 & 76.9 & 87.9 & 49.3 \\
\hline TC-13 & $2 / 15 / 2012$ & 171.1 & 231.6 & 79.2 & 72.9 & 48.5 \\
\hline TC-13 & $3 / 14 / 2012$ & 179.1 & 234.6 & 87.1 & 80.1 & 45.8 \\
\hline TC-13 & $7 / 24 / 2012$ & 159.9 & 239.2 & 72.6 & 72.9 & 51.0 \\
\hline TC-13 & $8 / 20 / 2012$ & 170.8 & 225.5 & 94.7 & 168.9 & 43.8 \\
\hline TC-13 & $9 / 15 / 2012$ & 244.9 & 229.5 & 196.9 & 245.2 & 21.4 \\
\hline TC-13 & $10 / 11 / 2012$ & 181.4 & 264.1 & 79.3 & 105.9 & 48.4 \\
\hline TC-13 & $11 / 6 / 2012$ & 153.9 & 225.1 & 73.2 & 66.4 & 50.7 \\
\hline TC-13 & $12 / 3 / 2012$ & 181.6 & 282.2 & 70.2 & 66.4 & 51.7 \\
\hline TC-13 & $12 / 28 / 2012$ & 141.8 & 209.2 & 68.9 & 80.1 & 52.6 \\
\hline
\end{tabular}


Appendix V (cont.). Mean, median, and mode grain size $[\mu \mathrm{m}]$ of sediment trap sediment and $\%$ trap sediment less than $75 \mu \mathrm{m}$ at TL1-2.

\begin{tabular}{|c|c|c|c|c|c|c|}
\hline Sample Name & Date Collected & Mean (um) & S.D. (um) & Median (um) & Mode (um) & $<75$ um (\%) \\
\hline TL1-2 & $9 / 2 / 2009$ & 80.9 & 118.4 & 43.5 & 55.1 & 68.6 \\
\hline TL1-2 & $10 / 14 / 2009$ & 109.6 & 181.7 & 47.9 & 55.1 & 64.8 \\
\hline TL1-2 & $11 / 8 / 2009$ & 87.3 & 140.1 & 41.7 & 34.6 & 67.9 \\
\hline TL1-2 & $12 / 3 / 2009$ & 73.0 & 117.6 & 37.9 & 34.6 & 73.3 \\
\hline TL1-2 & $12 / 30 / 2009$ & 183.5 & 378.2 & 52.2 & 60.5 & 61.8 \\
\hline TL1-2 & $1 / 25 / 2010$ & 96.9 & 155.7 & 49.2 & 60.5 & 63.4 \\
\hline TL1-2 & $2 / 20 / 2010$ & 92.8 & 140.4 & 44.6 & 60.5 & 65.7 \\
\hline TL1-2 & $3 / 19 / 2010$ & 107.3 & 202.9 & 45.6 & 60.5 & 64.9 \\
\hline TL1-2 & $9 / 18 / 2010$ & 246.6 & 231.2 & 194.4 & 223.4 & 23.0 \\
\hline TL1-2 & $10 / 13 / 2010$ & 343.1 & 352.7 & 261.4 & 429.2 & 29.3 \\
\hline TL1-2 & $11 / 13 / 2010$ & 153.0 & 257.0 & 35.7 & 28.7 & 66.7 \\
\hline TL1-2 & $12 / 4 / 2010$ & 94.4 & 155.8 & 43.3 & 66.5 & 66.5 \\
\hline TL1-2 & $12 / 31 / 2010$ & 164.6 & 335.5 & 41.8 & 31.5 & 66.5 \\
\hline TL1-2 & $1 / 25 / 2011$ & 130.8 & 202.0 & 60.3 & 66.5 & 57.1 \\
\hline TL1-2 & $2 / 15 / 2011$ & 139.4 & 185.6 & 80.4 & 116.3 & 47.7 \\
\hline TL1-2 & $4 / 13 / 2011$ & 444.7 & 471.9 & 246.0 & 751.1 & 22.9 \\
\hline TL1-2 & $6 / 5 / 2011$ & 240.6 & 313.7 & 116.4 & 140.1 & 37.6 \\
\hline TL1-2 & $6 / 29 / 2011$ & 604.5 & 529.3 & 511.0 & 751.1 & 20.1 \\
\hline TL1-2 & $7 / 27 / 2011$ & 480.4 & 500.1 & 261.5 & 751.1 & 24.2 \\
\hline TL1-2 & $8 / 26 / 2011$ & 132.0 & 198.0 & 63.3 & 116.3 & 54.6 \\
\hline TL1-2 & $9 / 17 / 2011$ & 125.8 & 208.1 & 49.3 & 60.5 & 61.2 \\
\hline TL1-2 & $10 / 13 / 2011$ & 155.5 & 248.1 & 60.4 & 66.5 & 56.1 \\
\hline TL1-2 & $11 / 7 / 2011$ & 99.4 & 172.4 & 45.1 & 60.5 & 66.4 \\
\hline TL1-2 & $12 / 3 / 2011$ & 113.7 & 189.9 & 47.1 & 60.5 & 64.0 \\
\hline TL1-2 & $12 / 31 / 2011$ & 97.7 & 141.9 & 52.9 & 66.5 & 61.8 \\
\hline TL1-2 & $1 / 24 / 2012$ & 140.0 & 206.8 & 54.2 & 31.5 & 58.4 \\
\hline TL1-2 & $2 / 18 / 2012$ & 136.7 & 184.9 & 59.0 & 31.5 & 57.1 \\
\hline TL1-2 & $3 / 16 / 2012$ & 181.1 & 275.9 & 81.1 & 87.9 & 47.6 \\
\hline TL1-2 & $6 / 30 / 2012$ & 204.1 & 291.2 & 88.9 & 80.1 & 44.7 \\
\hline TL1-2 & $7 / 26 / 2012$ & 274.7 & 402.2 & 100.3 & 96.5 & 42.2 \\
\hline TL1-2 & $9 / 17 / 2012$ & 92.3 & 152.8 & 40.8 & 34.6 & 69.2 \\
\hline TL1-2 & $10 / 13 / 2012$ & 182.4 & 264.9 & 87.5 & 96.5 & 45.1 \\
\hline TL1-2 & $11 / 8 / 2012$ & 137.0 & 204.6 & 69.6 & 80.1 & 52.5 \\
\hline TL1-2 & $12 / 3 / 2012$ & 178.8 & 295.4 & 45.6 & 31.5 & 62.1 \\
\hline TL1-2 & $12 / 30 / 2012$ & 120.1 & 195.8 & 55.6 & 66.4 & 59.4 \\
\hline & & & & & & \\
\hline
\end{tabular}


Appendix V (cont.). Mean, median, and mode grain size $[\mu \mathrm{m}]$ of sediment trap sediment and $\%$ trap sediment less than $75 \mu \mathrm{m}$ at TL2-6.

\begin{tabular}{|c|c|c|c|c|c|c|}
\hline Sample Name & Date Collected & Mean (um) & S.D. (um) & Median (um) & Mode (um) & $<75$ um (\%) \\
\hline TL2-6 & $8 / 23 / 2010$ & 63.3 & 89.9 & 32.4 & 31.5 & 76.6 \\
\hline TL2-6 & $9 / 18 / 2010$ & 344.7 & 282.9 & 289.4 & 429.2 & 19.3 \\
\hline TL2-6 & $10 / 13 / 2010$ & 281.7 & 378.1 & 140.5 & 168.9 & 30.9 \\
\hline TL2-6 & $11 / 13 / 2010$ & 184.9 & 278.4 & 81.8 & 96.5 & 47.4 \\
\hline TL2-6 & $12 / 4 / 2010$ & 179.0 & 276.7 & 68.4 & 66.5 & 52.7 \\
\hline TL2-6 & $12 / 31 / 2010$ & 190.3 & 317.6 & 70.8 & 66.5 & 51.8 \\
\hline TL2-6 & $1 / 25 / 2011$ & 139.3 & 209.6 & 65.4 & 72.9 & 54.5 \\
\hline TL2-6 & $2 / 15 / 2011$ & 121.6 & 174.4 & 63.4 & 72.9 & 55.6 \\
\hline TL2-6 & $3 / 18 / 2011$ & 227.9 & 292.5 & 119.2 & 140.1 & 35.9 \\
\hline TL2-6 & $4 / 13 / 2011$ & 406.9 & 456.2 & 194.8 & 684.2 & 27.9 \\
\hline TL2-6 & $7 / 1 / 2011$ & 186.4 & 265.3 & 86.2 & 87.9 & 45.8 \\
\hline TL2-6 & $7 / 27 / 2011$ & 150.9 & 211.2 & 74.3 & 87.9 & 50.3 \\
\hline TL2-6 & $8 / 26 / 2011$ & 116.8 & 156.1 & 64.3 & 105.9 & 54.3 \\
\hline TL2-6 & $9 / 17 / 2011$ & 150.2 & 223.2 & 71.6 & 87.9 & 51.5 \\
\hline TL2-6 & $10 / 13 / 2011$ & 173.1 & 205.5 & 79.8 & 116.3 & 48.3 \\
\hline TL2-6 & $11 / 7 / 2011$ & 118.6 & 175.5 & 62.7 & 72.9 & 56.4 \\
\hline TL2-6 & $12 / 3 / 2011$ & 154.3 & 231.8 & 67.9 & 66.5 & 52.9 \\
\hline TL2-6 & $12 / 31 / 2011$ & 135.6 & 195.3 & 70.6 & 80.1 & 52.3 \\
\hline TL2-6 & $1 / 24 / 2012$ & 123.4 & 193.2 & 57.8 & 72.9 & 58.3 \\
\hline TL2-6 & $2 / 18 / 2012$ & 129.6 & 186.8 & 66.1 & 72.9 & 54.4 \\
\hline TL2-6 & $3 / 16 / 2012$ & 136.6 & 172.6 & 79.2 & 96.5 & 48.0 \\
\hline TL2-6 & $6 / 30 / 2012$ & 214.2 & 309.4 & 86.0 & 80.1 & 46.4 \\
\hline TL2-6 & $7 / 26 / 2012$ & 172.5 & 233.3 & 86.7 & 127.7 & 45.9 \\
\hline TL2-6 & $8 / 26 / 2012$ & 123.9 & 189.3 & 55.6 & 66.5 & 58.9 \\
\hline TL2-6 & $9 / 17 / 2012$ & 480.4 & 506.5 & 284.8 & 684.2 & 32.0 \\
\hline TL2-6 & $10 / 13 / 2012$ & 232.6 & 313.3 & 115.5 & 127.6 & 36.6 \\
\hline TL2-6 & $11 / 8 / 2012$ & 136.0 & 209.3 & 68.0 & 80.1 & 53.3 \\
\hline TL2-6 & $12 / 2 / 2012$ & 156.1 & 276.9 & 65.6 & 66.4 & 55.0 \\
\hline TL2-6 & $12 / 30 / 2012$ & 118.9 & 193.6 & 57.3 & 66.4 & 59.8 \\
\hline & & & & & &
\end{tabular}


Appendix V (cont.). Mean, median, and mode grain size $[\mu \mathrm{m}]$ of sediment trap sediment and $\%$ trap sediment less than $75 \mu \mathrm{m}$ at TY-1.

\begin{tabular}{|c|c|c|c|c|c|c|}
\hline Sample Name & Date Collected & Mean (um) & S.D. (um) & Median (um) & Mode (um) & $<75$ um (\%) \\
\hline TY-1 & $9 / 18 / 2009$ & 226.5 & 314.1 & 108.6 & 105.9 & 37.9 \\
\hline TY-1 & $10 / 14 / 2009$ & 242.0 & 330.3 & 120.9 & 140.1 & 34.6 \\
\hline TY-1 & $11 / 8 / 2009$ & 240.8 & 324.9 & 117.4 & 127.7 & 36.3 \\
\hline TY-1 & $12 / 3 / 2009$ & 186.9 & 270.3 & 82.1 & 72.9 & 47.0 \\
\hline TY-1 & $12 / 30 / 2009$ & 179.7 & 270.6 & 72.2 & 66.5 & 51.2 \\
\hline TY-1 & $1 / 25 / 2010$ & 205.8 & 297.9 & 85.1 & 72.9 & 46.1 \\
\hline TY-1 & $2 / 20 / 2010$ & 190.1 & 284.7 & 79.3 & 72.9 & 48.2 \\
\hline TY-1 & $3 / 19 / 2010$ & 282.6 & 391.1 & 106.8 & 72.9 & 40.8 \\
\hline TY-1 & $8 / 23 / 2010$ & 376.0 & 435.0 & 199.7 & 203.5 & 26.6 \\
\hline TY-1 & $9 / 18 / 2010$ & 434.7 & 283.4 & 388.6 & 471.1 & 8.8 \\
\hline TY-1 & $10 / 13 / 2010$ & 413.0 & 389.4 & 310.0 & 356.1 & 15.5 \\
\hline TY-1 & $11 / 13 / 2010$ & 206.2 & 323.4 & 69.1 & 60.5 & 52.3 \\
\hline TY-1 & $12 / 4 / 2010$ & 260.3 & 335.3 & 127.3 & 168.9 & 35.8 \\
\hline TY-1 & $12 / 31 / 2010$ & 210.9 & 308.8 & 89.3 & 66.5 & 45.5 \\
\hline TY-1 & $1 / 25 / 2011$ & 168.5 & 239.4 & 79.4 & 72.9 & 48.2 \\
\hline TY-1 & $2 / 15 / 2011$ & 176.6 & 242.5 & 88.2 & 96.5 & 44.7 \\
\hline TY-1 & $3 / 18 / 2011$ & 390.8 & 421.6 & 217.2 & 203.5 & 24.1 \\
\hline TY-1 & $7 / 1 / 2011$ & 241.4 & 314.6 & 113.3 & 105.9 & 37.9 \\
\hline TY-1 & $7 / 27 / 2011$ & 269.6 & 369.7 & 123.5 & 153.8 & 36.2 \\
\hline TY-1 & $8 / 26 / 2011$ & 157.8 & 209.3 & 84.8 & 140.1 & 46.7 \\
\hline TY-1 & $9 / 17 / 2011$ & 185.2 & 255.6 & 83.8 & 72.9 & 46.7 \\
\hline TY-1 & $10 / 13 / 2011$ & 209.0 & 286.3 & 97.6 & 96.5 & 41.7 \\
\hline TY-1 & $11 / 7 / 2011$ & 153.3 & 232.8 & 65.9 & 66.5 & 54.0 \\
\hline TY-1 & $12 / 3 / 2011$ & 221.3 & 304.6 & 94.6 & 72.9 & 43.5 \\
\hline TY-1 & $12 / 31 / 2011$ & 185.6 & 274.5 & 74.1 & 66.5 & 50.5 \\
\hline TY-1 & $1 / 24 / 2012$ & 314.6 & 413.6 & 137.1 & 105.9 & 33.5 \\
\hline TY-1 & $2 / 18 / 2012$ & 173.5 & 258.2 & 76.1 & 72.9 & 49.6 \\
\hline TY-1 & $3 / 16 / 2012$ & 302.2 & 379.1 & 143.7 & 153.8 & 31.7 \\
\hline TY-1 & $7 / 26 / 2012$ & 197.2 & 274.8 & 86.8 & 72.9 & 45.9 \\
\hline TY-1 & $9 / 17 / 2012$ & 152.1 & 214.5 & 70.0 & 66.5 & 52.1 \\
\hline TY-1 & $10 / 13 / 2012$ & 283.1 & 376.9 & 127.2 & 127.6 & 36.0 \\
\hline TY-1 & $11 / 8 / 2012$ & 184.1 & 269.5 & 77.6 & 72.9 & 49.0 \\
\hline TY-1 & $12 / 2 / 2012$ & 136.1 & 219.6 & 56.7 & 60.5 & 59.0 \\
\hline TY-1 & $12 / 29 / 2012$ & 160.1 & 263.0 & 68.1 & 72.9 & 53.5 \\
\hline & & & & & & \\
\hline
\end{tabular}


Appendix V (cont.). Mean, median, and mode grain size [ $\mu \mathrm{m}]$ of sediment trap sediment and $\%$ trap sediment less than $75 \mu \mathrm{m}$ at TY-2.

\begin{tabular}{|c|c|c|c|c|c|c|}
\hline Sample Name & Date Collected & Mean (um) & S.D. (um) & Median (um) & Mode (um) & $<75$ um (\%) \\
\hline TY-2 & $9 / 18 / 2009$ & 342.2 & 447.7 & 129.5 & 1314.0 & 35.6 \\
\hline TY-2 & $10 / 14 / 2009$ & 318.6 & 395.5 & 157.0 & 168.9 & 30.1 \\
\hline TY-2 & $11 / 8 / 2009$ & 274.8 & 327.5 & 143.3 & 168.9 & 32.5 \\
\hline TY-2 & $12 / 3 / 2009$ & 220.5 & 374.2 & 69.5 & 60.5 & 52.2 \\
\hline TY-2 & $12 / 30 / 2009$ & 183.5 & 304.3 & 64.9 & 60.5 & 54.6 \\
\hline TY-2 & $1 / 25 / 2010$ & 200.5 & 319.2 & 74.7 & 66.5 & 50.3 \\
\hline TY-2 & $2 / 20 / 2010$ & 165.0 & 260.2 & 67.1 & 66.5 & 53.8 \\
\hline TY-2 & $3 / 19 / 2010$ & 226.4 & 306.6 & 95.3 & 72.9 & 43.1 \\
\hline TY-2 & $8 / 23 / 2010$ & 383.9 & 430.3 & 214.7 & 203.5 & 23.5 \\
\hline TY-2 & $9 / 18 / 2010$ & 415.5 & 272.8 & 370.8 & 471.1 & 9.1 \\
\hline TY-2 & $10 / 13 / 2010$ & 448.7 & 382.3 & 346.9 & 391.0 & 11.4 \\
\hline TY-2 & $11 / 13 / 2010$ & 235.6 & 315.7 & 108.1 & 105.9 & 39.9 \\
\hline TY-2 & $12 / 4 / 2010$ & 264.1 & 328.0 & 126.8 & 87.9 & 36.2 \\
\hline TY-2 & $12 / 31 / 2010$ & 244.5 & 340.3 & 101.4 & 80.1 & 40.7 \\
\hline TY-2 & $1 / 25 / 2011$ & 168.6 & 238.0 & 76.9 & 72.9 & 49.2 \\
\hline TY-2 & $2 / 15 / 2011$ & 156.7 & 222.4 & 80.4 & 87.9 & 47.6 \\
\hline TY-2 & $3 / 18 / 2011$ & 594.7 & 510.7 & 477.4 & 905.1 & 15.5 \\
\hline TY-2 & $4 / 13 / 2011$ & 426.8 & 403.9 & 301.6 & 567.8 & 18.2 \\
\hline TY-2 & $7 / 1 / 2011$ & 321.1 & 379.1 & 169.9 & 185.4 & 29.0 \\
\hline TY-2 & $7 / 27 / 2011$ & 282.7 & 367.0 & 139.9 & 185.4 & 33.3 \\
\hline TY-2 & $8 / 26 / 2011$ & 231.6 & 326.9 & 98.1 & 168.9 & 43.7 \\
\hline TY-2 & $9 / 17 / 2011$ & 181.5 & 272.0 & 77.3 & 72.9 & 49.0 \\
\hline TY-2 & $10 / 13 / 2011$ & 237.5 & 329.2 & 106.7 & 96.5 & 39.4 \\
\hline TY-2 & $11 / 7 / 2011$ & 168.5 & 267.0 & 67.5 & 66.5 & 53.4 \\
\hline TY-2 & $12 / 3 / 2011$ & 204.3 & 287.4 & 92.3 & 87.9 & 43.8 \\
\hline TY-2 & $12 / 31 / 2011$ & 161.0 & 240.7 & 69.5 & 66.5 & 52.5 \\
\hline TY-2 & $1 / 24 / 2012$ & 207.9 & 282.7 & 94.7 & 80.1 & 42.7 \\
\hline TY-2 & $2 / 18 / 2012$ & 204.2 & 287.7 & 83.7 & 66.5 & 46.9 \\
\hline TY-2 & $3 / 16 / 2012$ & 196.9 & 272.1 & 86.9 & 80.1 & 45.8 \\
\hline TY-2 & $7 / 26 / 2012$ & 246.0 & 330.1 & 109.5 & 127.7 & 39.7 \\
\hline TY-2 & $8 / 27 / 2012$ & 248.6 & 274.8 & 165.4 & 245.2 & 35.8 \\
\hline TY-2 & $9 / 17 / 2012$ & 168.4 & 255.7 & 64.2 & 55.1 & 54.3 \\
\hline TY-2 & $10 / 13 / 2012$ & 239.2 & 343.4 & 99.2 & 72.9 & 42.6 \\
\hline TY-2 & $11 / 8 / 2012$ & 229.0 & 331.4 & 93.8 & 72.9 & 44.0 \\
\hline TY-2 & $12 / 2 / 2012$ & 227.9 & 307.6 & 106.3 & 116.3 & 40.5 \\
\hline TY-2 & $12 / 29 / 2012$ & 189.5 & 275.4 & 85.9 & 80.1 & 45.9 \\
\hline & & & & & & \\
\hline
\end{tabular}


Appendix V (cont.). Mean, median, and mode grain size [ $\mu \mathrm{m}]$ of sediment trap sediment and $\%$ trap sediment less than $75 \mu \mathrm{m}$ at TT-1.

\begin{tabular}{|c|c|c|c|c|c|c|}
\hline Sample Name & Date Collected & Mean (um) & S.D. (um) & Median (um) & Mode (um) & $<75$ um (\%) \\
\hline TT-1 & $9 / 18 / 2009$ & 358.1 & 399.0 & 207.6 & 203.5 & 22.2 \\
\hline TT-1 & $10 / 14 / 2009$ & 287.0 & 356.1 & 156.4 & 185.4 & 29.2 \\
\hline TT-1 & $11 / 8 / 2009$ & 260.8 & 355.6 & 121.3 & 127.7 & 36.1 \\
\hline TT-1 & $12 / 3 / 2009$ & 301.7 & 426.8 & 106.6 & 66.5 & 41.9 \\
\hline TT-1 & $12 / 30 / 2009$ & 165.0 & 242.6 & 67.7 & 60.5 & 53.3 \\
\hline TT-1 & $1 / 25 / 2010$ & 181.8 & 274.7 & 64.6 & 55.1 & 54.4 \\
\hline TT-1 & $2 / 20 / 2010$ & 192.7 & 291.7 & 75.7 & 66.5 & 49.7 \\
\hline TT-1 & $3 / 19 / 2010$ & 270.9 & 351.6 & 124.0 & 80.1 & 37.0 \\
\hline TT-1 & $8 / 23 / 2010$ & 469.8 & 473.6 & 269.2 & 471.1 & 18.4 \\
\hline TT-1 & $9 / 18 / 2010$ & 493.7 & 278.4 & 467.9 & 567.8 & 6.3 \\
\hline TT-1 & $10 / 13 / 2010$ & 497.4 & 296.0 & 457.7 & 517.2 & 6.2 \\
\hline TT-1 & $11 / 13 / 2010$ & 187.2 & 296.3 & 67.0 & 60.5 & 53.3 \\
\hline TT-1 & $12 / 4 / 2010$ & 200.1 & 282.1 & 84.4 & 66.5 & 46.6 \\
\hline TT-1 & $12 / 31 / 2010$ & 150.7 & 232.9 & 59.9 & 55.1 & 57.0 \\
\hline TT-1 & $1 / 25 / 2011$ & 200.6 & 249.5 & 97.4 & 203.5 & 43.8 \\
\hline TT-1 & $2 / 15 / 2011$ & 229.3 & 294.0 & 124.4 & 168.9 & 35.9 \\
\hline TT-1 & $3 / 18 / 2011$ & 410.1 & 377.6 & 303.8 & 517.2 & 17.7 \\
\hline$\overline{T T-1}$ & $4 / 13 / 2011$ & 319.3 & 322.7 & 218.1 & 391.0 & 23.0 \\
\hline TT-1 & $7 / 1 / 2011$ & 286.1 & 314.3 & 171.4 & 203.5 & 25.5 \\
\hline TT-1 & $7 / 27 / 2011$ & 239.2 & 285.6 & 143.6 & 168.9 & 29.0 \\
\hline TT-1 & $8 / 26 / 2011$ & 137.7 & 208.0 & 51.5 & 31.5 & 59.6 \\
\hline TT-1 & $9 / 17 / 2011$ & 158.6 & 227.7 & 74.1 & 72.9 & 50.4 \\
\hline TT-1 & $10 / 13 / 2011$ & 258.9 & 360.3 & 117.6 & 127.7 & 36.3 \\
\hline TT-1 & $11 / 11 / 2011$ & 206.6 & 318.6 & 74.2 & 60.5 & 50.4 \\
\hline TT-1 & $12 / 3 / 2011$ & 178.4 & 268.4 & 73.9 & 66.5 & 50.5 \\
\hline TT-1 & $12 / 31 / 2011$ & 276.2 & 444.1 & 91.6 & 66.5 & 45.2 \\
\hline TT-1 & $1 / 24 / 2012$ & 230.9 & 320.6 & 96.5 & 66.5 & 43.1 \\
\hline TT-1 & $2 / 18 / 2012$ & 189.1 & 270.0 & 84.8 & 66.5 & 46.5 \\
\hline TT-1 & $3 / 16 / 2012$ & 192.6 & 276.9 & 83.0 & 72.9 & 46.9 \\
\hline TT-1 & $7 / 26 / 2012$ & 273.4 & 333.9 & 154.6 & 185.4 & 27.8 \\
\hline TT-1 & $8 / 27 / 2012$ & 236.0 & 269.4 & 144.0 & 223.4 & 36.2 \\
\hline TT-1 & $9 / 17 / 2012$ & 191.6 & 237.9 & 78.3 & 324.4 & 49.1 \\
\hline TT-1 & $10 / 13 / 2012$ & 223.0 & 333.7 & 88.3 & 60.5 & 45.9 \\
\hline TT-1 & $11 / 8 / 2012$ & 164.9 & 246.6 & 72.3 & 66.4 & 51.2 \\
\hline TT-1 & $12 / 2 / 2012$ & 198.0 & 277.1 & 88.1 & 72.9 & 45.4 \\
\hline TT-1 & $12 / 29 / 2012$ & 251.1 & 428.2 & 79.3 & 66.4 & 49.2 \\
\hline
\end{tabular}


Appendix VI. Benthic sediment mean, median, and mode grain size $(\mu \mathrm{m})$, and $\%$ benthic sediment less than $75 \mu \mathrm{m}$ at BC-1.

\begin{tabular}{|c|c|c|c|c|c|c|c|}
\hline Sample Name & Date Collected & Mean (um) & S.D. (um) & Median (um) & Mode (um) & $<75$ um (\%) & $\% \mathrm{~T}$ \\
\hline $\mathrm{BC}-1$ & $9 / 16 / 09$ & 90.0 & 102.0 & 57.9 & & 57.7 & 61.6 \\
\hline $\mathrm{BC}-1$ & $10 / 12 / 09$ & 155.4 & 188.9 & 94.3 & 96.5 & 41.3 & 51.9 \\
\hline BC-1 & $11 / 7 / 09$ & 102.0 & 129.4 & 64.2 & 80.1 & 55.5 & 51.9 \\
\hline $\mathrm{BC}-1$ & $12 / 29 / 09$ & 223.1 & 387.1 & 83.5 & 153.8 & 46.7 & 47.4 \\
\hline BC-1 & $1 / 24 / 10$ & 131.4 & 139.7 & 91.8 & 153.8 & 42.7 & 50.6 \\
\hline $\mathrm{BC}-1$ & $2 / 19 / 10$ & 102.9 & 143.2 & 61.7 & 72.9 & 57.3 & 47.8 \\
\hline $\mathrm{BC}-1$ & $3 / 17 / 10$ & 178.2 & 312.3 & 82.7 & 87.9 & 46.6 & 51.9 \\
\hline $\mathrm{BC}-1$ & $7 / 25 / 10$ & 269.7 & 327.0 & 124.6 & 623.3 & 43.5 & 27.7 \\
\hline $\mathrm{BC}-1$ & $8 / 20 / 10$ & 142.7 & 185.7 & 73.8 & 153.8 & 50.5 & 55.0 \\
\hline $\mathrm{BC}-1$ & $9 / 15 / 10$ & 205.7 & 256.7 & 100.4 & 168.9 & 43.2 & 58.4 \\
\hline $\mathrm{BC}-1$ & $10 / 11 / 10$ & 104.0 & 123.3 & 67.2 & 80.1 & 54.5 & 40.0 \\
\hline BC-1 & $11 / 7 / 10$ & 133.0 & 168.2 & 79.5 & 96.5 & 48.1 & 68.6 \\
\hline $\mathrm{BC}-1$ & $12 / 2 / 10$ & 130.3 & 182.8 & 69.0 & 80.1 & 52.7 & 57.1 \\
\hline $\mathrm{BC}-1$ & $12 / 29 / 10$ & 93.3 & 141.6 & 49.3 & 66.5 & 64.4 & 58.9 \\
\hline $\mathrm{BC}-1$ & $1 / 23 / 11$ & 142.4 & 211.3 & 71.1 & 80.1 & 51.7 & 63.2 \\
\hline BC-1 & $2 / 13 / 11$ & 214.4 & 255.0 & 132.7 & 168.9 & 31.2 & 61.1 \\
\hline BC-1 & $3 / 16 / 11$ & 228.5 & 195.4 & 178.7 & 203.5 & 16.9 & 56.6 \\
\hline$B C-1$ & $4 / 11 / 11$ & 284.9 & 215.9 & 223.1 & 203.5 & 7.1 & 50.4 \\
\hline BC-1 & $6 / 3 / 11$ & 180.8 & 204.7 & 119.3 & 185.4 & 35.6 & 45.9 \\
\hline$B C-1$ & $6 / 29 / 11$ & 279.3 & 247.1 & 209.0 & 203.5 & 9.0 & 56.8 \\
\hline $\mathrm{BC}-1$ & $7 / 25 / 11$ & 159.2 & 166.4 & 124.1 & 140.1 & 24.9 & 55.3 \\
\hline $\mathrm{BC}-1$ & $8 / 20 / 11$ & 176.0 & 204.5 & 119.1 & 140.1 & 30.9 & 48.6 \\
\hline $\mathrm{BC}-1$ & $9 / 15 / 11$ & 191.0 & 251.2 & 91.6 & 72.9 & 43.0 & \\
\hline BC-1 & $10 / 11 / 11$ & & & & & & 39.5 \\
\hline $\mathrm{BC}-1$ & $11 / 5 / 11$ & 142.6 & 179.0 & 85.3 & 80.1 & 44.8 & 45.1 \\
\hline BC-1 & $12 / 1 / 11$ & 185.4 & 202.2 & 122.6 & 203.5 & 35.0 & \\
\hline BC-1 & $12 / 29 / 11$ & 128.3 & 140.7 & 97.6 & 116.3 & 36.5 & 45.5 \\
\hline BC-1 & $1 / 21 / 12$ & 186.1 & 165.9 & 133.9 & 116.3 & 17.2 & 41.3 \\
\hline BC-1 & $2 / 15 / 12$ & 122.7 & 147.5 & 79.1 & 87.9 & 48.0 & 46.7 \\
\hline $\mathrm{BC}-1$ & $3 / 14 / 12$ & 125.5 & 123.6 & 97.1 & 116.3 & 37.9 & 49.8 \\
\hline BC-1 & $6 / 18 / 12$ & 209.3 & 183.7 & 165.9 & 168.9 & 10.3 & 48.2 \\
\hline $\mathrm{BC}-1$ & $7 / 24 / 12$ & 191.7 & 167.9 & 160.0 & 185.4 & 21.0 & 45.8 \\
\hline BC-1 & $8 / 20 / 12$ & 273.8 & 209.4 & 224.4 & 245.2 & 12.5 & 32.8 \\
\hline BC-1 & $9 / 15 / 12$ & 132.5 & 150.5 & 90.6 & 116.3 & 42.5 & 44.2 \\
\hline $\mathrm{BC}-1$ & $10 / 11 / 12$ & 272.4 & 345.0 & 137.2 & 168.9 & 32.9 & 32.2 \\
\hline BC-1 & $11 / 6 / 12$ & 132.1 & 144.9 & 89.1 & 87.9 & 41.2 & 40.6 \\
\hline BC-1 & $12 / 3 / 12$ & 145.9 & 201.5 & 86.6 & 87.9 & 43.9 & 34.8 \\
\hline BC-1 & $12 / 28 / 12$ & 206.3 & 187.7 & 151.1 & 140.1 & 14.1 & 31.9 \\
\hline
\end{tabular}


Appendix VI (cont.). Benthic sediment mean, median, and mode grain size $(\mu \mathrm{m})$, and $\%$ benthic sediment less than $75 \mu \mathrm{m}$ at BC-3.

\begin{tabular}{|c|c|c|c|c|c|c|c|}
\hline Sample Name & Date Collected & Mean (um) & S.D. (um) & Median (um) & Mode (um) & $<75$ um (\%) & $\% \mathrm{~T}$ \\
\hline$B C-3$ & $9 / 16 / 09$ & 308.0 & 251.6 & 253.1 & 391.0 & 16.3 & 54.5 \\
\hline$B C-3$ & $10 / 12 / 09$ & 239.3 & 233.3 & 179.8 & 245.2 & 27.3 & 60.9 \\
\hline $\mathrm{BC}-3$ & $11 / 7 / 09$ & 261.5 & 241.1 & 212.4 & 295.5 & 26.7 & 65.4 \\
\hline BC-3 & $12 / 2 / 09$ & 220.7 & 424.8 & 68.4 & 1584.0 & 53.6 & 73.4 \\
\hline $\mathrm{BC}-3$ & $12 / 29 / 09$ & 165.9 & 163.7 & 111.2 & 96.5 & 33.9 & 66.3 \\
\hline $\mathrm{BC}-3$ & $1 / 24 / 10$ & 175.0 & 167.5 & 134.6 & 223.4 & 33.4 & 70.4 \\
\hline$B C-3$ & $2 / 19 / 10$ & 194.6 & 188.2 & 144.0 & 223.4 & 29.9 & 50.4 \\
\hline $\mathrm{BC}-3$ & $3 / 17 / 10$ & 216.1 & 215.2 & 165.7 & 223.4 & 32.8 & 78.5 \\
\hline $\mathrm{BC}-3$ & $7 / 25 / 10$ & 203.3 & 340.2 & 101.8 & 127.7 & 39.2 & 85.7 \\
\hline $\mathrm{BC}-3$ & $8 / 20 / 10$ & 271.2 & 342.2 & 183.3 & 324.4 & 31.8 & 82.2 \\
\hline $\mathrm{BC}-3$ & $9 / 15 / 10$ & 151.9 & 161.9 & 107.9 & 153.8 & 37.8 & 86.6 \\
\hline $\mathrm{BC}-3$ & $10 / 11 / 10$ & 247.9 & 187.3 & 212.9 & 223.4 & 16.7 & 95.9 \\
\hline $\mathrm{BC}-3$ & $11 / 7 / 10$ & 169.0 & 161.7 & 131.3 & 153.8 & 26.4 & 94.5 \\
\hline $\mathrm{BC}-3$ & $12 / 2 / 10$ & 289.6 & 216.7 & 251.9 & 295.5 & 15.0 & 85.0 \\
\hline $\mathrm{BC}-3$ & $12 / 29 / 10$ & 211.3 & 271.5 & 105.1 & 203.5 & 41.1 & 70.2 \\
\hline $\mathrm{BC}-3$ & $1 / 23 / 11$ & 172.3 & 193.0 & 106.0 & 96.5 & 29.9 & 63.8 \\
\hline$B C-3$ & $2 / 13 / 11$ & 115.9 & 149.0 & 86.6 & 80.1 & 37.7 & 89.6 \\
\hline$B C-3$ & $3 / 16 / 11$ & 255.1 & 258.3 & 163.3 & 80.1 & 26.5 & 86.0 \\
\hline $\mathrm{BC}-3$ & $4 / 11 / 11$ & 200.0 & 247.0 & 101.0 & 80.1 & 37.2 & 89.3 \\
\hline $\mathrm{BC}-3$ & $6 / 3 / 11$ & 166.9 & 178.5 & 111.9 & 105.9 & 13.0 & 92.2 \\
\hline $\mathrm{BC}-3$ & $6 / 29 / 11$ & 374.4 & 297.9 & 304.1 & 429.2 & 13.2 & 88.4 \\
\hline$B C-3$ & $7 / 25 / 11$ & 90.1 & 34.3 & 89.5 & 87.9 & 28.6 & 94.8 \\
\hline$B C-3$ & $8 / 20 / 11$ & 116.5 & 42.6 & 112.2 & 116.3 & 12.3 & 94.5 \\
\hline $\mathrm{BC}-3$ & $9 / 15 / 11$ & 247.5 & 184.2 & 204.5 & 223.4 & 8.9 & \\
\hline $\mathrm{BC}-3$ & $10 / 13 / 11$ & 192.3 & 182.6 & 127.5 & 105.9 & 20.9 & 88.6 \\
\hline $\mathrm{BC}-3$ & $11 / 5 / 11$ & 160.7 & 119.6 & 133.3 & 127.7 & 10.4 & 87.8 \\
\hline $\mathrm{BC}-3$ & $12 / 1 / 11$ & 119.3 & 60.4 & 111.9 & 116.3 & 18.2 & \\
\hline $\mathrm{BC}-3$ & $12 / 29 / 11$ & 99.8 & 46.5 & 93.0 & 96.5 & 30.9 & 88.8 \\
\hline $\mathrm{BC}-3$ & $1 / 21 / 12$ & 160.7 & 157.4 & 114.8 & 105.9 & 19.0 & 88.2 \\
\hline $\mathrm{BC}-3$ & $2 / 15 / 12$ & 173.8 & 169.4 & 120.9 & 105.9 & 13.0 & 87.9 \\
\hline $\mathrm{BC}-3$ & $3 / 14 / 12$ & 118.6 & 87.2 & 97.6 & 96.5 & 23.1 & 88.3 \\
\hline $\mathrm{BC}-3$ & $6 / 28 / 12$ & 149.5 & 138.7 & 118.7 & 116.3 & 10.3 & 89.5 \\
\hline$B C-3$ & $7 / 24 / 12$ & 182.2 & 216.9 & 120.1 & 127.7 & 28.0 & 86.6 \\
\hline $\mathrm{BC}-3$ & $8 / 20 / 12$ & 199.9 & 177.5 & 152.7 & 140.1 & 6.1 & 89.5 \\
\hline $\mathrm{BC}-3$ & $9 / 15 / 12$ & 156.8 & 92.4 & 137.5 & 127.7 & 9.1 & 87.7 \\
\hline $\mathrm{BC}-3$ & $10 / 11 / 12$ & 152.4 & 142.9 & 124.5 & 127.6 & 10.2 & 88.4 \\
\hline $\mathrm{BC}-3$ & $11 / 6 / 12$ & 132.6 & 111.2 & 113.9 & 116.3 & 18.9 & 81.7 \\
\hline $\mathrm{BC}-3$ & $12 / 3 / 12$ & 107.8 & 57.7 & 100.0 & 105.9 & 23.5 & 86.4 \\
\hline $\mathrm{BC}-3$ & $12 / 28 / 12$ & 166.8 & 128.6 & 139.4 & 140.1 & 6.2 & 87.1 \\
\hline
\end{tabular}


Appendix VI (cont.). Benthic sediment mean, median, and mode grain size $(\mu \mathrm{m})$, and $\%$ benthic sediment less than $75 \mu \mathrm{m}$ at BC-5.

\begin{tabular}{|c|c|c|c|c|c|c|c|}
\hline Sample Name & Date Collected & Mean (um) & S.D. (um) & Median (um) & Mode (um) & $<75$ um (\%) & \%T \\
\hline BC-5 & $9 / 16 / 09$ & 112.9 & 108.3 & 90.3 & 127.7 & 42.6 & 86.0 \\
\hline$B C-5$ & $10 / 12 / 09$ & 133.3 & 144.6 & 95.4 & 116.3 & 41.6 & 88.5 \\
\hline$B C-5$ & $11 / 7 / 09$ & 129.4 & 171.0 & 71.0 & 96.5 & 51.6 & \begin{tabular}{|l|}
87.7 \\
\end{tabular} \\
\hline $\mathrm{BC}-5$ & $12 / 2 / 09$ & 234.1 & 413.7 & 90.3 & 153.8 & 44.7 & 88.3 \\
\hline$B C-5$ & $12 / 29 / 09$ & 107.3 & 154.5 & 52.5 & 72.9 & 59.5 & 84.0 \\
\hline BC-5 & $1 / 24 / 10$ & 118.3 & 141.3 & 77.4 & 153.8 & 49.0 & \begin{tabular}{|l|}
88.5 \\
\end{tabular} \\
\hline $\mathrm{BC}-5$ & $2 / 19 / 10$ & 109.2 & 145.5 & 63.9 & 96.5 & 55.1 & 89.5 \\
\hline$B C-5$ & $3 / 17 / 10$ & 124.2 & 198.4 & 69.1 & 96.5 & 52.7 & 90.8 \\
\hline BC-5 & $7 / 25 / 10$ & 137.2 & 198.8 & 26.4 & 185.4 & 52.0 & 83.4 \\
\hline$B C-5$ & $8 / 20 / 10$ & 170.3 & 272.1 & 32.4 & 116.3 & 39.4 & 88.7 \\
\hline BC-5 & $9 / 15 / 10$ & 101.8 & 142.4 & 28.6 & 80.1 & 54.9 & 88.1 \\
\hline BC-5 & $10 / 11 / 10$ & 132.9 & 200.9 & 39.0 & 105.9 & 51.5 & 90.8 \\
\hline BC-5 & $11 / 7 / 10$ & 89.7 & 132.1 & 44.1 & 60.5 & 61.8 & 92.1 \\
\hline BC-5 & $12 / 2 / 10$ & 101.1 & 164.7 & 19.6 & 66.5 & 60.1 & 91.6 \\
\hline$B C-5$ & $12 / 29 / 10$ & 151.9 & 222.0 & 30.7 & 72.9 & 46.4 & 89.8 \\
\hline BC-5 & $1 / 23 / 11$ & 141.6 & 177.2 & 33.0 & 140.1 & 43.0 & 90.7 \\
\hline BC-5 & $2 / 13 / 11$ & 226.9 & 385.1 & 36.1 & 72.9 & 41.9 & 93.0 \\
\hline BC-5 & $3 / 16 / 11$ & 154.5 & 213.1 & 23.6 & 185.4 & 46.9 & 90.2 \\
\hline BC-5 & $4 / 11 / 11$ & 158.8 & 218.7 & 24.9 & 72.9 & 45.2 & 90.6 \\
\hline BC-5 & $6 / 3 / 11$ & 188.4 & 268.0 & 30.8 & 140.1 & 37.5 & 90.2 \\
\hline BC-5 & $6 / 29 / 11$ & 168.5 & 216.4 & 35.9 & 140.1 & 38.4 & 91.4 \\
\hline BC-5 & $7 / 25 / 11$ & 124.6 & 196.7 & 30.1 & 66.5 & 55.4 & 91.4 \\
\hline$B C-5$ & $8 / 20 / 11$ & 177.3 & 236.7 & 28.4 & 168.9 & 41.6 & 90.0 \\
\hline BC-5 & $9 / 15 / 11$ & 204.2 & 255.1 & 27.5 & 127.7 & 31.6 & \\
\hline$B C-5$ & $10 / 11 / 11$ & 163.0 & 221.3 & 52.9 & 127.7 & 41.7 & 90.6 \\
\hline$B C-5$ & $11 / 5 / 11$ & 128.2 & 177.5 & 24.1 & 185.5 & 46.2 & 84.1 \\
\hline BC-5 & $12 / 1 / 11$ & 121.7 & 172.6 & 34.9 & 96.5 & 50.1 & \\
\hline$B C-5$ & $12 / 29 / 11$ & 169.5 & 193.2 & 34.3 & 127.7 & 28.4 & 88.9 \\
\hline BC-5 & $1 / 21 / 12$ & 166.2 & 198.9 & 43.5 & 140.1 & 33.6 & 89.1 \\
\hline BC-5 & $2 / 15 / 12$ & 129.7 & 178.9 & 21.1 & 96.5 & 46.0 & 89.3 \\
\hline$B C-5$ & $3 / 14 / 12$ & 171.7 & 217.2 & 39.2 & 116.3 & 34.9 & 88.5 \\
\hline BC-5 & $6 / 28 / 12$ & 156.4 & 200.5 & 26.5 & 116.3 & 41.3 & 89.3 \\
\hline$B C-5$ & $7 / 24 / 12$ & 174.7 & 217.7 & 41.7 & 127.7 & 34.4 & 86.3 \\
\hline BC-5 & $8 / 26 / 12$ & 187.4 & 206.9 & 32.2 & 127.7 & 24.7 & 88.5 \\
\hline BC-5 & $9 / 15 / 12$ & 147.8 & 212.6 & 29.2 & 80.1 & 46.6 & 89.5 \\
\hline BC-5 & $10 / 11 / 12$ & 168.9 & 234.7 & 57.4 & 60.5 & 45.0 & 37.0 \\
\hline BC-5 & $11 / 6 / 12$ & 139.8 & 192.1 & 44.6 & 116.3 & 46.2 & 88.6 \\
\hline BC-5 & $12 / 3 / 12$ & 163.6 & 202.9 & 50.5 & 153.8 & 31.5 & 86.4 \\
\hline BC-5 & $12 / 28 / 12$ & 249.6 & 332.5 & 41.3 & 185.4 & 37.1 & 86.5 \\
\hline
\end{tabular}


Appendix VI (cont.). Benthic sediment mean, median, and mode grain size $(\mu \mathrm{m})$, and $\%$ benthic sediment less than $75 \mu \mathrm{m}$ at BC-8.

\begin{tabular}{|c|c|c|c|c|c|c|c|}
\hline Sample Name & Date Collected & \begin{tabular}{|l|} 
Mean (um) \\
\end{tabular} & S.D. (um) & Median (um) & Mode (um) & $<75$ um (\%) & $\% \mathrm{~T}$ \\
\hline $\mathrm{BC}-8$ & $9 / 16 / 09$ & 108.8 & 150.0 & 64.2 & 66.5 & 57.1 & 78.6 \\
\hline BC-8 & $10 / 12 / 09$ & 129.0 & 152.4 & 77.7 & 72.9 & 48.5 & 79.1 \\
\hline BC-8 & $11 / 7 / 09$ & 122.1 & 167.7 & 70.0 & 72.9 & 53.0 & 75.5 \\
\hline BC-8 & $12 / 2 / 09$ & 134.6 & 252.2 & 62.8 & 72.9 & 56.7 & 78.6 \\
\hline BC-8 & $12 / 29 / 09$ & 106.3 & 136.8 & 62.8 & 72.9 & 56.7 & 77.1 \\
\hline BC-8 & $1 / 24 / 10$ & 121.9 & 153.1 & 76.1 & 80.1 & 49.3 & 78.4 \\
\hline BC-8 & $2 / 19 / 10$ & 103.5 & 129.8 & 69.5 & 72.9 & 53.8 & 80.6 \\
\hline BC-8 & $3 / 17 / 10$ & 98.1 & 125.8 & 61.1 & 72.9 & 58.1 & 80.7 \\
\hline BC-8 & $7 / 25 / 10$ & 90.7 & 159.2 & 59.3 & 66.5 & 67.1 & 83.4 \\
\hline $\mathrm{BC}-8$ & $8 / 20 / 10$ & 96.7 & 150.6 & 49.6 & 66.5 & 62.4 & 80.6 \\
\hline BC-8 & $9 / 15 / 10$ & 82.8 & 108.7 & 32.5 & 66.5 & 64.3 & 80.0 \\
\hline $\mathrm{BC}-8$ & $10 / 11 / 10$ & 70.4 & 108.8 & 38.4 & 60.5 & 73.6 & 79.8 \\
\hline BC-8 & $11 / 7 / 10$ & 103.1 & 123.5 & 62.9 & 87.9 & 53.3 & 86.0 \\
\hline$B C-8$ & $12 / 2 / 10$ & 79.7 & 130.3 & 61.4 & 72.9 & 69.7 & 86.6 \\
\hline BC-8 & $12 / 29 / 10$ & 115.7 & 184.1 & 61.1 & 80.1 & 57.1 & 85.3 \\
\hline BC-8 & $1 / 23 / 11$ & 90.6 & 123.3 & 24.5 & 72.9 & 61.5 & 79.7 \\
\hline BC-8 & $2 / 13 / 11$ & 118.3 & 145.1 & 29.5 & 96.5 & 43.7 & 74.4 \\
\hline BC-8 & $3 / 16 / 11$ & 121.9 & 175.0 & 60.5 & 72.9 & 55.4 & 84.1 \\
\hline $\mathrm{BC}-8$ & $4 / 11 / 11$ & 121.9 & 180.0 & 29.1 & 80.1 & 55.2 & 86.3 \\
\hline BC-8 & $6 / 3 / 11$ & 137.9 & 174.8 & 24.9 & 87.9 & 45.5 & 84.7 \\
\hline $\mathrm{BC}-8$ & $6 / 29 / 11$ & 138.3 & 177.1 & 28.8 & 105.9 & 47.2 & 79.9 \\
\hline BC-8 & $7 / 25 / 11$ & 118.7 & 184.4 & 22.8 & 66.5 & 58.7 & 80.7 \\
\hline$B C-8$ & $8 / 20 / 11$ & 98.1 & 141.7 & 41.1 & 72.9 & 61.5 & 81.9 \\
\hline BC-8 & $9 / 15 / 11$ & 136.5 & 196.5 & 34.3 & 80.1 & 51.3 & \\
\hline BC-8 & $10 / 11 / 11$ & 82.1 & 131.6 & 29.6 & 60.5 & 69.5 & 77.9 \\
\hline BC-8 & $11 / 5 / 11$ & 78.6 & 120.4 & 29.1 & 66.5 & 69.6 & 82.9 \\
\hline $\mathrm{BC}-8$ & $12 / 1 / 11$ & 92.5 & 150.8 & 23.9 & 66.5 & 66.0 & \\
\hline $\mathrm{BC}-8$ & $12 / 29 / 11$ & 91.9 & 148.2 & 24.9 & 72.9 & 65.2 & 79.0 \\
\hline $\mathrm{BC}-8$ & $1 / 21 / 12$ & 110.2 & 163.0 & 51.0 & 72.9 & 57.5 & 80.1 \\
\hline BC-8 & $2 / 15 / 12$ & 91.1 & 140.5 & 29.0 & 66.5 & 64.3 & 77.6 \\
\hline BC-8 & $3 / 14 / 12$ & 169.2 & 209.5 & 30.6 & 60.5 & 47.0 & 78.5 \\
\hline BC-8 & $6 / 28 / 12$ & 119.0 & 164.2 & 26.2 & 60.5 & 55.5 & 75.5 \\
\hline$B C-8$ & $7 / 24 / 12$ & 154.2 & 199.7 & 29.2 & 96.5 & 38.6 & 78.2 \\
\hline BC-8 & $8 / 20 / 12$ & 156.6 & 230.6 & 28.4 & 87.9 & 44.7 & 77.4 \\
\hline BC-8 & $9 / 15 / 12$ & 145.2 & 180.7 & 25.8 & 87.9 & 41.8 & 83.8 \\
\hline BC-8 & $12 / 28 / 12$ & 160.0 & 210.7 & 42.8 & 87.9 & 39.4 & 70.1 \\
\hline
\end{tabular}


Appendix VI (cont.). Benthic sediment mean, median, and mode grain size $(\mu \mathrm{m})$, and $\%$ benthic sediment less than $75 \mu \mathrm{m}$ at BC-10B.

\begin{tabular}{|c|c|c|c|c|c|c|c|}
\hline Sample Name & Date Collected & Mean (um) & S.D. (um) & Median (um) & Mode (um) & $<75$ um (\%) & \%T \\
\hline BC-10B & $9 / 16 / 09$ & 237.8 & 276.4 & 145.1 & 356.1 & 37.7 & 48.2 \\
\hline$B C-10 B$ & $10 / 12 / 09$ & 197.8 & 205.1 & 144.0 & 223.4 & 36.4 & 51.9 \\
\hline BC-10B & $11 / 7 / 09$ & 206.3 & 211.8 & 156.3 & 245.2 & 35.7 & 38.7 \\
\hline BC-10B & $12 / 2 / 09$ & 250.4 & 400.4 & 97.7 & 185.4 & 44.2 & 43.5 \\
\hline BC-10B & $12 / 29 / 09$ & 289.6 & 301.2 & 200.8 & 429.2 & 32.3 & 43.0 \\
\hline BC-10B & $1 / 24 / 10$ & 162.5 & 188.4 & 97.6 & 223.4 & 44.7 & 33.2 \\
\hline $\mathrm{BC}-10 \mathrm{~B}$ & $2 / 19 / 10$ & 260.5 & 294.6 & 138.0 & 517.2 & 40.6 & 34.8 \\
\hline BC-10B & $3 / 17 / 10$ & 266.6 & 248.4 & 211.9 & 269.2 & 24.8 & 30.7 \\
\hline BC-10B & $7 / 25 / 10$ & 475.4 & 479.4 & 331.8 & 391.0 & 17.7 & 39.8 \\
\hline $\mathrm{BC}-10 \mathrm{~B}$ & $8 / 20 / 10$ & 299.9 & 315.9 & 200.1 & 391.0 & 30.6 & 23.5 \\
\hline BC-10B & $9 / 15 / 10$ & 282.3 & 235.5 & 254.3 & 324.4 & 23.8 & 31.9 \\
\hline BC-10B & $10 / 11 / 10$ & 238.3 & 290.7 & 154.6 & 223.4 & 34.7 & 93.9 \\
\hline BC-10B & $11 / 8 / 10$ & 315.1 & 267.1 & 269.2 & 324.4 & 23.4 & 74.3 \\
\hline BC-10B & $12 / 2 / 10$ & 255.6 & 259.8 & 184.0 & 356.1 & 32.9 & 76.2 \\
\hline BC-10B & $12 / 29 / 10$ & 202.5 & 282.9 & 86.6 & 203.5 & 47.1 & 78.4 \\
\hline $\mathrm{BC}-10 \mathrm{~B}$ & $1 / 23 / 11$ & 169.7 & 219.2 & 78.4 & 185.4 & 49.1 & 77.9 \\
\hline BC-10B & $2 / 13 / 11$ & 308.2 & 215.6 & 281.4 & 324.4 & 14.2 & 36.9 \\
\hline BC-10B & $3 / 16 / 11$ & 209.7 & 262.7 & 106.7 & 223.4 & 43.3 & 67.4 \\
\hline BC-10B & $4 / 11 / 11$ & 211.2 & 267.8 & 103.7 & 203.5 & 43.7 & 46.1 \\
\hline BC-10B & $6 / 3 / 11$ & 246.9 & 277.9 & 147.4 & 203.5 & 35.1 & 66.1 \\
\hline BC-10B & $6 / 29 / 11$ & 324.6 & 298.6 & 259.2 & 391.0 & 24.4 & 49.1 \\
\hline BC-10B & $7 / 25 / 11$ & 262.3 & 302.4 & 153.9 & 203.5 & 34.9 & 42.9 \\
\hline$B C-10 B$ & $8 / 20 / 11$ & 209.7 & 251.2 & 106.8 & 223.4 & 43.4 & 70.6 \\
\hline BC-10B & $9 / 15 / 11$ & 294.6 & 275.8 & 225.9 & 429.2 & 27.0 & \\
\hline$B C-10 B$ & $10 / 11 / 11$ & 273.4 & 253.6 & 211.5 & 429.2 & 27.5 & 37.8 \\
\hline BC-10B & $11 / 5 / 11$ & 221.3 & 244.2 & 144.5 & 245.2 & 39.0 & 54.1 \\
\hline BC-10B & $12 / 1 / 11$ & 146.1 & 220.5 & 52.4 & 60.5 & 57.8 & \\
\hline$B C-10 B$ & $12 / 29 / 11$ & 282.4 & 273.1 & 210.7 & 429.2 & 29.6 & 48.6 \\
\hline $\mathrm{BC}-10 \mathrm{~B}$ & $1 / 21 / 12$ & 199.5 & 219.2 & 130.4 & 203.5 & 35.9 & 44.9 \\
\hline BC-10B & $2 / 15 / 12$ & 238.4 & 255.1 & 158.7 & 203.5 & 30.8 & 45.1 \\
\hline $\mathrm{BC}-10 \mathrm{~B}$ & $3 / 14 / 12$ & 291.1 & 249.5 & 235.8 & 269.2 & 18.6 & 40.2 \\
\hline BC-10B & $6 / 28 / 12$ & 173.2 & 226.2 & 78.9 & 223.4 & 49.0 & 43.5 \\
\hline BC-10B & $7 / 24 / 12$ & 173.4 & 214.1 & 90.4 & 203.5 & 46.2 & 47.5 \\
\hline BC-10B & $8 / 20 / 12$ & 365.6 & 274.5 & 317.7 & 429.2 & 12.8 & 444.0 \\
\hline $\mathrm{BC}-10 \mathrm{~B}$ & $9 / 15 / 12$ & 122.6 & 180.6 & 56.3 & 66.5 & 57.7 & 43.7 \\
\hline BC-10B & $10 / 11 / 12$ & 188.8 & 242.7 & 110.0 & 127.6 & 36.7 & 88.2 \\
\hline BC-10B & $11 / 6 / 12$ & 240.2 & 267.6 & 168.9 & 356.1 & 38.0 & 34.2 \\
\hline $\mathrm{BC}-10 \mathrm{~B}$ & $12 / 3 / 12$ & 166.6 & 218.3 & 84.1 & 116.3 & 46.9 & 35.0 \\
\hline $\mathrm{BC}-10 \mathrm{~B}$ & $12 / 28 / 12$ & 269.2 & 334.4 & 134.8 & 153.8 & 36.1 & 33.7 \\
\hline
\end{tabular}


Appendix VI (cont.). Benthic sediment mean, median, and mode grain size $(\mu \mathrm{m})$, and $\%$ benthic sediment less than $75 \mu \mathrm{m}$ at BC-11.

\begin{tabular}{|c|c|c|c|c|c|c|c|}
\hline Sample Name & Date Collected & Mean (um) & S.D. (um) & Median (um) & Mode (um) & $<75$ um (\%) & \%T \\
\hline BC-11 & $9 / 16 / 09$ & 142.0 & 208.1 & 53.1 & 66.5 & 58.2 & 12.2 \\
\hline BC-11 & $10 / 12 / 09$ & 106.4 & 140.3 & 47.2 & 60.5 & 61.0 & 11.0 \\
\hline BC-11 & $11 / 7 / 09$ & 169.1 & 221.4 & 74.0 & 223.4 & 50.3 & 12.4 \\
\hline BC-11 & $12 / 2 / 09$ & 210.6 & 379.5 & 55.7 & 60.5 & 57.4 & 14.5 \\
\hline BC-11 & $12 / 29 / 09$ & 92.8 & 5130.4 & 41.2 & 60.5 & 65.9 & 9.4 \\
\hline BC-11 & $1 / 24 / 10$ & 88.8 & 142.8 & 31.3 & 28.7 & 71.9 & \begin{tabular}{|l|}
11.2 \\
\end{tabular} \\
\hline BC-11 & $2 / 19 / 10$ & 243.0 & 310.9 & 89.6 & 684.2 & 46.8 & 3.4 \\
\hline BC-11 & $3 / 17 / 10$ & 137.9 & 197.4 & 51.7 & 60.5 & 58.7 & 8.6 \\
\hline BC-11 & $7 / 25 / 10$ & 182.2 & 273.9 & 56.3 & 185.4 & 55.8 & 11.7 \\
\hline BC-11 & $8 / 20 / 10$ & 211.7 & 299.8 & 52.1 & 824.5 & 55.4 & \begin{tabular}{|l|}
6.7 \\
\end{tabular} \\
\hline BC-11 & $9 / 15 / 10$ & 462.9 & 372.3 & 447.4 & 824.5 & 25.2 & \begin{tabular}{|l|}
9.4 \\
\end{tabular} \\
\hline BC-11 & $10 / 11 / 10$ & 201.9 & 273.9 & 60.4 & 517.2 & 53.4 & \begin{tabular}{|l|}
7.3 \\
\end{tabular} \\
\hline BC-11 & $11 / 7 / 10$ & 79.2 & 142.2 & 25.8 & 28.7 & 76.2 & 6.7 \\
\hline BC-11 & $12 / 2 / 10$ & 73.0 & 141.1 & 24.8 & 28.7 & 78.1 & 11.2 \\
\hline BC-11 & $12 / 29 / 10$ & 158.2 & 231.1 & 55.9 & 60.5 & 57.6 & 6.6 \\
\hline BC-11 & $1 / 23 / 01$ & 117.1 & 224.2 & 27.5 & 28.7 & 73.9 & 7.0 \\
\hline BC-11 & $2 / 13 / 11$ & 66.5 & 109.4 & 28.8 & 28.7 & 76.6 & 14.1 \\
\hline BC-11 & $3 / 16 / 11$ & 184.8 & 297.9 & 43.6 & 28.7 & 62.2 & 5.9 \\
\hline BC-11 & $4 / 11 / 11$ & 147.5 & 270.8 & 26.0 & 26.2 & 70.6 & 4.5 \\
\hline BC-11 & $6 / 3 / 11$ & 177.5 & 239.4 & 54.6 & 471.1 & 55.2 & \begin{tabular}{|l|}
6.7 \\
\end{tabular} \\
\hline BC-11 & $6 / 29 / 11$ & 334.5 & 424.4 & 71.0 & 905.1 & 50.6 & 6.9 \\
\hline BC-11 & $7 / 25 / 11$ & 275.1 & 273.0 & 201.6 & 391.0 & 31.3 & 9.0 \\
\hline BC-11 & $8 / 20 / 11$ & 263.8 & 299.3 & 141.4 & 571.2 & 41.9 & 10.0 \\
\hline BC-11 & $9 / 15 / 11$ & 117.1 & 215.9 & 26.2 & 28.7 & 72.7 & \\
\hline BC-11 & $10 / 11 / 11$ & 62.4 & 118.6 & 20.4 & 26.2 & 80.0 & \begin{tabular}{|l|}
4.7 \\
\end{tabular} \\
\hline BC-11 & $11 / 7 / 11$ & 82.0 & 143.0 & 28.0 & 28.7 & 74.5 & 6.5 \\
\hline BC-11 & $12 / 1 / 11$ & 54.3 & 92.9 & 20.0 & 26.2 & 82.0 & \\
\hline BC-11 & $12 / 29 / 11$ & 347.5 & 396.2 & 112.2 & 905.1 & 45.9 & 3.9 \\
\hline BC-11 & $1 / 21 / 12$ & 289.7 & 376.1 & 69.8 & 751.1 & 51.1 & 5.8 \\
\hline BC-11 & $2 / 15 / 12$ & 399.7 & 368.6 & 313.3 & 623.3 & 27.4 & \begin{tabular}{|l|}
3.7 \\
\end{tabular} \\
\hline BC-11 & $3 / 14 / 12$ & 195.8 & 291.0 & 43.5 & 28.7 & 59.4 & 3.6 \\
\hline BC-11 & $6 / 28 / 12$ & 227.5 & 313.9 & 44.0 & 567.8 & 58.3 & \begin{tabular}{|l|}
6.7 \\
\end{tabular} \\
\hline BC-11 & $7 / 24 / 12$ & 240.6 & 352.2 & 40.9 & 993.6 & 59.1 & 3.0 \\
\hline BC-11 & $8 / 27 / 12$ & 249.5 & 313.2 & 90.0 & 567.8 & 47.6 & \begin{tabular}{|l|}
7.1 \\
\end{tabular} \\
\hline BC-11 & $9 / 15 / 12$ & 27.6 & 35.1 & 11.5 & 7.1 & 89.6 & 6.4 \\
\hline BC-11 & $10 / 11 / 12$ & & & & & & 9.1 \\
\hline BC-11 & $11 / 6 / 12$ & 222.5 & 319.2 & 42.6 & 26.1 & 58.1 & \begin{tabular}{|l|}
7.3 \\
\end{tabular} \\
\hline BC-11 & $12 / 3 / 12$ & 489.8 & 402.2 & 428.2 & 751.1 & 19.1 & 7.3 \\
\hline BC-11 & $12 / 28 / 12$ & 469.4 & 365.5 & 441.4 & 684.2 & 21.2 & 6.1 \\
\hline
\end{tabular}


Appendix VI (cont.). Benthic sediment mean, median, and mode grain size $(\mu \mathrm{m})$, and $\%$ benthic sediment less than $75 \mu \mathrm{m}$ at BC-12.

\begin{tabular}{|c|c|c|c|c|c|c|c|}
\hline Sample Name & Date Collected & Mean (um) & S.D. (um) & Median (um) & Mode (um) & $<75$ um (\%) & \%T \\
\hline $\mathrm{BC}-12$ & $9 / 16 / 09$ & 411.3 & 353.6 & 365.2 & 623.3 & 26.7 & 8.2 \\
\hline BC-12 & $10 / 12 / 09$ & 397.1 & 327.7 & 332.6 & 471.1 & 16.1 & 4.7 \\
\hline BC-12 & $11 / 7 / 09$ & 502.6 & 368.4 & 499.2 & 751.1 & 19.4 & 6.4 \\
\hline BC-12 & $12 / 2 / 09$ & 349.1 & 481.3 & 83.4 & 1314.0 & 48.8 & 10.2 \\
\hline BC-12 & $12 / 29 / 09$ & 270.8 & 345.3 & 90.8 & 905.1 & 47.0 & 4.4 \\
\hline BC-12 & $1 / 24 / 10$ & 223.6 & 273.0 & 95.7 & 567.8 & 46.5 & 9.5 \\
\hline $\mathrm{BC}-12$ & $2 / 19 / 10$ & 320.2 & 299.8 & 235.7 & 245.2 & 23.7 & 5.2 \\
\hline$B C-12$ & $3 / 17 / 10$ & 502.7 & 344.9 & 473.2 & 623.3 & 12.9 & 4.6 \\
\hline $\mathrm{BC}-12$ & $7 / 25 / 10$ & 424.9 & 390.5 & 303.8 & 28.7 & 12.0 & 5.7 \\
\hline BC-12 & $8 / 20 / 10$ & 438.8 & 348.3 & 382.5 & 72.9 & 15.3 & 4.0 \\
\hline$B C-12$ & $9 / 15 / 10$ & 560.7 & 366.2 & 553.7 & 73.9 & 12.7 & 3.0 \\
\hline$B C-12$ & $10 / 11 / 10$ & 555.7 & 327.4 & 530.1 & 1739.0 & 7.2 & 4.7 \\
\hline$B C-12$ & $11 / 7 / 10$ & 459.5 & 321.1 & 413.1 & 28.7 & 13.4 & 3.8 \\
\hline$B C-12$ & $12 / 2 / 10$ & 589.7 & 383.9 & 593.2 & 66.5 & 14.3 & 3.4 \\
\hline$B C-12$ & $12 / 29 / 10$ & 178.8 & 262.1 & 52.0 & 66.5 & 57.6 & 4.0 \\
\hline$B C-12$ & $1 / 23 / 11$ & 340.7 & 365.8 & 205.8 & 66.5 & 36.6 & 4.1 \\
\hline$B C-12$ & $2 / 13 / 11$ & 274.5 & 289.8 & 164.6 & 31.5 & 41.6 & 7.0 \\
\hline$B C-12$ & $3 / 16 / 11$ & 528.0 & 316.7 & 510.6 & 168.9 & 9.5 & 3.5 \\
\hline$B C-12$ & $4 / 11 / 11$ & 385.2 & 307.3 & 333.3 & 66.5 & 18.6 & 5.0 \\
\hline$B C-12$ & $6 / 5 / 11$ & 553.5 & 418.2 & 520.1 & 203.5 & 16.4 & 3.9 \\
\hline $\mathrm{BC}-12$ & $6 / 29 / 11$ & 386.4 & 320.6 & 321.0 & 28.7 & 20.1 & 5.9 \\
\hline BC-12 & $7 / 27 / 11$ & 74.1 & 130.0 & 27.0 & 66.5 & 75.1 & 7.1 \\
\hline$B C-12$ & $8 / 20 / 11$ & 453.3 & 352.9 & 397.9 & 80.1 & 17.5 & 7.2 \\
\hline$B C-12$ & $9 / 15 / 11$ & 546.9 & 332.4 & 526.0 & 60.5 & 9.4 & \\
\hline BC-12 & $10 / 11 / 11$ & 412.6 & 354.7 & 380.3 & 31.5 & 28.1 & 1.2 \\
\hline$B C-12$ & $11 / 5 / 11$ & 314.0 & 271.2 & 274.3 & 28.7 & 26.6 & 4.4 \\
\hline$B C-12$ & $12 / 1 / 11$ & 504.7 & 332.2 & 462.3 & 66.5 & 10.5 & \\
\hline$B C-12$ & $12 / 29 / 11$ & 468.1 & 306.9 & 441.9 & 66.5 & 10.9 & 3.0 \\
\hline$B C-12$ & $1 / 21 / 12$ & 490.2 & 340.8 & 438.0 & 28.7 & 10.6 & 4.9 \\
\hline$B C-12$ & $2 / 15 / 12$ & 400.2 & 276.4 & 363.3 & 245.2 & 12.5 & 0.9 \\
\hline$B C-12$ & $6 / 28 / 12$ & 392.8 & 341.6 & 329.8 & 66.5 & 23.5 & 4.0 \\
\hline$B C-12$ & $7 / 24 / 12$ & 339.3 & 299.1 & 268.8 & 66.5 & 22.3 & 2.2 \\
\hline$B C-12$ & $8 / 20 / 12$ & 388.7 & 261.7 & 336.4 & 72.9 & 7.8 & 4.8 \\
\hline$B C-12$ & $9 / 15 / 12$ & 538.0 & 286.4 & 521.3 & 60.5 & 7.7 & 5.0 \\
\hline$B C-12$ & $10 / 11 / 12$ & 334.4 & 256.4 & 292.4 & 72.9 & 17.7 & 3.6 \\
\hline BC-12 & $11 / 6 / 12$ & 414.5 & 316.2 & 380.9 & 66.5 & 18.9 & 5.5 \\
\hline$B C-12$ & $12 / 3 / 12$ & 539.9 & 324.2 & 512.4 & 87.9 & 46.9 & 2.6 \\
\hline$B C-12$ & $12 / 28 / 12$ & 571.9 & 391.8 & 561.3 & 72.9 & 14.9 & 2.6 \\
\hline
\end{tabular}


Appendix VI (cont.). Benthic sediment mean, median, and mode grain size $(\mu \mathrm{m})$, and $\%$ benthic sediment less than $75 \mu \mathrm{m}$ at BC-13.

\begin{tabular}{|c|c|c|c|c|c|c|c|}
\hline Sample Name & Date Collected & Mean (um) & S.D. (um) & Median (um) & Mode (um) & $<75$ um (\%) & $\% \mathrm{~T}$ \\
\hline BC-13 & $8 / 20 / 10$ & 399.5 & 326.1 & 353.8 & 391.0 & 16.6 & 41.1 \\
\hline$B C-13$ & $9 / 15 / 10$ & 384.6 & 237.1 & 357.2 & 356.1 & 10.8 & 40.1 \\
\hline BC-13 & $10 / 11 / 10$ & 333.2 & 248.7 & 305.6 & 356.1 & 17.2 & 79.1 \\
\hline $\mathrm{BC}-13$ & $11 / 7 / 10$ & 247.2 & 224.4 & 215.1 & 269.2 & 28.3 & 79.6 \\
\hline BC-13 & $12 / 2 / 10$ & 212.4 & 203.8 & 177.1 & 223.4 & 31.1 & 67.3 \\
\hline$B C-13$ & $12 / 29 / 10$ & 334.6 & 239.4 & 301.5 & 324.4 & 14.8 & 40.0 \\
\hline$B C-13$ & $1 / 23 / 11$ & 270.8 & 233.9 & 246.5 & 356.1 & 28.3 & 36.0 \\
\hline$B C-13$ & $2 / 13 / 11$ & 478.6 & 267.8 & 437.9 & 429.2 & 6.2 & 42.2 \\
\hline BC-13 & $3 / 16 / 11$ & 360.6 & 243.7 & 324.6 & 324.4 & 11.6 & 55.4 \\
\hline$B C-13$ & $4 / 11 / 11$ & 412.4 & 218.4 & 361.2 & 324.4 & 2.4 & 54.6 \\
\hline BC-13 & $6 / 3 / 11$ & 339.6 & 234.1 & 306.4 & 324.4 & 12.5 & 46.7 \\
\hline $\mathrm{BC}-13$ & $6 / 29 / 11$ & 370.2 & 292.7 & 322.8 & 356.1 & 15.4 & 41.3 \\
\hline BC-13 & $7 / 25 / 11$ & 268.8 & 270.4 & 235.4 & 356.1 & 34.1 & 38.7 \\
\hline$B C-13$ & $8 / 20 / 11$ & 409.5 & 259.1 & 375.9 & 391.0 & 10.9 & 34.1 \\
\hline $\mathrm{BC}-13$ & $9 / 15 / 11$ & 365.4 & 272.8 & 314.5 & 324.4 & 12.2 & \\
\hline BC-13 & $10 / 11 / 11$ & 398.8 & 221.9 & 366.8 & 356.1 & 6.4 & 35.4 \\
\hline BC-13 & $11 / 5 / 11$ & 221.9 & 252.5 & 136.2 & 324.4 & 42.0 & 37.8 \\
\hline BC-13 & $12 / 1 / 11$ & 276.1 & 294.3 & 229.5 & 295.5 & 29.4 & \\
\hline BC-13 & $12 / 29 / 11$ & 375.5 & 253.6 & 326.9 & 324.4 & 8.9 & 37.0 \\
\hline BC-13 & $1 / 21 / 12$ & 428.4 & 253.7 & 387.1 & 391.0 & 7.3 & 41.2 \\
\hline BC-13 & $2 / 15 / 12$ & 404.7 & 234.2 & 359.7 & 356.1 & 5.6 & 33.1 \\
\hline BC-13 & $3 / 14 / 12$ & 347.0 & 228.0 & 307.8 & 324.4 & 9.1 & 4.2 \\
\hline BC-13 & $6 / 28 / 12$ & 332.1 & 208.0 & 296.3 & 295.5 & 7.4 & 45.6 \\
\hline$B C-13$ & $7 / 24 / 12$ & 254.4 & 218.1 & 228.8 & 269.2 & 18.8 & 42.2 \\
\hline BC-13 & $8 / 20 / 12$ & 389.3 & 218.6 & 362.0 & 391.0 & 5.8 & 40.0 \\
\hline BC-13 & $9 / 15 / 12$ & 317.0 & 237.2 & 312.9 & 356.1 & 22.5 & 34.0 \\
\hline$B C-13$ & $10 / 11 / 12$ & 283.8 & 254.0 & 249.6 & 324.4 & 25.6 & 35.1 \\
\hline$B C-13$ & $11 / 6 / 12$ & 330.7 & 238.1 & 309.7 & 356.1 & 16.1 & 44.6 \\
\hline BC-13 & $12 / 3 / 12$ & 393.2 & 228.6 & 358.7 & 356.1 & 7.5 & 41.1 \\
\hline$B C-13$ & $12 / 28 / 12$ & 357.7 & 236.2 & 308.0 & 295.5 & 7.5 & 29.9 \\
\hline
\end{tabular}


Appendix VI (cont.). Benthic sediment mean, median, and mode grain size $(\mu \mathrm{m})$, and $\%$ benthic sediment less than $75 \mu \mathrm{m}$ at BL1-2.

\begin{tabular}{|c|c|c|c|c|c|c|c|}
\hline Sample Name & Date Collected & Mean (um) & S.D. (um) & Median (um) & Mode (um) & $<75$ um (\%) & \%T \\
\hline BL1-2 & $9 / 18 / 09$ & 287.1 & 332.3 & 161.9 & 269.2 & 37.6 & 23.7 \\
\hline BL1-2 & $10 / 13 / 09$ & 268.3 & 284.6 & 175.8 & 517.2 & 37.9 & 25.1 \\
\hline BL1-2 & $11 / 8 / 09$ & 175.9 & 218.7 & 97.7 & 223.4 & 44.6 & 13.5 \\
\hline BL1-2 & $12 / 3 / 09$ & 180.7 & 225.7 & 85.9 & 203.5 & 47.5 & 28.5 \\
\hline BL1-2 & $12 / 30 / 09$ & 190.4 & 242.0 & 99.2 & 223.4 & 44.6 & 21.9 \\
\hline BL1-2 & $1 / 25 / 10$ & 239.3 & 257.9 & 161.5 & 269.2 & 37.6 & 18.2 \\
\hline BL1-2 & $2 / 20 / 10$ & 132.7 & 184.7 & 57.9 & 185.4 & 55.5 & 25.6 \\
\hline BL1-2 & $3 / 19 / 10$ & 195.5 & 219.5 & 123.0 & 223.4 & 40.0 & \\
\hline BL1-2 & $8 / 23 / 10$ & 368.7 & 329.3 & 298.3 & 391.0 & 24.7 & 20.6 \\
\hline BL1-2 & $9 / 18 / 10$ & 520.5 & 344.9 & 478.7 & 684.2 & 11.1 & 41.8 \\
\hline BL1-2 & $10 / 13 / 10$ & 531.7 & 436.9 & 510.7 & 751.1 & 23.7 & 43.7 \\
\hline BL1-2 & $11 / 13 / 10$ & 360.8 & 306.2 & 314.4 & 471.1 & 25.8 & 17.2 \\
\hline BL1-2 & $12 / 4 / 10$ & 370.2 & 315.9 & 317.9 & 517.2 & 25.4 & 24.5 \\
\hline BL1-2 & $12 / 31 / 10$ & 183.6 & 262.5 & 50.0 & 28.7 & 56.4 & 31.1 \\
\hline BL1-2 & $1 / 25 / 11$ & 249.6 & 270.7 & 165.9 & 295.5 & 38.6 & 24.5 \\
\hline BL1-2 & $2 / 15 / 11$ & 370.8 & 310.7 & 317.4 & 429.2 & 22.0 & 22.0 \\
\hline BL1-2 & $3 / 18 / 11$ & 324.6 & 291.2 & 261.8 & 324.4 & 23.4 & 24.4 \\
\hline BL1-2 & $4 / 13 / 11$ & 287.9 & 272.2 & 229.0 & 295.5 & 28.4 & 30.5 \\
\hline BL1-2 & $6 / 5 / 11$ & 405.6 & 327.9 & 346.3 & 429.2 & 17.7 & \\
\hline BL1-2 & $7 / 1 / 11$ & 465.1 & 364.0 & 411.3 & & 18.6 & 23.5 \\
\hline BL1-2 & $7 / 27 / 11$ & 251.5 & 289.2 & 159.0 & 269.2 & 40.2 & 25.8 \\
\hline BL1-2 & $8 / 22 / 11$ & 293.5 & 278.8 & 233.2 & 295.5 & 27.5 & 36.2 \\
\hline BL1-2 & $9 / 15 / 11$ & 370.2 & 315.3 & 301.6 & 429.2 & 20.5 & 25.8 \\
\hline BL1-2 & $10 / 11 / 11$ & 92.6 & 156.7 & 27.1 & 26.2 & 70.6 & 21.6 \\
\hline BL1-2 & $11 / 7 / 11$ & 77.2 & 135.1 & 26.1 & 28.7 & 73.4 & 33.8 \\
\hline BL1-2 & $12 / 3 / 11$ & 449.4 & 341.4 & 396.6 & 623.3 & 16.9 & \\
\hline BL1-2 & $12 / 31 / 11$ & 375.9 & 293.7 & 312.6 & 324.4 & 13.8 & 21.4 \\
\hline BL1-2 & $1 / 24 / 12$ & 323.1 & 271.7 & 264.6 & 295.5 & 19.5 & 19.1 \\
\hline BL1-2 & $2 / 18 / 12$ & 366.7 & 301.7 & 298.7 & 324.4 & 16.5 & 24.5 \\
\hline BL1-2 & $3 / 16 / 12$ & 309.4 & 314.1 & 225.8 & 269.2 & 26.5 & 9.6 \\
\hline BL1-2 & $6 / 30 / 12$ & 313.8 & 292.5 & 244.4 & 295.5 & 25.2 & 17.5 \\
\hline BL1-2 & $7 / 26 / 12$ & 348.1 & 319.6 & 270.6 & 429.2 & 24.4 & 22.9 \\
\hline BL1-2 & $8 / 26 / 12$ & 427.7 & 322.6 & 370.5 & 567.8 & 17.2 & 32.7 \\
\hline BL1-2 & $9 / 17 / 12$ & 210.3 & 250.9 & 120.3 & 245.2 & 42.9 & 25.6 \\
\hline BL1-2 & $10 / 13 / 12$ & 421.7 & 315.9 & 359.0 & 471.1 & 13.3 & 25.4 \\
\hline BL1-2 & $11 / 8 / 12$ & 289.6 & 346.0 & 132.3 & 567.7 & 42.4 & 30.6 \\
\hline BL1-2 & $12 / 2 / 12$ & 389.1 & 329.2 & 312.3 & 567.7 & 19.9 & 22.7 \\
\hline BL1-2 & $12 / 30 / 12$ & 461.3 & 314.3 & 390.6 & 429.2 & 6.7 & 22.8 \\
\hline
\end{tabular}


Appendix VI (cont.). Benthic sediment mean, median, and mode grain size $(\mu \mathrm{m})$, and $\%$ benthic sediment less than $75 \mu \mathrm{m}$ at BL2-6.

\begin{tabular}{|c|c|c|c|c|c|c|c|}
\hline Sample Name & Date Collected & Mean (um) & S.D. (um) & Median (um) & Mode (um) & $<75$ um (\%) & \%T \\
\hline BL2-6 & $8 / 23 / 10$ & 513.6 & 272.6 & 475.4 & 517.2 & 4.8 & 28.4 \\
\hline BL2-6 & $9 / 18 / 10$ & 593.9 & 342.2 & 593.4 & 751.1 & 9.5 & 21.6 \\
\hline BL2-6 & $10 / 13 / 10$ & 573.6 & 371.5 & 525.2 & 623.3 & 8.3 & 11.5 \\
\hline BL2-6 & $11 / 13 / 10$ & 426.5 & 325.7 & 382.0 & 471.1 & 18.1 & 13.6 \\
\hline$B L 2-6$ & $12 / 4 / 10$ & 500.3 & 328.4 & 460.0 & 567.8 & 10.8 & 39.4 \\
\hline BL2-6 & $12 / 31 / 10$ & 208.9 & 274.6 & 72.6 & 28.7 & 50.6 & 19.5 \\
\hline$B L 2-6$ & $1 / 25 / 11$ & 434.1 & 298.7 & 370.4 & 391.0 & 6.7 & 14.7 \\
\hline BL2-6 & $2 / 15 / 11$ & 333.1 & 250.8 & 308.9 & 391.0 & 19.4 & 7.6 \\
\hline BL2-6 & $3 / 18 / 11$ & 388.2 & 372.6 & 286.6 & 517.2 & 25.0 & 9.1 \\
\hline$B L 2-6$ & $4 / 13 / 11$ & 491.5 & 289.6 & 442.9 & 471.1 & 5.2 & 10.7 \\
\hline BL2-6 & $6 / 5 / 11$ & 479.0 & 279.1 & 426.3 & 429.2 & 4.4 & 9.2 \\
\hline BL2-6 & $7 / 1 / 11$ & 461.3 & 334.3 & 391.9 & 471.1 & 8.1 & 12.7 \\
\hline BL2-6 & $7 / 27 / 11$ & 140.9 & 188.7 & 65.9 & 87.9 & 53.2 & 11.4 \\
\hline BL2-6 & $8 / 22 / 11$ & 571.1 & 311.9 & 537.4 & 623.3 & 5.4 & 25.0 \\
\hline BL2-6 & $9 / 17 / 11$ & 383.7 & 286.2 & 341.8 & 429.2 & 16.3 & 18.7 \\
\hline BL2-6 & $10 / 13 / 11$ & 345.0 & 319.9 & 282.8 & 471.1 & 29.1 & 12.3 \\
\hline BL2-6 & $11 / 7 / 11$ & 186.0 & 246.5 & 76.3 & 223.4 & 49.7 & 12.9 \\
\hline BL2-6 & $12 / 3 / 11$ & 613.2 & 321.9 & 587.1 & 751.1 & 4.4 & \\
\hline BL2-6 & $12 / 31 / 11$ & 373.1 & 284.9 & 317.5 & 391.0 & 14.0 & 14.7 \\
\hline$B L 2-6$ & $1 / 24 / 12$ & 416.5 & 305.5 & 373.5 & 517.2 & 15.1 & 10.1 \\
\hline BL2-6 & $2 / 18 / 12$ & 426.1 & 268.0 & 384.5 & 429.2 & 8.3 & 25.6 \\
\hline$B L 2-6$ & $3 / 14 / 12$ & 494.7 & 326.1 & 448.6 & 517.2 & 9.4 & 12.0 \\
\hline BL2-6 & $6 / 30 / 12$ & 376.5 & 281.5 & 342.5 & 391.0 & 18.4 & 12.5 \\
\hline$B L 2-6$ & $7 / 25 / 12$ & 387.8 & 270.4 & 340.5 & 356.1 & 11.0 & 11.2 \\
\hline BL2-6 & $8 / 26 / 12$ & 449.9 & 292.1 & 411.0 & 471.1 & 9.3 & 17.6 \\
\hline BL2-6 & $9 / 17 / 12$ & 307.1 & 263.7 & 274.3 & 391.0 & 27.3 & 17.7 \\
\hline BL2-6 & $10 / 13 / 12$ & 393.3 & 276.4 & 349.7 & 390.9 & 12.7 & 10.2 \\
\hline BL2-6 & $11 / 8 / 12$ & 216.0 & 283.2 & 70.7 & 429.2 & 50.8 & 8.9 \\
\hline BL2-6 & $12 / 2 / 12$ & 447.2 & 308.6 & 395.1 & 429.2 & 10.9 & 11.8 \\
\hline BL2-6 & $12 / 30 / 12$ & 459.3 & 3.9 & 411.0 & 517.2 & 9.8 & 14.3 \\
\hline
\end{tabular}


Appendix VI (cont.). Benthic sediment mean, median, and mode grain size $(\mu \mathrm{m})$, and $\%$ benthic sediment less than $75 \mu \mathrm{m}$ at BY-1.

\begin{tabular}{|c|c|c|c|c|c|c|c|}
\hline Sample Name & Date Collected & Mean (um) & S.D. (um) & Median (um) & Mode (um) & $<75$ um (\%) & \%T \\
\hline BY-1 & $9 / 18 / 09$ & 587.5 & 391.8 & 580.0 & 751.1 & 13.3 & 10.8 \\
\hline BY-1 & $10 / 13 / 09$ & 387.6 & 379.5 & 262.8 & 824.5 & 33.8 & 10.7 \\
\hline BY-1 & $11 / 8 / 09$ & 582.5 & 418.1 & 566.6 & 751.1 & 16.8 & 12.5 \\
\hline BY-1 & $12 / 3 / 09$ & 599.5 & 453.0 & 543.0 & 751.1 & 15.4 & 16.1 \\
\hline BY-1 & $12 / 30 / 09$ & 473.7 & 404.9 & 432.5 & 751.1 & 25.6 & \begin{tabular}{|l|}
8.7 \\
\end{tabular} \\
\hline BY-1 & $1 / 25 / 10$ & 487.0 & 348.0 & 463.8 & 684.2 & 15.7 & 8.2 \\
\hline BY-1 & $2 / 20 / 10$ & 448.3 & 345.7 & 423.5 & 684.2 & 20.8 & 9.3 \\
\hline BY-1 & $3 / 19 / 10$ & 564.9 & 402.3 & 552.7 & 751.1 & 15.6 & 6.6 \\
\hline BY-1 & $7 / 25 / 10$ & 522.0 & 435.0 & 430.5 & 623.3 & 14.4 & \\
\hline BY-1 & $8 / 23 / 10$ & 534.6 & 349.5 & 530.3 & 684.2 & 14.1 & 9.9 \\
\hline BY-1 & $9 / 18 / 10$ & 658.7 & 278.4 & 652.0 & 751.1 & 3.5 & 5.6 \\
\hline BY-1 & $10 / 13 / 10$ & 653.1 & 339.0 & 589.8 & 623.3 & 0.9 & 5.9 \\
\hline BY-1 & $12 / 4 / 10$ & 609.4 & 294.9 & 586.1 & 623.3 & 4.6 & 8.8 \\
\hline BY-1 & $12 / 31 / 10$ & 590.7 & 289.3 & 559.0 & 623.3 & 3.4 & 7.3 \\
\hline BY-1 & $1 / 25 / 11$ & 613.7 & 300.1 & 585.4 & 623.3 & 3.7 & 8.8 \\
\hline BY-1 & $2 / 15 / 11$ & 538.1 & 303.3 & 520.4 & 623.3 & 8.5 & \\
\hline BY-1 & $3 / 18 / 11$ & 539.1 & 328.2 & 599.0 & 751.1 & 9.6 & 19.0 \\
\hline BY-1 & $4 / 13 / 11$ & 540.1 & 291.7 & 520.4 & 567.8 & 7.4 & \begin{tabular}{|l|}
7.0 \\
\end{tabular} \\
\hline BY-1 & $6 / 5 / 11$ & 541.1 & 571.9 & 702.7 & 1739.0 & 0.5 & 10.7 \\
\hline BY-1 & $7 / 1 / 11$ & 542.1 & 338.8 & 766.2 & 905.1 & 5.9 & 6.1 \\
\hline BY-1 & $7 / 27 / 11$ & 145.1 & 210.5 & 56.7 & 35.5 & 57.2 & 11.7 \\
\hline BY-1 & $8 / 22 / 11$ & 483.3 & 284.5 & 454.5 & 517.2 & 7.7 & 19.4 \\
\hline BY-1 & $9 / 17 / 11$ & 492.8 & 292.0 & 463.7 & 517.2 & 8.4 & 15.4 \\
\hline BY-1 & $10 / 13 / 11$ & 528.1 & 305.6 & 501.0 & 567.8 & 8.0 & 11.5 \\
\hline BY-1 & $11 / 7 / 11$ & 410.6 & 326.2 & 376.1 & 517.2 & 21.7 & 7.6 \\
\hline BY-1 & $12 / 3 / 11$ & 581.4 & 302.9 & 551.8 & 623.3 & 4.0 & \\
\hline BY-1 & $12 / 31 / 11$ & 491.7 & 404.2 & 453.2 & 751.1 & 21.4 & 31.6 \\
\hline BY-1 & $1 / 24 / 12$ & 623.2 & 323.8 & 616.5 & 751.1 & 6.6 & 12.6 \\
\hline BY-1 & $2 / 18 / 12$ & 497.3 & 307.7 & 460.5 & 517.2 & 8.5 & 15.3 \\
\hline BY-1 & $3 / 16 / 12$ & 568.0 & 390.6 & 587.9 & 751.1 & 16.9 & 12.3 \\
\hline BY-1 & $6 / 30 / 12$ & 430.6 & 288.8 & 391.0 & 471.1 & 10.3 & 23.2 \\
\hline BY-1 & $7 / 26 / 12$ & 468.7 & 309.1 & 442.6 & 517.2 & 13.1 & 7.5 \\
\hline BY-1 & $8 / 27 / 12$ & 751.1 & 269.2 & 745.6 & 824.5 & 2.5 & 5.0 \\
\hline BY-1 & $9 / 17 / 12$ & 634.7 & 335.9 & 657.6 & 751.1 & 11.0 & 15.2 \\
\hline BY-1 & $10 / 13 / 12$ & 498.4 & 281.6 & 475.7 & 517.2 & 7.7 & 6.3 \\
\hline BY-1 & $11 / 8 / 12$ & 352.8 & 295.1 & 322.0 & 517.2 & 26.5 & 12.2 \\
\hline BY-1 & $12 / 2 / 12$ & 614.8 & 337.9 & 601.0 & 751.1 & 6.9 & 6.8 \\
\hline BY-1 & $12 / 29 / 12$ & 597.9 & 282.8 & 589.0 & 684.2 & 4.4 & 0.9 \\
\hline
\end{tabular}


Appendix VI (cont.). Benthic sediment mean, median, and mode grain size $(\mu \mathrm{m})$, and $\%$ benthic sediment less than $75 \mu \mathrm{m}$ at BY-2.

\begin{tabular}{|c|c|c|c|c|c|c|c|}
\hline Sample Name & Date Collected & Mean (um) & S.D. (um) & Median (um) & Mode (um) & $<75$ um (\%) & $\% \mathrm{~T}$ \\
\hline BY-2 & $9 / 18 / 09$ & 453.4 & 375.6 & 404.7 & 684.2 & 22.4 & 5.0 \\
\hline BY-2 & $10 / 13 / 09$ & 559.5 & 359.0 & 571.0 & 751.1 & 13.8 & 5.7 \\
\hline BY-2 & $11 / 8 / 09$ & 78.5 & 152.4 & 28.3 & 28.7 & 76.8 & 6.7 \\
\hline BY-2 & $12 / 3 / 09$ & 695.0 & 519.0 & 668.0 & 905.1 & 18.0 & 8.8 \\
\hline BY-2 & $12 / 30 / 09$ & 522.4 & 356.5 & 501.7 & 684.2 & 13.7 & 4.1 \\
\hline BY-2 & $1 / 25 / 10$ & 477.2 & 376.7 & 427.1 & 684.2 & 18.4 & 6.7 \\
\hline BY-2 & $2 / 20 / 10$ & 499.3 & 339.1 & 487.5 & 684.2 & 15.0 & 5.1 \\
\hline BY-2 & $3 / 19 / 10$ & 602.7 & 334.8 & 582.7 & 684.2 & 6.6 & 5.4 \\
\hline BY-2 & $8 / 23 / 10$ & 542.4 & 349.8 & 521.9 & 623.3 & 11.2 & 3.1 \\
\hline BY-2 & $9 / 18 / 10$ & 794.4 & 302.3 & 798.4 & 905.1 & 2.8 & 3.9 \\
\hline BY-2 & $10 / 13 / 10$ & 685.3 & 331.8 & 661.3 & 751.1 & 4.1 & 5.6 \\
\hline BY-2 & $11 / 13 / 10$ & 791.1 & 288.3 & 790.0 & 824.5 & 2.5 & 3.3 \\
\hline BY-2 & $12 / 4 / 10$ & 728.0 & 308.8 & 730.8 & 824.5 & 3.7 & 3.7 \\
\hline BY-2 & $12 / 31 / 10$ & 669.1 & 422.0 & 714.0 & 824.5 & 16.8 & 5.2 \\
\hline BY-2 & $1 / 25 / 11$ & 671.2 & 388.2 & 707.4 & 824.5 & 12.9 & 6.3 \\
\hline BY-2 & $2 / 15 / 11$ & 372.3 & 305.3 & 350.8 & 517.2 & 25.7 & 50.0 \\
\hline BY-2 & $3 / 18 / 11$ & 721.3 & 356.4 & 758.2 & 905.1 & 9.1 & 4.1 \\
\hline BY-2 & $4 / 13 / 11$ & 562.3 & 387.3 & 587.4 & 751.1 & 19.2 & 4.4 \\
\hline BY-2 & $6 / 5 / 11$ & 595.1 & 428.8 & 629.1 & 824.5 & 20.7 & 37.5 \\
\hline BY-2 & $7 / 1 / 11$ & 542.2 & 295.2 & 516.9 & 567.8 & 6.7 & 8.8 \\
\hline BY-2 & $7 / 27 / 11$ & 98.9 & 172.4 & 34.8 & 28.7 & 70.6 & 7.8 \\
\hline BY-2 & $8 / 22 / 11$ & 696.1 & 294.9 & 693.3 & 751.1 & 3.6 & 5.3 \\
\hline BY-2 & $9 / 17 / 11$ & 307.2 & 344.0 & 118.9 & 623.3 & 44.6 & 5.0 \\
\hline BY-2 & $10 / 13 / 11$ & 653.5 & 320.3 & 658.1 & 824.5 & 6.1 & 6.2 \\
\hline BY-2 & $11 / 7 / 11$ & 811.4 & 298.2 & 811.5 & 824.5 & 2.7 & 4.8 \\
\hline BY-2 & $12 / 3 / 11$ & 714.3 & 308.3 & 714.2 & 824.5 & 4.0 & \\
\hline BY-2 & $12 / 31 / 11$ & 662.0 & 332.6 & 661.0 & 751.1 & 6.1 & 5.1 \\
\hline BY-2 & $1 / 24 / 12$ & 573.6 & 303.6 & 559.8 & 684.2 & 6.2 & 6.4 \\
\hline BY-2 & $2 / 18 / 12$ & 616.0 & 343.5 & 626.2 & 751.1 & 9.7 & 2.5 \\
\hline BY-2 & $6 / 28 / 12$ & 493.3 & 358.1 & 490.9 & 684.2 & 19.3 & 3.1 \\
\hline BY-2 & $7 / 26 / 12$ & 684.4 & 369.2 & 722.0 & 905.1 & & 5.1 \\
\hline BY-2 & $8 / 27 / 12$ & 602.8 & 289.1 & 589.4 & 623.3 & 4.9 & 3.4 \\
\hline BY-2 & $9 / 17 / 12$ & 604.0 & 329.2 & 615.6 & 751.1 & 9.5 & 6.5 \\
\hline BY-2 & $10 / 13 / 12$ & 631.8 & 297.2 & 626.1 & 751.1 & 5.0 & 4.5 \\
\hline BY-2 & $11 / 8 / 12$ & 532.4 & 374.6 & 545.6 & 751.1 & 18.8 & 4.7 \\
\hline BY-2 & $12 / 2 / 12$ & 692.4 & 315.0 & 712.4 & 824.5 & 5.8 & 4.7 \\
\hline BY-2 & $12 / 29 / 12$ & 730.1 & 295.5 & 346.6 & 8.2 & 4.6 & 3.9 \\
\hline
\end{tabular}


Appendix VI (cont.). Benthic sediment mean, median, and mode grain size $(\mu \mathrm{m})$, and $\%$ benthic sediment less than $75 \mu \mathrm{m}$ at BT-1.

\begin{tabular}{|c|c|c|c|c|c|c|c|}
\hline Sample Name & Date Collected & \begin{tabular}{|l|} 
Mean (um) \\
\end{tabular} & S.D. (um) & Median (um) & Mode (um) & $<75$ um (\%) & $\% \mathrm{~T}$ \\
\hline BT-1 & $9 / 18 / 09$ & 699.3 & 229.0 & 686.4 & 684.2 & 0.0 & 20.6 \\
\hline BT-1 & $10 / 13 / 09$ & 557.3 & 296.4 & 540.9 & 623.3 & 6.8 & 17.4 \\
\hline BT-1 & $11 / 8 / 09$ & 644.1 & 320.2 & 649.7 & 751.1 & 6.8 & 19.6 \\
\hline BT-1 & $12 / 3 / 09$ & 635.9 & 345.6 & 628.7 & 751.1 & 8.4 & 19.4 \\
\hline BT-1 & $12 / 30 / 09$ & 549.9 & 287.7 & 533.1 & 623.3 & 5.8 & 19.7 \\
\hline BT-1 & $1 / 25 / 10$ & 601.1 & 294.9 & 583.5 & 684.2 & 4.3 & 17.5 \\
\hline BT-1 & $2 / 20 / 10$ & 537.3 & 246.5 & 521.0 & 567.8 & 3.9 & 17.5 \\
\hline BT-1 & $3 / 19 / 10$ & 619.4 & 323.6 & 618.1 & 684.2 & 7.1 & 19.6 \\
\hline BT-1 & $7 / 25 / 10$ & 695.3 & 380.4 & 344.7 & 684.2 & 4.2 & \\
\hline BT-1 & $8 / 23 / 10$ & 561.4 & 294.0 & 546.1 & 623.3 & 6.3 & 14.9 \\
\hline BT-1 & $9 / 18 / 10$ & 642.9 & 245.8 & 624.0 & 623.3 & 2.0 & 18.6 \\
\hline BT-1 & $10 / 13 / 10$ & 769.6 & 334.5 & 715.7 & 824.5 & 0.0 & 15.1 \\
\hline BT-1 & $11 / 13 / 10$ & 713.0 & 293.8 & 699.9 & 751.1 & 3.0 & 12.9 \\
\hline BT-1 & $12 / 4 / 10$ & 693.0 & 271.1 & 670.8 & 751.1 & 1.4 & 16.8 \\
\hline BT-1 & $12 / 31 / 10$ & 725.0 & 264.5 & 704.1 & 751.1 & 1.5 & 18.2 \\
\hline BT-1 & $1 / 25 / 11$ & 732.7 & 284.4 & 713.3 & 751.1 & 1.3 & 13.2 \\
\hline BT-1 & $2 / 15 / 11$ & 668.3 & 290.1 & 657.1 & 684.2 & 3.9 & 17.5 \\
\hline BT-1 & $3 / 18 / 11$ & 761.0 & 277.4 & 749.8 & 751.1 & 2.2 & 20.9 \\
\hline BT-1 & $4 / 13 / 11$ & 765.6 & 289.6 & 748.1 & 824.5 & 1.6 & 17.0 \\
\hline BT-1 & $6 / 5 / 11$ & 642.7 & 291.4 & 619.3 & 684.2 & 2.8 & 16.1 \\
\hline BT-1 & $7 / 1 / 11$ & 690.8 & 296.4 & 678.5 & 751.1 & 3.1 & \\
\hline BT-1 & $7 / 27 / 11$ & 760.9 & 294.3 & 754.1 & 824.5 & 1.4 & 20.8 \\
\hline BT-1 & $8 / 22 / 11$ & 657.0 & 261.6 & 630.2 & 684.2 & 1.2 & 16.9 \\
\hline BT-1 & $9 / 17 / 11$ & 686.5 & 270.8 & 668.6 & 684.2 & 2.3 & 18.3 \\
\hline BT-1 & $10 / 13 / 11$ & 650.7 & 283.0 & 631.8 & 684.2 & 2.7 & 16.6 \\
\hline BT-1 & $11 / 7 / 11$ & 718.9 & 271.0 & 704.2 & 751.1 & 2.1 & 19.8 \\
\hline BT-1 & $12 / 3 / 11$ & 592.3 & 290.6 & 571.1 & 623.3 & 4.1 & \\
\hline BT-1 & $12 / 31 / 11$ & 609.6 & 264.6 & 580.7 & 623.3 & 2.0 & 15.1 \\
\hline BT-1 & $1 / 24 / 12$ & 335.5 & 297.7 & 290.8 & 517.2 & 29.1 & 16.9 \\
\hline BT-1 & $2 / 18 / 12$ & 700.4 & 276.7 & 681.5 & 751.1 & 1.5 & 14.6 \\
\hline BT-1 & $3 / 16 / 12$ & 654.4 & 286.5 & 634.2 & 684.2 & 2.6 & 19.6 \\
\hline BT-1 & $6 / 30 / 12$ & 669.1 & 275.0 & 645.3 & 684.2 & 1.5 & 18.4 \\
\hline BT-1 & $7 / 26 / 12$ & 538.6 & 277.0 & 564.0 & 623.3 & 4.3 & 18.3 \\
\hline BT-1 & $8 / 27 / 12$ & 635.2 & 255.9 & 609.6 & 623.3 & 1.5 & 18.6 \\
\hline BT-1 & $9 / 17 / 12$ & 611.4 & 263.7 & 585.0 & 623.3 & 2.4 & 18.1 \\
\hline BT-1 & $10 / 13 / 12$ & 581.6 & 291.7 & 555.4 & 623.3 & 4.4 & 21.8 \\
\hline BT-1 & $11 / 8 / 12$ & 573.1 & 317.8 & 559.4 & 623.3 & 7.8 & 16.8 \\
\hline BT-1 & $12 / 2 / 12$ & 600.8 & 261.2 & 585.2 & 623.3 & 3.1 & 18.6 \\
\hline BT-1 & $12 / 29 / 12$ & 649.9 & 266.8 & 626.3 & 684.2 & 1.4 & 16.6 \\
\hline
\end{tabular}


Appendix VII. Total accumulation rates $\left(\Sigma \mathrm{AR}, \mathrm{mg} / \mathrm{cm}^{2} / \mathrm{d}\right)$ at Coral Bay sites.

\begin{tabular}{|c|c|c|c|c|c|c|c|c|}
\hline \multirow[t]{2}{*}{ Sampling Date } & \multicolumn{4}{|c|}{ 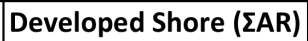 } & \multicolumn{2}{|c|}{ Minimally Developed Shore (IAR) } & \multicolumn{2}{|c|}{ 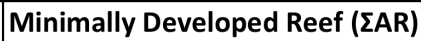 } \\
\hline & TC-1B & TC-3B & TC-5 & TC-8 & TC-10B & TC-13 & TC-11 & TC-12 \\
\hline $9 / 10 / 08$ & & & 10.8 & & & & & \\
\hline $9 / 30 / 08$ & & & 19.1 & & & & & \\
\hline $10 / 22 / 08$ & & & 24.2 & & & & & \\
\hline $11 / 13 / 08$ & & & 15.5 & & & & & \\
\hline $12 / 5 / 08$ & & & 17.6 & & & & & \\
\hline $12 / 31 / 08$ & & & 10.3 & & & & & \\
\hline $1 / 21 / 09$ & & & 16.7 & & & & & \\
\hline $2 / 13 / 09$ & & & 9.1 & & & & & \\
\hline $3 / 4 / 09$ & & & 14.9 & & & & & \\
\hline $3 / 25 / 09$ & & & 3.8 & & & & & \\
\hline $9 / 2 / 09$ & 15.2 & 39.2 & & & & & & \\
\hline $9 / 16 / 09$ & 15.9 & 42.5 & 10.6 & 8.9 & 3.7 & & & \\
\hline $10 / 12 / 09$ & 1.8 & 8.3 & 10.8 & 5.6 & 1.6 & & 1.6 & 1.8 \\
\hline $11 / 7 / 09$ & 2.3 & 5.4 & 10.3 & 5.2 & 1.5 & & 2.2 & 1.5 \\
\hline $12 / 2 / 09$ & 3.3 & 32.9 & 14.5 & 17.3 & 8.5 & & 2.9 & 2.3 \\
\hline $12 / 29 / 09$ & 19.0 & 144.1 & & 25.2 & 11.0 & & 5.9 & 7.1 \\
\hline $1 / 24 / 10$ & 9.0 & 36.6 & 6.9 & 8.3 & 3.4 & & 2.8 & 3.0 \\
\hline $2 / 19 / 10$ & 9.9 & 15.8 & 14.0 & 12.5 & 7.2 & & 5.1 & 5.5 \\
\hline $3 / 17 / 10$ & 2.6 & 3.8 & 9.0 & 5.1 & 1.8 & & 2.4 & 2.0 \\
\hline $6 / 5 / 10$ & & 12.7 & 14.3 & 8.1 & 4.0 & & 2.7 & 3.4 \\
\hline $7 / 25 / 10$ & 19.3 & 58.3 & 46.1 & 50.3 & 17.0 & & 5.1 & 10.6 \\
\hline $8 / 20 / 10$ & 2.1 & 3.9 & 10.3 & 14.5 & 1.9 & 2.4 & 2.4 & 2.1 \\
\hline $9 / 15 / 10$ & 19.8 & 101.3 & 21.9 & 29.2 & 4.2 & 9.9 & 6.3 & 12.4 \\
\hline $10 / 11 / 10$ & 40.2 & 298.0 & 60.4 & 72.3 & 85.0 & 128.7 & 7.3 & 12.9 \\
\hline $11 / 8 / 10$ & 62.8 & 245.0 & 42.0 & 26.0 & 43.6 & 68.3 & 11.1 & 34.1 \\
\hline $12 / 2 / 10$ & 7.1 & 26.4 & 18.2 & 28.5 & 9.6 & 7.3 & 2.7 & 2.6 \\
\hline $12 / 29 / 10$ & 12.4 & 32.5 & 17.9 & 20.5 & 6.7 & 6.3 & 3.8 & 2.9 \\
\hline $1 / 23 / 11$ & 29.4 & 82.7 & 15.7 & 28.0 & 10.5 & 11.1 & 5.8 & 8.6 \\
\hline $2 / 13 / 11$ & 38.3 & & 33.0 & 32.7 & 8.2 & 11.8 & 6.0 & 10.4 \\
\hline $3 / 16 / 11$ & 7.4 & 36.5 & 10.0 & 13.1 & 1.9 & 1.9 & 1.8 & 2.2 \\
\hline $4 / 11 / 11$ & 16.1 & 17.2 & 3.4 & 2.8 & 21.2 & 27.2 & 5.1 & 4.8 \\
\hline $6 / 3 / 11$ & & 11.4 & 15.0 & 17.8 & 3.2 & 4.7 & 2.1 & 2.3 \\
\hline $6 / 29 / 11$ & 8.3 & 6.8 & 17.1 & 12.5 & 3.3 & 6.8 & 2.8 & 3.5 \\
\hline $7 / 25 / 11$ & 29.5 & 22.7 & 21.3 & 17.0 & 7.5 & 0.9 & 6.0 & 12.8 \\
\hline $8 / 20 / 11$ & 36.0 & 21.4 & 30.6 & 24.7 & 10.4 & 33.2 & 11.4 & 23.1 \\
\hline $9 / 15 / 11$ & 52.8 & & 23.6 & 29.8 & 41.6 & & 31.6 & 132.4 \\
\hline $10 / 13 / 11$ & 36.5 & 85.1 & 13.7 & 17.8 & 3.7 & 7.7 & 3.3 & 3.4 \\
\hline $11 / 5 / 11$ & 6.7 & 17.2 & 13.0 & 15.5 & 2.8 & 4.5 & 3.4 & 2.5 \\
\hline $12 / 1 / 11$ & 6.7 & 18.6 & 16.8 & 15.0 & 3.4 & 9.0 & 3.2 & 3.3 \\
\hline $12 / 29 / 11$ & 15.6 & 70.4 & 16.1 & 18.4 & 5.7 & 8.8 & 3.7 & 4.3 \\
\hline $1 / 21 / 12$ & 54.1 & 131.5 & 21.0 & 18.2 & 10.0 & 20.7 & 9.6 & 10.7 \\
\hline $2 / 15 / 12$ & 18.7 & 68.2 & 26.0 & 28.2 & 7.3 & 10.0 & 6.3 & 4.6 \\
\hline $3 / 14 / 12$ & 40.3 & 120.2 & 23.6 & 49.9 & 11.6 & 20.8 & 6.7 & 9.6 \\
\hline $7 / 24 / 12$ & 32.7 & & 14.5 & 40.7 & 4.3 & 9.4 & 5.2 & 4.7 \\
\hline $8 / 20 / 12$ & 102.0 & & 18.6 & 33.0 & 16.8 & 61.3 & 14.5 & 42.7 \\
\hline $9 / 15 / 12$ & 209.1 & & 34.2 & & 24.9 & 141.5 & 34.9 & 137.7 \\
\hline $10 / 11 / 12$ & 29.5 & 20.2 & 4.7 & & 3.8 & 3.6 & 3.3 & 2.2 \\
\hline $11 / 5 / 12$ & 158.3 & 185.0 & 14.7 & & 8.4 & 3.2 & 5.9 & 9.6 \\
\hline $12 / 3 / 12$ & 27.7 & 52.5 & 9.2 & & 1.2 & 3.6 & 2.0 & 3.2 \\
\hline $12 / 28 / 12$ & 119.1 & 184.5 & 12.4 & 20.6 & 3.1 & 1.1 & 4.6 & 2.7 \\
\hline
\end{tabular}


Appendix VII (cont.). Total accumulation rates $\left(\Sigma \mathrm{AR}, \mathrm{mg} / \mathrm{cm}^{2} / \mathrm{d}\right)$ at Lameshur Bay sites.

\begin{tabular}{|c|c|c|c|c|c|}
\hline \multirow[t]{2}{*}{ Sampling Date } & \multicolumn{2}{|c|}{ Minimally Developed Shore (IAR) } & \multicolumn{3}{|c|}{ 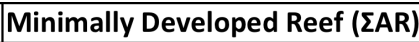 } \\
\hline & TL1-2 & TL2-6 & TY-1 & TY-2 & $\pi-1$ \\
\hline $9 / 19 / 07$ & 2.9 & & 1.6 & 1.4 & \\
\hline $10 / 3 / 07$ & 2.5 & & 3.1 & 2.7 & \\
\hline $10 / 14 / 07$ & 2.6 & & 2.1 & 1.8 & \\
\hline $10 / 23 / 07$ & 1.8 & & 0.8 & 1.2 & \\
\hline $11 / 3 / 07$ & 6.5 & & 4.9 & 5.9 & \\
\hline $11 / 16 / 07$ & 1.1 & & 2.1 & 1.9 & \\
\hline $11 / 30 / 07$ & 3.7 & & 2.0 & 2.2 & \\
\hline $8 / 21 / 08$ & 4.5 & & 1.4 & 1.2 & \\
\hline $8 / 27 / 08$ & 1.2 & & 1.7 & 13.3 & \\
\hline $9 / 10 / 08$ & 2.2 & & 15.4 & 16.3 & \\
\hline $9 / 30 / 08$ & 3.0 & & 2.6 & 2.4 & \\
\hline $10 / 22 / 08$ & 15.7 & & 90.4 & 106.8 & \\
\hline $11 / 13 / 08$ & 4.1 & & 1.1 & 0.8 & \\
\hline $12 / 5 / 08$ & 1.7 & & 1.4 & 1.2 & \\
\hline $12 / 31 / 08$ & 2.5 & & 1.1 & 1.1 & \\
\hline $1 / 21 / 09$ & 2.0 & & 1.7 & 1.3 & \\
\hline $2 / 13 / 09$ & 0.9 & & 1.3 & 1.2 & \\
\hline $3 / 4 / 09$ & 1.9 & & 2.0 & 1.5 & \\
\hline $3 / 25 / 09$ & 0.6 & & 1.0 & 0.7 & \\
\hline $8 / 21 / 09$ & 4.3 & & 1.4 & & 0.8 \\
\hline $9 / 2 / 09$ & 3.0 & 1.6 & & 0.0 & \\
\hline $9 / 16 / 09$ & 4.8 & 19.2 & 1.0 & & 0.7 \\
\hline $10 / 12 / 09$ & 12.7 & 1.1 & 1.1 & 1.1 & 0.7 \\
\hline $11 / 7 / 09$ & 3.9 & 1.8 & 1.1 & 1.3 & 0.9 \\
\hline $12 / 2 / 09$ & 6.0 & 12.4 & 1.5 & 1.5 & 1.2 \\
\hline $12 / 29 / 09$ & 7.2 & 9.3 & 1.2 & 2.0 & 0.9 \\
\hline $1 / 24 / 10$ & 6.1 & 7.8 & 1.7 & 1.6 & 1.1 \\
\hline $2 / 19 / 10$ & 5.9 & 6.0 & 1.7 & 1.6 & 1.2 \\
\hline $3 / 17 / 10$ & 4.0 & 12.8 & 1.5 & 1.6 & 0.9 \\
\hline $7 / 25 / 10$ & 2.7 & 1.6 & 0.9 & & 0.6 \\
\hline $8 / 20 / 10$ & 1.1 & 2.7 & & 0.7 & 0.9 \\
\hline $9 / 15 / 10$ & 528.3 & 202.5 & 124.1 & 0.7 & 143.0 \\
\hline $10 / 11 / 10$ & 475.1 & 197.4 & 157.4 & 219.1 & 217.1 \\
\hline $11 / 8 / 10$ & 9.7 & 17.8 & 2.5 & 142.8 & 1.3 \\
\hline $12 / 2 / 10$ & 7.5 & 4.0 & 1.3 & 1.5 & 1.0 \\
\hline $12 / 29 / 10$ & 12.9 & 5.8 & 1.8 & 0.8 & 1.1 \\
\hline $1 / 23 / 11$ & 7.0 & 9.3 & 1.6 & 0.6 & 0.9 \\
\hline $2 / 13 / 11$ & 3.8 & 8.8 & 1.4 & 1.1 & 0.8 \\
\hline $3 / 16 / 11$ & 0.4 & 0.8 & 1.2 & 1.0 & 1.0 \\
\hline $4 / 11 / 11$ & 16.1 & 27.2 & 1.3 & 0.8 & 21.2 \\
\hline $6 / 3 / 11$ & 0.9 & 3.6 & 1.7 & 1.2 & 1.0 \\
\hline $6 / 29 / 11$ & 0.8 & 5.2 & 1.0 & 0.9 & 0.2 \\
\hline $7 / 25 / 11$ & 0.6 & 5.7 & 1.0 & 1.2 & 0.4 \\
\hline $8 / 20 / 11$ & 6.7 & 18.5 & 10.6 & 12.6 & 7.4 \\
\hline $9 / 15 / 11$ & 5.1 & 5.2 & 2.2 & 2.1 & 1.2 \\
\hline $10 / 13 / 11$ & 3.2 & 4.2 & 1.1 & 1.0 & 0.9 \\
\hline $11 / 5 / 11$ & 3.4 & 4.6 & 1.7 & 1.8 & 1.7 \\
\hline $12 / 1 / 11$ & 2.2 & 2.8 & 1.0 & 1.1 & 0.9 \\
\hline $12 / 29 / 11$ & 3.0 & 3.5 & 1.0 & 1.4 & 1.1 \\
\hline $1 / 21 / 12$ & 3.9 & 4.5 & 1.5 & 2.0 & 1.6 \\
\hline $2 / 15 / 12$ & 2.3 & 1.6 & 1.7 & 1.6 & 1.2 \\
\hline $3 / 14 / 12$ & 2.0 & 1.4 & 1.5 & 2.5 & 1.4 \\
\hline $7 / 24 / 12$ & 3.0 & 1.8 & 1.1 & 1.2 & 1.5 \\
\hline $8 / 20 / 12$ & 16.1 & 14.0 & 24.7 & 34.9 & 17.3 \\
\hline $9 / 15 / 12$ & 1.5 & 0.7 & 1.1 & 1.0 & 0.7 \\
\hline $10 / 11 / 12$ & 2.3 & 1.9 & 1.7 & 1.3 & 1.2 \\
\hline $11 / 5 / 12$ & 5.0 & 8.3 & 2.8 & 2.1 & 2.7 \\
\hline $12 / 3 / 12$ & 1.3 & 1.4 & 1.4 & 1.0 & 0.7 \\
\hline $12 / 28 / 12$ & 2.4 & 2.2 & 2.0 & 1.4 & 0.8 \\
\hline
\end{tabular}


Appendix VII (cont.). Silt accumulation rates (SAR, $\mathrm{mg} / \mathrm{cm}^{2} / \mathrm{d}$ ) at Coral Bay sites.

\begin{tabular}{|c|c|c|c|c|c|c|c|c|}
\hline \multirow[t]{2}{*}{ Sampling Date } & \multicolumn{4}{|c|}{ Developed Shore (SAR) } & \multicolumn{2}{|c|}{ Minimally Developed Shore (SAR) } & \multicolumn{2}{|c|}{ Developed Reef (SAR) } \\
\hline & TC-1B & TC-3B & TC-5 & TC-8 & TC-10B & TC-13 & TC-11 & TC-12 \\
\hline $9 / 2 / 2009$ & 6.2 & 16.7 & 5.6 & 6.8 & 2.2 & & & \\
\hline $10 / 12 / 2009$ & 0.6 & 6.0 & 3.6 & 6.4 & 0.4 & & 1.3 & 1.0 \\
\hline $11 / 7 / 2009$ & 1.1 & 3.3 & 3.2 & 6.8 & 0.7 & & 1.7 & 0.8 \\
\hline $12 / 2 / 2009$ & 2.0 & 21.9 & 13.8 & 10.8 & 4.6 & & 2.3 & 0.8 \\
\hline $12 / 29 / 2009$ & 10.6 & 35.5 & 18.6 & & 6.9 & & 5.0 & 5.0 \\
\hline $1 / 24 / 2010$ & 5.3 & 16.3 & 6.6 & 3.9 & 2.2 & & 2.3 & 1.8 \\
\hline $2 / 19 / 2010$ & 5.1 & 7.9 & 8.7 & 8.1 & 4.1 & & 4.3 & 3.4 \\
\hline $3 / 17 / 2010$ & 1.4 & 2.4 & 3.4 & 5.3 & 0.6 & & 1.8 & 1.1 \\
\hline $8 / 20 / 2010$ & 1.3 & 2.1 & 12.2 & 5.9 & 1.2 & 1.5 & 1.8 & 1.4 \\
\hline $9 / 15 / 2010$ & & 44.3 & 22.1 & 17.5 & 2.5 & 5.3 & 5.3 & 6.4 \\
\hline $10 / 11 / 2010$ & 21.8 & \begin{tabular}{|l|}
111.4 \\
\end{tabular} & 51.6 & 33.5 & 36.6 & 60.6 & 6.1 & 8.0 \\
\hline $11 / 8 / 2010$ & 29.8 & 113.2 & 29.8 & 19.5 & 23.8 & 32.4 & 9.4 & 12.2 \\
\hline $12 / 2 / 2010$ & 4.0 & 14.3 & 15.1 & 22.0 & 5.5 & 4.3 & 1.5 & 1.8 \\
\hline $12 / 29 / 2010$ & 7.0 & 15.2 & 16.7 & 14.8 & 3.9 & 3.2 & 2.9 & 1.7 \\
\hline $1 / 23 / 2011$ & 14.4 & 26.4 & 21.0 & 12.8 & 5.9 & 5.8 & 4.4 & 5.0 \\
\hline $2 / 13 / 2011$ & 15.5 & & 23.3 & 22.0 & 4.6 & 6.0 & 4.4 & 6.7 \\
\hline $3 / 16 / 2011$ & 3.5 & 27.1 & 7.6 & 9.3 & 0.6 & 0.7 & 1.0 & 1.3 \\
\hline $4 / 11 / 2011$ & 8.3 & 9.0 & 16.3 & 20.4 & 1.7 & & 2.0 & 3.5 \\
\hline $6 / 29 / 2011$ & 3.5 & 2.9 & 13.3 & \begin{tabular}{|l|}
9.5 \\
\end{tabular} & 1.5 & 3.4 & 1.7 & \\
\hline $7 / 25 / 2011$ & 11.9 & 11.8 & 13.0 & 13.9 & 4.1 & 0.2 & 4.3 & \\
\hline $8 / 20 / 2011$ & 19.7 & 11.2 & 24.0 & 19.0 & 6.3 & 17.1 & 9.1 & 13.9 \\
\hline $9 / 15 / 2011$ & 23.1 & & 20.3 & 14.3 & 22.2 & 41.0 & 21.9 & 44.9 \\
\hline $10 / 11 / 2011$ & 15.4 & 36.1 & \begin{tabular}{|l|}
9.7 \\
\end{tabular} & 13.3 & 1.5 & 3.3 & 2.6 & 2.1 \\
\hline $11 / 5 / 2011$ & 3.3 & 9.3 & 9.0 & 12.0 & 1.1 & 2.4 & 2.7 & 1.4 \\
\hline $12 / 1 / 2011$ & 3.8 & 11.6 & 13.9 & 11.8 & 1.9 & 5.5 & 2.5 & 1.4 \\
\hline $12 / 29 / 2011$ & 7.2 & 24.2 & & 13.2 & 3.6 & 4.9 & 2.7 & 2.8 \\
\hline $1 / 21 / 2012$ & 20.5 & 37.7 & \begin{tabular}{|l|}
13.7 \\
\end{tabular} & 16.1 & 5.3 & 10.6 & 8.4 & 6.3 \\
\hline $2 / 15 / 2012$ & 8.1 & & 20.0 & 22.9 & 3.8 & 5.2 & 3.5 & 2.9 \\
\hline $3 / 14 / 2012$ & 19.3 & 30.7 & 10.0 & 32.9 & 7.0 & 9.4 & 3.6 & 5.4 \\
\hline $7 / 24 / 2012$ & 14.4 & & 11.1 & 23.1 & 1.9 & 3.7 & 3.7 & 2.8 \\
\hline $8 / 20 / 2012$ & 50.1 & & \begin{tabular}{|l|}
15.0 \\
\end{tabular} & 20.3 & 11.4 & 25.5 & 12.0 & 10.1 \\
\hline $9 / 15 / 2012$ & 95.6 & & 19.3 & & 2.1 & 27.8 & 26.9 & 35.7 \\
\hline $10 / 11 / 2012$ & 8.5 & 6.5 & \begin{tabular}{|l|}
3.2 \\
\end{tabular} & & 1.6 & 1.7 & 2.5 & 0.8 \\
\hline $11 / 6 / 2012$ & 54.1 & 10.4 & 9.2 & & 3.4 & 1.6 & 4.2 & 5.6 \\
\hline $12 / 3 / 2012$ & 9.3 & 20.6 & 6.2 & & 0.6 & 1.8 & 1.3 & 1.3 \\
\hline $12 / 28 / 2012$ & 46.6 & 69.2 & 8.7 & 10.3 & 1.6 & 0.6 & 3.7 & 1.5 \\
\hline
\end{tabular}


Appendix VII (cont.). Total accumulation rates (SAR, $\left.\mathrm{mg} / \mathrm{cm}^{2} / \mathrm{d}\right)$ at Lameshur Bay sites.

\begin{tabular}{|c|c|c|c|c|c|}
\hline \multirow[t]{2}{*}{ Sampling Date } & \multicolumn{2}{|c|}{ Minimally Developed Shore (SAR) } & \multicolumn{3}{|c|}{ Minimally Developed Reef (SAR) } \\
\hline & TL1-2 & TL2-6 & TY-1 & TY-2 & $\pi-1$ \\
\hline $9 / 2 / 2009$ & 2.0 & & 0.5 & 0.4 & 0.1 \\
\hline $10 / 14 / 2009$ & 8.2 & & 0.3 & 0.3 & 0.2 \\
\hline $11 / 8 / 2009$ & 2.6 & & 0.3 & 0.5 & 0.3 \\
\hline $12 / 3 / 2009$ & 4.4 & & 0.8 & 1.0 & 0.5 \\
\hline $12 / 30 / 2009$ & 4.4 & & 0.9 & 0.9 & 0.5 \\
\hline $1 / 25 / 2010$ & 3.9 & & 0.9 & 0.7 & 0.6 \\
\hline $2 / 20 / 2010$ & 3.9 & & 0.8 & 0.8 & 0.6 \\
\hline $3 / 19 / 2010$ & 2.6 & & 0.6 & 0.6 & 0.3 \\
\hline $8 / 20 / 2010$ & & 2.0 & & 0.2 & 0.2 \\
\hline $9 / 18 / 2010$ & 0.4 & 39.1 & 10.6 & 20.0 & 33.3 \\
\hline $10 / 13 / 2010$ & 32.9 & 61.0 & 24.2 & 15.9 & 13.4 \\
\hline $11 / 13 / 2010$ & 139.2 & 8.4 & 1.9 & 0.7 & 0.7 \\
\hline $12 / 4 / 2010$ & 6.4 & 2.1 & 0.4 & 0.3 & 0.5 \\
\hline $12 / 31 / 2010$ & 5.0 & 3.0 & 0.8 & 0.3 & 0.6 \\
\hline $1 / 25 / 2011$ & 8.6 & 5.0 & 0.8 & 0.6 & 0.4 \\
\hline $2 / 15 / 2011$ & 4.0 & 4.9 & 0.7 & 0.6 & 0.2 \\
\hline $3 / 18 / 2011$ & & 0.3 & 0.3 & 0.1 & 0.2 \\
\hline $4 / 13 / 2011$ & 1.8 & 0.5 & & 0.2 & \\
\hline $6 / 29 / 2011$ & 0.2 & 2.4 & 0.4 & 0.3 & 0.1 \\
\hline $7 / 27 / 2011$ & 0.2 & 2.9 & 0.4 & 0.4 & 0.1 \\
\hline $8 / 26 / 2011$ & 3.7 & 10.0 & 4.9 & 5.5 & 4.4 \\
\hline $9 / 17 / 2011$ & 3.1 & 2.7 & 1.0 & 1.0 & 0.6 \\
\hline $10 / 13 / 2011$ & 1.8 & 2.0 & 0.4 & 0.4 & 0.3 \\
\hline $11 / 7 / 2011$ & 2.2 & 2.6 & 0.9 & 1.0 & 0.9 \\
\hline $12 / 3 / 2011$ & 1.4 & 1.5 & 0.4 & 0.5 & 0.5 \\
\hline $12 / 31 / 2011$ & 1.8 & 1.8 & 0.5 & 0.7 & 0.5 \\
\hline $1 / 24 / 2012$ & 2.4 & 2.6 & 0.5 & 0.9 & 0.6 \\
\hline $2 / 18 / 2012$ & 1.1 & 0.8 & 0.7 & 0.7 & 0.5 \\
\hline $3 / 16 / 2012$ & 0.8 & 0.7 & 0.4 & 1.1 & 0.7 \\
\hline $6 / 30 / 2012$ & 0.4 & 0.6 & & & \\
\hline $7 / 26 / 2012$ & 1.8 & 1.2 & 0.7 & 0.6 & 0.1 \\
\hline $8 / 20 / 2012$ & & 8.4 & & 13.0 & 6.0 \\
\hline $9 / 17 / 2012$ & 0.9 & 0.2 & 0.6 & 0.4 & 0.4 \\
\hline $10 / 13 / 2012$ & 1.1 & 0.7 & 0.6 & 0.6 & 0.5 \\
\hline $11 / 8 / 2012$ & 2.6 & 4.4 & 1.4 & 0.9 & 1.4 \\
\hline $12 / 3 / 2012$ & 0.8 & 0.7 & 0.8 & 0.4 & 0.3 \\
\hline $12 / 30 / 2012$ & 1.5 & 0.5 & 1.0 & 0.6 & 0.4 \\
\hline
\end{tabular}

